Cochrane Database of Systematic Reviews

\title{
Endoscopic release for carpal tunnel syndrome (Review)
}

Vasiliadis HS, Georgoulas P, Shrier I, Salanti G, Scholten RJPM

Vasiliadis HS, Georgoulas P, Shrier I, Salanti G, Scholten RJPM.

Endoscopic release for carpal tunnel syndrome.

Cochrane Database of Systematic Reviews 2014, Issue 1. Art. No.: CD008265.

DOI: 10.1002/14651858.CD008265.pub2.

www.cochranelibrary.com 
TABLE OF CONTENTS

HEADER 1

ABSTRACT

PLAIN LANGUAGE SUMMARY

SUMMARY OF FINDINGS

BACKGROUND

OBJECTIVES

METHODS

RESULTS

Figure 1.

Figure 2.

Figure 3.

Figure 4.

Figure 5.

Figure 6.

Figure 7.

DISCUSSION

AUTHORS' CONCLUSIONS

ACKNOWLEDGEMENTS

REFERENCES

CHARACTERISTICS OF STUDIES

DATA AND ANALYSES

Analysis 1.1. Comparison 1 Endoscopic versus open or mini-open carpal tunnel release, Outcome 1 Overall improvement at 3 months or less.

Analysis 1.2. Comparison 1 Endoscopic versus open or mini-open carpal tunnel release, Outcome 2 Overall satisfaction at 3 months or less.

Analysis 1.3. Comparison 1 Endoscopic versus open or mini-open carpal tunnel release, Outcome 3 Symptom Severity Scale (Levine) at 3 months or less.

Analysis 1.4. Comparison 1 Endoscopic versus open or mini-open carpal tunnel release, Outcome 4 Function Status Scale at 3 months or less.

Analysis 1.5. Comparison 1 Endoscopic versus open or mini-open carpal tunnel release, Outcome 5 Pain at 3 months or less (corr $=0.5$ ).

Analysis 1.6. Comparison 1 Endoscopic versus open or mini-open carpal tunnel release, Outcome 6 Pain at 3 months or less (corr $=0.9$ ).

Analysis 1.7. Comparison 1 Endoscopic versus open or mini-open carpal tunnel release, Outcome 7 Pain at 3 months or less (corr $=0.1$ ).

Analysis 1.8. Comparison 1 Endoscopic versus open or mini-open carpal tunnel release, Outcome 8 Pain (dichotomous) at 3 months or less.

Analysis 1.9. Comparison 1 Endoscopic versus open or mini-open carpal tunnel release, Outcome 9 Numbness (dichotomous) at 3 months or less.

Analysis 1.10. Comparison 1 Endoscopic versus open or mini-open carpal tunnel release, Outcome 10 Grip strength at 3 months or less.

Analysis 1.11. Comparison 1 Endoscopic versus open or mini-open carpal tunnel release, Outcome 11 Overall improvement at more than 3 months.

Analysis 1.12. Comparison 1 Endoscopic versus open or mini-open carpal tunnel release, Outcome 12 Overall satisfaction at more than 3 months.

Analysis 1.13. Comparison 1 Endoscopic versus open or mini-open carpal tunnel release, Outcome 13 Symptom Severity Scale (Levine) at more than 3 months.

Analysis 1.14. Comparison 1 Endoscopic versus open or mini-open carpal tunnel release, Outcome 14 Function Status Scale at more than 3 months.

Analysis 1.15. Comparison 1 Endoscopic versus open or mini-open carpal tunnel release, Outcome 15 Pain at more than 3 months.

Analysis 1.16. Comparison 1 Endoscopic versus open or mini-open carpal tunnel release, Outcome 16 Pain (dichotomous) at more than 3 months. 
Analysis 1.17. Comparison 1 Endoscopic versus open or mini-open carpal tunnel release, Outcome 17 Numbness at more than 3 months.

Analysis 1.18. Comparison 1 Endoscopic versus open or mini-open carpal tunnel release, Outcome 18 Numbness (dichotomous) at more than 3 months.

Analysis 1.19. Comparison 1 Endoscopic versus open or mini-open carpal tunnel release, Outcome 19 Grip strength at more than 3 months.

Analysis 1.20. Comparison 1 Endoscopic versus open or mini-open carpal tunnel release, Outcome 20 Time to return to work. . Analysis 1.21. Comparison 1 Endoscopic versus open or mini-open carpal tunnel release, Outcome 21 Recurrence. ................ Analysis 1.22. Comparison 1 Endoscopic versus open or mini-open carpal tunnel release, Outcome 22 Reoperations. ............. Analysis 1.23. Comparison 1 Endoscopic versus open or mini-open carpal tunnel release, Outcome 23 Major complications. .... Analysis 1.24. Comparison 1 Endoscopic versus open or mini-open carpal tunnel release, Outcome 24 Minor complications. ... Analysis 1.25. Comparison 1 Endoscopic versus open or mini-open carpal tunnel release, Outcome 25 Total complications. ... Analysis 2.1. Comparison 2 One- or two-portal endoscopic versus open and mini-open carpal tunnel release, Outcome 1 Overall satisfaction at 3 months or less.

Analysis 2.2. Comparison 2 One- or two-portal endoscopic versus open and mini-open carpal tunnel release, Outcome 2 Overall improvement at 3 months or less.

Analysis 2.3. Comparison 2 One- or two-portal endoscopic versus open and mini-open carpal tunnel release, Outcome 3 Symptom Severity Scale (Levine) at 3 months or less.

Analysis 2.4. Comparison 2 One- or two-portal endoscopic versus open and mini-open carpal tunnel release, Outcome 4 Function Status Scale at 3 months or less.

Analysis 2.5. Comparison 2 One- or two-portal endoscopic versus open and mini-open carpal tunnel release, Outcome 5 Pain at 3 months or less (corr $=0.5$ ).

Analysis 2.6. Comparison 2 One- or two-portal endoscopic versus open and mini-open carpal tunnel release, Outcome 6 Pain at 3 months or less (corr $=0.1$ ).

Analysis 2.7. Comparison 2 One- or two-portal endoscopic versus open and mini-open carpal tunnel release, Outcome 7 Pain at 3 months or less (corr $=0.9$ ).

Analysis 2.8. Comparison 2 One- or two-portal endoscopic versus open and mini-open carpal tunnel release, Outcome 8 Pain (dichotomous) at 3 months or less.

Analysis 2.9. Comparison 2 One- or two-portal endoscopic versus open and mini-open carpal tunnel release, Outcome 9 Numbness (dichotomous) at 3 months or less.

Analysis 2.10. Comparison 2 One- or two-portal endoscopic versus open and mini-open carpal tunnel release, Outcome $10 \mathrm{Grip}$ strength at 3 months or less.

Analysis 2.11. Comparison 2 One- or two-portal endoscopic versus open and mini-open carpal tunnel release, Outcome 11 Overall satisfaction at more than 3 months.

Analysis 2.12. Comparison 2 One- or two-portal endoscopic versus open and mini-open carpal tunnel release, Outcome 12 Overall improvement at more than 3 months.

Analysis 2.13. Comparison 2 One- or two-portal endoscopic versus open and mini-open carpal tunnel release, Outcome 13 Symptom Severity Scale (Levine) at more than 3 months.

Analysis 2.14. Comparison 2 One- or two-portal endoscopic versus open and mini-open carpal tunnel release, Outcome 14 Function Status Scale at more than 3 months.

Analysis 2.15. Comparison 2 One- or two-portal endoscopic versus open and mini-open carpal tunnel release, Outcome 15 Pain at more than 3 months.

Analysis 2.16. Comparison 2 One- or two-portal endoscopic versus open and mini-open carpal tunnel release, Outcome 16 Pain (dichotomous) at more than 3 months.

Analysis 2.17. Comparison 2 One- or two-portal endoscopic versus open and mini-open carpal tunnel release, Outcome 17 Numbness at more than 3 months.

Analysis 2.18. Comparison 2 One- or two-portal endoscopic versus open and mini-open carpal tunnel release, Outcome 18 Numbness (dichotomous) at more than 3 months.

Analysis 2.19. Comparison 2 One- or two-portal endoscopic versus open and mini-open carpal tunnel release, Outcome 19 Grip strength at more than 3 months.

Analysis 2.20. Comparison 2 One- or two-portal endoscopic versus open and mini-open carpal tunnel release, Outcome 20 Time to return to work.

Analysis 2.21. Comparison 2 One- or two-portal endoscopic versus open and mini-open carpal tunnel release, Outcome 21 Recurrence.

Analysis 2.22. Comparison 2 One- or two-portal endoscopic versus open and mini-open carpal tunnel release, Outcome 22 Reoperations. 
Analysis 2.23. Comparison 2 One- or two-portal endoscopic versus open and mini-open carpal tunnel release, Outcome 23 Major complications.

Analysis 2.24. Comparison 2 One- or two-portal endoscopic versus open and mini-open carpal tunnel release, Outcome 24 Minor complications.

Analysis 2.25. Comparison 2 One- or two-portal endoscopic versus open and mini-open carpal tunnel release, Outcome 25 Total complications.

Analysis 3.1. Comparison 3 Sensitivity analysis 1 (low risk of bias for incomplete outcome data), Outcome 1 Symptom Severity Scale (Levine) at 3 months or less.

Analysis 3.2. Comparison 3 Sensitivity analysis 1 (low risk of bias for incomplete outcome data), Outcome 2 Function Status Scale at 3 months or less.

Analysis 3.3. Comparison 3 Sensitivity analysis 1 (low risk of bias for incomplete outcome data), Outcome 3 Pain at 3 months or less (corr $=0.5$ ).

Analysis 3.4. Comparison 3 Sensitivity analysis 1 (low risk of bias for incomplete outcome data), Outcome 4 Pain at 3 months or less (corr $=0.1$ ).

Analysis 3.5. Comparison 3 Sensitivity analysis 1 (low risk of bias for incomplete outcome data), Outcome 5 Pain at 3 months or less (corr $=0.9$ ).

Analysis 3.6. Comparison 3 Sensitivity analysis 1 (low risk of bias for incomplete outcome data), Outcome 6 Grip strength at 3 months or less.

Analysis 3.7. Comparison 3 Sensitivity analysis 1 (low risk of bias for incomplete outcome data), Outcome 7 Pain (dichotomous) at more than 3 months.

Analysis 3.8. Comparison 3 Sensitivity analysis 1 (low risk of bias for incomplete outcome data), Outcome 8 Numbness (dichotomous) at more than 3 months.

Analysis 3.9. Comparison 3 Sensitivity analysis 1 (low risk of bias for incomplete outcome data), Outcome 9 Time to return to work.

Analysis 3.10. Comparison 3 Sensitivity analysis 1 (low risk of bias for incomplete outcome data), Outcome 10 Reoperations. .. Analysis 3.11. Comparison 3 Sensitivity analysis 1 (low risk of bias for incomplete outcome data), Outcome 11 Major complications.

Analysis 3.12. Comparison 3 Sensitivity analysis 1 (low risk of bias for incomplete outcome data), Outcome 12 Minor complications.

Analysis 3.13. Comparison 3 Sensitivity analysis 1 (low risk of bias for incomplete outcome data), Outcome 13 Total complications.

Analysis 4.1. Comparison 4 Sensitivity analysis 2 (exclusion of inappropriate adjustment for bilateral involvement), Outcome 1 Overall improvement at more than 3 months.

Analysis 4.2. Comparison 4 Sensitivity analysis 2 (exclusion of inappropriate adjustment for bilateral involvement), Outcome 2 Symptom Severity Scale (Levine) at 3 months or less.

Analysis 4.3. Comparison 4 Sensitivity analysis 2 (exclusion of inappropriate adjustment for bilateral involvement), Outcome 3 Pain at 3 months or less (corr $=0.5$ ).

Analysis 4.4. Comparison 4 Sensitivity analysis 2 (exclusion of inappropriate adjustment for bilateral involvement), Outcome 4 Pain at 3 months or less (corr $=0.1$ ).

Analysis 4.5. Comparison 4 Sensitivity analysis 2 (exclusion of inappropriate adjustment for bilateral involvement), Outcome 5 Pain at 3 months or less (corr $=0.9$ ).

Analysis 4.6. Comparison 4 Sensitivity analysis 2 (exclusion of inappropriate adjustment for bilateral involvement), Outcome 6 Pain (dichotomous) at 3 months or less.

Analysis 4.7. Comparison 4 Sensitivity analysis 2 (exclusion of inappropriate adjustment for bilateral involvement), Outcome 7 Pain (dichotomous) at more than 3 months.

Analysis 4.8. Comparison 4 Sensitivity analysis 2 (exclusion of inappropriate adjustment for bilateral involvement), Outcome 8 Numbness (dichotomous) at 3 months or less.

Analysis 4.9. Comparison 4 Sensitivity analysis 2 (exclusion of inappropriate adjustment for bilateral involvement), Outcome 9 Numbness (dichotomous) at more than 3 months.

Analysis 4.10. Comparison 4 Sensitivity analysis 2 (exclusion of inappropriate adjustment for bilateral involvement), Outcome 10 Function Status Scale at 3 months or less.

Analysis 4.11. Comparison 4 Sensitivity analysis 2 (exclusion of inappropriate adjustment for bilateral involvement), Outcome 11 Grip strength at 3 months or less.

Analysis 4.12. Comparison 4 Sensitivity analysis 2 (exclusion of inappropriate adjustment for bilateral involvement), Outcome 12 Recurrence. 
Analysis 4.13. Comparison 4 Sensitivity analysis 2 (exclusion of inappropriate adjustment for bilateral involvement), Outcome 13 Reoperations.

Analysis 4.14. Comparison 4 Sensitivity analysis 2 (exclusion of inappropriate adjustment for bilateral involvement), Outcome 14 Major complications.

Analysis 4.15. Comparison 4 Sensitivity analysis 2 (exclusion of inappropriate adjustment for bilateral involvement), Outcome 15 Minor complications.

Analysis 4.16. Comparison 4 Sensitivity analysis 2 (exclusion of inappropriate adjustment for bilateral involvement), Outcome 16 Total complications.

ADDITIONAL TABLES

APPENDICES

CONTRIBUTIONS OF AUTHORS 
[Intervention Review]

\section{Endoscopic release for carpal tunnel syndrome}

Haris S Vasiliadis 1 ,2, Petros Georgoulas ${ }^{3}$, Ian Shrier 4 , Georgia Salanti ${ }^{5}$, Rob JPM Scholten 6

1Department of Orthopaedics, University of Ioannina, Ioannina, Greece. 2Molecular Cell Biology and Regenerative Medicine, Sahlgrenska University Hospital, Gothenburg University, Gothenburg, Sweden. ${ }^{3}$ University of Ioannina, Ioannina, Greece. ${ }^{4}$ Centre for Clinical Epidemiology, Jewish General Hospital, Lady Davis Institute for Medical Research, McGill University, Montreal, Canada. ${ }^{5}$ Department of Hygiene and Epidemiology, University of Ioannina School of Medicine, Ioannina, Greece. ${ }^{6} J u l i u s$ Center for Health Sciences and Primary Care, University Medical Center Utrecht, Utrecht, Netherlands

Contact address: Haris S Vasiliadis, Department of Orthopaedics, University of Ioannina, Ioannina, Greece. vasiliadismd@gmail.com, hvasil@cc.uoi.gr.

Editorial group: Cochrane Neuromuscular Group

Publication status and date: New, published in Issue 1, 2014.

Citation: Vasiliadis HS, Georgoulas P, Shrier I, Salanti G, Scholten RJPM. Endoscopic release for carpal tunnel syndrome. Cochrane Database of Systematic Reviews 2014, Issue 1. Art. No.: CD008265. DOI: 10.1002/14651858.CD008265.pub2.

Copyright ( 2014 The Cochrane Collaboration. Published by John Wiley \& Sons, Ltd.

\section{A B S T R A C T}

\section{Background}

Carpal tunnel syndrome (CTS) is the most common compressive neuropathy of the upper extremity. It is caused by increased pressure on the median nerve between the transverse carpal ligament and the carpal bones. Surgical treatment consists of the release of the nerve by cutting the transverse carpal ligament. This can be done either with an open approach or endoscopically.

\section{Objectives}

To assess the effectiveness and safety of the endoscopic techniques of carpal tunnel release compared to any other surgical intervention for the treatment of CTS. More specifically, to evaluate the relative impact of endoscopic techniques in relieving symptoms, producing functional recovery (return to work and return to daily activities) and reducing complication rates.

\section{Search methods}

This review fully incorporates the results of searches conducted up to 5 November 2012, when we searched the Cochrane Neuromuscular Disease Group Specialized Register, CENTRAL, MEDLINE and EMBASE. There were no language restrictions. We reviewed the reference lists of relevant articles and contacted trial authors. We also searched trial registers for ongoing trials. We performed a preliminary screen of searches to November 2013 to identify any additional recent publications.

\section{Selection criteria}

We included any randomised controlled trials (RCTs) and quasi-RCTs comparing endoscopic carpal tunnel release (ECTR) with any other surgical intervention for the treatment of CTS.

\section{Data collection and analysis}

We used standard methodological procedures expected by the Cochrane Collaboration.

\section{Main results}

Twenty-eight studies (2586 hands) were included. Twenty-three studies compared ECTR to standard open carpal tunnel release (OCTR), five studies compared ECTR with OCTR using a modified incision, and two studies used a three-arm design to compare ECTR, standard OCTR and modified OCTR. 
At short-term follow-up (three months or less), only one study provided data for overall improvement. We found no differences on the Symptom Severity Scale (SSS) (scale zero to five) (five studies, standardised mean difference (SMD) $-0.13,95 \% \mathrm{Cl}-0.47$ to 0.21 ) or on the Functional Status Scale (FSS) (scale zero to five) (five studies, SMD $-0.23,95 \% \mathrm{Cl}-0.60$ to 0.14 ) within three months postoperatively between ECTR and OCTR. Pain scores favoured ECTR over conventional OCTR (two studies, SMD $-0.41,95 \% \mathrm{Cl}-0.65$ to -0.18 ). No difference was found between ECTR and OCTR (standard and modified) when pain was assessed on non-continuous dichotomous scales (five studies, RR $0.69,95 \% \mathrm{Cl} 0.33$ to 1.45 ). Also, no difference was found in numbness (five studies, RR $1.14 ; 95 \% \mathrm{Cl} 0.76$ to 1.71 ). Grip strength was increased after ECTR when compared with OCTR (six studies, SMD 0.36, 95\% Cl 0.09 to 0.63 ). This corresponds to a mean difference (MD) of $4 \mathrm{~kg}$ (95\% $\mathrm{Cl} 1$ to $6.9 \mathrm{~kg}$ ) when compared with OCTR, which is probably not clinically significant.

In the long term (more than three months postoperatively) there was no significant difference in overall improvement between ECTR and OCTR (four studies, RR $1.04,95 \% \mathrm{Cl} 0.95$ to 1.14 ). SSS and FSS were also similar in both treatment groups (two studies, $\mathrm{MD} 0.02,95 \% \mathrm{Cl}-0.18$ to 0.22 for SSS and MD $0.01,95 \% \mathrm{Cl}-0.14$ to 0.16 for FSS). ECTR and OCTR did not differ in the long term in pain (six studies, RR $0.88,95 \%$ $\mathrm{Cl} 0.57$ to 1.38 ) or in numbness (four studies, RR $0.64,95 \% \mathrm{Cl} 0.31$ to 1.35 ). Results from grip strength testing favoured ECTR (two studies, SMD $1.13,95 \% \mathrm{Cl} 0.56$ to 1.71$)$, corresponding to an MD of $11 \mathrm{~kg}(95 \% \mathrm{Cl} 6.2$ to 18.81$)$. Participants treated with ECTR returned to work or daily activities eight days earlier than participants treated with OCTR (four studies, MD -8.10 days, $95 \% \mathrm{Cl}-14.28$ to -1.92 days).

Both treatments were equally safe with only a few reports of major complications (mainly with complex regional pain syndrome) (15 studies, RR $1.00,95 \% \mathrm{Cl} 0.38$ to 2.64$)$.

ECTR resulted in a significantly lower rate of minor complications ( 18 studies, RR $0.55,95 \% \mathrm{Cl} 0.38$ to 0.81 ), corresponding to a $45 \%$ relative drop in the probability of complications ( $95 \% \mathrm{Cl} 62 \%$ to $19 \%$ ). ECTR more frequently resulted in transient nerve problems (ie, neurapraxia, numbness, and paraesthesiae), while OCTR had more wound problems (ie, infection, hypertrophic scarring, and scar tenderness). ECTR was safer than OCTR when the total number of complications were assessed ( 20 studies, $\mathrm{RR} 0.60,95 \% \mathrm{Cl} 0.40$ to 90 ) representing a relative drop in the probability by $40 \%(95 \% \mathrm{Cl} 60 \%$ to $10 \%)$.

Rates of recurrence of symptoms and the need for repeated surgery were comparable between ECTR and OCTR groups.

The overall risk of bias in studies that contribute data to these results is rather high; fewer than $25 \%$ of the included studies had adequate allocation concealment, generation of allocation sequence or blinding of the outcome assessor.

The quality of evidence in this review may be considered as generally low. Five of the studies were presented only as abstracts, with insufficient information to judge their risk of bias. In selection bias, attrition bias or other bias (baseline differences and financial conflict of interest) we could not reach a safe judgement regarding a high or low risk of bias. Blinding of participants is impossible due to the nature of interventions.

We identified three further potentially eligible studies upon updating searches just prior to publication. These compared ECTR with OCTR (two studies) or mini-open carpal tunnel release (one study) and will be fully assessed when we update the review.

\section{Authors' conclusions}

In this review, with support from low quality evidence only, OCTR and ECTR for carpal tunnel release are about as effective as each other in relieving symptoms and improving functional status, although there may be a functionally significant benefit of ECTR over OCTR in improvement in grip strength. ECTR appears to be associated with fewer minor complications compared to OCTR, but we found no difference in the rates of major complications. Return to work is faster after endoscopic release, by eight days on average. Conclusions from this review are limited by the high risk of bias, statistical imprecision and inconsistency in the included studies.

\section{PLAIN LANGUAGE SUMMARY}

\section{Endoscopic release for carpal tunnel syndrome}

\section{Review question}

We reviewed the evidence about how safe and effective endoscopic carpal tunnel release (ECTR) is, compared to any other type of surgery for carpal tunnel syndrome (CTS).

\section{Background}

CTS is the most common cause of nerve compression in the arm. The carpal tunnel is the space between a ligament that stretches across the wrist and the bones below. In CTS there is increased pressure on a nerve (the median nerve) as it passes over the wrist towards the palm of the hand through the carpal tunnel. To release the pressure on the nerve in the carpal tunnel, surgeons cut the ligament. This operation can be done as traditional 'open' surgery (OCTR), or through an endoscope (ECTR), using a small camera with one or two small cuts in the skin.

We searched widely for trials that compared ECTR with other types of surgery. 


\section{Study characteristics}

We found 28 studies, involving 2586 people, that were suitable for the review. We considered results at less than three months and more than three months after surgery.

\section{Key results and quality of the evidence}

With support from low quality evidence only, OCTR and ECTR are about as effective as each other in relieving symptoms and improving hand function in CTS. ECTR probably has lower rates of minor complications (such as scar pain and infections) than OCTR but similar rates of major complications. ECTR also allows a faster return to work or daily activities. However, limitations in the studies in this review limit the quality of this evidence.

Only one study declared a conflict of interest and nine studies clearly reported no conflict of interest. Four studies were funded from an academic source. Evaluation following the GRADE assessment reveals a low to moderate quality of evidence for the outcomes provided.

The evidence in the review is current to November 2012. We re-ran the search shortly before publication and we will fully assess three further studies from this search when the review is updated. 


\begin{tabular}{|c|c|c|c|c|c|c|}
\hline \multicolumn{7}{|c|}{$\begin{array}{l}\text { S U M M A R Y O F F I N D I N G S } \\
\text { Summary of findings for the main comparison. Endoscopic versus open or mini-open carpal tunnel release for carpal tunnel syndrome }\end{array}$} \\
\hline \multicolumn{7}{|c|}{ Endoscopic versus open or mini-open carpal tunnel release for carpal tunnel syndrome } \\
\hline \multicolumn{7}{|c|}{$\begin{array}{l}\text { Patient or population: participants with carpal tunnel syndrome } \\
\text { Settings: } \\
\text { Intervention: endoscopic versus open or mini-open carpal tunnel release }\end{array}$} \\
\hline \multirow[t]{3}{*}{ Outcomes } & \multicolumn{2}{|c|}{$\begin{array}{l}\text { Illustrative comparative risks } \\
(95 \% \mathrm{Cl})\end{array}$} & \multirow[t]{3}{*}{$\begin{array}{l}\text { Relative effect } \\
(95 \% \mathrm{Cl})\end{array}$} & \multirow[t]{3}{*}{$\begin{array}{l}\text { No of Participants } \\
\text { (studies) }\end{array}$} & \multirow{3}{*}{$\begin{array}{l}\text { Quality of the } \\
\text { evidence } \\
\text { (GRADE) }\end{array}$} & \multirow[t]{3}{*}{ Comments } \\
\hline & Assumed risk & $\begin{array}{l}\text { Corresponding } \\
\text { risk }\end{array}$ & & & & \\
\hline & $\begin{array}{l}\text { Open or } \\
\text { mini-open } \\
\text { carpal tunnel } \\
\text { release (OC- } \\
\text { TR) }\end{array}$ & $\begin{array}{l}\text { Endoscopic carpal } \\
\text { tunnel release } \\
\text { (ECTR) }\end{array}$ & & & & \\
\hline $\begin{array}{l}\text { Symptom Severity Scale (Levine) at } \\
\mathbf{3} \text { months or less } \\
\text { Participants' self assessment ques- } \\
\text { tionnaire. Scale from: } 1 \text { to } 5 \text {. }\end{array}$ & & $\begin{array}{l}\text { The mean symp- } \\
\text { tom severity score } \\
\text { at } 3 \text { months or less } \\
\text { in the } \\
\text { ECTR groups was } \\
\mathbf{0 . 1 3} \text { standard de- } \\
\text { viations lower } \\
\text { ( } 0.47 \text { lower to } 0.21 \\
\text { higher) } 1\end{array}$ & & $\begin{array}{l}551 \\
\text { (5 studies) }\end{array}$ & $\begin{array}{l}\oplus \oplus \ominus \ominus \\
\text { low }^{2,3}\end{array}$ & $\begin{array}{l}\text { SMD }-0.13 \\
(95 \% \mathrm{Cl}-0.47 \\
\text { to } 0.21)\end{array}$ \\
\hline $\begin{array}{l}\text { Functional Status Scale (Levine) at } 3 \\
\text { months or less } \\
\text { Participants' self assessment ques- } \\
\text { tionnaire. Scale from: } 1 \text { to } 5 .\end{array}$ & & $\begin{array}{l}\text { The mean function- } \\
\text { al status score at } 3 \\
\text { months or less in } \\
\text { the ECTR groups } \\
\text { was } \\
\mathbf{0 . 2 3} \text { standard de- } \\
\text { viations lower } \\
\text { (0.6 lower to } 0.14 \\
\text { higher) } 1\end{array}$ & & $\begin{array}{l}551 \\
\text { (5 studies) }\end{array}$ & $\begin{array}{l}\oplus \oplus \ominus \ominus \\
\text { low } 2,3\end{array}$ & $\begin{array}{l}\text { SMD }-0.23 \\
(95 \% \mathrm{Cl}-0.60 \\
\text { to } 0.14)\end{array}$ \\
\hline
\end{tabular}

or population: participants with carpal tunnel syndrome

Settings: 


\begin{tabular}{|c|c|c|c|c|c|c|}
\hline $\begin{array}{l}\text { Grip strength at } 3 \text { months or less } \\
\text { Dynamometer }\end{array}$ & & $\begin{array}{l}\text { The mean grip } \\
\text { strength at } 3 \\
\text { months or less in } \\
\text { the ECTR groups } \\
\text { was } \\
\mathbf{0 . 3 6} \text { standard de- } \\
\text { viations higher } \\
\text { (0.09 to } 0.63 \text { high- } \\
\text { er) } 1\end{array}$ & & $\begin{array}{l}560 \\
\text { ( } 6 \text { studies })\end{array}$ & $\begin{array}{l}\oplus \oplus \oplus \ominus \\
\text { moderate }^{2}\end{array}$ & $\begin{array}{l}\text { SMD } 0.36 \\
(95 \% \mathrm{Cl} 0.09 \\
\text { to } 0.63)\end{array}$ \\
\hline $\begin{array}{l}\text { Overall improvement at more than } \mathbf{3} \\
\text { months } \\
\text { Participants' subjective evaluation }\end{array}$ & 781 per 1000 & $\begin{array}{l}\mathbf{8 1 2} \text { per } \mathbf{1 0 0 0} \\
\text { (742 to } 891)\end{array}$ & $\begin{array}{l}\text { RR } 1.04 \\
(0.95 \text { to } 1.14)\end{array}$ & $\begin{array}{l}317 \\
\text { (4 studies) }\end{array}$ & $\begin{array}{l}\oplus \oplus \ominus \ominus \\
\text { low }^{2,4}\end{array}$ & \\
\hline $\begin{array}{l}\text { Symptom Severity Scale (Levine) at } \\
\text { more than } \mathbf{3} \text { months } \\
\text { Participants' self assessment ques- } \\
\text { tionnaire. Scale from: } 1 \text { to } 5 \text {. }\end{array}$ & $\begin{array}{l}\text { The mean } \\
\text { symptom } \\
\text { severity scale } \\
\text { in more than } \\
3 \text { months } \\
\text { ranged across } \\
\text { control } \\
\text { groups from } \\
\mathbf{1 . 4 2} \text { to } \mathbf{1 . 8} \\
\text { points }\end{array}$ & $\begin{array}{l}\text { The mean symp- } \\
\text { tom severity score } \\
\text { at more than } 3 \\
\text { months in the ECTR } \\
\text { groups was } \\
\text { 0.02 higher } \\
\text { ( } 0.18 \text { lower to } 0.22 \\
\text { higher) }\end{array}$ & & $\begin{array}{l}273 \\
\text { ( } 2 \text { studies) }\end{array}$ & $\begin{array}{l}\oplus \oplus \ominus \ominus \\
\text { low }^{2,4}\end{array}$ & \\
\hline $\begin{array}{l}\text { Function Status Scale (Levine) at } \\
\text { more than } \mathbf{3} \text { months } \\
\text { Participants' self assessment ques- } \\
\text { tionnaire. Scale from: } 1 \text { to } 5 .\end{array}$ & $\begin{array}{l}\text { The mean } \\
\text { Function Sta- } \\
\text { tus Scale in } \\
\text { more than } \\
3 \text { months } \\
\text { ranged across } \\
\text { control } \\
\text { groups from } \\
\mathbf{0 . 5} \text { to } \mathbf{0 . 9} \\
\text { points }\end{array}$ & $\begin{array}{l}\text { The mean Func- } \\
\text { tion Status Score } \\
\text { at more than } 3 \\
\text { months in the ECTR } \\
\text { groups was } \\
\mathbf{0 . 0 1} \text { higher } \\
\text { ( } 0.14 \text { lower to } 0.16 \\
\text { higher) }\end{array}$ & & $\begin{array}{l}273 \\
\text { ( } 2 \text { studies) }\end{array}$ & $\begin{array}{l}\oplus \oplus \ominus \ominus \\
\text { low }^{2,4}\end{array}$ & \\
\hline $\begin{array}{l}\text { Grip strength at more than } \mathbf{3} \text { months } \\
\text { Dynamometer. Scale from: } 0 \text { to } 50 .\end{array}$ & & $\begin{array}{l}\text { The mean grip } \\
\text { strength at more } \\
\text { than } 3 \text { months in } \\
\text { the ECTR groups } \\
\text { was } \\
\mathbf{1 . 1 3} \text { standard de- } \\
\text { viations higher } \\
\text { (0.56 to } 1.71 \text { high- } \\
\text { er) } 5\end{array}$ & & $\begin{array}{l}56 \\
\text { ( } 2 \text { studies) }\end{array}$ & $\begin{array}{l}\oplus \oplus \ominus \ominus \\
\text { low } 2,4\end{array}$ & $\begin{array}{l}\text { SMD } 1.13 \\
\text { (0.56 to } 1.71)\end{array}$ \\
\hline
\end{tabular}




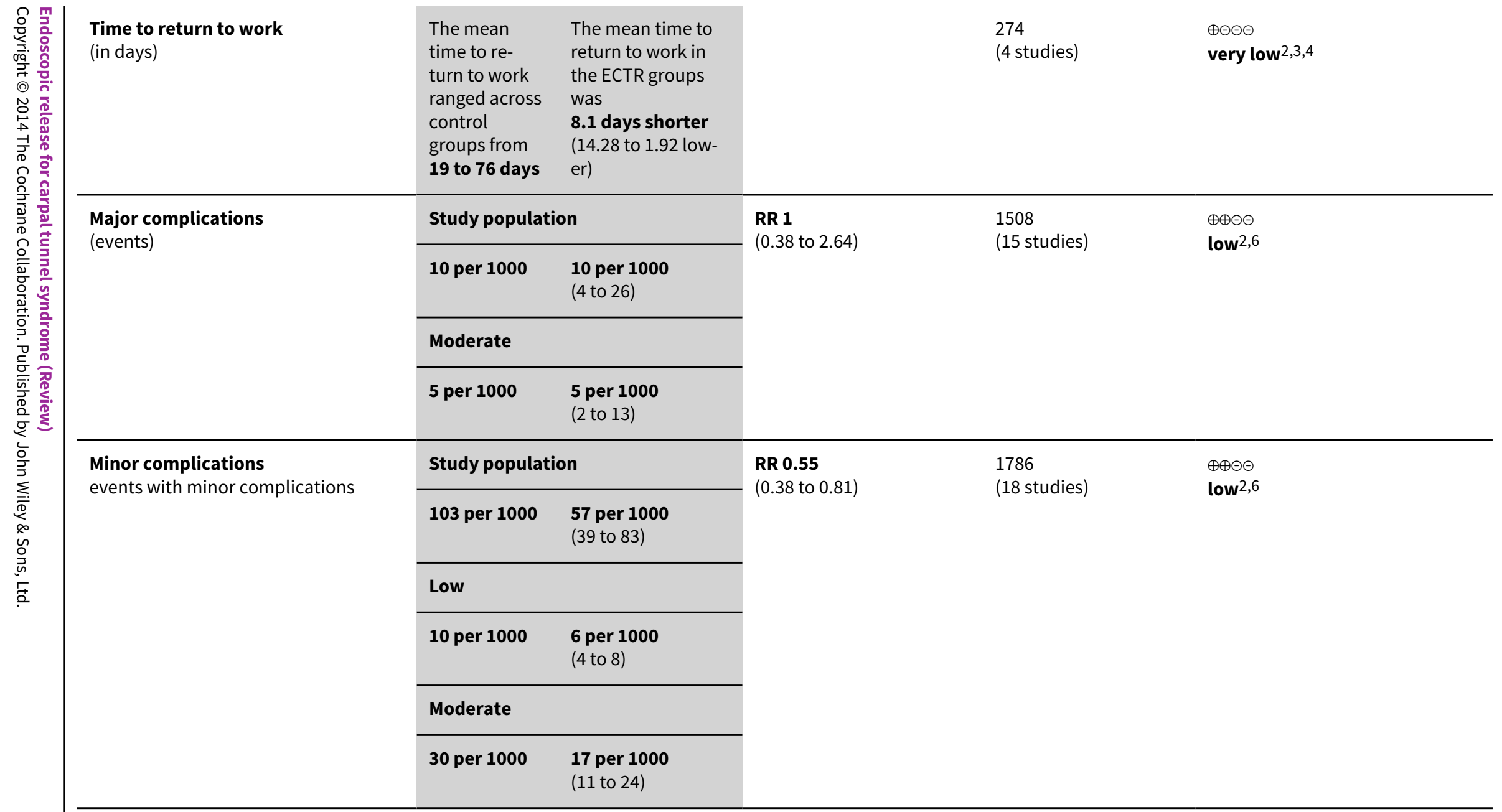

*The basis for the assumed risk (eg the median control group risk across studies) is provided in footnotes. The corresponding risk (and its $95 \% \mathrm{Cl}$ ) is based on the assumed risk in the comparison group and the relative effect of the intervention (and its $95 \% \mathrm{Cl}$ ).

CI: confidence interval; ECTR: endoscopic carpal tunnel release; RR: risk ratio; SMD: standardised mean difference

GRADE Working Group grades of evidence

High quality: Further research is very unlikely to change our confidence in the estimate of effect.

Moderate quality: Further research is likely to have an important impact on our confidence in the estimate of effect and may change the estimate.

Low quality: Further research is very likely to have an important impact on our confidence in the estimate of effect and is likely to change the estimate.

Very low quality: We are very uncertain about the estimate.

a 1 This is a difference in standard deviations. An SMD $<0.41$ represents a small difference between groups. 


\section{B A C K G R O U N D}

Carpal tunnel syndrome (CTS) is the most common compressive neuropathy of the upper extremity, with a prevalence of clinically and electrophysiologically confirmed diagnosis being $2.7 \%$ of the general population (Atroshi 1999). The incidence of newly diagnosed cases of CTS in the UK is 90 men and 193 women per 100,000 visits to primary care departments per year (Latinovic 2006). The equivalent figures in the Netherlands are 90 and 280 per 100,000 visits per year (Bongers 2007). Approximately 500,000 operations for CTS are performed every year in the US, at a cost of over USD 2 billion annually (Palmer 1995). According to US Department of Labour figures (2009), a sick leave of at least 30 days per year is recorded in approximately $45 \%$ of people with CTS, with a median of 28 days away from work, which suggests important insurance-related consequences (U.S. Department of Labor 2009).

\section{Description of the condition}

CTS is caused by median nerve neuropathy, where the nerve passes along the carpal tunnel at the wrist. Increased pressure on the median nerve between the transverse carpal ligament and the carpal bones dorsally is usually the trigger that compromises the nerve's blood supply and leads to oedema, causing functional impairment and clinically evident symptoms (Fuchs 1991). CTS can be secondary when there is an obvious pathology that puts pressure on the median nerve or that indirectly contributes to the median neuropathy (Stevens 1992). The vast majority of cases though are usually considered idiopathic and most commonly affect women between 40 and 70 years of age (Atroshi 1999; Phalen 1966).

The first symptoms that people with CTS notice, and which often lead them to medical services, are paraesthesia and numbness in the distribution area of the median nerve often accompanied by pain. The symptoms are typically more apparent during the night and usually disturb sleep. Atrophy of the thenar muscles due to insufficient innervation by the median nerve appears gradually in the longer term and the person eventually notices weakness.

Electrophysiological tests (nerve conduction studies) have been used to support the clinical diagnosis of CTS, and to distinguish CTS from other lesions of the peripheral or central nervous system. The tests usually reveal a decreased conduction velocity and increased latency in the part of the median nerve located along the carpal tunnel (Jordan 2002).

In the early stages of CTS, conservative treatment is recommended to improve quality of life. This consists of rest, splinting or anti-inflammatory medication either orally or in the form of perineural corticosteroid injections (O'Connor 2003; Piazzini 2007). About $20 \%$ of people with CTS might improve without treatment of any kind (Padua 2001), but if conservative or surgical treatments fail, chronic pressure on the median nerve can lead to irreversible nerve damage and permanent muscle weakness (Gelberman 1988), even if the person undergoes surgery at a later date. Surgical intervention is eventually recommended in $30 \%$ to $40 \%$ of people with CTS (Latinovic 2006; Wilson 2003).

\section{Description of the intervention}

Surgical treatment of CTS consists of cutting the transverse ligament of the palm, thus releasing the pressure on the underlying median nerve (Ablove 1994; Richman 1989). Cannon and Love first described carpal tunnel release in 1946. The surgery was per- formed under direct vision, with a skin incision along the axis of the palm, followed by dissection of the subcutaneous tissue and cutting of the underlying transverse ligament. Following the first description of the surgical technique, many modifications were published, mainly regarding the shape and the extent of the surgical incision. More recent literature usually suggests less extended surgical trauma with an incision no more than $2 \mathrm{~cm}$ to $3 \mathrm{~cm}$ in length (Higgins 2002; MacKinnon 2005). Additional interventions have also been suggested in the past in order to increase the efficacy of CTS surgical treatment. Epineurotomy or even internal neurolysis of the median nerve have been performed, but are not common and are not performed except for specific indications (Curtis 1973; Fissette 1979). Reconstruction of the transverse ligament has also been proposed but authors have not managed to demonstrate its superiority, as several studies have shown an increased recurrence rate with this procedure (Karlsson 1997).

All techniques described above have the common step of dividing the skin and underlying tissue in addition to the transverse ligament. Endoscopic carpal tunnel release (ECTR) is a relatively new procedure, first being described in 1989 by Chow and Okutsu (Chow 1989; Okutsu 1989). It requires the use of special instrumentation, including an endoscopic camera, optic fibre light source and a monitor. The procedure is performed with one or two small incisions (portals) proximal or distal to the carpal tunnel. Instrumentation is advanced through those portals, underneath the transverse ligament. With the aid of a camera, the surgeon obtains indirect access to the bottom surface of the transverse ligament. The ligament is cut from its lower surface with a knife, thus preserving the subcutaneous tissue and the overlying skin. Several variations of the endoscopic method have been subsequently developed, although the two more commonly used techniques are the one-portal technique described by Agee (Agee 1992; Agee 1994), and the two-portal technique described by Chow (Chow 1989; Chow 1993).

\section{How the intervention might work}

The proposed advantage of ECTR over open techniques is that by accessing and dividing the transverse carpal ligament from within the carpal tunnel, the surgeon leaves overlying structures intact. This is thought to decrease postoperative morbidity by reducing pain, providing faster trauma healing, shortening patients' rehabilitation time and allowing an earlier return to work. The skin and subcutaneous tissue palmar to the transverse ligament have also been considered to have a pulley effect over the digital flexor tendons. Thus, preservation of these overlying tissues might enhance the increase in grip strength of the hand postoperatively (Macdermid 2003; Vasiliadis 2010).

ECTR should also be studied from a financial point of view. ECTR has been attacked on the grounds of the increased cost of instrumentation and surgeons' training expenses (Lorgelly 2005). On the other hand, an earlier return to work and a shorter period of sick leave must also be included in any evaluation of the total economic impact of the operation (Saw 2003).

Finally, there is a controversy regarding the safety of ECTR compared to conventional open carpal tunnel release (OCTR). Given that it takes longer for a surgeon to master the ECTR technique, some authors suggest that it is a dangerous surgical option for patients. 


\section{Why it is important to do this review}

Since it was first described in 1989, endoscopic treatment of CTS has become increasingly popular. Among the surgical options, it is considered to be less invasive and to lead to faster postoperative rehabilitation due to decreased surgical trauma.

Companies launch new or improved instrument for ECTR regularly, and subsequent marketing also contributes to wider use of the technique. However, endoscopic surgery is costly and requires specialised training and equipment.

There is therefore interest in, and a need for, an evaluation of the current endoscopic technique. The main questions that need to be answered relate to its efficacy and safety compared to OCTR, which remains the gold standard method for carpal tunnel release. Despite the first studies' scepticism regarding the safety of ECTR, after a period of modifications to the method and growing experience, endoscopic and open methods appear to have comparable complication rates according to more recent studies and reviews (Boeckstyns 1999). With endoscopic surgery, the limited surgical trauma is believed to offer better rehabilitation and a faster recovery, removing all the complications of incision (Vasiliadis 2006).

The first review comparing surgical treatments of CTS was published in 2001 (Gerritsen 2001). Scholten et al. have since published updates of that review in The Cochrane Library in 2002, 2004 and 2007 (Scholten 2007).

Due to the increasing number of studies since Scholten 2007, the review of surgical treatment for CTS has been split into smaller reviews, of which this is the first. This review focuses on ECTR techniques. The Scholten 2007 review is the reference for other surgical interventions for CTS until it is superseded by new, focused reviews.

\section{O B JECTIVES}

To assess the effectiveness and safety of the endoscopic techniques of carpal tunnel release compared to any other surgical intervention for the treatment of carpal tunnel syndrome. More specifically, to evaluate the relative impact of the endoscopic techniques in relieving symptoms, producing functional recovery (return to work and return to daily activities) and reducing complication rates.

\section{METHODS}

\section{Criteria for considering studies for this review}

\section{Types of studies}

We considered any randomised controlled trial (RCT) and quasi-RCT comparing endoscopic carpal tunnel release (ECTR) with any other surgical intervention for the treatment of carpal tunnel syndrome (CTS). We did not apply any language restriction.

Measurement of particular outcomes was not used as an eligibility criterion for study inclusion.

\section{Types of participants}

We included studies with participants with clinical diagnosis of CTS with or without electrophysiological confirmation. We accepted the authors' definition of CTS and their views of what constituted electrophysiological confirmation.

\section{Types of interventions}

We considered studies comparing ECTR with any other surgical intervention. This included open carpal tunnel release (OCTR) and its variations, OCTR with mini-open technique and OCTR with concomitant interventions (such as lengthening of flexor retinaculum, internal neurolysis, epineurotomy or tenosynovectomy). We also included studies comparing different techniques of ECTR with each other.

\section{Types of outcome measures}

\section{Primary outcomes}

The primary outcome assessed was overall improvement of symptoms, considering any measure in which participants indicated the intensity of their complaints compared to the pre-operative status. We considered questionnaires measuring the overall improvement of symptoms with ratings of the kind 'improved' or 'not improved' or any patient-reported questionnaire assessing overall satisfaction.

\section{Secondary outcomes}

We evaluated the following secondary outcome measures.

1. Improvement of CTS symptoms, as measured by the Symptom Severity Score (SSS) (Levine 1993) or any other measure for improvement in pain, paraesthesiae, or nocturnal paraesthesia. If data for symptoms were presented separately for pain or paraesthesia they were used as long as they were measured using a validated instrument.

2. Disability measured with the Disabilities of the Arm, Shoulder and Hand (DASH) questionnaire (Hudak 1996).

3. Function measured with the Functional Status Scale (FSS) questionnaire (Levine 1993).

4. Grip strength.

5. Time to return to work or to resume activities of daily living.

We took both short-term (less than or equal to three months) and long-term (greater than three months) measures of overall improvement and improvement in CTS symptoms into consideration. In cases where multiple time points were reported, as the shortterm measure we used the closest measure to three months. For long-term effects, we used the latest follow-up measurement (if at more than three months).

We also assessed the risk of complications as reported by the authors, which were measured as the proportion of patients with:

1. recurrence;

2. re-operations;

3. major complications (for example, nerve, vascular or tendon injuries); and

4. minor complications (for example, pain, scar disorders).

\section{Search methods for identification of studies}

\section{Electronic searches}

On 18 November 2013, we searched the Cochrane Neuromuscular Disease Group Specialized Register, CENTRAL (2013, Issue 11 in The Cochrane Library), MEDLINE (January 1966 to November 2013) and EMBASE (January 1980 to November 2013). There were no language 
restrictions in the search strategy. We reviewed the reference lists of relevant articles and contacted trial authors.

This review fully incorporates the results of searches conducted up to November 2012. We updated the search in November 2013, to identify any additional studies to address in the next update.

The detailed search strategies are in the appendices: Appendix 1 (Cochrane Neuromuscular Disease Group Specialized Register), Appendix 2 (CENTRAL), Appendix 3 (MEDLINE), and Appendix 4 (EMBASE).

\section{Searching other resources}

We searched reference lists of all primary studies and review articles for additional references. We also searched trial registers for ongoing trials: US National Institutes of Health ClinicalTrials.gov (www.clinicaltrials.gov) (June 2013), Current Controlled Trials (www.controlled-trials.com) (ISRCTN Register, Action Medical Research (UK), The Wellcome Trust (UK), UK trials (UK)) (June 2013), UK Clinical Trials Gateway (www.ukctg.nihr.ac.uk/default.aspx) (June 2013) and the World Health Organization Clinical Trials Registry Platform (www.who.int/ictrp/en/) (June 2013) (see Appendix 5).

\section{Data collection and analysis}

\section{Selection of studies}

Two review authors (HSV, IS) independently scanned records retrieved by the initial search. We included only RCTs and quasi-RCTs. We excluded obviously irrelevant studies and we retrieved for further evaluation the full text of studies chosen by at least one of the two authors. The authors resolved disagreements by discussion.

To be included, a study had to meet the following criteria:

1. the study population consisted of people with CTS;

2. ECTR was compared with an open surgical technique; and

3. the study was designed as an RCT.

\section{Data extraction and management}

Two review authors (HSV, PG) extracted data independently using pre-standardised forms. Data extraction forms included information on methods, participants, interventions and outcomes. We compared extracted data and resolved differences by discussion. One author (HSV) entered the data into the Cochrane software Review Manager 5 (RevMan) (RevMan 2012), and another author (PG) checked the data entry on completion.

\section{Assessment of risk of bias in included studies}

Two review authors (HSV, PG) independently assessed the risk of bias for each trial using the Cochrane Collaboration's tool described in the Cochrane Handbook for Systematic Reviews of Interventions (Higgins 2011b, updated Higgins 2011a).

We assessed the adequacy of sequence generation, allocation concealment and blinding (of participants, personnel and outcome assessors) and we made judgements about the possible impact of incomplete outcome data, selective outcome reporting and other sources of bias. We evaluated each item as at low, high or unclear risk of bias.
The criteria for judging the risk of bias in each study are given in details in table 8.5.c of the Cochrane Handbook for Systematic Reviews of Interventions (Higgins 2011b). We have presented the bias items that we adapted to the context of our review below in more detail.

\section{Blinding}

It is not possible to blind either surgeons or the participants to the performed operation. Surgical incisions are always obvious. Thus, we scored all studies as at high risk of bias for the item 'blinding of participants and personnel', unless otherwise reported by the authors. However, the outcome assessor could be blinded (for example, for assessing grip strength).

We gave the following judgements: 'low' when assessors were blinded to the performed operation technique, 'high' when they were not blinded and 'unclear' if the authors gave no information regarding the blinding of outcome assessment.

\section{Addressing incomplete outcomes}

We collected the number of dropouts and reasons for attrition or exclusion. We evaluated whether intention-to-treat (ITT) analysis had been performed and recorded differences in attrition between intervention groups.

The judgement was 'low risk of bias' when there were no missing values in the outcome data, when the numbers of and reasons for missing values were not likely to affect the outcome, or when imputations to achieve ITT analysis were appropriate. When the extent of missing outcome data and the reasons for missing data were likely to have affected the outcome, then the judgement was 'high risk of bias'. Our assessment was 'unclear' when trial authors did not provide enough information about the amount of attrition and the reasons for it.

\section{Selective reporting}

We evaluated the possibility of selective reporting. We based our judgements primarily on comparing the study protocols (if these could be identified) with the published report. We searched in www.clinicaltrials.gov and www.controlled-trials.com (ISRCTN Register, Action Medical Research (UK), the Wellcome Trust (UK), and UK trials (UK)) to identify protocols of the included studies. In the absence of the protocols we evaluated whether reports presented all expected outcomes and whether there was agreement between the methods section and the results.

The judgement was 'low risk of bias' when it was clear from the protocol, the published report, or both that all outcomes were fully reported. We classified trials as at 'high risk of bias' when it was clear that the articles did not present results for some measured outcomes. We classified papers as 'unclear' when it was not clear whether the report presented results for all analysed outcomes.

\section{Other bias}

We considered two additional sources of bias.

Trial sponsors (usually manufacturers of the instrumentation needed in ECTR) could have biased the results. Our judgement was 'high risk of bias' if there was a sponsor and 'low risk of bias' when there was a statement that the trial had not received any funding from a party with a vested interest; otherwise the judgement was 'unclear'. 
As we anticipated that trials would have small sample sizes, we considered that the presence of baseline differences might have an impact on the results. We classified studies with baseline imbalance in important participant characteristics as at 'high risk of bias'. If there were no such differences or these differences at baseline were not clinically relevant, we classified the study as being at 'low risk of bias'. We reserved 'unclear risk of bias' for studies with insufficient information to form a judgement.

\section{Measures of treatment effect}

\section{Dichotomous data}

We described dichotomous data using the risk ratio with 95\% confidence interval $(\mathrm{Cl})$.

\section{Continuous data}

For continuous outcomes measured with the same scale, we used the mean difference and $95 \% \mathrm{Cl}$. When studies used different scales for the same outcome, we calculated the standardised mean difference. We collected results based on change scores only if final values were not available.

\section{Unit of analysis issues}

Bilateral CTS and surgical treatment of both hands are common in such trials. If results are reported for the first hand only, we used these to bypass the problem of dependency.

In the event of bilateral involvement where study authors analysed and presented data for hands rather than for participants, we had planned to extract effect sizes that account for the dependency of observations (such as effects calculated with generalised estimating equations or methods for cluster randomised trials). Many studies randomise participants in both groups: randomisation takes place for the first hand whereas the second hand is operated with the alternative technique. In such cases we extracted outcomes taking into account the paired nature of the data by seeking information on paired statistics and estimate standard errors as described in Section 16.4.6 of the Cochrane Handbook for Systematic Reviews of Interventions (Higgins 2011b, updated Higgins 2011a). When the correlation coefficient was not provided to derive the appropriate adjusted estimate we employed a correlation of 0.5 for the standard analysis and we used two other extreme values of 0.1 and 0.9 in a sensitivity analysis.

In some cases, we could not obtain adjusted estimates and in other cases, only a subset of the participants underwent operations on both hands and it was unclear whether randomisation took place for hands or participants. In these cases, we collected crude estimates based on outcomes pertaining to hands along with the number of randomised participants who contributed information from both hands to evaluate the degree of dependence in the outcomes.

In this latter case, we used sensitivity analysis to evaluate the extent to which the conclusions of the meta-analysis might be altered by failure to account for bilateral involvement in individual trials.

In the case of three-arm studies with more than two eligible study groups, the sample size and event rate of the ECTR group were divided by two, so that the participants randomised to ECTR were not double counted.

\section{Dealing with missing data}

With the purpose of including all participants randomised to any intervention, we made every effort to extract data according to the ITT principle; that is, to analyse participants as randomised. When outcome data were not available for some participants, we included the data as reported and we recorded the analysis method (for example, whether results pertain to per protocol or available cases analysis) and noted the lack of ITT as a risk of bias.

\section{Assessment of heterogeneity}

We evaluated the presence of clinical heterogeneity by comparing the participants' characteristics and the methodology across studies (see Data synthesis). We assessed statistical heterogeneity by visual inspection of the forest plots along with consideration of the test for heterogeneity and the 12 statistic. We examined possible sources of heterogeneity by means of subgroup analysis.

\section{Assessment of reporting biases}

For outcomes with at least ten studies, we drew funnel plots to assess the association between study size and effect size. Where appropriate, we used contour enhanced funnel plots to distinguish between reporting bias and other causes of asymmetry.

\section{Data synthesis}

We synthesised outcome data from studies sufficiently similar in participant characteristics (for example, age, sex, grip strength, distal motor/sensory latency) and methodology followed (length of follow-up, diagnostic criteria) using a random-effects model. We also calculated summary estimates according to fixed-effect models as part of the sensitivity analysis. We decided a priori that if the $95 \% \mathrm{Cl}$ for the random-effects summary estimate included the $95 \%$ $\mathrm{Cl}$ for the fixed-effect summary estimate, we would report only the former as it appropriately conveys heterogeneity.

\section{Subgroup analysis and investigation of heterogeneity}

For outcomes with enough studies, we undertook pre-specified subgroup analyses to investigate differences in the effect sizes and heterogeneity across subgroups. The subgroups were: a) the open technique used (standard incision or modified incision including mini-open techniques, with or without concomitant procedures such as neurolysis or transverse ligament reconstruction); and b) the endoscopic technique (one or two portals).

\section{Sensitivity analysis}

We conducted sensitivity analyses to assess the robustness of the conclusions. We planned to exclude studies according to the following characteristics.

1. High or unclear risk of bias for incomplete outcome data.

2. Inappropriate adjustment for bilateral involvement.

3. High or unclear risk of bias for allocation concealment.

Only complications were reported in a sufficiently large number of studies to allow sensitivity analysis and very few studies were at low risk of bias (nine for incomplete outcome data and two for allocation concealment). Therefore, we performed sensitivity analysis only when enough studies (three or more) per outcome were available. 


\section{'Summary of findings' table}

We included the outcomes: overall improvement (main outcome), SSS, FSS, grip strength, time to return to work, reoperations, and major complications (for example, nerve, vascular or tendon injuries) in the 'Summary of findings' table.

For continuous outcomes (SSS, FSS, grip strength, time to return to work), we used the range of mean values in the control group (nonendoscopic intervention) as assumed risk.

For binary outcomes (overall improvement, re-operations and major complications) we calculated the assumed risk from the control intervention of the included RCTs by simply merging samples, as we did not expect important variations and we anticipated a small number of studies.

For both types of outcome, we used the summary estimate from the meta-analysis to calculate the corresponding risk for endoscopic surgery, using the open technique as the reference, according to Schünemann 2008.

The protocol of this review was published in the Cochrane Library (Vasiliadis 2010b).

\section{RES U LTS}

\section{Description of studies}

\section{Results of the search}

From the searches to November 2012, the number of possibly relevant studies identified from each database were as follows: 58 from the Cochrane Neuromuscular Disease Group Specialized Register, 137 from CENTRAL, 294 from MEDLINE and 174 from EMBASE. We found a total of 663 publications from database searches and one from other sources. After removal of the duplicated abstracts, 545 were left for evaluation.

A total of 72 titles and abstracts regarding various surgical treatment options for carpal tunnel syndrome (CTS) seemed to fulfil the inclusion criteria and required further discussion between the authors. After discussion, we excluded 23; thus we evaluated 49 studies. We included seven studies reported only as abstracts and retrieved 42 full manuscripts for further evaluation. We finally judged seven abstracts and 26 manuscripts to fulfil the inclusion criteria for this systematic review. We have illustrated the study selection process in a flow diagram (Figure 1). 
Figure 1. Study flow diagram (does not include the results of search in November 2013, which will be fully assessed in the next update).

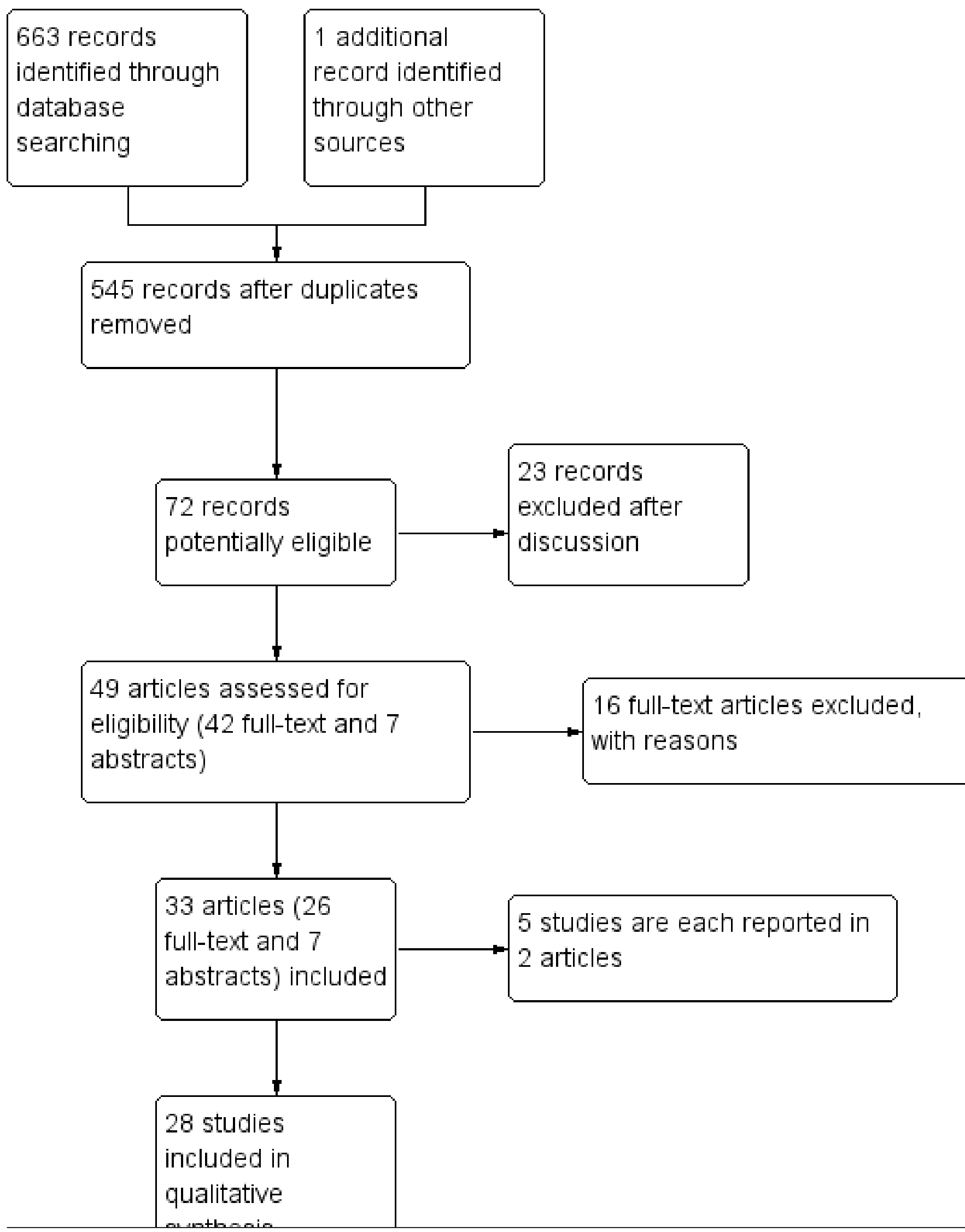


Five papers were removed because of duplication. One study was published twice (in German and in English), so the results of both sets of papers were combined (Benedetti/Sennwald 1995). Atroshi 2006 and Atroshi 2009 presented short-term and long-term data respectively, from the same study. In one study (Foucher 1993), the results were duplicated in another publication in manuscript form (Braga 1996), and also in an abstract (Foucher 1994). We were unable to find Ugurlu 2009 in a full manuscript and we included it in the Studies awaiting classification.

Thus, we finally included 28 genuine studies in the review. Details of the participants, interventions and outcomes in these studies are presented in Characteristics of included studies.

Since the last update of Scholten 2007, we have identified four new studies (Incoll 2004; Malhotra 2007; Tian 2007; Tüzüner 2008). We also included Giele 2000; Koskella 1996; Sørensen 1997 and Werber 1996, which were awaiting assessment in Scholten 2007, and Schäfer 1996, which was previously excluded as a quasi-randomised trial.

Shortly before publication, in November 2013, we checked an updated search for additional studies and identified three further potentially eligible trials (Aslani 2012; Ejiri 2012; Kang 2013). These have not yet been incorporated into the results and will be addressed in the next update. See Characteristics of studies awaiting classification for details.

\section{Included studies}

Twenty-eight studies were finally included in this review (see Characteristics of included studies). Five of the studies were presented only as an abstract (Giele 2000; Incoll 2004; Koskella 1996; Sørensen 1997; Werber 1996).

In total, 2586 hands were assessed, 1316 treated with endoscopic carpal tunnel release (ECTR) and 1270 with open carpal tunnel release (OCTR). Twenty-five studies compared ECTR with standard OCTR (Agee 1992; Atroshi 2006; Benedetti/Sennwald 1995; Brown 1993; Dumontier 1995; Eichhorn 2003; Erdmann 1994; Ferdinand 2002; Foucher 1993; Giele 2000; Hoefnagels 1997; Incoll 2004; Jacobsen 1996; Koskella 1996; Macdermid 2003; Malhotra 2007; Saw 2003; Schäfer 1996; Sørensen 1997; Stark 1996; Tian 2007; Trumble 2002; Tüzüner 2008; Werber 1996; Westphal 2000) (Table 1), and five studies compared ECTR with OCTR using a modified incision (Eichhorn 2003; Mackenzie 2000; Rab 2006; Sørensen 1997; Wong 2003) (Table 2). In Eichhorn 2003 and Sørensen 1997, both conventional open and mini-open techniques were compared with ECTR.

Different types of ECTR were applied. All techniques were aimed at dividing the transverse carpal ligament from within the carpal tunnel but differed in the way in which this was achieved. Eleven studies addressed Agee's one-portal technique (Agee 1992; Benedetti/Sennwald 1995; Ferdinand 2002; Foucher 1993; Hoefnagels 1997; Mackenzie 2000; Malhotra 2007; Saw 2003; Schäfer 1996; Stark 1996; Trumble 2002), and five studies evaluated other one-portal techniques (Sørensen 1997; Tian 2007; Tüzüner 2008; Werber 1996; Westphal 2000). The other techniques evaluated included the Menon's one-portal technique (Tüzüner 2008), the Concept CTS Relief Kit (Sørensen 1997), the Okutsu technique (Tian 2007), the Endo-Cartris technique (Westphal 2000), with one paper not describing the technique adequately enough to be categorised
(Werber 1996). In nine studies Chow's two-portal technique was used (Atroshi 2006; Brown 1993; Dumontier 1995; Eichhorn 2003; Erdmann 1994; Jacobsen 1996; Macdermid 2003; Rab 2006; Wong 2003). Three studies did not describe the exact ECTR technique used (Giele 2000; Incoll 2004; Koskella 1996).

Nineteen studies solely addressed patients with electrophysiologically-confirmed CTS (Agee 1992; Atroshi 2006; Benedetti/Sennwald 1995; Brown 1993; Eichhorn 2003; Erdmann 1994; Ferdinand 2002; Hoefnagels 1997; Jacobsen 1996; Koskella 1996; Macdermid 2003; Mackenzie 2000; Malhotra 2007; Rab 2006; Sørensen 1997; Tian 2007; Trumble 2002; Tüzüner 2008; Wong 2003); one study addressed both patients with and without electrophysiologically-confirmed CTS (Stark 1996) and two studies addressed patients with clinical CTS where electrophysiological confirmation was not required (Foucher 1993; Saw 2003). In two studies it was not clear how CTS was diagnosed (Dumontier 1995; Westphal 2000).

One study also addressed patients with secondary CTS (Erdmann 1994). In nine studies the type of CTS was not mentioned (Eichhorn 2003; Foucher 1993; Hoefnagels 1997; Incoll 2004; Koskella 1996; Macdermid 2003; Schäfer 1996; Sørensen 1997; Werber 1996).

Only participants with unilateral CTS were included in nine studies (Atroshi 2006; Benedetti/Sennwald 1995; Dumontier 1995; Foucher 1993; Hoefnagels 1997; Macdermid 2003; Schäfer 1996; Werber 1996; Westphal 2000). Sørensen 1997 gave no information about unilateral or bilateral involvement.

In six studies only patients with bilateral CTS were included (Ferdinand 2002; Giele 2000; Incoll 2004; Rab 2006; Stark 1996; Wong 2003). In two of those studies the first hand was randomised to either ECTR or OCTR and, after full recovery of the first hand (Stark 1996), or after at least six months (Rab 2006), the other hand received the alternative treatment. In both studies the timing of the procedures was discarded and in one the analysis pertained to all hands, violating the assumption of independent observation (Stark 1996). In the other three studies, ECTR was randomly allocated to one hand only (Ferdinand 2002; Incoll 2004; Wong 2003). The other hand was treated with the alternative procedure in the same session in Ferdinand 2002 and Wong 2003. No information about the time of second surgery is given in Giele 2000 and Incoll 2004. One of the six studies with a matched design applied an appropriate statistical analysis (Ferdinand 2002). Two further studies provided data for which we were able to obtain relative treatment effects for pain adjusted for matching, assuming a correlation coefficient of 0.5 (Rab 2006; Wong 2003). We subsequently evaluated the impact of this assumption in a sensitivity analysis.

In 10 studies some (but not all) of the participants had bilateral CTS (Agee 1992; Brown 1993; Erdmann 1994; Jacobsen 1996; Koskella 1996; Mackenzie 2000; Saw 2003; Tian 2007; Trumble 2002; Tüzüner 2008). In Malhotra 2007, one participant (out of 60) had a bilateral open surgery. In Agee 1992, randomisation of participants with bilateral CTS was discarded because participants who were randomised to ECTR refused to undergo OCTR as a second procedure. Therefore, the 25 participants with bilateral CTS were omitted from further analysis. For the other nine studies that included some participants with bilateral CTS, the articles provided no further details regarding the analysis. 


\section{Excluded studies}

We excluded 16 trials from this systematic review (see Characteristics of excluded studies). We excluded 10 studies because the participants were not randomised (Dimitriou 1997; Flores 2005; Futami 1995; Hallock 1995; Povlsen 1997; Uchiyama 2002; Uchiyama 2004; Vasiliadis 2010; Worseg 1996; Zhao 2004), and three studies assessed the validity of scores (Atroshi 2007; Katz 1994b), or responsiveness of measures (Katz 1994a). Bal 2008; Cellocco 2005 and Lorgelly 2005 compared open with mini-open techniques.
In Agee 1992, inadequate randomisation applied to the 25 participants with bilateral involvement, but not to the remaining 97 participants with unilateral involvement. Data regarding return to work were presented separately for those 97 participants and these data were included in our review.

\section{Risk of bias in included studies}

The results of the 'Risk of bias' assessment are presented in the Characteristics of included studies and summarised in Figure 2. Additionally, we have provided a brief descriptive account of the studies below. 
Figure 2. 'Risk of bias' summary: review authors' judgements about each 'Risk of bias' item for each included study. Green $(+)=$ low risk of bias; yellow (?) = unclear risk of bias; red $(-)=$ high risk of bias

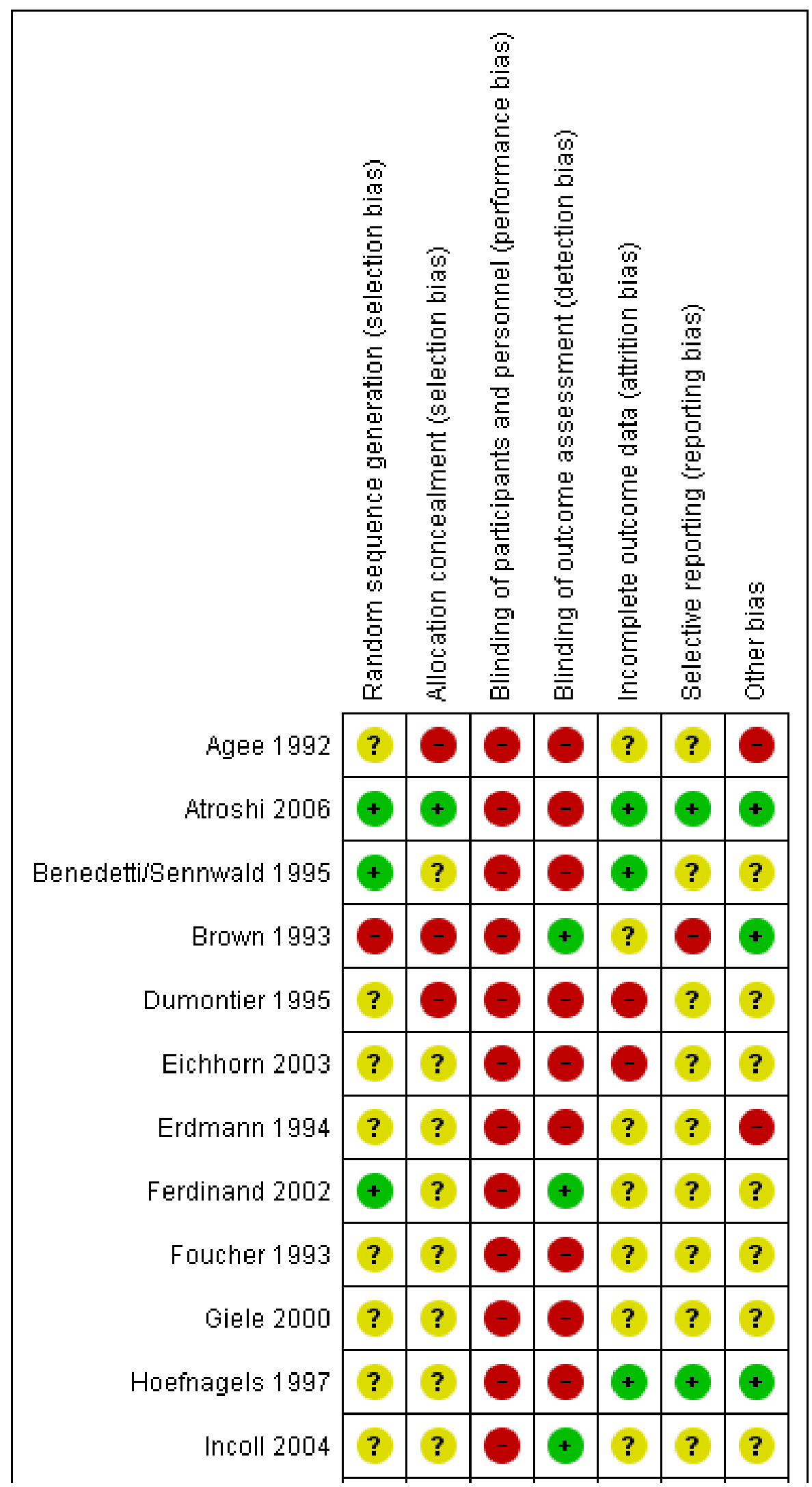


Figure 2. (Continued)

\begin{tabular}{|c|c|c|c|c|c|c|c|}
\hline Ruerragess I syi & : & : & $\sigma$ & $\sigma$ & + & + & 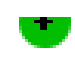 \\
\hline Incoll 2004 & $?$ & $?$ & & + & $?$ & $?$ & $?$ \\
\hline Jacobsen 1996 & $?$ & $?$ & & & + & $?$ & $?$ \\
\hline Koskella 1996 & $?$ & $?$ & & & $?$ & $?$ & $?$ \\
\hline Macdermid 2003 & $?$ & $?$ & & + & $?$ & $?$ & $?$ \\
\hline Mackenzie 2000 & $?$ & 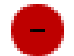 & & & & $?$ & $?$ \\
\hline Malhotra 2007 & $?$ & $?$ & & & $?$ & $?$ & + \\
\hline Rab 2006 & $?$ & & & & + & 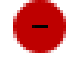 & $?$ \\
\hline Saw 2003 & + & $?$ & & . & + & $?$ & \\
\hline Schäfer 1996 & & & & & + & $?$ & $?$ \\
\hline Stark 1996 & $?$ & $?$ & & 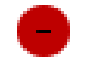 & + & 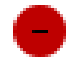 & $?$ \\
\hline Sgrensen 1997 & $?$ & $?$ & & & $?$ & $?$ & $?$ \\
\hline Tian 2007 & $?$ & $?$ & & & $?$ & $?$ & $?$ \\
\hline Trumble 2002 & $?$ & 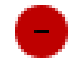 & & + & $?$ & 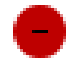 & + \\
\hline Tüzüner 2008 & + & + & & & + & + & 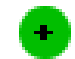 \\
\hline Werber 1996 & $?$ & $?$ & & & $?$ & $?$ & $?$ \\
\hline Westphal 2000 & $?$ & $?$ & & 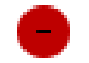 & $?$ & $?$ & $?$ \\
\hline Wong 2003 & + & $?$ & & & $?$ & & + \\
\hline
\end{tabular}




\section{Allocation}

Appropriate sequence generation to ensure randomisation seemed likely in seven studies (Atroshi 2006; Benedetti/Sennwald 1995; Brown 1993; Ferdinand 2002; Saw 2003; Tüzüner 2008; Wong 2003). Schäfer 1996 was a quasi-randomised trial, as the treatment was allocated according to the day of the week (odd or even). None of the other trials adequately described the method of randomisation.

Allocation concealment was adequate in three studies (Atrosh 2006; Brown 1993; Tüzüner 2008). The method of allocation concealment was judged to be inappropriate, resulting in a high risk of bias, in six trials (Agee 1992; Dumontier 1995; Mackenzie 2000; Rab 2006; Schäfer 1996; Trumble 2002). The method of concealment was not clearly described in 19 studies.

\section{Blinding}

Owing to the type of intervention, the participants and personnel could not be blinded and, therefore, we scored this item 'high risk of bias' for all studies.

Outcome assessors were blinded to the intervention in six studies (Brown 1993; Ferdinand 2002; Incoll 2004; Macdermid 2003; Saw 2003; Trumble 2002).

In Atroshi 2006, the authors say that "Before each postoperative examination, the patients were instructed not to discuss the type of operation and had their palm and distal forearm covered with a stockinette (an elastic, sleeve-like dressing) concealing the scars. The assessor was thus blinded to the surgical method." However, there was no reference to blinding in the five-year follow-up (of Atroshi 2009). Given that most of the outcomes were patient-assessed questionnaires and that complications and the long-term outcomes were assessed in the latest follow-up of Atroshi 2009, we concluded that there was a high risk of performance and detection bias for this study.

\section{Incomplete outcome data}

In nine studies the risk of attrition bias was considered to be low (Atroshi 2006; Benedetti/Sennwald 1995; Hoefnagels 1997; Jacobsen 1996; Rab 2006; Saw 2003; Schäfer 1996; Stark 1996; Tüzüner 2008). None of the participants were lost to follow-up in Jacobsen 1996, Rab 2006, Schäfer 1996, Stark 1996 and Tüzüner 2008. The number of participants lost to follow-up or converted to another treatment was equally distributed between the groups, or in three studies was too small to qualitatively affect the final outcome (Atroshi 2006; Benedetti/Sennwald 1995; Hoefnagels 1997). In Malhotra 2007, six participants out of 36 and four out of 34 were lost to follow-up from the OCTR and ECTR groups respectively, at both one and six months. Although the number was comparable between groups, the incidence was quite large (15\%) and the trial authors provided no explanation. Therefore, we judged the risk of attrition bias to be unclear. In Saw 2003, with respect to measures repeated over time, the investigators used a 'last observation carried forward' strategy to impute missing values. The review authors judged this study to be at low risk of attrition bias.

Three studies had a high risk of attrition bias (Dumontier 1995; Eichhorn 2003; Mackenzie 2000). Many participants did not provide outcomes in Dumontier 1995 (27 of 85 at three months and 65 of 85 at six months). In Eichhorn 2003, ECTR participants that intraoper- atively went to open surgery were excluded from the analysis. In Mackenzie 2000 there was no information about the number of participants initially enrolled. In Agee 1992, the authors reported that only one to two participants in each group were missing for the activities of daily living outcome, but only said "a small number of observations was missing" when referring to other variables. Participants with bilateral involvement were also excluded from the analysis. We judged the risk of bias in this study to be unclear.

For the rest of the trials, insufficient information was provided to draw a safe conclusion.

\section{Selective reporting}

Only three of the studies were judged to be free of selective reporting (Atroshi 2006; Hoefnagels 1997; Tüzüner 2008).

Some but not all pre-specified outcomes and time points were reported in an adequate way in Brown 1993, Eichhorn 2003, Jacobsen 1996, Rab 2006, Saw 2003, Schäfer 1996, Stark 1996, Trumble 2002 and Wong 2003. Also, all the trials presented as abstracts provided insufficient information (Giele 2000; Incoll 2004; Koskella 1996; Sørensen 1997; Werber 1996).

No numerical data were provided for any of the outcomes in Foucher 1993. Agee 1992, Ferdinand 2002, Mackenzie 2000, Malhotra 2007, Stark 1996, Tian 2007 and Westphal 2000 gave no standard deviations (SDs) for any of the outcomes and we were not able to extract them from other statistics (for example, $\mathrm{P}$ values). Only diagrams, with no further information (definite outcomes, SDs, etc), were provided in Erdmann 1994, and Macdermid 2003. Overall, poor reporting characterised the majority of the included trials.

Funnel plots for all outcomes with at least ten studies appeared reasonably symmetric. However, the small differences between fixedeffect and random-effects models for complications might suggest that small studies give different results compared to large studies.

\section{Other potential sources of bias}

Only six of the studies were judged to be free of other bias (Atroshi 2006; Brown 1993; Malhotra 2007; Trumble 2002; Tüzüner 2008; Wong 2003). They clearly did not have baseline differences and the trials were not sponsored by a party with vested interests. Atroshi 2006, Hoefnagels 1997, Malhotra 2007 and Trumble 2002 had a form of financial support, but from an academic source.

In Agee 1992, the authors declared a conflict of interest as the study was supported in part by the manufacturer of the device used for the release. Nine studies clearly reported no conflict of interest (Atroshi 2006; Brown 1993; Ferdinand 2002; Incoll 2004; Macdermid 2003; Malhotra 2007; Trumble 2002; Tüzüner 2008; Wong 2003).

Baseline differences were found in Erdmann 1994 and Saw 2003.

None of the other studies provided sufficient information to draw a safe conclusion regarding baseline differences or financial support. Therefore, we judged their risk of bias as unclear.

\section{Effects of interventions}

See: Summary of findings for the main comparison Endoscopic versus open or mini-open carpal tunnel release for carpal tunnel syndrome 


\section{Endoscopic versus open and modified open carpal tunnel} release

\section{Short-term efficacy results (three months or less)}

Out of 25 studies that compared ECTR with OCTR, 18 presented results on the short-term effects (Agee 1992; Atroshi 2006; Brown 1993; Dumontier 1995; Erdmann 1994; Ferdinand 2002; Giele 2000; Hoefnagels 1997; Incoll 2004; Macdermid 2003; Malhotra 2007; Saw 2003; Sørensen 1997; Stark 1996; Tian 2007; Trumble 2002; Tüzüner 2008; Westphal 2000). In 11 of the 18 studies, no differences were found between the groups for the outcomes assessed (Agee 1992; Atroshi 2006; Brown 1993; Dumontier 1995; Erdmann 1994; Hoefnagels 1997; Macdermid 2003; Saw 2003; Stark 1996; Tüzüner 2008; Westphal 2000). Seven studies concluded a superiority of ECTR over OCTR (Ferdinand 2002; Giele 2000; Incoll 2004; Malhotra 2007; Sørensen 1997; Tian 2007; Trumble 2002) (Table 1; Table 2).
Overall improvement and overall satisfaction were assessed only in Brown 1993, where no difference was found between ECTR and OCTR (Analysis 1.1; Analysis 1.2).

Meta-analysis was possible for five studies that assessed the Symptom Severity Scale (SSS) and the same five had assessed the Function Status Scale (FSS) (Atroshi 2006; Hoefnagels 1997; Rab 2006; Trumble 2002; Westphal 2000). SSS and FSS as described in the original study of Levine correspond to a scale from one to five, with one being the most favourable outcome (Levine 1993). Westphal 2000 reported a modification of SSS and FSS, which necessitated the use of standardised mean difference (SMD) as the summary estimate. Summary estimates showed no statistically significant differences between ECTR and OCTR either in SSS (five studies, 551 participants, SMD -0.13 , 95\% confidence interval $(\mathrm{Cl})-0.47$ to 0.21 ) (Analysis 1.3; Figure 3) or in FSS (five studies, 551 participants, SMD $-0.23,95 \% \mathrm{Cl}-0.60$ to 0.14 ) (Analysis 1.4 ; Figure 4). In both metaanalyses there was large heterogeneity, with 12 of $74 \%$ and $78 \%$, respectively. The Disabilities of the Arm, Shoulder and Hand (DASH) questionnaire was not assessed in any of the studies.

Figure 3. Forest plot of comparison: 1 Endoscopic versus open or mini-open carpal tunnel release, outcome: 1.3 Symptom Severity Scale (Levine) at 3 months or less.

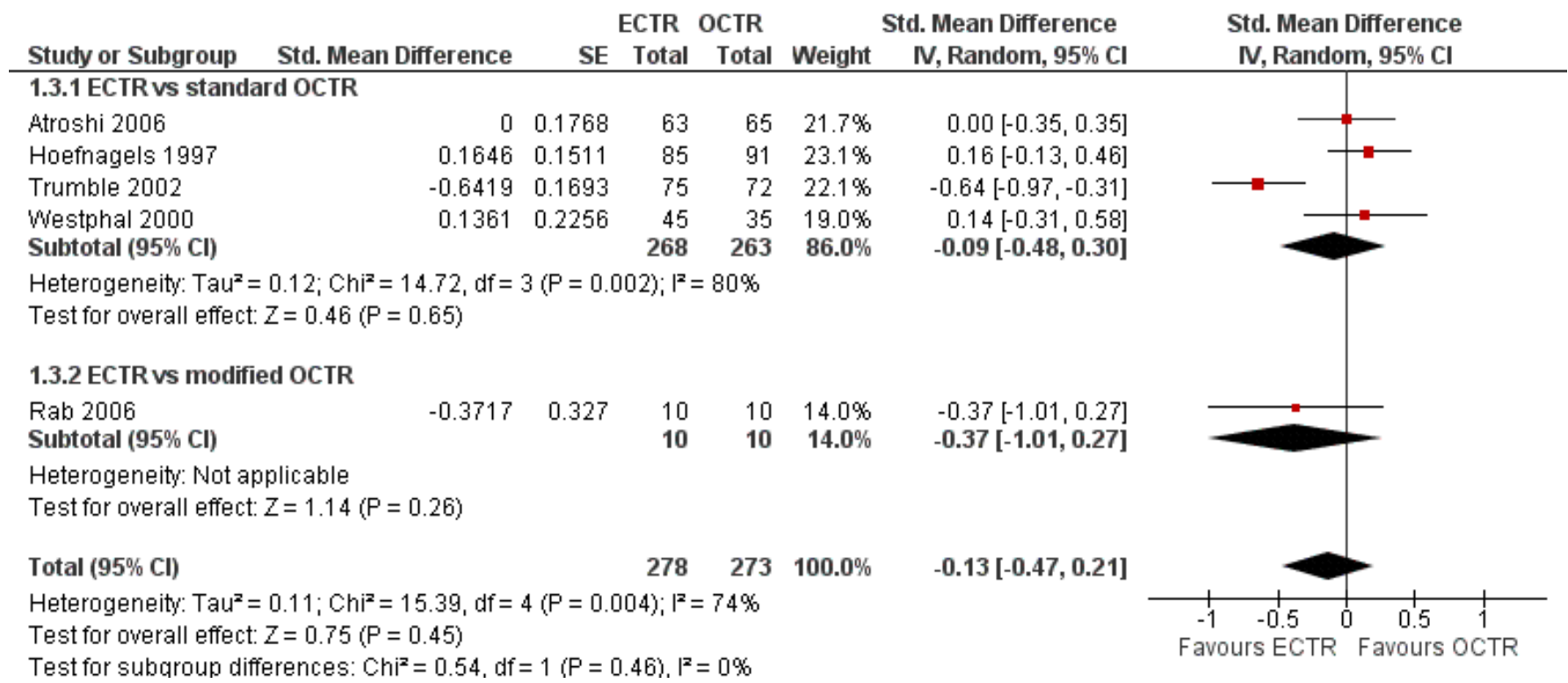


Figure 4. Forest plot of comparison: 1 Endoscopic versus open or mini-open carpal tunnel release, outcome: 1.4 Function Status Scale at 3 months or less.

\begin{tabular}{|c|c|c|c|c|c|c|c|}
\hline Study or Subgroup & Std. Mean Difference & SE & $\begin{array}{l}\text { ECTR } \\
\text { Total }\end{array}$ & $\begin{array}{l}\text { OCTR } \\
\text { Total }\end{array}$ & Weight & $\begin{array}{l}\text { Std. Mean Difference } \\
\text { IV, Random, } 95 \% \text { Cl }\end{array}$ & $\begin{array}{l}\text { Std. Mean Difference } \\
\text { IV, Random, } 95 \% \mathrm{Cl}\end{array}$ \\
\hline \multicolumn{8}{|c|}{ 1.4.1 ECTR vs standard OCTR } \\
\hline Atroshi 2006 & 0 & 0.1768 & 63 & 65 & $21.6 \%$ & $0.00[-0.35,0.35]$ & \\
\hline Hoefnagels 1997 & 0 & 0.1508 & 85 & 91 & $22.8 \%$ & $0.00[-0.30,0.30]$ & \\
\hline Trumble 2002 & -0.8121 & 0.1718 & 75 & 72 & $21.8 \%$ & $-0.81[-1.15,-0.48]$ & $\longleftrightarrow$ \\
\hline Westphal 2000 & 0.0903 & 0.2255 & 45 & 35 & $19.3 \%$ & $0.09[-0.35,0.53]$ & \\
\hline Subtotal $(95 \% \mathrm{Cl})$ & & & 268 & 263 & $85.5 \%$ & $-0.19[-0.61,0.23]$ & \\
\hline \multicolumn{8}{|c|}{$\begin{array}{l}\text { Heterogeneity: } \operatorname{Tau}^{2}=0.15 ; \mathrm{Chi}^{2}=17.39, \mathrm{df}=3(\mathrm{P}=0.0006) ; \mathrm{I}^{2}=83 \% \\
\text { Test for overall effect: } Z=0.87(P=0.39)\end{array}$} \\
\hline \multicolumn{8}{|c|}{ 1.4.2 ECTR vs modified OCTR } \\
\hline $\begin{array}{l}\text { Rab } 2006 \\
\text { Subtotal }(95 \% \mathrm{Cl})\end{array}$ & -0.4843 & 0.3343 & $\begin{array}{l}10 \\
10\end{array}$ & $\begin{array}{l}10 \\
10\end{array}$ & $\begin{array}{l}14.5 \% \\
14.5 \%\end{array}$ & $\begin{array}{l}-0.48[-1.14,0.17] \\
-0.48[-1.14,0.17]\end{array}$ & \\
\hline \multicolumn{8}{|c|}{$\begin{array}{l}\text { Heterogeneity: Not applicable } \\
\text { Test for overall effect: } Z=1.45(P=0.15)\end{array}$} \\
\hline Total $(95 \% \mathrm{Cl})$ & & & 278 & 273 & $100.0 \%$ & $-0.23[-0.60,0.14]$ & \\
\hline \multicolumn{7}{|c|}{$\begin{array}{l}\text { Heterogeneity: } \mathrm{Tau}^{2}=0.13 ; \mathrm{Chi}^{2}=18.07, \mathrm{df}=4(\mathrm{P}=0.001) ; \mathrm{I}^{2}=78 \% \\
\text { Test for overall effect: } Z=1.22(\mathrm{P}=0.22)\end{array}$} & \begin{tabular}{cc|cc} 
& 1 & 1 \\
-1 & -0.5 & 0 & 0.5 \\
& Favours ECTR & Favours 0
\end{tabular} \\
\hline
\end{tabular}

Meta-analysis of four studies assessing a pain score (Analysis 1.5) showed that pain did not differ significantly between ECTR and OC TR (four studies, 358 participants, SMD $-0.21,95 \% \mathrm{Cl}-0.72$ to 0.30 ). A similar conclusion is supported by the five studies assessing pain on a dichotomous scale (Agee 1992; Dumontier 1995; Malhotra 2007; Stark 1996; Wong 2003) (Analysis 1.8): a difference in pain between ECTR and OCTR could not be demonstrated nor refuted (five studies, 348 participants, risk ratio (RR) $0.69,95 \% \mathrm{Cl} 0.33$ to 1.45 ). A large heterogeneity was found $\left(1^{2}=79 \%\right)$.
No statistically significant difference in numbness was found when synthesizing five studies comparing ECTR with OCTR ( 5 studies, 435 participants, RR $1.14,95 \% \mathrm{Cl} 0.76$ to 1.71 ) (Analysis 1.9).

Regarding grip strength, the summary estimate from the six studies included in the meta-analysis favoured ECTR ( 6 studies, 560 participants, SMD 0.36, 95\% Cl 0.09 to 0.63) (Analysis 1.10; Figure 5). This demonstrates a statistically significant difference. Assuming an SD of 11 (as in Atroshi 2006), this corresponds to a mean difference (MD) of $4 \mathrm{~kg}(95 \% \mathrm{Cl} 1$ to $6.9 \mathrm{~kg})$ favouring ECTR when compared with OCTR. This difference is relatively low and probably not clinically significant.

Figure 5. Forest plot of comparison: 1 Endoscopic versus open or mini-open carpal tunnel release, outcome: 1.10 Grip strength at 3 months or less.

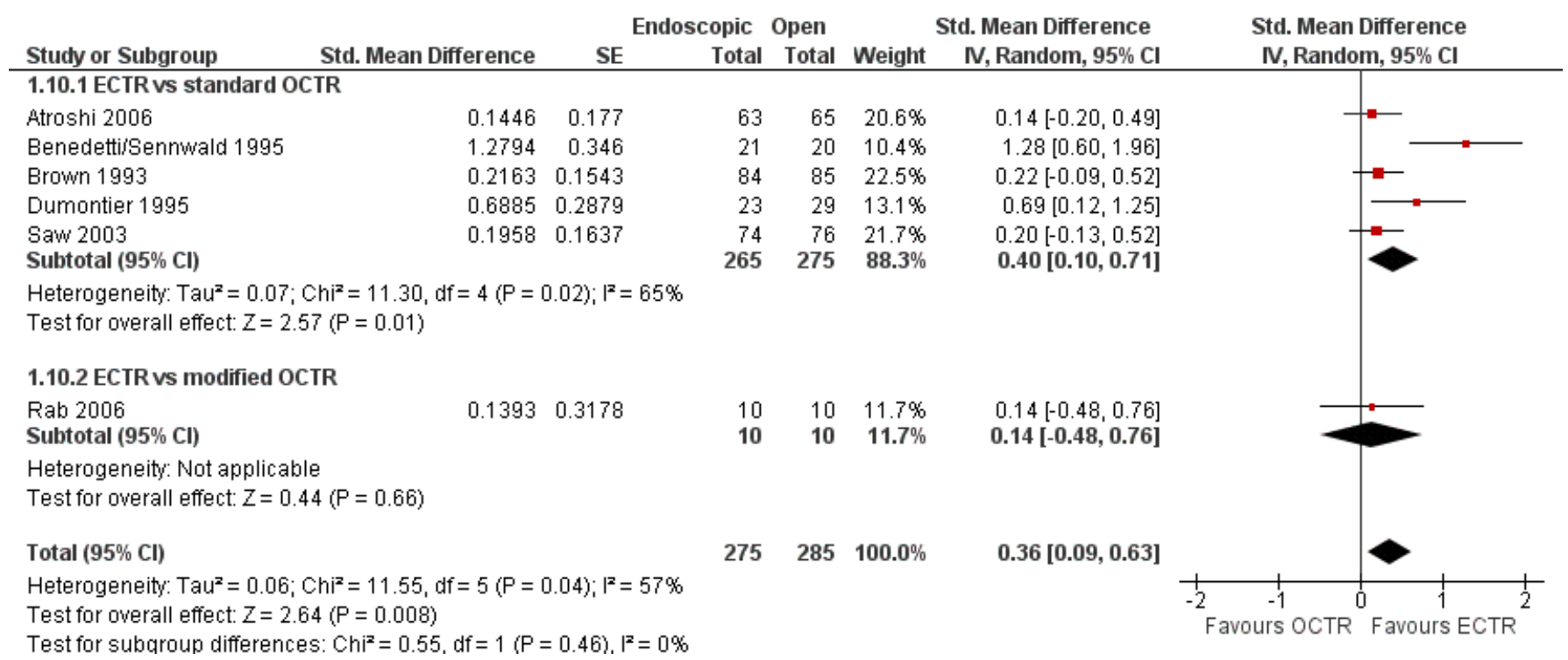




\section{Long-term efficacy results (more than three months)}

Eleven studies reported long-term symptom outcomes, comparing ECTR with conventional open release (Agee 1992; Atroshi 2006; Dumontier 1995; Eichhorn 2003; Erdmann 1994; Ferdinand 2002; Mackenzie 2000; Malhotra 2007; Schäfer 1996; Stark 1996; Trumble 2002). No significant differences in symptoms were found in any of the studies, except in Ferdinand 2002, which favoured ECTR, and Macdermid 2003, which favoured OCTR. Atroshi 2006 also found a slight superiority of ECTR for pain at one year, which however was not evident at five-year follow-up (Atroshi 2009). Only Wong 2003 reported long-term symptom outcomes comparing ECTR with mini-open release.

Four studies assessed overall improvement, reporting no significant difference between ECTR and open release (four studies, 317 participants, RR $1.04,95 \% \mathrm{Cl} 0.95$ to $1.14, \mathrm{I}^{2}=0 \%$ ) (Analysis 1.11). Overall satisfaction was reported only in Trumble 2002; the results suggested no difference between the two procedures (Analysis 1.12). SSS and FSS were assessed in two studies (Atroshi 2006; Trumble 2002), with similar scores in both treatments: MD 0.02, $95 \% \mathrm{Cl}-0.18$ to 0.22 (2 studies, 273 participants) for SSS and MD $0.01,95 \% \mathrm{Cl}-0.14$ to 0.16 (two studies, 273 participants) for FSS, respectively (Analysis 1.13; Analysis 1.14). The DASH questionnaire was not assessed in any of the studies. Pain was on average the same in both groups in all six studies that were included in the meta-analysis, with a total estimate that did not favour any of the treatments (six studies, 407 participants, RR $0.88,95 \% \mathrm{Cl} 0.57$ to $1.38, \mathrm{I}^{2}=0 \%$ ) (Analysis 1.15; Analysis 1.16). In addition, no significant difference was found for numbness between the procedures (four studies, 234 participants, RR $0.64,95 \% \mathrm{Cl} 0.31$ to $1.35, \mathrm{I} 2=0 \%$ ) (Analysis 1.17; Analysis 1.18). Meta-analysis for grip strength was possible by synthesising two studies (Benedetti/Sennwald 1995; Dumontier 1995). The mean estimate favoured ECTR (two studies, 56 participants, SMD $1.13,95 \% \mathrm{Cl} 0.56$ to 1.71 ) (Analysis 1.19). Assuming a SD of 11 (as in Atroshi 2006), this corresponds to an MD of $11 \mathrm{~kg}$ favouring ECTR (95\% Cl 6.2 to $18.81 \mathrm{~kg}$ ).

\section{Return to work}

Twenty studies assessed the time to return to work, expressed in many different formats. In 10 of them, ECTR-treated participants had a significantly earlier recovery (Agee 1992; Atroshi 2006; Benedetti/Sennwald 1995; Brown 1993; Erdmann 1994; Saw 2003; Schäfer 1996; Stark 1996; Tian 2007; Trumble 2002; Werber 1996). In one study OCTR participants returned earlier to work (Dumontier 1995), and seven studies recorded a non-significant difference (Foucher 1993; Hoefnagels 1997; Jacobsen 1996; Koskella 1996; Macdermid 2003; Sørensen 1997; Westphal 2000). In Atroshi 2006, return to work among participants who were on sick leave before surgery $(n=16)$ was eight days earlier for those who underwent OCTR (MD 8.00, 95\% Cl-62.59 to 78.59), but for participants not on sick leave before surgery $(n=112)$, it was five days earlier for the ECTR group (MD $-5.00,95 \% \mathrm{Cl}-11.49$ to 1.49 ). Synthesizing the outcome from both subgroups yielded an MD which favoured ECTR by 4.9 days; however, not significantly (MD $-4.89,95 \% \mathrm{Cl}-11.35$ to 1.57 ).
Meta-analysis was possible for four of the studies (Atroshi 2006; Benedetti/Sennwald 1995; Jacobsen 1996; Saw 2003). The mean estimate significantly favoured ECTR, revealing a faster return to work by on average of eight days (4 studies, 274 participants, MD $-8.10,95 \% \mathrm{Cl}-14.28$ to -1.92 ) (Analysis 1.20). This estimate did not significantly change with the addition of the group of participants on sick leave before surgery, assessed in Atroshi 2006 (MD altered to $-7.99,95 \% \mathrm{Cl}-13.93$ to -2.05$)$. However, the between-studies variation was important $(12=75 \%)$.

Time to return to work is potentially subject to several confounding factors and may substantially differ between different national health systems or different patient groups (in terms of age, occupation, etc) (Cowan 2012). However, we assume that the arms in an RCT are similar in all the factors that might affect the recovery to work or activities of daily living. Therefore, we anticipate that despite the anticipated high heterogeneity in absolute values, the difference between groups is a reliable outcome.

\section{Safety}

Twenty-six of the studies assessed the number of participants with complications. Only Incoll 2004 and Tüzüner 2008 did not report complications.

Very few participants (14 out of 1508) reported major complications resulting in permanent damage or major impairments (for example, complex regional pain syndrome (CRPS), severe sympathetic reflex dystrophy, algodystrophy or severe pain). In one study, one mild case and one severe case of CRPS were recorded out of 25 hands in the OCTR group (Trumble 2002). There were two reports of CRPS (one in each group) in Benedetti/Sennwald 1995, and one report in the ECTR group of Foucher 1993. Malhotra 2007 reported two individuals with symptoms consistent with sympathetic reflex dystrophy, in the OCTR group. In one participant the symptoms were mild and resolved briefly, while in the other the symptoms were more protracted. Agee 1992 reported one injury to the deep motor branch of the ulnar nerve in an OCTR-treated participant. Atroshi 2006 reported no nerve, vascular, or tendon injuries, and no wound complications at one year; however, at five years' follow-up, they reported five ECTR and three OCTR participants with moderate or severe pain (Atroshi 2009). We classified these events as major complications. Meta-analysis of 15 studies (in six of which major complications occurred) did not reveal any difference between ECTR and conventional OCTR (15 studies, 1508 participants, RR 1.00, $95 \% \mathrm{Cl} 0.38$ to $2.64, \mathrm{I}^{2}=0 \%$ ) (Analysis 1.23 ). The fixed-effect metaanalysis gave slightly different but compatible results (15 studies, RR $0.94,95 \% \mathrm{Cl} 0.38$ to 2.34 ).

Upon synthesis of 19 studies from which data on minor complications could be extracted, ECTR appeared safer than open release (18 studies in total, 17 studies with events, 1786 participants, RR $0.55,95 \% \mathrm{Cl} 0.38$ to $0.81,12=10 \%$ ) (Analysis 1.24 ; Figure 6 ). This corresponds to $45 \%(95 \% \mathrm{Cl} 62 \%$ to $19 \%$ ) less risk for minor complications in the ECTR treated participants when compared with OCTR. 
Figure 6. Forest plot of comparison: 1 Endoscopic versus open or mini-open carpal tunnel release, outcome: 1.24 Minor complications.
ECTR
OCTR
Risk Ratio
Risk Ratio

Study or Subgroup

Events Total Events Total Weight M-H, Random, 95\% Cl

1.24.1 ECTR vs standard OCTR

Agee 1992

Atroshi 2006

$\begin{array}{lllll}2 & 82 & 3 & 65 & 4.4 \%\end{array}$

Benedetti/Sennwald 1995

563

$8-63 \quad 10.8 \%$

Brown 1993

Eichhorn 2003

Erdmann 1994

Ferdinand 2002

Giele 2000

Jacobsen 1996

Malhotra 2007

Saw 2003

Stark 1996

Tian 2007

Trumble 2002

Werber 1996

Westphal 2000

Subtotal $(95 \% \mathrm{Cl})$

$\begin{array}{lllll}5 & 23 & 10 & 22 & 14.1 \%\end{array}$

$\begin{array}{lllll}4 & 84 & 0 & 85 & 1.7 \%\end{array}$

$\begin{array}{lllll}0 & 64 & 2 & 60 & 1.6 \%\end{array}$

$\begin{array}{lllll}3 & 53 & 20 & 52 & 9.5 \%\end{array}$

$\begin{array}{rrrrr}1 & 25 & 1 & 25 & 2.0 \%\end{array}$

$\begin{array}{lllll}3 & 60 & 3 & 60 & 5.5 \%\end{array}$

$\begin{array}{lllll}3 & 16 & 1 & 16 & 3.0 \%\end{array}$

$\begin{array}{lllll}0 & 30 & 10 & 31 & 1.8 \%\end{array}$

$\begin{array}{lllll}2 & 74 & 3 & 76 & 4.4 \%\end{array}$

$\begin{array}{lllll}0 & 20 & 1 & 20 & 1.5 \%\end{array}$

$\begin{array}{rrrrr}12 & 34 & 23 & 36 & 28.9 \%\end{array}$

$\begin{array}{rrrrr}0 & 97 & 1 & 95 & 1.4 \%\end{array}$

$246 \quad 0 \quad 44 \quad 1.6 \%$

Total events

345

$\begin{array}{lll}0 & 44 & 1.6 \% \\ 3 & 35 & 5.7 \%\end{array}$

$816 \quad 785 \quad 98.0 \%$

Heterogeneity: $\operatorname{Tau}^{2}=0.10 ; \mathrm{Chi}^{2}=17.80, \mathrm{df}=15(\mathrm{P}=0.27) ; \mathrm{I}^{2}=16 \%$

Test for overall effect: $Z=2.79(P=0.005)$

\subsubsection{ECTR vs modified OCTR}

Eichhorn 2003

Mackenzie 2000

Rab 2006

Subtotal $(95 \% \mathrm{Cl})$

Total events

$\begin{array}{ll}0 & 64 \\ 1 & 22 \\ 0 & 10 \\ & 96\end{array}$

$\begin{array}{ll}0 & 65 \\ 1 & 14\end{array}$

65

$2.0 \%$

$0 \quad 10$

$89 \quad 2.0 \%$

1

1

Heterogeneity: Not applicable

Test for overall effect: $Z=0.33(P=0.74)$

\section{Total $(95 \% \mathrm{Cl})$}

912

Total events 46

$874 \quad 100.0 \%$ 90

Heterogeneity: $\mathrm{Tau}^{2}=0.06 ; \mathrm{Chi}^{2}=17.81, \mathrm{df}=16(\mathrm{P}=0.34) ; \mathrm{I}^{2}=10 \%$

Test for overall effect: $Z=3.02$ ( $P=0.003$ )

Test for subqroup differences: $\mathrm{Chi}^{2}=0.01, \mathrm{df}=1(\mathrm{P}=0.92), \mathrm{I}^{2}=0 \%$
$0.53[0.09,3.07]$

$0.63[0.22,1.81]$

$0.48[0.19,1.18]$

$9.11[0.50,166.54]$

$0.19[0.01,3.83]$

$0.15[0.05,0.47]$

$1.00[0.07,15.12]$

$1.00[0.21,4.76]$

$3.00[0.35,25.87]$

$0.05[0.00,0.80]$

$0.68[0.12,3.98]$

$0.33[0.01,7.72]$

$0.55[0.33,0.93]$

$0.33[0.01,7.92]$

$4.79[0.24,97.00]$

$0.78[0.17,3.62]$

$0.55[0.37,0.84]$

M-H, Random, 95\% Cl

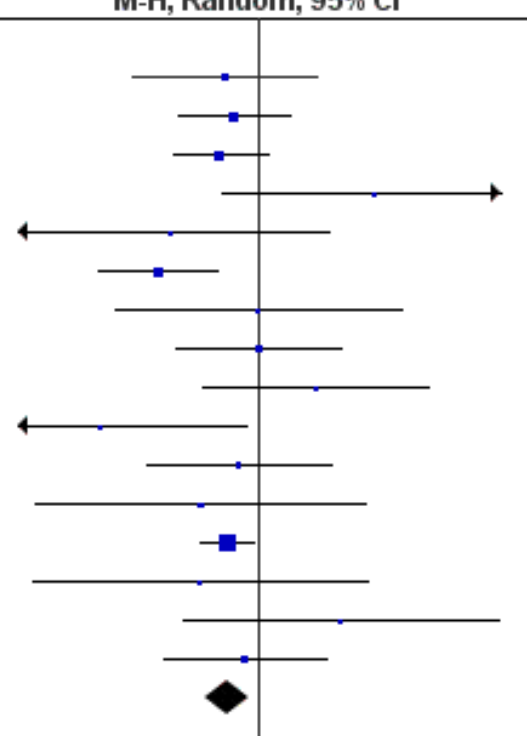

ECTR was associated with more transient nerve problems (for example, neurapraxia, numbness or paraesthesiae) and OCTR with more wound problems (for example, infection, hypertrophic scarring or scar tenderness). In a few participants, ECTR had to be abandoned and OCTR was performed instead. Thirteen hands randomised to ECTR were finally converted to OCTR owing to intraoperative difficulties (one in Atroshi 2006, one in Benedetti/Sennwald 1995, two in Foucher 1993 and nine in Saw 2003).
In 19 studies, the total number of participants with complications was given or this information could be extracted. ECTR gives a significantly lower rate of complications (19 studies, 1850 participants, RR $0.60,95 \% \mathrm{Cl} 0.40$ to 0.90$)$, providing a $40 \%$ less risk (95\% $\mathrm{Cl} 60$ to 10) (Analysis 1.25; Figure 7). 
Figure 7. Forest plot of comparison: 1 Endoscopic versus open or mini-open carpal tunnel release, outcome: 1.25 Total complications.
ECTR
OCTR
Odds Ratio
Odds Ratio

Study or Subgroup

Events Total Events Total Weight M-H, Random, 95\% Cl

1.25.1 ECTR vs standard OCTR

Agee 1992

Atroshi 2006

$\begin{array}{rrrrr}4 & 82 & 4 & 65 & 8.2 \% \\ 10 & 63 & 11 & 63 & 19.0 \%\end{array}$

Benedetti/Sennwald 1995

1063

Eichhorn 2003

Erdmann 1994

Ferdinand 2002

Foucher 1993

Giele 2000

Jacobsen 1996

Koskella 1996

Saw 2003

Schäfer 1996

Stark 1996

Tian 2007

Trumble 2002

Werber 1996

Westphal 2000

Subtotal $(\mathbf{9 5} \% \mathrm{Cl})$

Total events

$\begin{array}{ll}6 & 23 \\ 0 & 64\end{array}$

$10.7 \%$

253

63

125

199

360

316

18

274

047

220

$\begin{array}{rrr}11 & 22 & 10.7 \% \\ 2 & 60 & 1.8 \%\end{array}$

$\begin{array}{lll}7 & 52 & 6.3 \%\end{array}$

$325 \quad 3.1 \%$

$0 \quad 77 \quad 1.6 \%$

$360 \quad 6.2 \%$

$\begin{array}{lll}3 & 60 & 6.2 \% \\ 1 & 16 & 2.9 \%\end{array}$

$\begin{array}{rrr}0 & 9 & 1.5 \% \\ 3 & 76 & 5.0 \%\end{array}$

054

$3 \quad 20$

$5.0 \%$

1234

$4.6 \%$

$23 \quad 36 \quad 17.4 \%$

0 97

395

$1.9 \%$

246

$044 \quad 1.8 \%$

$3 \quad 45$

$3 \quad 35 \quad 6.0 \%$

856

$809 \quad \mathbf{9 8 . 0} \%$

Heterogeneity: $\operatorname{Tau}^{2}=0.00 ; \mathrm{Chi}^{2}=12.51, \mathrm{df}=15(\mathrm{P}=0.64) ; \mathrm{I}^{2}=0 \%$

Test for overall effect: $Z=2.46(P=0.01)$

1.25.2 ECTR vs modified OCTR

Eichhorn 2003

Mackenzie 2000

Rab 2006

Subtotal $(95 \% \mathrm{Cl})$

Total events

Heterogeneity: Not applicable

Test for overall effect: $Z=0.33(P=0.74)$

Total $(95 \% \mathrm{Cl})$

Total events

952 53

$898 \quad 100.0 \%$ 78

Heterogeneity: $\operatorname{Tau}^{2}=0.00 ; \mathrm{Chi}^{2}=12.51, \mathrm{df}=16(P=0.71) ; \mathrm{I}^{2}=0 \%$

Test for overall effect: $Z=2.48(P=0.01)$

Test for subqroup differences: $\mathrm{Chi}^{2}=0.00, \mathrm{df}=1(\mathrm{P}=0.98), \mathrm{I}^{2}=0 \%$
$0.78[0.19,3.25]$

$0.89[0.35,2.28]$

$0.35[0.10,1.23]$

$0.18[0.01,3.86]$

$0.25[0.05,1.28]$

$0.31[0.03,3.16]$

$2.36[0.09,58.75]$

$1.00[0.19,5.16]$

$3.46[0.32,37.47]$

$3.80[0.13,107.31]$

$0.68[0.11,4.17]$

Not estimable

$0.63[0.09,4.24]$

$0.31[0.12,0.82]$

$0.14[0.01,2.66]$

$5.00[0.23,107.14]$

$0.76[0.14,4.03]$

$0.60[0.39,0.90]$

Not estimable

$0.62[0.04,10.78]$

Not estimable $0.62[0.04,10.78]$

$0.60[0.40,0.90]$ M-H, Random, 95\% Cl
Data on participants with recurrence of symptoms could be extracted from 12 of the studies. Meta-analysis also favoured ECTR but this difference was not significant (nine studies with events, RR 0.81 , $95 \% \mathrm{Cl} 0.46$ to 1.42 ) (Analysis 1.21).

The need for repeated surgery was assessed in 11 studies. There was no statistical significant difference between ECTR and OCTR release (nine studies with events, 1116 participants, RR 1.06, 95\% Cl 0.54 to $2.08,12=10 \%$ ) (Analysis 1.22 ).

\section{Subgroup analysis}

Subgrouping to different open release techniques (conventional OCTR/mini-open techniques)

For pain assessed in the short term, in the studies comparing ECTR to conventional OCTR (Atroshi 2006; Saw 2003), ECTR was less painful (two studies, 278 participants, SMD $-0.41,95 \% \mathrm{Cl}-0.65$ to -0.18 ) (Analysis 1.5). Assuming an SD of 23 for a score on a range from zero (no pain) to 100 (severe pain) (extracted from Atroshi 2006), this SMD corresponds to an MD of $-9.43(95 \% \mathrm{Cl}-14.95$ to -4.14). Two additional studies comparing ECTR to modified OCTR were highly heterogeneous ( $12=87 \%$ ) (Rab 2006; Wong 2003). Wong 2003 favoured OCTR, while Rab 2006 found no difference, with no difference overall between the two methods (two studies, 80 participants, SMD $0.01,95 \% \mathrm{Cl}-1.07$ to 1.08 ). The difference between subgroups of the meta-analysis was not important $(P=0.45)$. When we assessed pain as a dichotomous outcome, we found a difference favouring mini-open against conventional OCTR $(P=0.01,12$ $=84.3 \%$ ) (Analysis 1.8). However, only one of the five studies compared ECTR with mini-open release. There was high heterogeneity for both subgroups of the analysis ( $12=76 \%$ and $79 \%$, respectively).

Regarding grip strength assessed in the short term (Analysis 1.10), five studies compared ECTR with conventional OCTR, and showed a significantly stronger grip for ECTR participants (five studies, 540 
participants, SMD 0.40, 95\% Cl 0.10 to 0.71) (Atroshi 2006; Benedetti/Sennwald 1995; Brown 1993; Dumontier 1995; Saw 2003). Assuming an SD of 11 (as in Atroshi 2006), this corresponds to an MD of $4.4 \mathrm{~kg}(95 \% \mathrm{Cl} 1.1$ to $7.81 \mathrm{~kg})$. This difference is relatively small and probably not clinically significant. Only one study compared ECTR with modified open release and it showed a nonsignificant difference at 12 weeks ( 20 participants, SMD $0.14,95 \% \mathrm{Cl}-0.48$ to 0.76 ) (Rab 2006).

No subgroup analysis was possible for measurements taken at long-term follow-up, as only Wong 2003 from among the ECTR versus mini-open trials reported such information.

No differences were demonstrated between subgroups for open and mini-open techniques for any of the safety outcomes (Analysis 1.21; Analysis 1.23; Analysis 1.24; Analysis 1.25). We found subgroup differences only in re-operation rate (Analysis 1.22). However, the heterogeneity was very high $\left(I^{2}=73.9\right)$ and the number of studies comparing ECTR with mini-open CTR was very low (only one), limiting the clinical relevance of this finding.

\section{Subgrouping to different ECTR techniques (one-portal or two-portal ECTR)}

We also assessed the outcomes presented above distinguishing between the two main ECTR techniques (one-portal and two-portal techniques) (Analysis 2.1; Analysis 2.2; Analysis 2.3; Analysis 2.4; Analysis 2.5; Analysis 2.6; Analysis 2.7; Analysis 2.8; Analysis 2.9; Analysis 2.9; Analysis 2.10; Analysis 2.11; Analysis 2.12; Analysis 2.13; Analysis 2.14; Analysis 2.15; Analysis 2.16; Analysis 2.17; Analysis 2.18; Analysis 2.19; Analysis 2.20; Analysis 2.21; Analysis 2.22; Analysis 2.23; Analysis 2.24; Analysis 2.25). No important differences were found between the two endoscopic techniques. In five studies assessing pain as a dichotomous outcome less than three months postoperatively, one-portal ECTR (two studies) was better than two-portal ECTR (three studies) (test for subgroup differences: $P=0.0002, I^{2}=93.0 \%$, indirect $R R 0.05,95 \% \mathrm{Cl} 0.01$ to 0.22 ) (Analysis 2.8). However, such a difference was not evident when pain was assessed as a continuous outcome (Analysis 2.5; Analysis 2.6; Analysis 2.7) or when pain was assessed more than three months postoperatively. In total, there was no evidence that one of the two endoscopic techniques was more efficacious or safe when compared indirectly. However, we found no studies directly comparing one-versus two-portal CTR and the indirect comparison was informed by few studies per outcome.

\section{Sensitivity analysis}

1. In the sensitivity analysis for attrition bias, we included only nine studies at low risk of bias (Atroshi 2006; Benedetti/Sennwald 1995; Hoefnagels 1997; Jacobsen 1996; Rab 2006; Saw 2003; Schäfer 1996; Stark 1996; Tüzüner 2008) (Analysis 3.1; Analysis 3.2; Analysis 3.3; Analysis 3.4; Analysis 3.5; Analysis 3.6; Analysis 3.7; Analysis 3.8; Analysis 3.9; Analysis 3.10; Analysis 3.11; Analysis 3.12; Analysis 3.13). Pain assessed as continuous data in three studies, seemed now to favour ECTR at three months (Analysis 3.3; Analysis 3.4; Analysis 3.5). However, in studies adequately addressing incomplete data, ECTR and OCTR do not seem to differ in grip strength and complication rates (Analysis 3.6; Analysis 3.12; Analysis 3.13). This sensitivity analysis revealed no other differences when compared with the main results.

2. We also performed sensitivity analysis excluding the studies that did not adjust appropriately for participants with bilateral involve- ment. Thirteen studies in total were excluded from the analysis. In three studies only people with bilateral CTS were included (Giele 2000; Incoll 2004; Stark 1996). Nine studies included bilateral CTS but provided no further details (Brown 1993; Erdmann 1994; Jacobsen 1996; Koskella 1996; Mackenzie 2000; Saw 2003; Tian 2007; Trumble 2002; Tüzüner 2008), whereas Sørensen 1997 provided no information about unilateral or bilateral involvement (Analysis 4.1; Analysis 4.2; Analysis 4.3; Analysis 4.4; Analysis 4.5; Analysis 4.6; Analysis 4.7; Analysis 4.8; Analysis 4.9; Analysis 4.10; Analysis 4.11; Analysis 4.12; Analysis 4.13; Analysis 4.14; Analysis 4.15; Analysis 4.16). From this analysis, minor complications still favour ECTR, but this is marginally insignificant (RR $0.54,95 \% \mathrm{Cl} 0.32$ to 0.94 ) (Analysis 4.15). In total complications no differences are found (RR 0.72, $95 \% \mathrm{Cl} 0.45$ to 1.14 ) (Analysis 4.16). Grip strength remains on average greater for ECTR participants in the short term (four studies, SMD $0.52,95 \% \mathrm{Cl} 0.03$ to 1.02 ) (Analysis 4.11), corresponding to an MD of $5.72 \mathrm{~kg}$ ( $95 \% \mathrm{Cl} 0.33$ to $11.22 \mathrm{~kg}$ ) assuming an SD of 11 (Atroshi 2006).

3. Sensitivity analysis according to high or unclear risk of bias for allocation concealment was not possible as we judged only two studies to be at low risk of bias (Atroshi 2006; Tüzüner 2008).

4. We performed a post hoc analysis using Peto's odds ratio for complications. The results do not materially change compared to the Mantel-Haenszel fixed-effect method with RR.

5. Two studies had bilateral involvement and results were not adjusted (Rab 2006; Wong 2003). Analyses of these studies were undertaken assuming that the correlation coefficient between the two groups was 0.5 . Changing the coefficient to 0.1 and 0.9 did not materially change the conclusions on pain, SSS, functional status, or grip strength.

\section{DISCUSSION}

\section{Summary of main results}

This review included 28 studies that compared endoscopic carpal tunnel release (ECTR) with standard open carpal tunnel release (OCTR) or modified OCTR for carpal tunnel syndrome (CTS). In total, 2586 hands were assessed. Twenty-three studies compared ECTR with standard OCTR, three studies with modified OCTR and two studies compared ECTR with both standard and modified OCTR. Sixteen studies addressed a one-portal technique for ECTR and nine studies a two-portal technique. The exact endoscopic technique was not defined in three studies.

\section{Short-term effects}

There was very limited evidence from assessment of overall improvement of overall satisfaction. Clinical scores (Symptom Severity Scale (SSS) and Function Status Scale (FSS)), assessed by five studies, did not indicate that any treatment option was superior to another. Pain after ECTR and OCTR (conventional or modified) was also equal, although ECTR was superior when compared with conventional OCTR. However, assessment of pain scales favoured ECTR at short-term follow-up, when only studies with a low risk of attrition bias were considered.

No differences were found in the incidence of residual numbness.

The meta-analysis revealed that participants treated with ECTR had an increased grip strength (standardised mean difference 
(SMD) $0.36,95 \% \mathrm{Cl} 0.09$ to 0.63 ), especially when compared with conventional OCTR. However, the difference was relatively small and probably not clinically significant, corresponding to a mean diffference (MD) of $4 \mathrm{~kg}$. Grip strength was found to be equal between ECTR and OCTR when only studies with a low risk of attrition bias were considered.

\section{Long-term effects}

From the studies assessing clinical outcomes at least three months after the surgery, there was no evidence that any technique was superior for any of the outcomes assessed, except for grip strength.

For grip strength, data from two studies indicated that ECTR was superior to conventional OCTR (SMD $1.13,95 \% \mathrm{Cl} 0.56$ to 1.71 ). We estimated the corresponding MD to be $11 \mathrm{~kg}$, which is potentially clinically relevant.

\section{Return to work}

Meta-analysis of four studies assessing return to work showed a faster return to work for ECTR by eight days. This superiority was marginal when we removed studies with inappropriate adjustment for participants with bilateral involvement from the meta-analysis.

\section{Safety}

The incidence of complications was assessed in 26 studies.

Only a small number of major complications was found for both treatment options ( $0.9 \%$ for both ECTR and OCTR). These were mainly instances of complex regional pain syndrome. No difference was revealed from the meta-analysis of 15 studies (1508 participants).

Regarding minor complications, there was a lower incidence for ECTR treated participants. Meta-analysis assessed 18 studies (1786 participants) showing an incidence of 5\% for ECTR and $10.2 \%$ for OCTR participants ( $11.3 \%$ for conventional OCTR). From only three studies comparing ECTR with modified OCTR, no difference was found. ECTR more often resulted in transient nerve problems (caused by intraoperative injury), whereas OCTR had more wound problems (for example, infection or scar tenderness).

Assessing the total number of complications as extracted from 19 studies (1850 participants), ECTR was superior. The incidence was 5.5\% for ECTR and $8.7 \%$ for OCTR. The additional benefit with ECTR was marginal when we excluded from the meta-analysis studies with inappropriate adjustment for participants with bilateral involvement.

The incidence of recurrence (12 studies assessed, 1228 participants) was equal between ECTR and OCTR (3.2\% and 4.6\% respectively).

Reoperation rates were also equal (2.8\% for ECTR and $2.5 \%$ for OC$\mathrm{TR})$, according to data from 10 studies (1116 participants).

\section{Overall completeness and applicability of evidence}

In this review, we included open and different mini-open (modified) techniques. The extent of the skin incision may differ among surgeons, especially between the different modified open techniques. In order to minimise the effect of this potential bias, we performed subgroup analysis assessing separately open and modified open techniques compared with ECTR.
Different ECTR techniques could also potentially differ in outcome, in particular techniques with one rather than two incisions. However, there was no evidence from the subgroup analysis that either of the ECTR techniques (one-portal or two-portal) was superior to the other. There was no study directly comparing different ECTR techniques with each other.

Surgical treatment of CTS is generally performed under local anaesthesia, unless special reasons exist. Therefore, in most of the studies such information was not even provided. This is why we did not systematically extract or assess the type of anaesthesia in this review.

The primary outcome of this systematic review, being the overall improvement of symptoms at less than three months, was reported in only one of the included RCTs.

Five of the studies were presented only in an abstract (Giele 2000; Incoll 2004; Koskella 1996; Sørensen 1997; Werber 1996). Therefore, the reports of these studies provided little information regarding the exact methodology and only some information regarding the outcomes.

In some studies bilateral involvement was also assessed. However, this was not always clearly defined.

CTS can be treated by different specialties such as plastic surgeons or general orthopaedic surgeons, who may or may not be specialised in hand surgery. To our knowledge, there are no studies comparing outcomes of CTR based on the specialty of the surgeon. Furthermore, CTR is a common operation, and all specialities are expected to have adequate experience. Therefore, we did not perform a subgroup analysis analysing the studies separately, according to the specialty of the surgeon.

We did not include assessment of cost effectiveness among the aims of this review. However, two of the RCTs assessed the costeffectiveness of ECTR and OCTR. Saw 2003 reported an increased cost of the equipment for ECTR versus OCTR, by GBP 98 . However, this was accompanied with a faster return to work by eight days, resulting in an overall net saving of GBP 438 per employed patient treated with ECTR. Trumble 2002 reported no difference in cost between the two interventions.

\section{Quality of the evidence}

The quality of evidence in this review may be considered as quite low. Five of the studies were presented only in abstracts, with not enough information regarding the risk of bias. This might also increase the publication bias.

Funnel plots do not appear to be asymmetric, which suggestis that there are no systematic differences between small and large studies. The apparent symmetry could indicate the absence of clear evidence of publication bias, although we cannot exclude the possibility of such bias.

For selection bias, attrition bias or other bias (mainly from baseline differences but also from the financing of the studies), we could not reach a safe judgement regarding whether there was a high or low risk of bias. Therefore, in many cases we considered the risk of bias to be unclear. 
Blinding of participants was considered not to be applicable in any of the studies. However, such a judgement was due to the nature of interventions (it was not possible to hide the skin incision from participants until the last follow-up), rather than reflecting a low quality of information.

Heterogeneity in SSS and FSS and statistical imprecision (low sample size, low number of events or both) limit further the credibility of the findings of this review.

\section{Potential biases in the review process}

None identified.

\section{Agreements and disagreements with other studies or reviews}

Gerritsen 2001 found no evidence for a superiority of ECTR, based on seven studies. However, no pooling of the studies was performed in this systematic review. It seems that ECTR produces more transient nerve problems (neurapraxia, numbness or paraesthesia) and OCTR more wound problems (infection, hypertrophic scarring or scar tenderness). Gerritsen 2001 also stated that because OCTR is technically less demanding, it incurs a lower risk of complications and fewer added costs. However, the authors did not present any evidence for this, as neither complications nor cost effectiveness were assessed in the review.

Sanati 2011 also found an earlier return to work after ECTR. The authors highlighted the remarkable inconsistencies in how different randomised clinical trials (RCTs) examined return to work as an outcome measure.

Boeckstyns 1999 focused on complications, assessing 54 publications (from case reports to RCTs). They found no differences, except that ECTR resulted in a higher rate $(4.3 \%$ versus $0.9 \%)$ of reversible nerve damage (that is, transient neurapraxias).

Benson 2006 (literature search up to 2001) assessed 68 articles that included complications as one of the outcomes, irrespective of the type of study (the review even included studies with no comparator). The authors focused on complications caused by damage to nerves, arteries or tendons. Complications not involving structural injury or which were subjective in nature (for example, CRPS, scar hypersensitivity and would healing problems) were not included. The review found the overall proportion of complications for the OCTR technique to be $0.74 \%$, and for the ECTR technique to be $1.63 \%(P<0.005)$. However, this difference was mainly the result of an increased incidence of transient neurapraxias after ECTR. Transient neurapraxias were reported in $1.45 \%$ of ECTR cases and in only $0.25 \%$ of OCTR cases. When transient neurapraxias were not encountered, ECTR seemed to be safer than OCTR (OCTR $0.49 \%$ versus ECTR 0.19\%; P < 0.005). When only extrabursal ECTR was analysed, this superiority of ECTR was even more obvious. Transbursal ECTR was associated with an increased rate of transient neurapraxias. Finally, damage to median or ulnar nerves was not statistically different between open or endoscopic techniques $(0.11 \%$ versus $0.13 \%$ ). The findings of this study seem to be comparable with our findings. It seems from our data (on minor complications) that ECTR results in more frequent transient neurapraxias, while OCTR results in wound healing problems, infections or painful scars. Because Benson 2006 excluded complications closely related to OCTR, OCTR appeared safer than ECTR. Another major nonstructural complication, mainly found after OCTR, namely CRPS, was also not included in Benson 2006, which therefore potentially underestimates the major complications of OCTR.

Thoma 2004 (search from 1989 up to 2001/2002) assessed 13 RCTs. The authors found that grip and pinch strength favoured ECTR at three months. There was no difference in pain and return to work in the studies assessed (four and three studies, respectively). They found that ECTR was three times more likely to cause neurapraxia (reversible nerve injury) than OCTR (six RCTs, pooled odds ratio (OR) $0.336,95 \% \mathrm{Cl} 0.117$ to 0.908 ). However, ECTR was associated with less scar tenderness (pooled OR $3.78,95 \% \mathrm{Cl} 2.16$ to 6.59 ). Both neurapraxia and scar tenderness were included as minor complications in our systematic review. Thoma 2004 did not include summarised complications, so a direct comparison with their findings is not possible. However, it has also been obvious during our data extraction that most of the minor complications after ECTR (when mentioned in detail) were transient neurapraxias, while most of the OCTR minor complications were due to skin problems (for example, scar tenderness or skin infections). However, such outcomes (specific complications) were not included in our systematic review.

A main difference between this study and ours is the rate of complications per intervention. It seems that $5.5 \%$ versus $8.5 \%$ for total complications and $5 \%$ versus $9.5 \%$ for minor complications for ECTR and OCTR respectively are much higher that the incidence found in Benson 2006, or other similar studies. This is mainly due to the definition of complications as given by the authors and the complications included from each study. For example, we considered all minor complications in our review, including wound infections or painful scars, which increased the total number. In addition, our review included the additional studies by Tian 2007 and Atroshi 2006, which reported an increased rate of complications.

The transbursal approach for ECTR was associated with an increased rate of complications. This was the main reason why this approach was abandoned and the extrabursal technique finally prevailed. Benson 2006, from a higher number of studies (although not limited to RCTs), assessed 22,327 ECTR and 5669 OCTR cases. The authors concluded that the transbursal approach to the carpal tunnel, which was popular when the endoscopic technique was first developed, was associated with a significantly higher complication rate of neurapraxia when compared with the extrabursal approach ( $2.8 \%$ versus $0.9 \%$, respectively). However, in our review we did not exclude participants treated with the transbursal approach. Had we done so, we would expect the rate of neurapraxias (that is, minor complications) after extrabursal ECTR to be even lower than that reported for both approaches in this current review.

From our review, ECTR seems to provide a lower rate of minor complications (Figure 7). It seems from the data that three of the studies provide a risk ratio that (not significantly) favours OCTR. All of these studies were published at a time when experience with the technique was just developing (Brown 1993; Jacobsen 1996; Werber 1996). For example, at least one was performed with a transbursal technique that was later abandoned due to a higher risk of complications (Jacobsen 1996).

From 1966 up to 2001, more than twice as many cases of ECTR were available in the literature than OCTR. However, ECTR was only first described in 1989 (Benson 2006), and the increased interest in the safety of the new ECTR approach would be expected to lead to increased publication of complications even if the complication rate were the same between the two approaches. Our finding that the 
complication rate in RCTs is the same between the two approaches strongly suggests that this was likely to have been the case.

\section{AUTHORS' CONCLUSIONS}

\section{Implications for practice}

Grip strength was greater in endoscopic carpal tunnel release at three months or less after the surgery; however, only a few studies assessed this outcome and the difference is probably not clinically significant. At time points more than three months after the surgery, ECTR showed a more pronounced superiority in grip strength, which was probably clinically significant. However, the value of this finding is moderated by the fact that only two studies reported this outcome. Return to work was faster after endoscopic release, by eight days.

Given the results of this meta-analysis, endoscopic surgery might offer an advantage in time to return to work and recovery of grip strength. This might have implications for those who rely on hand function day to day, in whom early recovery of grip strength and early return to work or full daily activities is important.

Endoscopic carpal tunnel release is as safe as open release (that is, the number of major complications is similar). There is some evidence in favour of endoscopic release over open release in the rate of minor complications and the total number of complications.

The findings in this review should be considered with caution, as their credibility is limited by shortcomings in study design and in the reporting of the included trials.

\section{Implications for research}

There is still uncertainty about whether endoscopic carpal tunnel release produces a better outcome than open carpal tunnel release or modified open techniques in terms of pain, relief of symptoms and functional recovery, as this review found no clear differences for these important outcomes between the techniques. However, the few studies that assessed these outcomes were at high risk of bias, which prevents us from reaching a safe conclusion about the potential superiority of any of the techniques. There is a need for higher quality study design and reporting to increase the credibility of the findings. Studies should regularly use clinical questionnaires to measure outcomes. Moreover, investigators should consider collecting information about adverse events prospectively and report them in detail. Research questions regarding the added benefit of endoscopic carpal tunnel release in relieving pain and improving functional recovery in either the short or long term are not yet answered.

More studies should be conducted to assess the cost-effectiveness of endoscopic carpal tunnel release compared with conventional open carpal tunnel release.

\section{ACKNOWLEDGEMENTS}

Ms Angela Gunn, Trials Search Co-ordinator, Cochrane Neuromuscular Disease Group, MRC Centre for Neuromuscular Diseases, National Hospital for Neurology and Neurosurgery, London, UK developed the search strategies.

The Cochrane Neuromuscular Disease Group for editorial and methodological support.

The editorial base of the Cochrane Neuromuscular Disease Group is supported by the MRC Centre for Neuromuscular Diseases. 


\section{RE F E R E N C E S}

\section{References to studies included in this review}

Agee 1992 \{published data only\}

Agee JM, McCarroll HR Jr, Tortosa RD, Berry DA, Szabo RM, Peimer CA. Endoscopic release of the carpal tunnel: a randomized prospective multicenter study. Journal of Hand Surgery 1992;17(6):987-95. [PUBMED: 1430964]

\section{Atroshi 2006 \{published data only\}}

Atroshi I, Hofer M, Larsson GU, Ornstein E, Johnsson R, Ranstam J. Open compared with 2-portal endoscopic carpal tunnel release: a 5-year follow-up of a randomized controlled trial. Journal of Hand Surgery 2009;34(2):266-72. [PUBMED: 19181226]

Atroshi I, Larsson GU, Ornstein E, Hofer M, Johnsson R, Ranstam J. Outcomes of endoscopic surgery compared with open surgery for carpal tunnel syndrome among employed patients: randomised controlled trial. BMJ (Clinical Research Ed.) 2006;332(7556):1473. [PUBMED: 16777857]

\section{Benedetti/Sennwald 1995 \{published data only\}}

Benedetti VR, Sennwald G. Agee endoscopic decompression of the median nerve: prospective study with comparison to open decompression [Endoskopische Dekompression des N. medianus nach Agee: Prospektive Studie mit Vergleich zur offenen Dekompression]. Handchirurgie, Mikrochirurgie, Plastische Chirurgie 1996;28(3):151-5. [PUBMED: 8767947]

Sennwald GR, Benedetti R. The value of one-portal endoscopic carpal tunnel release: a prospective randomized study. Knee Surgery, Sports Traumatology, Arthroscopy 1995;3(2):113-6. [PUBMED: 7553006]

\section{Brown 1993 \{published data only\}}

Brown RA, Gelberman RH, Seiler JG 3rd, Abrahamsson SO, Weiland AJ, Urbaniak JR, et al. Carpal tunnel release. A prospective, randomized assessment of open and endoscopic methods. Journal of Bone \& Joint Surgery. American Volume 1993;75(9):1265-75. [PUBMED: 8408148]

\section{Dumontier 1995 \{published data only\}}

Dumontier C, Sokolow C, Leclercq C, Chauvin P. Early results of conventional versus two-portal endoscopic carpal tunnel release. A prospective study. Journal of Hand Surgery (Edinburgh, Scotland) 1995;20(5):658-62. [PUBMED: 8543875]

\section{Eichhorn 2003 \{published data only\}}

Eichhorn JD, Dieterich K. Open versus endoscopic carpal tunnel release. Results of a prospective study [Offene versus endoskopische Karpaltunnelspaltungen. Ergebnisse einer prospektiven Studie]. Chirurgische Praxis 2003;61:279-83. [EMBASE: 2003168434]

\section{Erdmann 1994 \{published data only\}}

Erdmann MW. Endoscopic carpal tunnel decompression. Journal of Hand Surgery (Edinburgh, Scotland) 1994;19(1):5-13. [PUBMED: 8169480]

\section{Ferdinand 2002 \{published data only\}}

Ferdinand RD, MacLean JG. Endoscopic versus open carpal tunnel release in bilateral carpal tunnel syndrome. A prospective, randomised, blinded assessment. Journal of Bone \& Joint Surgery. British Volume 2002;84(3):375-9. [PUBMED: 12002496]

\section{Foucher 1993 \{published data only\}}

* Foucher G, Bush N, Van Overstraeten L, Gautherie M, Jesel M. Carpal tunnel syndrome. Can it still be a controversial topic?. Chirurgie 1993;119(1-2):80-4.

Foucher G, Van Overstraeten L, Braga Da Silva J. Prospective randomized study of grasp after three different techniques of carpal tunnel release (CTR). Journal of Hand Surgery. British Volume 1994;19(Suppl 1):13.

\section{Giele 2000 \{published data only\}}

Giele H. Bilateral simultaneous carpal tunnel release to prospectively compare endoscopic and open techniques. Journal of Hand Surgery. British Volume 2000;25B(Suppl 1):28-9, Abstract no: 36 .

\section{Hoefnagels 1997 \{published data only\}}

Hoefnagels WAJ, Van Kleef JGF, Mastenbroek GGA, De Blok A, Breukelman A J, De Krom MCT. Surgical treatment of carpal tunnel syndrome: endoscopic or classical (open)? A prospective randomized trial [Operatieve behandeling wegens carpaletunnelsyndroom: endoscopisch of klassiek (open)? Een prospectief gerandomiseerd onderzoek]. Nederlands Tijdschrift Voor Geneeskunde 1997;141(18):878-82.

Incoll 2004 \{published data only\}

Incoll IW, Bateman E, Myers A. Endoscopic vs open carpal tunnel release. Journal of Bone \& Joint Surgery. British Volume. 2004; Vol. 86B, issue Suppl IV:478-d.

\section{Jacobsen 1996 \{published data only\}}

Jacobsen MB, Rahme H. A prospective, randomized study with an independent observer comparing open carpal tunnel release with endoscopic carpal tunnel release. Journal of Hand Surgery (Edinburgh, Scotland) 1996;21(2):202-4. [PUBMED: 8732400]

Koskella 1996 \{published data only\}

Koskella KR, Alexander C. A comparison between open and endoscopic carpal tunnel release. Orthopaedic Transactions 1996;20(4):1102.

\section{Macdermid 2003 \{published data only\}}

Macdermid JC, Richards RS, Roth JH, Ross DC, King GJ. Endoscopic versus open carpal tunnel release: a randomized trial. Journal of Hand Surgery 2003;28(3):475-80. [PUBMED: 12772108]

\section{Mackenzie 2000 \{published data only\}}

Mackenzie DJ, Hainer R, Wheatley MJ. Early recovery after endoscopic vs. short-incision open carpal tunnel release. Annals of Plastic Surgery 2000;44(6):601-4. [PUBMED: 10884075] 
Malhotra 2007 \{published data only\}

Malhotra R, Kiran EK, Dua A, Mallinath SG, Bhan S. Endoscopic versus open carpal tunnel release: a short-term comparative study. Indian Journal of Orthopaedics 2007;41(1):57-61. [PUBMED: 21124684]

\section{Rab 2006 \{published data only\}}

Rab M, Grünbeck M, Beck H, Haslik W, Schrögendorfer KF, Schiefer HP, et al. Intra-individual comparison between open and 2-portal endoscopic release in clinically matched bilateral carpal syndrome. Journal of Plastic, Reconstructive \& Aesthetic Surgery 2006;59(7):730-6. [PUBMED: 16782569]

\section{Saw 2003 \{published data only\}}

Saw NL, Jones S, Shepstone L, Meyer M, Chapman PG, Logan AM. Early outcome and cost-effectiveness of endoscopic versus open carpal tunnel release: a randomized prospective trial. Journal of Hand Surgery (Edinburgh, Scotland) 2003;28(5):444-9. [PUBMED: 12954254]

\section{Schäfer 1996 \{published data only\}}

Schäfer W, Sander KE, Walter A, Weitbrecht WU. Agee endoscopic operation of carpal tunnel syndrome in comparison with open surgical technique [Endoskopische Operation des Karpaltunnelsyndroms nach Agee im Vergleich mit der offenen Operationstechnik]. Handchirurgie, Mikrochirurgie, Plastische Chirurgie 1996;28(3):143-6.

\section{Stark 1996 \{published data only\}}

Stark B, Engkvist-Löfmark C. Endoscopic operation or conventional open surgical technique in carpal tunnel syndrome: a prospective comparative study. Handchirurgie, Mikrochirurgie, Plastische Chirurgie 1996;28(3):128-32. [PUBMED: 8767942]

\section{Sørensen 1997 \{published data only\}}

Sørensen Al, Boeckstyns M, Nielsen NS, Haugegard M. Carpal tunnel release, a comparison of 3 methods - a preliminary report. Acta Orthopaedica Scandinavica 1997;68(Suppl 277):24-5

\section{Tian 2007 \{published data only\}}

Tian Y, Zhao H, Wang T. Prospective comparison of endoscopic and open surgical methods for carpal tunnel syndrome. Chinese Medical Sciences Journal 2007;22(2):104-7. [PUBMED: 17763582]

\section{Trumble 2002 \{published data only\}}

Trumble TE, Diao E, Abrams RA, Gilbert-Anderson MM. Singleportal endoscopic carpal tunnel release compared with open release: a prospective, randomized trial. Journal of Bone \& Joint Surgery. American Volume 2002;84-A(7):1107-15. [PUBMED: 12107308]

\section{Tüzüner 2008 \{published data only\}}

Tüzüner S, Inceoglu S, Bilen FE. Median nerve excursion in response to wrist movement after endoscopic and open carpal tunnel release. Journal of Hand Surgery 2008;33(7):1063-8. [PUBMED: 18762098]

\section{Werber 1996 \{published data only\}}

Werber KD, Braver RB, Richtarsky I. Endoscopic carpal tunnel release versus open procedure: a prospective randomized study. Journal of Hand Surgery. British Volume 1996;21 B Suppl 1:11-2.

\section{Westphal 2000 \{published data only\}}

Westphal KP, Bayat M, Wustner-Hofmann M, Hofmann A. Course of clinical symptoms before and after surgical decompression in carpal tunnel surgery. Lymphologie in Forschung Und Praxis 2000;4(2):69-73. [EMBASE: 2002067974]

\section{Wong 2003 \{published data only\}}

Wong KC, Hung LK, Ho PC, Wong JM. Carpal tunnel release. A prospective, randomised study of endoscopic versus limitedopen methods. Journal of Bone \& Joint Surgery. British Volume 2003;85(6):863-8. [PUBMED: 12931807]

\section{References to studies excluded from this review}

\section{Atroshi 2007 \{published data only\}}

Atroshi I, Gummesson C, McCabe SJ, Ornstein E. The SF-6D health utility index in carpal tunnel syndrome. Journal of Hand Surgery. European Volume 2007;32(2):198-202. [PUBMED: 17223234]

\section{Bal 2008 \{published data only\}}

Bal E, Piskin A, Ada S, Ademoglu Y, Toros T, Kayalar M. [Comparison between two mini incision techniques utilized in carpal tunnel release] [Acik karpal tunel gevsetmesinde iki farkli mini kesi yonteminin karsilastirilmasi]. Acta Orthopaedica et Traumatologica Turcica 2008;42(4):234-7. [PUBMED: 19060516]

\section{Cellocco 2005 \{published data only\}}

Cellocco P, Rossi C, Bizzarri F, Patrizio L, Costanzo G. Mini-open blind procedure versus limited open technique for carpal tunnel release: a 30-month follow-up study. Journal of Hand Surgery 2005;30(3):493-9. [PUBMED: 15925158]

\section{Dimitriou 1997 \{published data only\}}

Dimitriou GG, Kapetanos G, Koukou C, Symeonides PP. Bilateral carpal tunnnel syndrome. Open vs endoscopic release. Journal of Hand Surgery. British and European Volume 1997;22 Suppl 1:59.

\section{Flores 2005 \{published data only\}}

Flores LP. [Endoscopic carpal tunnel release: a comparative study to the conventional open technique] [Descompressão do túnel do carpo pela técnica endoscópica: estudo comparativo com a técnica convencional aberta]. Arquivos de NeuroPsiquiatria 2005;63(3A):637-42. [PUBMED: 16172714]

Futami 1995 \{published data only\}

Futami T. Surgery for bilateral carpal tunnel syndrome. Endoscopic and open release compared in 10 patients. Acta Orthopaedica Scandinavica 1995;66(2):153-5.

Hallock 1995 \{published data only\}

Hallock GG, Lutz DA. Prospective comparison of minimal incision "open" and two-portal endoscopic carpal tunnel 
release. Plastic and Reconstructive Surgery 1995;96(4):941-7. [PUBMED: 7652069]

\section{Katz 1994a \{published data only\}}

Katz JN, Gelberman RH, Wright EA, Abrahamsson SO, Lew RA. A preliminary scoring system for assessing the outcome of carpal tunnel release. Journal of Hand Surgery 1994;19(4):531-8. [PUBMED: 7963303]

\section{Katz 1994b \{published data only\}}

Katz JN, Gelberman RH, Wright EA, Lew RA, Liang MH. Responsiveness of self-reported and objective measures of disease severity in carpal tunnel syndrome. Medical Care 1994;32(11):1127-33. [PUBMED: 7967853]

\section{Lorgelly 2005 \{published data only\}}

Lorgelly PK, Dias JJ, Bradley MJ, Burke FD. Carpal tunnel syndrome, the search for a cost-effective surgical intervention: a randomised controlled trial. Annals of the Royal College of Surgeons of England 2005;87(1):36-40. [PUBMED: 15720906]

\section{Povlsen 1997 \{published data only\}}

Povlsen B, Tegnell L, Revell M, Adolfsson L. Touch allodynia following endoscopic (single portal) or open decompression for carpal tunnel syndrome. Journal of Hand Surgery (Edinburgh, Scotland) 1997;22(3):325-7. [PUBMED: 9222910]

\section{Uchiyama 2002 \{published data only\}}

Uchiyama S, Toriumi H, Nakagawa H, Kamimura M, Ishigaki N, Miyasaka T. Postoperative nerve conduction changes after open and endoscopic carpal tunnel release. Clinical Neurophysiology 2002;113(1):64-70. [PUBMED: 11801426]

\section{Uchiyama 2004 \{published data only\}}

Uchiyama S, Yasutomi T, Fukuzawa T, Nakagawa H, Kamimura M, Miyasaka T. Median nerve damage during two-portal endoscopic carpal tunnel release. Clinical Neurophysiology 2004;115(1):59-63. [PUBMED: 14706469]

\section{Vasiliadis 2010 \{published data only\}}

Vasiliadis HS, Xenakis TA, Mitsionis G, Paschos N, Georgoulis A. Endoscopic versus open carpal tunnel release. Arthroscopy 2010;26(1):26-33. [PUBMED: 20117624]

\section{Worseg 1996 \{published data only\}}

Worseg AP, Kuzbari R, Korak K, Höcker K, Wiederer C, Tschabitscher M, et al. Endoscopic carpal tunnel release using a single-portal system. British Journal of Plastic Surgery 1996;49(1):1-10. [PUBMED: 8705095]

\section{Zhao 2004 \{published data only\}}

Zhao H, Zhao Y, Tian Y, Yang B, Qiu GX. [Comparison of endoscopic versus open surgical treatment of carpal tunnel syndrome]. Zhongguo yi xue ke xue yuan xue bao. Acta Academiae Medicinae Sinicae 2004;26(6):657-60. [PUBMED: 15663227]

\section{References to studies awaiting assessment}

Aslani 2012 \{published data only\}

Aslani HR, Alizadeh K, Eajazi A, Karimi A, Karimi MH, Zaferani Z, et al. Comparison of carpal tunnel release with three different techniques. Clinical Neurology and Neurosurgery 2012;114(7):965-8.

Braga 1996 \{published data only\}

Braga-Siva J, Fontes Neto P, Foucher G, Fridman M. Postoperative strength after surgical release of the carpal tunnel: A randomized prospective study. Revista Brasileira De Ortopedia 1996;31(4):355-7.

Ejiri 2012 \{published data only\}

Soichi E, Shin-ichi K, Masato M, Yasufumi S, Ryoichi K, Shinichi K. Short-term results of endoscopic (Okutsu method) versus palmar incision open carpal tunnel release: a prospective randomized controlled trial. Fukushima Journal of Medical Science 2012;58(1):49-59.

\section{Kang 2013 \{published data only\}}

Kang HJ, Koh IH, Lee TJ, Choi YR. Endoscopic carpal tunnel release is preferred over mini-open despite similar outcome: a randomized trial. Clinical Orthopaedics and Related Research 2013;471(5):1548-54.

\section{Ugurlu 2009 \{published data only\}}

Ugurlu MO, Öztürk AM, Tecimel O, Kiliçaslan K, Sener EE, Tosun N. The comparison of endoscopic and open carpal tunnel surgery results according to functional scores and cost effectiveness of treatment [Endoskopik ve Açik Teknikle Yapilan Karpal Tünel Cerrahi Sonuçlarinin Fonksiyonel Sonuçlar ve Tedavi Maliyeti Açisindan Karsilastirilmasi]. Turkiye Klinikleri Journal of Medical Sciences 2009;29(2):469-73.

\section{References to ongoing studies}

NCT00880295 \{unpublished data only\}

NCT00880295. Patient outcomes with endoscopic versus open carpal tunnel release. http://clinicaltrials.gov/show/ NCT00880295 (accessed 28 March 2013).

\section{NCT01756820 \{unpublished data only\}}

NCT01756820. Single-portal endoscopic carpal tunnel release versus Knifelight for carpal tunnel syndrome. A randomized control trial (CTS-HV). http://clinicaltrials.gov/ct2/show/ NCT01756820 (accessed 28 March 2013).

\section{Additional references}

\section{Ablove 1994}

Ablove RH, Peimer CA, Diao E, Oliverio R, Kuhn JP. Morphologic changes following endoscopic and two-portal subcutaneous carpal tunnel release. Journal of Hand Surgery 1994;19(5):821-6. [PUBMED: 7806811] 


\section{Agee 1994}

Agee JM, McCarroll HR, North ER. Endoscopic carpal tunnel release using the single proximal incision technique. Hand Clinics 1994;10(4):647-59. [PUBMED: 7868632]

\section{Atroshi 1999}

Atroshi I, Gummesson C, Johnsson R, Ornstein E, Ranstam J, Rosen I. Prevalence of carpal tunnel syndrome in a general population. JAMA 1999;282(2):153-8. [PUBMED: 10411196]

\section{Atroshi 2009}

Atroshi I, Hofer M, Larsson GU, Ornstein E, Johnsson R, Ranstam J. Open compared with 2-portal endoscopic carpal tunnel release: a 5-year follow-up of a randomized controlled trial. Journal of Hand Surgery 2009;34(2):266-72. [PUBMED: 19181226]

\section{Benedetti 1996}

Benedetti VR, Sennwald G. Agee endoscopic decompression of the median nerve: prospective study with comparison to open decompression [Endoskopische Dekompression des N. medianus nach Agee: Prospektive Studie mit Vergleich zur offenen Dekompression.]. Handchirurgie, Mikrochirurgie, Plastische Chirurgie 1996;28(3):151-5. [PUBMED: 8767947]

\section{Benson 2006}

Benson LS, Bare AA, Nagle DJ, Harder VS, Williams CS, Visotsky JL. Complications of endoscopic and open carpal tunnel release. Arthroscopy 2006;22(9):919-24, 924.e1-2. [PUBMED: 16952718]

\section{Boeckstyns 1999}

Boeckstyns ME, Sørensen AI. Does endoscopic carpal tunnel release have a higher rate of complications than open carpal tunnel release? An analysis of published series. Journal of Hand Surgery. British Volume 1999;24(1):9-15. [PUBMED: 10190596]

\section{Bongers 2007}

Bongers FJ, Schellevis FG, van den Bosch WJ, van der Zee J. Carpal tunnel syndrome in general practice (1987 and 2001): incidence and the role of occupational and non-occupational factors. British Journal of General Practice 2007;57(534):36-9. [PUBMED: 17244422]

\section{Chow 1989}

Chow JC. Endoscopic release of the carpal ligament: a new technique for carpal tunnel syndrome. Arthroscopy 1989;5(1):19-24. [PUBMED: 2706047]

\section{Chow 1993}

Chow JC. The Chow technique of endoscopic release of the carpal ligament for carpal tunnel syndrome: four years of clinical results. Arthroscopy 1993;9(3):301-14. [PUBMED: 8323616]

\section{Cowan 2012}

Cowan J, Makanji H, Mudgal C, Jupiter J, Ring D. Determinants of return to work after carpal tunnel release. Journal of Hand Surgery 2012;37(1):18-27. [PUBMED: 22137062]

\section{Curtis 1973}

Curtis RM, Eversmann WW Jr. Internal neurolysis as an adjunct to the treatment of the carpal-tunnel syndrome. Journal of Bone \& Joint Surgery. American Volume 1973;55(4):733-40. [PUBMED: 4283745]

\section{Fissette 1979}

Fissette J, Onkelinx A. Treatment of carpal tunnel syndrome. Comparative study with and without epineurolysis. The Hand 1979;11(2):206-10. [PUBMED: 488797]

\section{Foucher 1994}

Foucher G, Van Overstraeten L, Braga Da Silva J. Prospective randomized study of grasp after three different techniques of carpal tunnel release (CTR). Journal of Hand Surgery. British Volume 1994;19 Suppl 1:13.

\section{Fuchs 1991}

Fuchs PC, Nathan PA, Myers LD. Synovial histology in carpal tunnel syndrome. Journal of Hand Surgery 1991;16(4):753-8. [PUBMED: 1880380]

\section{Gelberman 1988}

Gelberman RH, Rydevik BL, Pess GM, Szabo RM, Lundborg G. Carpal tunnel syndrome. A scientific basis for clinical care. Orthopedic Clinics of North America 1988;19(1):115-24. [PUBMED: 3275920]

\section{Gerritsen 2001}

Gerritsen AA, Uitdehaag BM, van Geldere D, Scholten RJ, de Vet HC, Bouter LM. Systematic review of randomized clinical trials of surgical treatment for carpal tunnel syndrome. British Journal of Surgery 2001;88(10):1285-95. [PUBMED: 11578281]

\section{Higgins 2002}

Higgins JP, Graham TJ. Carpal tunnel release via limited palmar incision. Hand Clinics 2002;18(2):299-306. [PUBMED: 12371032]

\section{Higgins 2011a}

Higgins JPT, Green S (editors). Cochrane Handbook for Systematic Reviews of Interventions Version 5.1.0 [updated March 2011]. The Cochrane Collaboration, 2011. Available from www.cochrane-handbook.org.

\section{Higgins 2011b}

Higgins JPT, Altman DG, Sterne JAC (editors). Chapter 8: Assessing risk of bias in included studies. In: Higgins JPT, Green S (editors). Cochrane Handbook for Systematic Reviews of Interventions Version 5.1.0 (updated March 2011). The Cochrane Collaboration, 2011. Available from www.cochranehandbook.org.

\section{Hudak 1996}

Hudak PL, Amadio PC, Bombardier C. Development of an upper extremity outcome measure: the DASH (disabilities of the arm, shoulder and hand) [corrected]. The Upper Extremity Collaborative Group (UECG). American Journal of Industrial Medicine 1996;29(6):602-8. [PUBMED: 8773720] 


\section{Jordan 2002}

Jordan R, Carter T, Cummins C. A systematic review of the utility of electrodiagnostic testing in carpal tunnel syndrome. British Journal of General Practice 2002;52(481):670-3. [PUBMED: 12171229]

\section{Karlsson 1997}

Karlsson MK, Lindau T, Hagberg L. Ligament lengthening compared with simple division of the transverse carpal ligament in the open treatment of carpal tunnel syndrome. Scandinavian Journal of Plastic and Reconstructive Surgery and Hand Surgery / Nordisk Plastikkirurgisk Forening [and] Nordisk Klubb for Handkirurgi 1997;31(1):65-9. [PUBMED: 9075290]

\section{Latinovic 2006}

Latinovic R, Gulliford MC, Hughes RA. Incidence of common compressive neuropathies in primary care. Journal of Neurology, Neurosurgery \& Psychiatry 2006;77(2):263-5. [PUBMED: 16421136]

\section{Levine 1993}

Levine DW, Simmons BP, Koris MJ, Daltroy LH, Hohl GG, Fossel $\mathrm{AH}$, et al. A self-administered questionnaire for the assessment of severity of symptoms and functional status in carpal tunnel syndrome. Journal of Bone \& Joint Surgery. American Volume 1993;75(11):1585-92. [PUBMED: 8245050]

\section{MacKinnon 2005}

MacKinnon SE, Novak CB. Compressive neuropathies. In: Green DP, Hotchkiss RN, Pederson WC, Wolfe SW editor(s). Green's Operative Hand Surgery. 5th Edition. Vol. 1, Pennsylvania: Elsevier Churchill-Livingstone, 2005:1016-7.

\section{O'Connor 2003}

O'Connor D, Marshall S, Massy-Westropp N. Non-surgical treatment (other than steroid injection) for carpal tunnel syndrome. Cochrane Database of Systematic Reviews 2003, Issue 1. [DOI: 10.1002/14651858.CD003219; PUBMED: 12535461]

\section{Okutsu 1989}

Okutsu I, Ninomiya S, Takatori Y, Ugawa Y. Endoscopic management of carpal tunnel syndrome. Arthroscopy 1989;5(1):11-8. [PUBMED: 2706046]

\section{Padua 2001}

Padua L, Padua R, Aprile I, Pasqualetti P, Tonali P. Multiperspective follow-up of untreated carpal tunnel syndrome: a multicenter study. Neurology 2001;56(11):1459-66. [PUBMED: 11402101]

\section{Palmer 1995}

Palmer DH, Hanrahan LP. Social and economic costs of carpal tunnel surgery. Instructional Course Lectures 1995;44:167-72. [PUBMED: 7797856]

\section{Phalen 1966}

Phalen GS. The carpal-tunnel syndrome. Seventeen years' experience in diagnosis and treatment of six hundred fiftyfour hands. Journal of Bone \& Joint Surgery. American Volume 1966;48(2):211-28. [PUBMED: 5934271]

\section{Piazzini 2007}

Piazzini DB, Aprile I, Ferrara PE, Bertolini C, Tonali P, Maggi L, et al. A systematic review of conservative treatment of carpal tunnel syndrome. Clinical Rehabilitation 2007;21(4):299-314. [PUBMED: 17613571]

\section{RevMan 2012 [Computer program]}

The Nordic Cochrane Centre, The Cochrane Collaboration. Review Manager (RevMan). Version 5.2. Copenhagen: The Nordic Cochrane Centre, The Cochrane Collaboration, 2012.

\section{Richman 1989}

Richman JA, Gelberman RH, Rydevik BL, Hajek PC, Braun RM, Gylys-Morin VM, et al. Carpal tunnel syndrome: morphologic changes after release of the transverse carpal ligament. Journal of Hand Surgery 1989;14(5):852-7. [PUBMED: 2794405]

\section{Sanati 2011}

Sanati KA, Mansouri M, Macdonald D, Ghafghazi S, Macdonald E, Yadegarfar G. Surgical techniques and return to work following carpal tunnel release: a systematic review and meta-analysis. Journal of Occupational Rehabilitation 2011;21(4):474-81. [PUBMED: 21528400]

\section{Scholten 2007}

Scholten RJ, Mink van der Molen A, Uitdehaag BM, Bouter LM, de Vet HC. Surgical treatment options for carpal tunnel syndrome. Cochrane Database of Systematic Reviews 2007, Issue 4. [DOI: 10.1002/14651858.CD003905.pub3; PUBMED: 17943805]

\section{Schünemann 2008}

Schünemann HJ, Oxman AD, Higgins JPT, Vist GE, Glasziou P, Guyatt GH. Chapter 11: Presenting results and 'Summary of findings' tables. In: Higgins JPT, Green S editor(s). Cochrane Handbook for Systematic Reviews of Interventions Version 5.0.1 (updated September 2008). The Cochrane Collaboration, 2008. Available from www.cochrane-handbook.org.

\section{Sennwald 1995}

Sennwald GR, Benedetti R. The value of one-portal endoscopic carpal tunnel release: a prospective randomized study. Knee Surgery, Sports Traumatology, Arthroscopy 1995;3(2):113-6. [PUBMED: 7553006]

\section{Stevens 1992}

Stevens JC, Beard CM, O'Fallon WM, Kurland LT. Conditions associated with carpal tunnel syndrome. Mayo Clinic Proceedings 1992;67(6):541-8. [PUBMED: 1434881]

\section{Thoma 2004}

Thoma A, Veltri K, Haines T, Duku E. A systematic review of reviews comparing the effectiveness of endoscopic and open carpal tunnel decompression. Plastic and Reconstructive Surgery 2004;113(4):1184-91. [PUBMED: 15083019]

\section{U.S. Department of Labor 2009}

U.S. Department of Labor, Bureau of Labor Statistics. Occupational injuries and illnesses by selected characteristics news release. Table 11. Percent distribution of nonfatal occupational injuries and illnesses involving days away from work by selected injury or illness characteristics and number 
of days away from work, 2009 [This table was reissued in December 4, 2009]. http://www.bls.gov/news.release/archives/ osh2_12042009.htm, table 11 (accessed December 2013).

\section{Vasiliadis 2006}

Vasiliadis HS, Tokis AV, Andrikoula SI, Kordalis NV, Beris AE, Xenakis T, et al. Microsurgical dissection of the carpal tunnel with respect to neurovascular structures at risk during endoscopic carpal tunnel release. Arthroscopy 2006;22(8):807-12. [PUBMED: 16904575]

\section{Wilson 2003}

Wilson JK, Sevier TL. A review of treatment for carpal tunnel syndrome. Disability and Rehabilitation 2003;25(3):113-9.

[PUBMED: 12648000]

\section{CHARACTERISTICS OF STUDIES}

Characteristics of included studies [ordered by study ID]

\section{Agee 1992}

\begin{tabular}{ll}
\hline Methods & Multicentre study (10 centres) \\
\hline Participants & 122 participants (25 bilateral CTS), 147 hands (82 ECTR, 65 OCTR) \\
& No reference to age and sex of participants \\
& Participants had idiopathic CTS, with abnormal nerve studies but normal electromyograms \\
\hline
\end{tabular}

\begin{tabular}{ll}
\hline Interventions & 1-portal ECTR (Agee technique) vs OCTR \\
\hline Outcomes & Follow-up at 1, 2, 3, 6, 9, 13 and 26 weeks \\
& $\begin{array}{l}\text { Return to work, return of hand use, grip and pinch strength, monofilament sensory, motor testing of } \\
\text { thenar muscles, complications, medication used }\end{array}$ \\
\hline Notes & \\
\hline
\end{tabular}

\section{Risk of bias}

\begin{tabular}{|c|c|c|}
\hline Bias & Authors' judgement & Support for judgement \\
\hline $\begin{array}{l}\text { Random sequence genera- } \\
\text { tion (selection bias) }\end{array}$ & Unclear risk & No information given \\
\hline $\begin{array}{l}\text { Allocation concealment } \\
\text { (selection bias) }\end{array}$ & High risk & $\begin{array}{l}\text { Participants with bilateral CTS who had ECTR in the first hand frequently } \\
\text { refused to have OCTR in the contralateral hand, which is why the authors } \\
\text { changed the allocation strategy }\end{array}$ \\
\hline $\begin{array}{l}\text { Blinding of participants } \\
\text { and personnel (perfor- } \\
\text { mance bias) } \\
\text { All outcomes }\end{array}$ & High risk & No information given. Participants and personnel could not be blinded \\
\hline $\begin{array}{l}\text { Blinding of outcome as- } \\
\text { sessment (detection bias) } \\
\text { All outcomes }\end{array}$ & High risk & No information given. Participants and personnel could not be blinded \\
\hline $\begin{array}{l}\text { Incomplete outcome data } \\
\text { (attrition bias) }\end{array}$ & Unclear risk & $\begin{array}{l}\text { No reference to attrition or exclusions, "for some variables a small number of } \\
\text { observations was missing" }\end{array}$ \\
\hline
\end{tabular}

Endoscopic release for carpal tunnel syndrome (Review)

\section{References to other published versions of this review Vasiliadis 2010b}

Vasiliadis HS, Shrier I, Salanti G, Scholten RJPM. Endoscopic release for carpal tunnel syndrome. Cochrane Database of Systematic Reviews 2010, Issue 1. [CENTRAL: 008265; DOI: 10.1002/14651858.CD008265]

* Indicates the major publication for the study 
Agee 1992 (Continued)

All outcomes

Selective reporting (re- Unclear risk $\quad$ No SDs or accurate P values provided
porting bias)

Other bias High risk There were no baseline differences

The numbers in the 2 groups were not identical, probably because participants with bilateral CTS that had ECTR in the first hand frequently refused to have OCTR in the contralateral hand. In this case, the participants chose their treatment in the contralateral hand

The authors declared conflicts of interest. No information regarding funding sources for the study

Atroshi 2006

\begin{tabular}{|c|c|}
\hline Methods & Single centre RCT \\
\hline \multirow[t]{4}{*}{ Participants } & $\begin{array}{l}\text { Of the } 128 \text { participants who had participated in the previous randomised trial, } 2 \text { died and the other } 126 \\
\text { ( } 63 \text { participants in the OCTR group and } 63 \text { participants in the ECTR group) took part in this 5-year ex- } \\
\text { tended follow-up }\end{array}$ \\
\hline & Women: 65 (52 OCTR, 44 ECTR), mean age 44 (range 25 to 59) years \\
\hline & Men: 32 (13 OCTR, 19 ECTR), mean age 44 (range 26 to 59) years \\
\hline & $\begin{array}{l}\text { Eligibility criteria: } 1 \text {. primary idiopathic CTS; } 2 \text {. between } 25 \text { and } 60 \text { years of age; } 3 \text {. employed; } 4 \text {. with } \\
\text { symptoms of classic or probable CTS according to the diagnostic criteria in the Katz hand diagram; } 5 \text {. } \\
\text { nerve conduction test shows median neuropathy at the wrist (distal motor latency of } 4.5 \mathrm{~ms} \text {, wrist-dig- } \\
\text { it sensory latency of } 3.5 \mathrm{~ms} \text {, or sensory conduction velocity at the carpal tunnel segment of } 40 \mathrm{~m} / \mathrm{s} \text { ) but } \\
\text { no other abnormalities; } 6 \text {. symptom duration of at least } 3 \text { months; and } 7 \text {. inadequate response to 6- } \\
\text { weeks' treatment by wrist splint. People with CTR in the contralateral hand were excluded }\end{array}$ \\
\hline
\end{tabular}

2-portal ECTR (extrabursal) vs OCTR

Outcomes Follow-up at 3 and 6 weeks, 3 months, 1 year (Atroshi 2006) and 5 years (Atroshi 2009)

SSS, FSS, severity of pain in the scar or proximal palm, satisfaction (completely satisfied, very satisfied, rather satisfied, or dissatisfied)

\section{Risk of bias}

\begin{tabular}{lll}
\hline Bias & Authors' judgement & Support for judgement \\
\hline $\begin{array}{l}\text { Random sequence genera- } \\
\text { tion (selection bias) }\end{array}$ & Low risk & A computer generated randomisation list in blocks of 8 was used \\
\hline $\begin{array}{l}\text { Allocation concealment } \\
\text { (selection bias) }\end{array}$ & Low risk & $\begin{array}{l}\text { The participants were assigned to a treatment group in the operating room } \\
\text { immediately before surgery, according to a computer generated randomisa- } \\
\text { tion list. In the operating room the surgeon opened the lowest numbered of } \\
\text { sequentially numbered sealed opaque envelopes containing the group assign- } \\
\text { ment }\end{array}$ \\
\hline
\end{tabular}


Atroshi 2006 (Continued)

Blinding of participants and personnel (perfor-

High risk No information given. Participants and personnel could not be blinded mance bias)

All outcomes

\section{Blinding of outcome as- High risk} sessment (detection bias)

All outcomes

\begin{abstract}
In Atroshi 2006, the authors say "Before each postoperative examination, the patients were instructed not to discuss the type of operation and had their palm and distal forearm covered with a stockinette (an elastic, sleeve-like dressing) concealing the scars. The assessor was thus blinded to the surgical method." However, most of the outcomes were self assessed by the patients and participants were not blinded. There was no reference to blinding in the 5year follow-up report (Atroshi 2009)
\end{abstract}

ITT analysis performed (2 OCTR participants died for other reasons and 1 ECTR

was converted to OCTR)

Incomplete outcome data Low risk (attrition bias)

All outcomes

Selective reporting (re- Low risk
porting bias)

All data were reported as prespecified in the protocol. However, not all outcomes assessed in Atroshi 2006 were also assessed in the 5-year follow-up

Other bias Low risk No baseline differences

This study was supported by research grants from Skane County Council's Research and Development Foundation, Kristianstad University, and The Swedish Society of Medicine

The authors declared no conflict of interest

\begin{tabular}{ll}
\hline Methods & Randomised prospective study \\
\hline Participants & Sennwald 1995 \\
& 47 participants (mean age 52.6 years): 10 men (mean age 55.7 years) and 37 women (mean age 51.7 \\
years) & 25 participants (mean age 48.6 years) were treated with ECTR and 22 participants (mean age 57 years) \\
with an open procedure \\
Indications for surgery were based on positive clinical findings (Phalen's test) and positive neurocon- \\
ductive findings \\
Symptoms were present for an average of 37 weeks in both groups \\
Benedetti 1996 \\
45 participants (mean age 53 years), $79 \%$ women. Mean duration of symptoms 9 months \\
ECTR: 1-portal Agee technique (23 participants) vs OCTR (22 participants) \\
Electrophysiologically confirmed CTS, idiopathic CTS \\
1-portal ECTR (Agee technique) vs OCTR \\
Sennwald 1995 \\
Follow-up at 4, 8 and 12 weeks
\end{tabular}


Benedetti/Sennwald 1995 (Continued)

Grip and pinch strength, complications

Benedetti 1996

Return to work

Complications

Notes

In 1 ECTR participant, the surgery was converted to OCTR owing to poor visualisation of the ligament

\section{Risk of bias}

\begin{tabular}{lll}
\hline Bias & Authors' judgement & Support for judgement \\
\hline $\begin{array}{l}\text { Random sequence genera- } \\
\text { tion (selection bias) }\end{array}$ & Low risk & $\begin{array}{l}\text { The authors "used a lottery-like procedure. Slips, defining the procedure, } \\
\text { were drawn at random from a drum by the nurse giving the appointment for } \\
\text { surgery" (Sennwald 1995) }\end{array}$ \\
\hline $\begin{array}{l}\text { Allocation concealment } \\
\text { (selection bias) }\end{array}$ & Unclear risk & There is no reference to allocation concealment \\
\hline $\begin{array}{l}\text { Blinding of participants } \\
\text { and personnel (perfor- } \\
\text { mance bias) } \\
\text { All outcomes }\end{array}$ & High risk & No information given. Participants and personnel could not be blinded \\
\hline
\end{tabular}

$\begin{array}{lll}\text { Blinding of outcome as- } & \text { High risk No information given. Participants and personnel could not be blinded } \\ \text { sessment (detection bias) } & \text { N }\end{array}$
sessment (detection bias)

All outcomes

\begin{tabular}{|c|c|c|}
\hline Incomplete outcome data & Low risk & There is no reference to participants lost to follow-up \\
\hline All outcomes & & $\begin{array}{l}\text { Benedetti 1996; } 2 \text { participants were lost from the ECTR group and } 3 \text { from the } \\
\text { OCTR group for grip strength. No reasons are provided but numbers are small } \\
\text { and not likely to change the conclusions }\end{array}$ \\
\hline
\end{tabular}

\begin{tabular}{lll}
\hline $\begin{array}{l}\text { Selective reporting (re- } \\
\text { porting bias) }\end{array}$ & Unclear risk & $\begin{array}{l}\text { The authors present all the outcomes. They give P values for each comparison } \\
\text { (although no SDs) }\end{array}$ \\
\hline Other bias & Unclear risk & No difference in baseline characteristics between groups \\
& The authors do not mention conflicts of interest or financial support
\end{tabular}

Brown 1993

\begin{tabular}{ll}
\hline Methods & Multicentre RCT (4 centres) \\
\hline Participants & OCTR ( 85 hands in 75 participants) or 2-portal ECTR ( 84 hands in 76 participants). (Some participants \\
had OCTR in one hand and ECTR in the other) & \\
& $\begin{array}{l}\text { Average age } 55 \text { years (range } 25 \text { to } 87 \text { years); } 99 \text { women, } 46 \text { men. The dominant hand was involved in } \\
104 \text { participants. The average duration of the symptoms before the operation was } 25 \text { months (range } 2 \\
\text { months to } 10 \text { years). Diagnosis was clinical and confirmed electrophysiologically }\end{array}$ \\
& $\begin{array}{l}\text { All participants had either had failure of a trial of non-operative management with a wrist splint, } \\
\text { steroid injections into the carpal canal or both, or they had refused such a program. The duration of } \\
\text { pre-operative treatment ranged from no treatment to } 10 \text { years }\end{array}$
\end{tabular}


Brown 1993 (Continued)

Interventions 2-portal ECTR (extrabursal) vs OCTR

Outcomes Follow-up at 3 and 6 weeks and 3 months

Relief of numbness and paraesthesias, satisfaction with the procedure, interstitial pressures in the carpal canal; 2-point discrimination, Semmes-Weinstein monofilament, motor strength, electrophysiological testing and functional outcomes (grip strength, key pinch strength, tenderness of the scar, pillar pain, recovery of the ability to perform activities of daily living, and return to work)

Notes

\section{Risk of bias}

\begin{tabular}{|c|c|c|}
\hline Bias & Authors' judgement & Support for judgement \\
\hline $\begin{array}{l}\text { Random sequence genera- } \\
\text { tion (selection bias) }\end{array}$ & High risk & $\begin{array}{l}\text { After the decision to proceed with CTR had been made, a random draw was } \\
\text { done to determine which procedure a participant would have. Slips of paper } \\
\left(2 \mathrm{~cm}^{2}\right) \text {, labelled either group I or group II, were placed in an opaque hat; the } \\
\text { hat was lifted above eye level; and a single slip of paper was chosen by a mem- } \\
\text { ber of the operative team. Group I participants were assigned to standard OC- } \\
\text { TR and group Il participants to modified 2-portal ECTR }\end{array}$ \\
\hline
\end{tabular}

Allocation concealment High risk
(selection bias)

After the decision to proceed with CTR had been made, a random draw was done to determine which procedure a participant would have. Slips of paper $\left(2 \mathrm{~cm}^{2}\right)$, labelled either group I or group II, were placed in an opaque hat; the hat was lifted above eye level; and a single slip of paper was chosen by a member of the operative team. Group I participants were assigned to standard OCTR and group Il participants to modified 2-portal ECTR

\begin{tabular}{lll}
\hline $\begin{array}{l}\text { Blinding of participants } \\
\text { and personnel (perfor- } \\
\text { mance bias) } \\
\text { All outcomes }\end{array}$ & High risk & No information given. Participants and personnel could not be blinded \\
\hline $\begin{array}{l}\text { Blinding of outcome as- } \\
\text { sessment (detection bias) }\end{array}$ & Low risk & $\begin{array}{l}\text { The participants were evaluated by an independent observer who was blinded } \\
\text { all outcomes }\end{array}$ \\
pist always performed this task. All of the questions and evaluation techniques \\
were standardised to minimise interobserver variability. A stockinette with oc- \\
clusive $10 \mathrm{~cm} \times 10 \mathrm{~cm}$ cotton gauze was placed over the participant's wrist and \\
palm
\end{tabular}

Incomplete outcome data Unclear risk
(attrition bias)

"One hundred and forty-nine hands (88 per cent) had follow-up at twenty-one All outcomes days; 147 hands ( 87 per cent), at forty-two days; and 160 hands (95 per cent), at eighty-four days."

\begin{tabular}{lll}
\hline $\begin{array}{l}\text { Selective reporting (re- } \\
\text { porting bias) }\end{array}$ & High risk & Not all the prespecified outcomes at all time points were reported \\
\hline Other bias & Low risk & $\begin{array}{l}\text { "No benefits in any form have been received or will be received from a com- } \\
\text { mercial party related directly or indirectly to the subject of this article. No } \\
\text { funds were received in support of this study." } \\
\text { No baseline imbalance }\end{array}$ \\
\hline
\end{tabular}

Dumontier 1995

\begin{tabular}{ll}
\hline Methods & Single centre RCT \\
\hline \hline
\end{tabular}


Dumontier 1995 (Continued)

Participants 96 participants ( 40 OCTR vs 56 ECTR) (11 men, mean age 50.7 years; 85 women, mean age 53.4 years) out of 103 patients who were initially treated (43 OCTR vs 60 ECTR). Only participants with more than 1 month of follow-up were included in the analysis

\begin{tabular}{ll}
\hline Interventions & 2-portal ECTR (extrabursal) vs OCTR \\
\hline Outcomes & Follow-up at 2 weeks and 1, 3 and 6 months \\
& Numbness, pain, return to work, grip strength
\end{tabular}

Notes

\section{Risk of bias}

Bias Authors' judgement Support for judgement

Random sequence genera- Unclear risk tion (selection bias)
No information is given about the method of randomisation. "Randomization was made during the first consultation using a disposable examination sheet on which the type of surgery to be done was noted"

Groups were not equal (40 OCTR, 56 ECTR), with no explanation for this

\begin{tabular}{|c|c|c|}
\hline $\begin{array}{l}\text { Allocation concealment } \\
\text { (selection bias) }\end{array}$ & High risk & $\begin{array}{l}\text { Randomization was performed during the first consultation using a disposable } \\
\text { examination sheet on which the type of surgery to be done was noted }\end{array}$ \\
\hline
\end{tabular}

Blinding of participants High risk No information given. Participants and personnel could not be blinded
and personnel (performance bias)

All outcomes

\begin{tabular}{ll}
\hline $\begin{array}{l}\text { Blinding of outcome as- } \\
\text { sessment (detection bias) }\end{array}$ & High risk \\
All outcomes & \\
\hline Incomplete outcome data & High risk \\
(attrition bias) & \\
All outcomes &
\end{tabular}

Unclear risk

Selective reporting (reporting bias)

No information given. Participants and personnel could not be blinded

Other bias Unclear risk No baseline differences

No reference to conflicts of interest pants were examined at 2 weeks ( 35 open vs 44 endoscopic), 62 at 1 month ( 24 vs 38), 58 at 3 months ( 30 vs 28 ) and 20 were examined at 6 months ( 12 vs 8 ). No ITT analysis was conducted

Eichhorn 2003

\begin{tabular}{ll}
\hline Methods & RCT \\
\hline Participants & $\begin{array}{l}60 \text { hands OCTR, } 65 \text { hands mini-open, } 128 \text { hands ECTR. CTS was confirmed clinically and with EMG and } \\
\text { conduction velocity measurement. No information on participant age or sex }\end{array}$ \\
\hline Interventions & ECTR (Chow) vs OCTR vs mini-open CTR \\
\hline Outcomes & Complications \\
\hline
\end{tabular}


Eichhorn 2003 (Continued)

Notes

\section{Risk of bias}

\begin{tabular}{lll}
\hline Bias & Authors' judgement & Support for judgemen \\
\hline $\begin{array}{l}\text { Random sequence genera- } \\
\text { tion (selection bias) }\end{array}$ & Unclear risk & No information given \\
\hline $\begin{array}{l}\text { Allocation concealment } \\
\text { (selection bias) }\end{array}$ & Unclear risk & No information given \\
\hline
\end{tabular}

Blinding of participants $\quad$ High risk No information given. Participants and personnel could not be blinded
and personnel (perfor-

mance bias)

All outcomes

Blinding of outcome as-

High risk

No information given. Participants and personnel could not be blinded

sessment (detection bias)

All outcomes

$\begin{array}{ll}\begin{array}{l}\text { Incomplete outcome data } \\ \text { (attrition bias) }\end{array} & \text { High risk } \\ \text { All outcomes } & \text { analysis }\end{array}$

Selective reporting (re- $\quad$ Unclear risk $\quad$ No information given
porting bias)

Other bias Unclear risk No information given. No information on funding or conflicts of interest

Erdmann 1994

\begin{tabular}{ll}
\hline Methods & Single centre RCT (a cadaveric study and a pilot study preceded) \\
\hline Participants & 71 participants with 105 hands were recruited (53 ECTR, 52 OCTR) \\
ECTR group: mean age 52.7 years, male:female ratio $1: 3.7$ \\
OCTR group: mean age 54.1 years, male:female ratio 1:2 \\
The participants were divided into 2 main groups. Group A comprised 25 participants (50 hands) with \\
bilateral symptoms who underwent simultaneous surgery, with the dominant hand randomised to one \\
technique, and the other hand undergoing the alternative procedure. Group B comprised 46 partici- \\
pants ( 55 hands) with unilateral symptoms who were randomised per hand exclusively to either ECTR \\
or OCTR
\end{tabular}

\begin{tabular}{ll}
\hline Interventions & 2-portal ECTR (extrabursal) vs OCTR \\
\hline Outcomes & Follow-up at 1 and 2 weeks, 1,3 and 6 months and 1 year \\
& Grip and pinch strength, and carpal tunnel pain \\
& Time to relief of symptoms and return to work or activities of daily living \\
Electroneurophysiological tests at 3 months
\end{tabular}


Erdmann 1994 (Continued)

Risk of bias

\begin{tabular}{|c|c|c|}
\hline Bias & Authors' judgement & Support for judgement \\
\hline $\begin{array}{l}\text { Random sequence genera- } \\
\text { tion (selection bias) }\end{array}$ & Unclear risk & $\begin{array}{l}\text { Information given not adequate. "Randomization was performed using a } \\
\text { sealed envelope system" }\end{array}$ \\
\hline $\begin{array}{l}\text { Allocation concealment } \\
\text { (selection bias) }\end{array}$ & Unclear risk & $\begin{array}{l}\text { Information given not adequate. "Randomization was performed using a } \\
\text { sealed envelope system". (For group A participants (bilateral symptoms), no } \\
\text { allocation concealment was evident for the contralateral hand) }\end{array}$ \\
\hline $\begin{array}{l}\text { Blinding of participants } \\
\text { and personnel (perfor- } \\
\text { mance bias) } \\
\text { All outcomes }\end{array}$ & High risk & No information given. Participants and personnel could not be blinded \\
\hline $\begin{array}{l}\text { Blinding of outcome as- } \\
\text { sessment (detection bias) } \\
\text { All outcomes }\end{array}$ & High risk & No information given. Participants and personnel could not be blinded \\
\hline $\begin{array}{l}\text { Incomplete outcome data } \\
\text { (attrition bias) } \\
\text { All outcomes }\end{array}$ & Unclear risk & No information given regarding any missing data \\
\hline $\begin{array}{l}\text { Selective reporting (re- } \\
\text { porting bias) }\end{array}$ & Unclear risk & $\begin{array}{l}\text { Only diagrams were used. No absolute numbers were given and no SDs. How- } \\
\text { ever, the authors gave information regarding the statistical significance of the } \\
\text { comparisons }\end{array}$ \\
\hline \multirow[t]{2}{*}{ Other bias } & High risk & $\begin{array}{l}\text { The dominant hand was operated via ECTR in } 67 \% \text { of participants and via OC- } \\
\text { TR in } 41 \%\end{array}$ \\
\hline & & No information given regarding conflicts of interest or industry support \\
\hline
\end{tabular}

Ferdinand 2002

\begin{tabular}{ll}
\hline Methods & Single-centre RCT, bilateral CTS (each hand treated with each of the techniques) \\
\hline Participants & $\begin{array}{l}25 \text { participants ( } 20 \text { women, } 5 \text { men, mean age } 54.9 \text { years) with bilateral idiopathic CTS randomised to } \\
\text { undergo ECTR to one hand and OCTR to the other. CTR was undertaken sequentially under the same } \\
\text { anaesthetic }\end{array}$
\end{tabular}

\begin{tabular}{ll}
\hline Interventions & 1-portal ECTR (Agee technique) vs OCTR \\
\hline Outcomes & Follow-up at 6 weeks, 3 and 6 months and 1 year \\
& $\begin{array}{l}\text { Degree of resolution of symptoms, pain, tenderness (VAS), time of return to work, time of return to full } \\
\text { activity, patient satisfaction }\end{array}$ \\
\hline Notes & $\begin{array}{l}\text { In } 3 \text { hands allocated to ECTR, a conversion to OCTR was required due to inadequate view intraopera- } \\
\text { tively }\end{array}$ \\
\hline
\end{tabular}

\section{Risk of bias}

Bias Authors' judgement Support for judgement


Ferdinand 2002 (Continued)

$\begin{array}{ll}\begin{array}{l}\text { Random sequence genera- } \\ \text { tion (selection bias) }\end{array} & \text { Low risk }\end{array}$

Allocation concealment Unclear risk Method of concealment not described

(selection bias)

Blinding of participants High risk

No information given. Participants and personnel could not be blinded.

and personnel (perfor-

mance bias)

All outcomes

\begin{tabular}{|c|c|c|}
\hline $\begin{array}{l}\text { Blinding of outcome as- } \\
\text { sessment (detection bias) } \\
\text { All outcomes }\end{array}$ & Low risk & $\begin{array}{l}\text { The participant concealed the wounds with adherent dressings before each } \\
\text { assessment to ensure that the assessor continued to be blinded to the type of } \\
\text { release which had been performed }\end{array}$ \\
\hline
\end{tabular}

All outcomes

In 3 hands allocated to ECTR, a conversion to OCTR was obtained due to inade-

Incomplete outcome data Unclear risk

(attrition bias) quate view intraoperatively. However, there was no reference to ITT analysis

All outcomes

\begin{tabular}{lll}
\hline $\begin{array}{l}\text { Selective reporting (re- } \\
\text { porting bias) }\end{array}$ & Unclear risk & No SDs were reported \\
\hline Other bias & Unclear risk & The authors declare no benefits from commercial party \\
& It is not clear whether baseline differences occurred \\
\hline
\end{tabular}

\section{Foucher 1993}

\begin{tabular}{ll}
\hline Methods & RCT, part of a multicentre study, but outcomes from only 1 centre reported \\
\hline Participants & 69 OCTR, 128 OCTR with ligamentoplasty, 54 ECTR. In 2 cases ECTR was converted to OCTR \\
& No information given on age or sex of participants \\
& CTS was confirmed clinically and with EMG \\
\hline Interventions & 1-portal ECTR (Agee) vs OCTR vs OCTR with ligamentoplasty \\
\hline Outcomes & Up to 3 months follow-up \\
& Grip strength, pain, days out of work \\
\hline Notes & In French
\end{tabular}

\section{Risk of bias}

\begin{tabular}{lll}
\hline Bias & Authors' judgement & Support for judgement \\
\hline $\begin{array}{l}\text { Random sequence genera- } \\
\text { tion (selection bias) }\end{array}$ & Unclear risk & No information given \\
\hline $\begin{array}{l}\text { Allocation concealment } \\
\text { (selection bias) }\end{array}$ & Unclear risk & No information given \\
\hline $\begin{array}{l}\text { Blinding of participants } \\
\text { and personnel (perfor- } \\
\text { mance bias) }\end{array}$ & High risk & No information given. Participants and personnel could not be blinded \\
\hline
\end{tabular}


Foucher 1993 (Continued)

All outcomes

Blinding of outcome as-
sessment (detection bias) $\quad$ High risk No information given. Participants and personnel could not be blinded

sessment (detection bias)

All outcomes

Incomplete outcome data Unclear risk No information given
(attrition bias)

All outcomes

Selective reporting (re- Unclear risk No numerical data for most outcomes
porting bias)

porting bias)

\begin{tabular}{ll}
\hline Other bias $\quad$ Unclear risk $\quad$ No information given about baseline differences or financial support \\
\hline
\end{tabular}

\section{Giele 2000}

\begin{tabular}{ll}
\hline Methods & RCT in participants with bilateral CTS \\
\hline Participants & $\begin{array}{l}60 \text { participants (120 hands) were assessed. Participants with bilateral CTS underwent surgery simulta- } \\
\text { neously in both hands) Average age was 51 years (range } 27 \text { to } 91 \text { years), } 12 \text { men, } 38 \text { women }\end{array}$ \\
\hline Interventions & ECTR vs OCTR \\
\hline Outcomes & Follow-up at 12 days and 4, 8 and 12 weeks \\
& "Symptoms", "signs", 2-point discrimination, pinch and grip strength, complications \\
\hline Notes & Abstract
\end{tabular}

\section{Risk of bias}

\begin{tabular}{|c|c|c|}
\hline Bias & Authors' judgement & Support for judgement \\
\hline $\begin{array}{l}\text { Random sequence genera- } \\
\text { tion (selection bias) }\end{array}$ & Unclear risk & No information given \\
\hline $\begin{array}{l}\text { Allocation concealment } \\
\text { (selection bias) }\end{array}$ & Unclear risk & No information given \\
\hline $\begin{array}{l}\text { Blinding of participants } \\
\text { and personnel (perfor- } \\
\text { mance bias) } \\
\text { All outcomes }\end{array}$ & High risk & $\begin{array}{l}\text { No information given. Participants and personnel could not be blinded. (Re- } \\
\text { port states, "the patients were blinded to the randomisation" but this does not } \\
\text { clarify.) }\end{array}$ \\
\hline $\begin{array}{l}\text { Blinding of outcome as- } \\
\text { sessment (detection bias) } \\
\text { All outcomes }\end{array}$ & High risk & No information given. Participants and personnel could not be blinded \\
\hline $\begin{array}{l}\text { Incomplete outcome data } \\
\text { (attrition bias) } \\
\text { All outcomes }\end{array}$ & Unclear risk & No information given \\
\hline $\begin{array}{l}\text { Selective reporting (re- } \\
\text { porting bias) }\end{array}$ & Unclear risk & Insufficient information given \\
\hline
\end{tabular}


Giele 2000 (Continued)

$\begin{array}{ll}\text { Other bias } & \text { Unclear risk } \\ & \begin{array}{l}\text { No information given for baseline differences or for funding or conflicts of in- } \\ \text { terest }\end{array}\end{array}$

Hoefnagels 1997

\begin{tabular}{ll}
\hline Methods & RCT \\
\hline Participants & $\begin{array}{l}\text { Mean age } 51 \text { years (range 21 to } 87 \text { years), 74\% women. Mean duration of complaints } 21 \text { months. Mean } \\
\text { SSS (SD) } 3.0(0.8) \text { vs } 2.9(0.8) \text { ECTR vs OCTR. Mean FSS 2.1 (0.7) vs 2.2 (0.7) } \\
\text { Electrophysiologically confirmed CTS }\end{array}$ \\
\hline Interventions & $\begin{array}{l}\text { (1) ECTR: 1-portal Agee technique (87 participants) } \\
\text { (2) OCTR (91 participants) }\end{array}$ \\
\hline Outcomes & SSS, FSS, pinch strength (Citec manometer), pain and tingling (10-point VAS scale), electroneurophysio- \\
\hline logical tests at 3 months, satisfaction with result, return to work, complications
\end{tabular}

\section{Risk of bias}

\begin{tabular}{|c|c|c|}
\hline Bias & Authors' judgement & Support for judgement \\
\hline $\begin{array}{l}\text { Random sequence genera- } \\
\text { tion (selection bias) }\end{array}$ & Unclear risk & No information given ("A research nurse randomly assigned the patients to ...") \\
\hline $\begin{array}{l}\text { Allocation concealment } \\
\text { (selection bias) }\end{array}$ & Unclear risk & No information given ("A research nurse randomly assigned the patients to ...") \\
\hline $\begin{array}{l}\text { Blinding of participants } \\
\text { and personnel (perfor- } \\
\text { mance bias) } \\
\text { All outcomes }\end{array}$ & High risk & No information given. Participants and personnel could not be blinded \\
\hline $\begin{array}{l}\text { Blinding of outcome as- } \\
\text { sessment (detection bias) } \\
\text { All outcomes }\end{array}$ & High risk & No information given. Participants and personnel could not be blinded \\
\hline $\begin{array}{l}\text { Incomplete outcome data } \\
\text { (attrition bias) } \\
\text { All outcomes }\end{array}$ & Low risk & $\begin{array}{l}\text { Dropout rate described and acceptable ( } 2 \text { participants in ECTR group dropped } \\
\text { out: in } 1 \text { participant ECTR could not be performed, in another participant the } \\
\text { ECTR equipment was not available. Both participants were treated with OCTR } \\
\text { and were left out of the analyses }\end{array}$ \\
\hline $\begin{array}{l}\text { Selective reporting (re- } \\
\text { porting bias) }\end{array}$ & Low risk & All outcomes presented in the results were mentioned in the methods section \\
\hline Other bias & Low risk & $\begin{array}{l}\text { Groups similar at baseline. Funded by a grant from Dutch MRC. No information } \\
\text { on conflicts of interest }\end{array}$ \\
\hline
\end{tabular}

Incoll 2004

\begin{tabular}{ll}
\hline Methods & RCT \\
\hline
\end{tabular}


Incoll 2004 (Continued)

Participants 20 patients undergoing bilateral CTR were inducted. Each participant had one side performed as an EC-

TR and the other as an OCTR. ECTR side was randomised. No information on age or sex

\begin{tabular}{ll}
\hline Interventions & 1-portal ECTR vs OCTR \\
\hline Outcomes & Follow-up at 1,2 and 6 weeks \\
& Pain, function, satisfaction, objective strength, motion
\end{tabular}

Notes Abstract

\section{Risk of bias}

\begin{tabular}{|c|c|c|}
\hline Bias & Authors' judgement & Support for judgement \\
\hline $\begin{array}{l}\text { Random sequence genera- } \\
\text { tion (selection bias) }\end{array}$ & Unclear risk & No information given \\
\hline $\begin{array}{l}\text { Allocation concealment } \\
\text { (selection bias) }\end{array}$ & Unclear risk & No information given \\
\hline $\begin{array}{l}\text { Blinding of participants } \\
\text { and personnel (perfor- } \\
\text { mance bias) } \\
\text { All outcomes }\end{array}$ & High risk & No information given. Participants and personnel could not be blinded \\
\hline $\begin{array}{l}\text { Blinding of outcome as- } \\
\text { sessment (detection bias) } \\
\text { All outcomes }\end{array}$ & Low risk & Blinded hand therapist assessed the outcomes \\
\hline $\begin{array}{l}\text { Incomplete outcome data } \\
\text { (attrition bias) } \\
\text { All outcomes }\end{array}$ & Unclear risk & No information given \\
\hline $\begin{array}{l}\text { Selective reporting (re- } \\
\text { porting bias) }\end{array}$ & Unclear risk & Insufficient information given \\
\hline Other bias & Unclear risk & $\begin{array}{l}\text { No information for baseline differences. None of the authors received financial } \\
\text { support }\end{array}$ \\
\hline
\end{tabular}

\section{Jacobsen 1996}

\begin{tabular}{ll}
\hline Methods & Single-centre RCT \\
\hline Participants & $\begin{array}{l}32 \text { hands in } 29 \text { consecutive patients with idiopathic CTS (21 women, eight men, mean age 46 (24 to 59) } \\
\text { years). } 16 \text { hands treated with ECTR, 16 hands with conventional OCTR }\end{array}$ \\
\hline Interventions & 2-portal ECTR (transbursal - Chow) vs OCTR \\
\hline Outcomes & Follow-up at 2 and 6 weeks and 6 months \\
& Symptom relief, total number of analgesics, 2-point discrimination, nerve conduction test, sick leave \\
\hline
\end{tabular}

Notes 
Jacobsen 1996 (Continued)

Risk of bias

\begin{tabular}{|c|c|c|}
\hline Bias & Authors' judgement & Support for judgement \\
\hline $\begin{array}{l}\text { Random sequence genera- } \\
\text { tion (selection bias) }\end{array}$ & Unclear risk & No information given in the manuscript \\
\hline $\begin{array}{l}\text { Allocation concealment } \\
\text { (selection bias) }\end{array}$ & Unclear risk & No information given in the manuscript \\
\hline $\begin{array}{l}\text { Blinding of participants } \\
\text { and personnel (perfor- } \\
\text { mance bias) } \\
\text { All outcomes }\end{array}$ & High risk & No information given. Participants and personnel could not be blinded \\
\hline $\begin{array}{l}\text { Blinding of outcome as- } \\
\text { sessment (detection bias) } \\
\text { All outcomes }\end{array}$ & High risk & No information given. Participants and personnel could not be blinded \\
\hline $\begin{array}{l}\text { Incomplete outcome data } \\
\text { (attrition bias) } \\
\text { All outcomes }\end{array}$ & Low risk & No attrition/exclusions or missing data regarding the outcomes presented \\
\hline $\begin{array}{l}\text { Selective reporting (re- } \\
\text { porting bias) }\end{array}$ & Unclear risk & $\begin{array}{l}\text { Some of the outcomes (electrophysiological findings) were given in a narrative } \\
\text { way, with no numbers }\end{array}$ \\
\hline Other bias & Unclear risk & $\begin{array}{l}\text { No information for baseline differences of the arms or financial support of the } \\
\text { authors }\end{array}$ \\
\hline
\end{tabular}

Koskella 1996

\begin{tabular}{|c|c|c|}
\hline Methods & \multicolumn{2}{|l|}{$\mathrm{RCT}$} \\
\hline Participants & \multicolumn{2}{|c|}{$\begin{array}{l}17 \text { hands in } 16 \text { people (mean age } 50.4 \text { ) were assessed ( } 9 \text { OCTR, } 8 \text { ECTR). CTS was confirmed electro- } \\
\text { physiologically. No information on sex }\end{array}$} \\
\hline Interventions & \multicolumn{2}{|l|}{ 1-portal ECTR vs OCTR } \\
\hline \multirow[t]{2}{*}{ Outcomes } & \multicolumn{2}{|c|}{ Follow-up at 3 and 6 weeks and 3,6 and 12 months } \\
\hline & \multicolumn{2}{|c|}{ Functional outcome, grip, pinch, complications } \\
\hline Notes & \multicolumn{2}{|l|}{ Abstract } \\
\hline \multicolumn{3}{|l|}{ Risk of bias } \\
\hline Bias & Authors' judgement & Support for judgement \\
\hline $\begin{array}{l}\text { Random sequence genera- } \\
\text { tion (selection bias) }\end{array}$ & Unclear risk & No information given \\
\hline $\begin{array}{l}\text { Allocation concealment } \\
\text { (selection bias) }\end{array}$ & Unclear risk & No information given \\
\hline
\end{tabular}


Koskella 1996 (Continued)

Blinding of participants High risk No information given. Participants and personnel could not be blinded and personnel (performance bias)

All outcomes

\begin{tabular}{lll}
\hline $\begin{array}{l}\text { Blinding of outcome as- } \\
\text { sessment (detection bias) } \\
\text { All outcomes }\end{array}$ & High risk & No information given. Participants and personnel could not be blinded \\
\hline $\begin{array}{l}\text { Incomplete outcome data } \\
\text { (attrition bias) } \\
\text { All outcomes }\end{array}$ & Unclear risk & No information given \\
\hline $\begin{array}{l}\text { Selective reporting (re- } \\
\text { porting bias) }\end{array}$ & Unclear risk & Insufficient information given \\
\hline Other bias & Unclear risk & $\begin{array}{l}\text { No information given on baseline differences or on financial support or con- } \\
\text { flicts of interest }\end{array}$ \\
\hline
\end{tabular}

Macdermid 2003

\begin{tabular}{ll}
\hline Methods & Single centre RCT \\
\hline Participants & $\begin{array}{l}\text { Participants were randomised in an unbalanced design with a 3:1 probability of receiving an endoscop- } \\
\text { ic procedure (91 ECTR, 32 OCTR). Age } 45 \pm 15 \text { for ECTR and } 53 \pm 16 \text { for OCTR. Women comprised } 68 \% \text { of } \\
\text { both arms (demographics were similar between groups) } \\
\text { CTS confirmed by electrophysiology, and participants had poor response to } 6 \text { months' conservative } \\
\text { treatment }\end{array}$
\end{tabular}

\begin{tabular}{ll}
\hline Interventions & 2-portal ECTR (transbursal - Chow technique) vs OCTR \\
\hline Outcomes & Follow-up at 1 and 6 weeks and 3 months \\
& $\begin{array}{l}\text { SSS, serious complications, grip strength, pinch strength, sensory threshold, pain (McGill pain ques- } \\
\text { tionnaire), time to return to work, rate of repeat procedures (at }>2 \text { years follow-up) }\end{array}$ \\
\hline
\end{tabular}

Notes

\section{Risk of bias}

\begin{tabular}{lll}
\hline Bias & Authors' judgement & Support for judgement \\
\hline $\begin{array}{l}\text { Random sequence genera- } \\
\text { tion (selection bias) }\end{array}$ & Unclear risk & No information given in the manuscript \\
\hline $\begin{array}{l}\text { Allocation concealment } \\
\text { (selection bias) }\end{array}$ & Unclear risk & No information given in the manuscript \\
\hline $\begin{array}{l}\text { Blinding of participants } \\
\text { and personnel (perfor- } \\
\text { mance bias) }\end{array}$ & High risk & No information given. Participants and personnel could not be blinded \\
\begin{tabular}{l} 
All outcomes \\
\hline
\end{tabular}
\end{tabular}


Macdermid 2003 (Continued)
Blinding of outcome as-
Low risk
The authors state that "all evaluations were performed by a blinded evalua- sessment (detection bias) tor" , although there was no additional information given regarding the way of All outcomes blinding (eg gloves used)

\begin{tabular}{|c|c|c|}
\hline $\begin{array}{l}\text { Incomplete outcome data } \\
\text { (attrition bias) }\end{array}$ & Unclear risk & $\begin{array}{l}\text { No information given in the manuscript regarding potentially losses to fol- } \\
\text { low-up and how they were addressed }\end{array}$ \\
\hline
\end{tabular}

All outcomes low-up and how they were addressed

Selective reporting (re- Unclear risk The authors only provide diagrams, with no SDs or P values
porting bias)

$\begin{array}{ll}\text { Other bias } & \begin{array}{l}\text { Gnclear risk } \\ \text { sis was provided regarding measurements at baseline, although such mea- } \\ \text { surements had been conducted }\end{array} \\ \text { The authors declare no conflict of interest or financial support }\end{array}$

Mackenzie 2000

\begin{tabular}{ll}
\hline Methods & Single centre, randomised prospective study \\
\hline Participants & 36 hands in 26 men had complete follow-up. 22 hands in 15 participants had ECTR and 14 hands in 11 \\
participants had mini-open technique. No information on age of participants. Because only 2 women \\
were enrolled, they were not included in the analysis. Participants were also excluded if they expressed \\
a desire for one technique over the other. Diagnosis was confirmed by electrophysiological study. Most \\
participants, but not all, had failed conservative treatment prior to surgery
\end{tabular}

\begin{tabular}{ll}
\hline Interventions & 1-portal ECTR (Agee technique) vs mini-open CTR \\
\hline Outcomes & Follow-up at 1, 2 and 4 weeks \\
& Grip, pinch strength, SSS, FSS \\
\hline Notes &
\end{tabular}

\section{Risk of bias}

\begin{tabular}{|c|c|c|}
\hline Bias & Authors' judgement & Support for judgement \\
\hline $\begin{array}{l}\text { Random sequence genera- } \\
\text { tion (selection bias) }\end{array}$ & Unclear risk & No information given \\
\hline $\begin{array}{l}\text { Allocation concealment } \\
\text { (selection bias) }\end{array}$ & High risk & $\begin{array}{l}\text { Participants were excluded if they expressed a desire for one technique over } \\
\text { the other }\end{array}$ \\
\hline $\begin{array}{l}\text { Blinding of participants } \\
\text { and personnel (perfor- } \\
\text { mance bias) } \\
\text { All outcomes }\end{array}$ & High risk & No information given. Participants and personnel could not be blinded \\
\hline $\begin{array}{l}\text { Blinding of outcome as- } \\
\text { sessment (detection bias) } \\
\text { All outcomes }\end{array}$ & High risk & No information given. Participants and personnel could not be blinded \\
\hline
\end{tabular}


Mackenzie 2000 (Continued)

Incomplete outcome data High risk No reference to the number of participants initially enrolled; quote: "26 male (attrition bias) patients had complete follow-up and comprise this analysis"; reasons for attriAll outcomes tion not provided

No ITT analysis was used

Selective reporting (re- Unclear risk $\quad$ Because only 2 women were enrolled, they were not included in the analysis
porting bias)
No SDs or specific $P$ values are given

Other bias Unclear risk No baseline differences were found

The authors do not mention conflicts of interest or financial support

Malhotra 2007

\begin{tabular}{ll}
\hline Methods & Single-centre RCT \\
\hline Participants & 36 participants (age 44.6 years, dominant hand in 23 participants, 12 women) in the ECTR group \\
& 34 participants ( 35 wrists) (age 45.3 years, dominant hand in 22 participants, 23 women) in the OCTR \\
& group \\
& 30 participants ( 30 wrists) and 30 participants ( 31 wrists) were available for follow-up in the ECTR and \\
OCTR groups respectively
\end{tabular}

\begin{tabular}{ll}
\hline Interventions & ECTR (1-portal Agee technique) vs open (short incision of 3 to $4 \mathrm{~cm}$ ) CTR \\
\hline Outcomes & $\begin{array}{l}\text { Follow-up at } 1 \text { and } 6 \text { months postoperatively } \\
\text { Symptoms, function, electrophysiological studies, complications, grip strength, time to return to daily } \\
\text { activities }\end{array}$ \\
\hline Notes & \\
\hline
\end{tabular}

\section{Risk of bias}

\begin{tabular}{|c|c|c|}
\hline Bias & Authors' judgement & Support for judgement \\
\hline $\begin{array}{l}\text { Random sequence genera- } \\
\text { tion (selection bias) }\end{array}$ & Unclear risk & $\begin{array}{l}\text { Randomisation was performed using a 'sealed envelope' technique. No infor- } \\
\text { mation is given regarding the way of sequence generation }\end{array}$ \\
\hline $\begin{array}{l}\text { Allocation concealment } \\
\text { (selection bias) }\end{array}$ & Unclear risk & Randomisation was performed using a 'sealed envelope' technique \\
\hline $\begin{array}{l}\text { Blinding of participants } \\
\text { and personnel (perfor- } \\
\text { mance bias) } \\
\text { All outcomes }\end{array}$ & High risk & No information given. Participants and personnel could not be blinded \\
\hline $\begin{array}{l}\text { Blinding of outcome as- } \\
\text { sessment (detection bias) } \\
\text { All outcomes }\end{array}$ & High risk & No information given. Participants and personnel could not be blinded \\
\hline $\begin{array}{l}\text { Incomplete outcome data } \\
\text { (attrition bias) } \\
\text { All outcomes }\end{array}$ & Unclear risk & $\begin{array}{l}\text { There were } 34 \text { participants ( } 35 \text { wrists) in the OCTR group. Out of these, } 30 \text { par- } \\
\text { ticipants ( } 31 \text { wrists) were available for follow-up. } 30 \text { out of } 36 \text { participants were } \\
\text { available in ECTR group. No ITT analysis was performed }\end{array}$ \\
\hline
\end{tabular}


Malhotra 2007 (Continued)

Selective reporting (re- $\quad$ Unclear risk $\quad$ No SDs or specific $\mathrm{P}$ values are given
porting bias)

\begin{tabular}{ll}
\hline Other bias & Low risk \\
& $\begin{array}{l}\text { There were no baseline differences. The authors declare no conflict of interest. } \\
\text { The study was funded from academic resources }\end{array}$
\end{tabular}

Rab 2006

\begin{tabular}{|c|c|}
\hline Methods & Single centre RCT, intra-individual comparison \\
\hline Participants & $\begin{array}{l}10 \text { participants (mean age } 56.2 \pm 8.2 \text { years, } 4 \text { women, } 6 \text { men) with bilateral CTS were enrolled. Diagno- } \\
\text { sis based on positive history, examination and positive electrophysiological studies. Out of } 150 \text { partici- } \\
\text { pants who were enrolled, } 75 \text { had bilateral CTS. } 10 \text { of them who had no dominance of symptoms in one } \\
\text { hand participated in the study. After randomisation, one hand was treated with ECTR ( } 10 \text { hands) and } \\
\text { the other with OCTR ( } 10 \text { hands). The second operation was performed at least } 6 \text { months after the first }\end{array}$ \\
\hline Interventions & 2-portal ECTR (Chow technique) vs mini-open CTR (2 minimised incisions) \\
\hline \multirow[t]{2}{*}{ Outcomes } & Follow-up at 2 weeks and 1, 2, 3, 6 and 12 months \\
\hline & $\begin{array}{l}\text { VAS pain, SSS, FSS, grip strength, key grip and pinch strength, 2-point discrimination, electrophysiolog- } \\
\text { ical study at } 6 \text { and } 12 \text { months }\end{array}$ \\
\hline Notes & $\begin{array}{l}\text { Participants were also excluded if they expressed a desire for one technique over the other. Performing } \\
\text { the OCTR and the 2-portal ECTR techniques, the palmar aponeurosis was not additionally divided to- } \\
\text { gether with the flexor retinaculum between both incisions }\end{array}$ \\
\hline
\end{tabular}

\section{Risk of bias}

Bias Authors' judgement Support for judgement

Random sequence genera- Unclear risk tion (selection bias)

Allocation concealment High risk
(selection bias)

No information given in the manuscript regarding the method used for the randomisation. Intra-individual comparison between hands revealed no baseline differences

u

"After randomisation with sealed envelopes the patients were informed about the surgical technique, which was chosen". No reference to "opaque" envelopes. In addition, the concealment was not adequate as the participants were aware of the method to be used

\begin{tabular}{|c|c|c|}
\hline $\begin{array}{l}\text { Blinding of participants } \\
\text { and personnel (perfor- } \\
\text { mance bias) } \\
\text { All outcomes }\end{array}$ & High risk & $\begin{array}{l}\text { The participants were informed about the surgical technique, which was cho- } \\
\text { sen }\end{array}$ \\
\hline
\end{tabular}

\begin{tabular}{|c|c|c|}
\hline $\begin{array}{l}\text { Blinding of outcome as- } \\
\text { sessment (detection bias) } \\
\text { All outcomes }\end{array}$ & High risk & No information given. Participants and personnel could not be blinded \\
\hline $\begin{array}{l}\text { Incomplete outcome data } \\
\text { (attrition bias) } \\
\text { All outcomes }\end{array}$ & Low risk & None of the participants were lost to follow-up \\
\hline $\begin{array}{l}\text { Selective reporting (re- } \\
\text { porting bias) }\end{array}$ & High risk & $\begin{array}{l}\text { Not all the outcomes in all time points were reported as prespecified in the } \\
\text { protocol }\end{array}$ \\
\hline
\end{tabular}


Rab 2006 (Continued)

$\begin{array}{ll}\text { Onclear risk } & \text { No baseline differences } \\ & \text { "In } 10 \text { out of these } 75 \text { patients suffering from bilateral CTS no dominance of } \\ \text { symptoms on one hand could be detected in the preoperative examination } \\ \text { and statistical analysis revealed no significant differences between both af- } \\ \text { fected hands." }\end{array}$

No information on financial support of the authors

Saw 2003

\begin{tabular}{ll}
\hline Methods & Single centre RCT \\
\hline Participants & 123 patients gave informed consent and were enrolled into the study \\
& 74 participants (the authors probably mean hands) were randomised to ECTR (21 men, 53 women, \\
mean age 54 (SD 15) and 76 to OCTR (19 men, 57 women, mean age 50 (SD 15) & \\
& The diagnosis of CTS was made clinically. Nerve conduction tests were performed only when there was \\
clinical doubt & \\
Participants with bilateral CTS had their releases sequentially with the more affected hand first. Once \\
these participants felt that they could use the operated hand normally they underwent the second pro- \\
cedure. The shortest interval was 7 months
\end{tabular}

Interventions 1 -portal ECTR (Agee technique) vs OCTR

Outcomes Follow-up at 1, 3, 6 and 12 weeks

SSS, FSS, VAS for tenderness, grip strength, number of days off work, cost effectiveness analysis

\begin{tabular}{ll}
\hline Notes & An area-under-the-curve (AUC) analysis was performed for the repeated measures \\
$9(12 \%)$ of the ECTR procedures were converted to OCTR
\end{tabular}

\section{Risk of bias}

\begin{tabular}{lll}
\hline Bias & Authors' judgement & Support for judgement \\
\hline $\begin{array}{l}\text { Random sequence genera- } \\
\text { tion (selection bias) }\end{array}$ & Low risk & Block randomisation was used \\
\hline $\begin{array}{l}\text { Allocation concealment } \\
\text { (selection bias) }\end{array}$ & Unclear risk & $\begin{array}{l}\text { Sealed envelopes were used. However, no additional information was given } \\
\text { (opaque or closed) }\end{array}$ \\
\hline $\begin{array}{l}\text { Blinding of participants } \\
\text { and personnel (perfor- } \\
\text { mance bias) } \\
\text { All outcomes }\end{array}$ & High risk & No information given. Participants and personnel could not be blinded \\
\hline
\end{tabular}

\begin{tabular}{|c|c|c|}
\hline $\begin{array}{l}\text { Blinding of outcome as- } \\
\text { sessment (detection bias) } \\
\text { All outcomes }\end{array}$ & Low risk & $\begin{array}{l}\text { The assessor was blinded to the procedure by placing a stockinette over the } \\
\text { wrist of the participant }\end{array}$ \\
\hline
\end{tabular}

\begin{tabular}{|c|c|c|}
\hline $\begin{array}{l}\text { Incomplete outcome data } \\
\text { (attrition bias) } \\
\text { All outcomes }\end{array}$ & Low risk & $\begin{array}{l}\text { An ITT analysis was used. Participants were analysed as randomised to the } \\
\text { study and not with respect to the surgical procedure actually used. With re- }\end{array}$ \\
\hline
\end{tabular}


Saw 2003 (Continued)

spect to measures repeated over time, a 'last observation carried forward' strategy was used to impute missing values

\begin{tabular}{lll}
\hline $\begin{array}{l}\text { Selective reporting (re- } \\
\text { porting bias) }\end{array}$ & Unclear risk & $\begin{array}{l}\text { Although the authors give all the outcomes, they present full information only } \\
\text { for the final follow-up. The intermediate data are given only in diagrams, with } \\
\text { no accurate numbers given and also no SDs }\end{array}$ \\
\hline Other bias & High risk & $\begin{array}{l}\text { The participants in the ECTR group were, on average, about } 5 \text { years older than } \\
\text { those in the OCTR group and were more likely to have the left hand operated } \\
\text { on. Clinical measurements were similar }\end{array}$ \\
The authors do not mention conflicts of interest or financial support
\end{tabular}

\section{Schäfer 1996}

\begin{tabular}{ll}
\hline Methods & Quasi-randomised trial \\
\hline Participants & 54 OCTR (13 men, 41 women), 47 ECTR (17 men, 30 women); mean age 53 years \\
\hline Interventions & 1-portal ECTR (Agee) vs OCTR \\
\hline Outcomes & Follow-up at 9 months \\
& Complications, grip strength, return to work \\
\hline
\end{tabular}

Notes

\section{Risk of bias}

\begin{tabular}{|c|c|c|}
\hline Bias & Authors' judgement & Support for judgement \\
\hline $\begin{array}{l}\text { Random sequence genera- } \\
\text { tion (selection bias) }\end{array}$ & High risk & Quasi-randomised, according to the day of the week (odd or even) \\
\hline $\begin{array}{l}\text { Allocation concealment } \\
\text { (selection bias) }\end{array}$ & High risk & Quasi-randomised, according to the day of the week (odd or even) \\
\hline $\begin{array}{l}\text { Blinding of participants } \\
\text { and personnel (perfor- } \\
\text { mance bias) } \\
\text { All outcomes }\end{array}$ & High risk & No information given. Participants and personnel could not be blinded \\
\hline $\begin{array}{l}\text { Blinding of outcome as- } \\
\text { sessment (detection bias) } \\
\text { All outcomes }\end{array}$ & High risk & No information given. Participants and personnel could not be blinded \\
\hline $\begin{array}{l}\text { Incomplete outcome data } \\
\text { (attrition bias) } \\
\text { All outcomes }\end{array}$ & Low risk & No participants lost to follow-up \\
\hline $\begin{array}{l}\text { Selective reporting (re- } \\
\text { porting bias) }\end{array}$ & Unclear risk & No $P$ values and SDs of all outcomes \\
\hline Other bias & Unclear risk & No baseline differences. No information given on financial support \\
\hline
\end{tabular}


Stark 1996

\begin{tabular}{ll}
\hline Methods & RCT \\
\hline Participants & $\begin{array}{l}\text { 20 participants with bilateral CTS (average age 53 years), } 1 \text { hand with OCTR and } 1 \text { with ECTR (2 to } 4 \\
\text { months' interval). No information on sex } \\
\text { CTS was confirmed clinically and with EMG }\end{array}$ \\
\hline Interventions & 1-portal ECTR (Agee) vs OCTR \\
\hline Outcomes & Follow-up at 2, 4 and 12 weeks and 8 months \\
& Clinical evaluation, movement of hand and fingers, 2-point discrimination, grip strength \\
\hline Notes &
\end{tabular}

\section{Risk of bias}

\begin{tabular}{|c|c|c|}
\hline Bias & Authors' judgement & Support for judgement \\
\hline $\begin{array}{l}\text { Random sequence genera- } \\
\text { tion (selection bias) }\end{array}$ & Unclear risk & No information given \\
\hline $\begin{array}{l}\text { Allocation concealment } \\
\text { (selection bias) }\end{array}$ & Unclear risk & No information given \\
\hline $\begin{array}{l}\text { Blinding of participants } \\
\text { and personnel (perfor- } \\
\text { mance bias) } \\
\text { All outcomes }\end{array}$ & High risk & No information given. Participants and personnel could not be blinded \\
\hline $\begin{array}{l}\text { Blinding of outcome as- } \\
\text { sessment (detection bias) } \\
\text { All outcomes }\end{array}$ & High risk & No information given. Participants and personnel could not be blinded \\
\hline $\begin{array}{l}\text { Incomplete outcome data } \\
\text { (attrition bias) } \\
\text { All outcomes }\end{array}$ & Low risk & No participants lost to follow-up \\
\hline $\begin{array}{l}\text { Selective reporting (re- } \\
\text { porting bias) }\end{array}$ & High risk & $\begin{array}{l}\text { No P values and SDs of all outcomes. No values for some measurements (eg } \\
\text { grip strength) }\end{array}$ \\
\hline Other bias & Unclear risk & $\begin{array}{l}\text { No information on baseline differences. No information given for financial sup- } \\
\text { port }\end{array}$ \\
\hline
\end{tabular}

Sørensen 1997

\begin{tabular}{ll}
\hline Methods & Prospective, randomised, blinded trial in patients with bilateral CTS \\
\hline Participants & $\begin{array}{l}\text { 48 patients were assessed. CTS was confirmed with EMG and conduction velocity measurement. No in- } \\
\text { formation for age or sex }\end{array}$ \\
\hline Interventions & ECTR vs OCTR vs mini-open CTR \\
\hline Outcomes & Follow-up at $1,2,3,6,12$ and 24 weeks \\
\hline
\end{tabular}


Sørensen 1997 (Continued)

Pain VAS, paraesthesia VAS, grip strength, wrist motion, pillar pain, sick leave

\begin{tabular}{|c|c|c|}
\hline Notes & Abstract & \\
\hline \multicolumn{3}{|l|}{ Risk of bias } \\
\hline Bias & Authors' judgement & Support for judgement \\
\hline $\begin{array}{l}\text { Random sequence genera- } \\
\text { tion (selection bias) }\end{array}$ & Unclear risk & No information given \\
\hline $\begin{array}{l}\text { Allocation concealment } \\
\text { (selection bias) }\end{array}$ & Unclear risk & No information given \\
\hline $\begin{array}{l}\text { Blinding of participants } \\
\text { and personnel (perfor- } \\
\text { mance bias) } \\
\text { All outcomes }\end{array}$ & High risk & No information given. Participants and personnel could not be blinded \\
\hline $\begin{array}{l}\text { Blinding of outcome as- } \\
\text { sessment (detection bias) } \\
\text { All outcomes }\end{array}$ & High risk & No information given. Participants and personnel could not be blinded \\
\hline $\begin{array}{l}\text { Incomplete outcome data } \\
\text { (attrition bias) } \\
\text { All outcomes }\end{array}$ & Unclear risk & No information given \\
\hline $\begin{array}{l}\text { Selective reporting (re- } \\
\text { porting bias) }\end{array}$ & Unclear risk & Insufficient information given \\
\hline Other bias & Unclear risk & $\begin{array}{l}\text { No information given on baseline differences, financial support or conflicts of } \\
\text { interest }\end{array}$ \\
\hline
\end{tabular}

Tian 2007

\begin{tabular}{ll}
\hline Methods & Single centre RCT \\
\hline Participants & $\begin{array}{l}70 \text { hands in } 62 \text { participants: } 16 \text { men (18 hands) and } 46 \text { women (52 hands), average age 52 years (range } \\
30 \text { to } 70) ; 34 \text { hands (32 participants) treated with ECTR; } 36 \text { hands (30 participants) treated with OCTR } \\
\text { CTS was confirmed clinically and with EMG }\end{array}$ \\
\hline Interventions & 1-portal ECTR (Okutsu) vs OCTR \\
\hline Outcomes & Follow-up at 18 to 48 months (average 2 years) \\
& Patient satisfaction, 2-point discrimination, grip strength, electromyography test, time of operation, in- \\
hospital stay, return to work
\end{tabular}

Notes

\section{Risk of bias}


Tian 2007 (Continued)
Random sequence genera- Unclear risk
No information given tion (selection bias)

\begin{tabular}{lll}
\hline $\begin{array}{l}\text { Allocation concealment } \\
\text { (selection bias) }\end{array}$ & Unclear risk & No information given
\end{tabular}

\begin{tabular}{|c|c|c|}
\hline $\begin{array}{l}\text { Blinding of participants } \\
\text { and personnel (perfor- } \\
\text { mance bias) } \\
\text { All outcomes }\end{array}$ & High risk & No information given. Participants and personnel could not be blinded \\
\hline $\begin{array}{l}\text { Blinding of outcome as- } \\
\text { sessment (detection bias) } \\
\text { All outcomes }\end{array}$ & High risk & No information given. Participants and personnel could not be blinded \\
\hline $\begin{array}{l}\text { Incomplete outcome data } \\
\text { (attrition bias) } \\
\text { All outcomes }\end{array}$ & Unclear risk & No information given \\
\hline $\begin{array}{l}\text { Selective reporting (re- } \\
\text { porting bias) }\end{array}$ & Unclear risk & No SDs are given for all outcomes \\
\hline Other bias & Unclear risk & $\begin{array}{l}\text { No information on baseline differences. No information given on financial sup- } \\
\text { port }\end{array}$ \\
\hline
\end{tabular}

Trumble 2002

\begin{tabular}{|c|c|}
\hline Methods & Multicentre RCT ( 3 centres) \\
\hline \multirow[t]{3}{*}{ Participants } & $\begin{array}{l}161 \text { participants ( } 209 \text { hands) were enrolled. } 6 \text { participants ( } 8 \text { hands) in the ECTR group and } 8 \text { partici- } \\
\text { pants ( } 9 \text { hands) in the OCTR group were lost to follow-up after less than } 1 \text { year and were excluded from } \\
\text { the study. } 147 \text { participants ( } 192 \text { hands) (average age } 56 \text { years, range } 24 \text { to } 74 \text { years) were included. }\end{array}$ \\
\hline & $\begin{array}{l}75 \text { participants ( } 48 \text { women, } 27 \text { men, } 97 \text { hands) were treated with ECTR and } 72 \text { participants ( } 48 \text { women, } \\
24 \text { men, } 95 \text { hands) with OCTR were analysed }\end{array}$ \\
\hline & $\begin{array}{l}\text { The diagnosis was made clinically with electrophysiological confirmation (participants met the Amer- } \\
\text { ican Association of Electrodiagnostic Medicine diagnostic criteria for CTS). Participants had had fail- } \\
\text { ure of conservative treatment (splint) or steroid injection. The average age was } 66 \text { years (range } 24 \text { to } 74 \\
\text { years). There were } 95 \text { women and } 52 \text { men. The dominant hand was involved in } 106 \text { participants. The } \\
\text { duration of symptoms before the operation averaged } 32 \text { months (range } 4 \text { months to } 11 \text { years) }\end{array}$ \\
\hline
\end{tabular}

\begin{tabular}{ll}
\hline Interventions & 1-portal ECTR (Agee technique) vs OCTR \\
\hline Outcomes & Follow-up at 2, 4, 8, 12, 26 and 52 weeks \\
& $\begin{array}{l}\text { SSS, FSS, overall satisfaction VAS, 2-point discrimination and Semmes-Weinstein monofilament tests, } \\
\text { grip strength, pinch strength, scar sensitivity, complications, cost of treatment }\end{array}$
\end{tabular}

Notes $\begin{aligned} & \text { Participants with bilateral CTS had the procedure that had been randomly assigned to the first hand } \\ & \text { performed on the contralateral hand as well }\end{aligned}$

No tenosynovectomy or neurolysis was additionally performed

\section{Risk of bias}


Trumble 2002 (Continued)

\begin{tabular}{|c|c|c|}
\hline Bias & Authors' judgement & Support for judgement \\
\hline $\begin{array}{l}\text { Random sequence genera- } \\
\text { tion (selection bias) }\end{array}$ & Unclear risk & $\begin{array}{l}\text { The procedure was determined "drawing a randomly assigned marked slip of } \\
\text { paper from an envelope". No further details were given regarding the way of } \\
\text { randomisation }\end{array}$ \\
\hline $\begin{array}{l}\text { Allocation concealment } \\
\text { (selection bias) }\end{array}$ & High risk & $\begin{array}{l}\text { Randomisation was achieved by "drawing a randomly assigned marked slip of } \\
\text { paper from an envelope". This does not ensure allocation concealment }\end{array}$ \\
\hline $\begin{array}{l}\text { Blinding of participants } \\
\text { and personnel (perfor- } \\
\text { mance bias) } \\
\text { All outcomes }\end{array}$ & High risk & No information given. Participants and personnel could not be blinded \\
\hline $\begin{array}{l}\text { Blinding of outcome as- } \\
\text { sessment (detection bias) } \\
\text { All outcomes }\end{array}$ & Low risk & $\begin{array}{l}\text { The observer, a research assistant, was blinded to the type of procedure by } \\
\text { placement of a stockinette over the participant's hand }\end{array}$ \\
\hline $\begin{array}{l}\text { Incomplete outcome data } \\
\text { (attrition bias) } \\
\text { All outcomes }\end{array}$ & Unclear risk & $\begin{array}{l}6 \text { participants ( } 8 \text { hands) in the endoscopic group and } 8 \text { participants ( } 9 \text { hands) } \\
\text { in the open release group were lost to follow-up after less than } 1 \text { year and were } \\
\text { excluded from the study. No ITT analysis was performed }\end{array}$ \\
\hline $\begin{array}{l}\text { Selective reporting (re- } \\
\text { porting bias) }\end{array}$ & High risk & $\begin{array}{l}\text { The authors do not report all the outcomes at all time points. The data pre- } \\
\text { sented also lack valuable information ie SDs or Cls or accurate } P \text { values }\end{array}$ \\
\hline Other bias & Low risk & $\begin{array}{l}\text { No baseline differences were found } \\
1 \text { or more of the authors had funding grants but none had any support from a } \\
\text { commercial entity }\end{array}$ \\
\hline
\end{tabular}

Tüzüner 2008

\begin{tabular}{ll}
\hline Methods & $\begin{array}{l}\text { Single centre RCT measuring the excursion of median nerve before and after the release (anatomical } \\
\text { study) }\end{array}$
\end{tabular}

Participants 16 hands in 13 participants with idiopathic primary CTS unresponsive to conservative care were included. The intervention was ECTR in 8 hands ( 7 participants) and OCTR in 8 hands ( 6 participants). 1 participant had bilateral ECTR at the same time. 2 additional participants had bilateral releases, ECTR on one side and OCTR on the other side on a different day. All participants were women, with a mean age of 52 years (range 38 to 60 years)

Diagnosis was made clinically and with an electrodiagnostic study

\begin{tabular}{ll}
\hline Interventions & 1-portal ECTR (Menon technique) vs OCTR \\
\hline Outcomes & Measurements were intraoperative. No follow-up measurements were conducted \\
& Longitudinal excursion and volar displacement of the median nerve were recorded based on continu- \\
& ous fluoroscopic imaging for each wrist during controlled movement from full flexion to full extension. \\
A marker was used to mark the median nerve
\end{tabular}

\begin{tabular}{ll}
\hline Notes & This was an anatomical study \\
None of the outcomes were used in our systematic review
\end{tabular}

\section{Risk of bias}


Tüzüner 2008 (Continued)

\begin{tabular}{|c|c|c|}
\hline Bias & Authors' judgement & Support for judgement \\
\hline $\begin{array}{l}\text { Random sequence genera- } \\
\text { tion (selection bias) }\end{array}$ & Low risk & $\begin{array}{l}\text { Previously prepared numbered and sealed opaque envelopes were used. This } \\
\text { is adequate assuming that there was sequential numbering of the envelopes }\end{array}$ \\
\hline $\begin{array}{l}\text { Allocation concealment } \\
\text { (selection bias) }\end{array}$ & Low risk & Sealed opaque envelopes were used \\
\hline $\begin{array}{l}\text { Blinding of participants } \\
\text { and personnel (perfor- } \\
\text { mance bias) } \\
\text { All outcomes }\end{array}$ & High risk & No information given. Participants and personnel could not be blinded \\
\hline $\begin{array}{l}\text { Blinding of outcome as- } \\
\text { sessment (detection bias) } \\
\text { All outcomes }\end{array}$ & High risk & No information given. Participants and personnel could not be blinded \\
\hline $\begin{array}{l}\text { Incomplete outcome data } \\
\text { (attrition bias) } \\
\text { All outcomes }\end{array}$ & Low risk & $\begin{array}{l}\text { Due to the nature of the study (intraoperative measurements) no participants } \\
\text { were lost }\end{array}$ \\
\hline $\begin{array}{l}\text { Selective reporting (re- } \\
\text { porting bias) }\end{array}$ & Low risk & All the outcomes were presented adequately \\
\hline Other bias & Low risk & $\begin{array}{l}\text { No baseline differences were found regarding the measurements and sex (all } \\
\text { were women) }\end{array}$ \\
\hline & & The authors declare no benefits in any form related to the study \\
\hline
\end{tabular}

Werber 1996

\begin{tabular}{ll}
\hline Methods & RCT \\
\hline Participants & 90 participants (44 OCTR, 46 ECTR). No information on age or sex \\
\hline Interventions & OCTR vs 1-portal ECTR \\
\hline Outcomes & Follow-up at 6 months \\
\hline Notes & Abstract \\
\hline
\end{tabular}

\section{Risk of bias}

\begin{tabular}{lll}
\hline Bias & Authors' judgement & Support for judgement \\
\hline $\begin{array}{l}\text { Random sequence genera- } \\
\text { tion (selection bias) }\end{array}$ & Unclear risk & No information given \\
\hline $\begin{array}{l}\text { Allocation concealment } \\
\text { (selection bias) }\end{array}$ & Unclear risk & No information given \\
\hline $\begin{array}{l}\text { Blinding of participants } \\
\begin{array}{l}\text { and personnel (perfor- } \\
\text { mance bias) }\end{array}\end{array}$ & High risk & No information given. Participants and personnel could not be blinded \\
All outcomes & \\
\hline
\end{tabular}


Werber 1996 (Continued)

$\begin{array}{lll}\text { Blinding of outcome as- } & \text { High risk No information given. Participants and personnel could not be blinded } \\ \text { sessment (detection bias) }\end{array}$

All outcomes

\begin{tabular}{lll}
\hline $\begin{array}{l}\text { Incomplete outcome data } \\
\text { (attrition bias) } \\
\text { All outcomes }\end{array}$ & Unclear risk & No information given \\
\hline $\begin{array}{l}\text { Selective reporting (re- } \\
\text { porting bias) }\end{array}$ & Unclear risk & Insufficient information given \\
\hline Other bias & Unclear risk & $\begin{array}{l}\text { No information given regarding baseline differences, funding or conflicts of in- } \\
\text { terest }\end{array}$ \\
\hline
\end{tabular}

\section{Westphal 2000}

\begin{tabular}{ll}
\hline Methods & Single centre RCT \\
\hline Participants & 35 OCTR, 45 ECTR. No information on age or sex \\
\hline Interventions & 1-portal (ENDO-CARTRIS ${ }^{\oplus}$ ) ECTR vs OCTR \\
\hline Outcomes & Follow-up at 4 weeks and 3 months \\
& $\begin{array}{l}\text { Modified SSS, modified FSS, clinical evaluation, numbness, pain, strength, Phalen, Tinel, 2-point dis- } \\
\text { crimination, EMG }\end{array}$ \\
\hline
\end{tabular}

\section{Notes}

\section{Risk of bias}

\begin{tabular}{|c|c|c|}
\hline Bias & Authors' judgement & Support for judgement \\
\hline $\begin{array}{l}\text { Random sequence genera- } \\
\text { tion (selection bias) }\end{array}$ & Unclear risk & No information given \\
\hline $\begin{array}{l}\text { Allocation concealment } \\
\text { (selection bias) }\end{array}$ & Unclear risk & No information given \\
\hline $\begin{array}{l}\text { Blinding of participants } \\
\text { and personnel (perfor- } \\
\text { mance bias) } \\
\text { All outcomes }\end{array}$ & High risk & No information given. Participants and personnel could not be blinded \\
\hline $\begin{array}{l}\text { Blinding of outcome as- } \\
\text { sessment (detection bias) } \\
\text { All outcomes }\end{array}$ & High risk & No information given. Participants and personnel could not be blinded \\
\hline $\begin{array}{l}\text { Incomplete outcome data } \\
\text { (attrition bias) } \\
\text { All outcomes }\end{array}$ & Unclear risk & No information given \\
\hline $\begin{array}{l}\text { Selective reporting (re- } \\
\text { porting bias) }\end{array}$ & Unclear risk & No $P$ values and SDs of all outcomes \\
\hline
\end{tabular}


Westphal 2000 (Continued)

Other bias Unclear risk No baseline differences. No information given about financial support

Wong 2003

\begin{tabular}{|c|c|}
\hline Methods & Intra-individual comparison (simultaneous bilateral release was performed) \\
\hline \multirow[t]{3}{*}{ Participants } & 30 participants with bilateral idiopathic CTS had simultaneous bilateral release (60 hands) \\
\hline & 28 women and 2 men; mean age 47 years ( 35 to 73 ) \\
\hline & $\begin{array}{l}\text { Diagnosis was made clinically confirmed by a reduced conduction velocity. All participants had under- } \\
\text { gone conservative treatment without improvement. Simultaneous bilateral release was performed }\end{array}$ \\
\hline Interventions & 2-portal ECTR (extrabursal Chow technique) vs limited OCTR (use of special device) \\
\hline \multirow[t]{2}{*}{ Outcomes } & The participants were reviewed at 2, 4,8 and 16 weeks and at 6 and 12 months after surgery \\
\hline & $\begin{array}{l}\text { Grip and pinch strength, 2-point discrimination ( } 4 \text { and } 12 \text { weeks, and } 6 \text { and } 12 \text { months), postoperative } \\
\text { pain (VAS), complications }\end{array}$ \\
\hline
\end{tabular}

Notes

\section{Risk of bias}

\begin{tabular}{|c|c|c|}
\hline Bias & Authors' judgement & Support for judgement \\
\hline $\begin{array}{l}\text { Random sequence genera- } \\
\text { tion (selection bias) }\end{array}$ & Low risk & $\begin{array}{l}\text { The dominant hand was randomly allocated to either ECTR or LOCTR using } \\
\text { a random number table and the opposite hand was treated using the other } \\
\text { technique }\end{array}$ \\
\hline $\begin{array}{l}\text { Allocation concealment } \\
\text { (selection bias) }\end{array}$ & Unclear risk & No information given \\
\hline $\begin{array}{l}\text { Blinding of participants } \\
\text { and personnel (perfor- } \\
\text { mance bias) } \\
\text { All outcomes }\end{array}$ & High risk & No information given. Participants and personnel could not be blinded \\
\hline $\begin{array}{l}\text { Blinding of outcome as- } \\
\text { sessment (detection bias) } \\
\text { All outcomes }\end{array}$ & High risk & No information given. Participants and personnel could not be blinded \\
\hline $\begin{array}{l}\text { Incomplete outcome data } \\
\text { (attrition bias) } \\
\text { All outcomes }\end{array}$ & Unclear risk & There was no reference to missing participants \\
\hline $\begin{array}{l}\text { Selective reporting (re- } \\
\text { porting bias) }\end{array}$ & High risk & $\begin{array}{l}\text { Not all the outcomes were presented and valuable information was also miss- } \\
\text { ing (SDs or even mean values) }\end{array}$ \\
\hline Other bias & Low risk & $\begin{array}{l}\text { No baseline differences were found } \\
\text { The authors declare no benefits in any form related to the study }\end{array}$ \\
\hline
\end{tabular}

CTR: carpal tunnel release; CTS: carpal tunnel syndrome; ECTR: endoscopic carpal tunnel release; EMG: electromyography; FSS: Functional Status Scale; ITT: intention-to-treat; OCTR: open carpal tunnel release; SD: standard deviation; SSS: Symptom Severity Scale; VAS: visual analogue scale; RCT: randomised controlled trial 
Characteristics of excluded studies [ordered by study ID]

\begin{tabular}{|c|c|}
\hline Study & Reason for exclusion \\
\hline Atroshi 2007 & Not an RCT. Evaluation of the SF-6D health utility index \\
\hline Bal 2008 & Not an RCT. Compared 2 mini skin incision techniques \\
\hline Cellocco 2005 & $\begin{array}{l}\text { ECTR not involved. Mini-open blind technique for carpal tunnel release (group A) compared with a } \\
\text { limited open technique (group B) }\end{array}$ \\
\hline Dimitriou 1997 & Not an RCT \\
\hline Flores 2005 & Not an RCT. 2 groups of 15 participants underwent ECTR or conventional CTR \\
\hline Futami 1995 & $\begin{array}{l}\text { Not an RCT. } 10 \text { participants with bilateral CTS underwent ECTR in one hand and conventional OCTR } \\
\text { in the other }\end{array}$ \\
\hline Hallock 1995 & $\begin{array}{l}\text { Not an RCT. } 53 \text { participants ( } 71 \text { hands) underwent OCTR using a minimal incision, which was com- } \\
\text { parable in composition to a group of } 47 \text { participants ( } 66 \text { hands) who had a 2-portal ECTR }\end{array}$ \\
\hline Katz 1994a & Not an RCT. Assessment of a global scoring system using data from an RCT (Brown 1993) \\
\hline Katz 1994b & Not an RCT. Responsiveness of questionnaires, using data from an RCT (Brown 1993) \\
\hline Lorgelly 2005 & $\begin{array}{l}\text { ECTR not involved. Evaluates the cost, effectiveness and cost-effectiveness of minimally invasive } \\
\text { surgery compared with conventional OCTR }\end{array}$ \\
\hline Povlsen 1997 & Not an RCT \\
\hline Uchiyama 2002 & $\begin{array}{l}\text { Not an RCT. The first } 33 \text { consecutive patients ( } 33 \text { hands) subjected to ECTR were prospectively com- } \\
\text { pared with the following } 33 \text { consecutive patients ( } 33 \text { hands), who were treated by OCTR }\end{array}$ \\
\hline Uchiyama 2004 & Not an RCT. ECTR or OCTR was performed based on participant preference \\
\hline Vasiliadis 2010 & Not an RCT. 37 underwent ECTR according to Chow and 35 were assigned to the open method \\
\hline Worseg 1996 & $\begin{array}{l}\text { Not an RCT. } 126 \text { participants were enrolled in this study, } 64 \text { of them were treated endoscopically } \\
\text { and } 62 \text { by OCTR }\end{array}$ \\
\hline Zhao 2004 & Not an RCT \\
\hline
\end{tabular}

ECTR: endoscopic carpal tunnel release; OCTR: open carpal tunnel release; RCT: randomised controlled trial.

Characteristics of studies awaiting assessment [ordered by study ID]

Aslani 2012

\begin{tabular}{ll}
\hline Methods & Single centre, prospective, randomised trial \\
\hline Participants & 105 participants ( 10 men, 95 women) over 50 years old, median age 54.2 years (30 to 65 years). At \\
least 6 months had elapsed since the start of their symptoms \\
ECTR (32 participants) vs OCTR (36 participants) vs mini-OCTR (28 participants). 8 participants had \\
bilateral involvement
\end{tabular}


Aslani 2012 (Continued)

Interventions

Outcomes
ECTR (Chow technique) vs OCTR vs mini-OCTR

Outcomes measured at 2, 4 and 16 weeks

Clinical symptoms (numbness, nocturnal pain, wrist pain, weakness and stiffness); diagnostic tests (Tinel, Phalen and compression); electrodiagnostic examinations (electromyography, nerve conduction velocity); evaluation of strength to grasp an object between 2 fingers (with dynamometer); length of time to resume personal tasks (combing hair, brushing teeth and writing); and satisfaction with the surgery

\section{Notes}

\section{Braga 1996}

\section{Methods}

\section{Participants}

Interventions

\section{Outcomes}

\section{Ejiri 2012}

\begin{tabular}{ll}
\hline Methods & Single centre prospective randomised trial \\
\hline Participants & 101 hands (79 participants): ECTR in 51 hands ( 40 participants), OCTR in 50 hands (39 participants) \\
& ECTR mean age 59 years; women 48 hands, 37 participants \\
& OCTR age 58 years, women 43 hands, 34 participants \\
\hline
\end{tabular}

\begin{tabular}{ll}
\hline Interventions & ECTR (Okutsu technique) vs OCTR \\
\hline Outcomes & Outcomes measured at 4 and 12 weeks postoperatively \\
& $\begin{array}{l}\text { Change in subjective symptoms, activities of daily living, electrophysiological study, sensation, } \\
\text { muscle strength }\end{array}$
\end{tabular}

\section{Notes}

\section{Kang 2013}

\begin{tabular}{ll}
\hline Methods & Single centre prospective randomised trial \\
\hline Participants & $\begin{array}{l}\text { 52 patients with bilateral CTS, one hand randomised to undergo ECTR and the other to undergo mi- } \\
\text { ni-OCTR }\end{array}$ \\
\hline Interventions & ECTR vs mini-OCTR \\
\hline
\end{tabular}


Kang 2013 (Continued)

Outcomes Outcomes measured at 3 months

Boston Carpal Tunnel Questionnaire (BCTQ) and Disabilities of the Arm, Shoulder and Hand (DASH) questionnaire, patients' preference

Notes

Ugurlu 2009

Methods

\section{Participants}

Interventions

\section{Outcomes}

Notes

In Turkish

ECTR: endoscopic carpal tunnel release; OCTR: open carpal tunnel release

Characteristics of ongoing studies [ordered by study ID]

NCT00880295

\begin{tabular}{ll}
\hline Trial name or title & Patient outcomes with endoscopic versus open carpal tunnel release \\
\hline Methods & ECTR vs OCTR \\
& Randomised, double-blind (subject, caregiver, investigator, outcomes assessor)
\end{tabular}

\begin{tabular}{ll}
\hline Participants & Estimated enrolment of 68 participants \\
Inclusion criteria: patients between the ages of 18 and 75 , with documented clinical and EMG \\
proven CTS \\
Exclusion criteria: recurrent CTS, inflammatory arthropathy, peripheral neuropathy, diabetes, \\
pregnant at the time of enrollment
\end{tabular}

\begin{tabular}{ll}
\hline Interventions & ECTR versus OCTR \\
\hline Outcomes & $\begin{array}{l}\text { Primary outcome: patient satisfaction via surveys used in prior publications (24 weeks) } \\
\text { Secondary outcomes: length of time to return to work; clinical data for recovery from CTS including } \\
\text { a thorough physical examination and EMG; complication rates }\end{array}$ \\
\hline Starting date & 10 April 2009 \\
\hline Contact information & $\begin{array}{l}\text { Randy Hauck MD } \\
\text { Tel: } 7175314340 \\
\text { rhauck@hmc.psu.edu }\end{array}$ \\
\hline Notes & Penn State University, USA \\
Recruiting (4 August 2010)
\end{tabular}


Trial name or title
One-portal endoscopic carpal tunnel release versus Knifelight for carpal tunnel syndrome. A randomised control trial (CTS-HV)
Consecutive patients. Computer generated randomisation to be performed by an independent source contacted by phone upon the participant's arrival (central randomisation). Randomisation will be performed per arm

The participants will not be informed of their intervention (blinding of participants)

An independent assessor will assess the outcomes (blinding of outcome assessors)
Estimated enrolment of 40 participants. Consecutive patients over 35 years old with electrophysiologically confirmed CTS will be included. Participants to have had at least 3 months of conventional treatment with no relief of symptoms. Secondary CTS, rheumatoid diseases, previous hand trauma will be excluded

\begin{tabular}{ll}
\hline Starting date & January 2013 \\
\hline Contact information & Haris S Vasiliadis \\
& University of loannina, Greece \\
& vasiliadismd@gmail.com \\
\hline Notes & Not yet recruiting
\end{tabular}

CTR: carpal tunnel release; CTS: carpal tunnel syndrome; ECTR: endoscopic carpal tunnel release; EMG: electromyography; OCTR: open carpal tunnel release; VAS: visual analogue scale

\section{DATA AND ANALYSES}


Comparison 1. Endoscopic versus open or mini-open carpal tunnel release

\begin{tabular}{|c|c|c|c|c|}
\hline Outcome or subgroup title & $\begin{array}{l}\text { No. of } \\
\text { studies }\end{array}$ & $\begin{array}{l}\text { No. of } \\
\text { partici- } \\
\text { pants }\end{array}$ & Statistical method & Effect size \\
\hline 1 Overall improvement at 3 months or less & 1 & & $\begin{array}{l}\text { Risk Ratio (M-H, Random, 95\% } \\
\mathrm{Cl})\end{array}$ & Totals not selected \\
\hline 1.1 ECTR vs modified OCTR & 1 & & $\begin{array}{l}\text { Risk Ratio (M-H, Random, 95\% } \\
\mathrm{Cl})\end{array}$ & $0.0[0.0,0.0]$ \\
\hline 2 Overall satisfaction at 3 months or less & 1 & & $\begin{array}{l}\text { Mean Difference (IV, Random, } \\
95 \% \mathrm{CI})\end{array}$ & Totals not selected \\
\hline 2.1 ECTR vs modified OCTR & 1 & & $\begin{array}{l}\text { Mean Difference (IV, Random, } \\
95 \% \mathrm{CI})\end{array}$ & $0.0[0.0,0.0]$ \\
\hline $\begin{array}{l}3 \text { Symptom Severity Scale (Levine) at } 3 \\
\text { months or less }\end{array}$ & 5 & 551 & $\begin{array}{l}\text { Std. Mean Difference (Random, } \\
95 \% \mathrm{Cl} \text { ) }\end{array}$ & $-0.13[-0.47,0.21]$ \\
\hline 3.1 ECTR vs standard OCTR & 4 & 531 & $\begin{array}{l}\text { Std. Mean Difference (Random, } \\
95 \% \mathrm{Cl} \text { ) }\end{array}$ & $-0.09[-0.48,0.30]$ \\
\hline 3.2 ECTR vs modified OCTR & 1 & 20 & $\begin{array}{l}\text { Std. Mean Difference (Random, } \\
95 \% \mathrm{Cl} \text { ) }\end{array}$ & $-0.37[-1.01,0.27]$ \\
\hline 4 Function Status Scale at 3 months or less & 5 & 551 & $\begin{array}{l}\text { Std. Mean Difference (Random, } \\
95 \% \mathrm{Cl} \text { ) }\end{array}$ & $-0.23[-0.60,0.14]$ \\
\hline 4.1 ECTR vs standard OCTR & 4 & 531 & $\begin{array}{l}\text { Std. Mean Difference (Random, } \\
95 \% \mathrm{Cl} \text { ) }\end{array}$ & $-0.19[-0.61,0.23]$ \\
\hline 4.2 ECTR vs modified OCTR & 1 & 20 & $\begin{array}{l}\text { Std. Mean Difference (Random, } \\
95 \% \mathrm{Cl} \text { ) }\end{array}$ & $-0.48[-1.14,0.17]$ \\
\hline 5 Pain at 3 months or less (corr $=0.5$ ) & 4 & 358 & $\begin{array}{l}\text { Std. Mean Difference (Random, } \\
95 \% \mathrm{Cl} \text { ) }\end{array}$ & $-0.21[-0.72,0.30]$ \\
\hline 5.1 ECTR vs standard OCTR & 2 & 278 & $\begin{array}{l}\text { Std. Mean Difference (Random, } \\
95 \% \mathrm{Cl} \text { ) }\end{array}$ & $-0.41[-0.65,-0.18]$ \\
\hline 5.2 ECTR vs modified OCTR & 2 & 80 & $\begin{array}{l}\text { Std. Mean Difference (Random, } \\
95 \% \mathrm{Cl} \text { ) }\end{array}$ & $0.01[-1.07,1.08]$ \\
\hline 6 Pain at 3 months or less (corr $=0.9$ ) & 4 & & $\begin{array}{l}\text { Std. Mean Difference (Random, } \\
95 \% \mathrm{Cl} \text { ) }\end{array}$ & $-0.20[-0.58,0.18]$ \\
\hline 6.1 ECTR vs standard OCTR & 2 & & $\begin{array}{l}\text { Std. Mean Difference (Random, } \\
95 \% \mathrm{Cl} \text { ) }\end{array}$ & $-0.41[-0.65,-0.18]$ \\
\hline 6.2 ECTR vs modified OCTR & 2 & & $\begin{array}{l}\text { Std. Mean Difference (Random, } \\
95 \% \mathrm{Cl} \text { ) }\end{array}$ & $0.00[-0.48,0.48]$ \\
\hline 7 Pain at 3 months or less (corr $=0.1$ ) & 4 & & $\begin{array}{l}\text { Std. Mean Difference (Random, } \\
95 \% \mathrm{Cl} \text { ) }\end{array}$ & $-0.20[-0.74,0.34]$ \\
\hline
\end{tabular}




\begin{tabular}{|c|c|c|c|c|}
\hline Outcome or subgroup title & $\begin{array}{l}\text { No. of } \\
\text { studies }\end{array}$ & $\begin{array}{l}\text { No. of } \\
\text { partici- } \\
\text { pants }\end{array}$ & Statistical method & Effect size \\
\hline 7.1 ECTR vs standard OCTR & 2 & & $\begin{array}{l}\text { Std. Mean Difference (Random, } \\
95 \% \mathrm{Cl} \text { ) }\end{array}$ & $-0.41[-0.65,-0.18]$ \\
\hline 7.2 ECTR vs modified OCTR & 2 & & $\begin{array}{l}\text { Std. Mean Difference (Random, } \\
95 \% \mathrm{Cl} \text { ) }\end{array}$ & $0.01[-1.43,1.46]$ \\
\hline 8 Pain (dichotomous) at 3 months or less & 5 & 348 & $\begin{array}{l}\text { Risk Ratio (M-H, Random, 95\% } \\
\text { Cl) }\end{array}$ & $0.69[0.33,1.45]$ \\
\hline 8.1 ECTR vs standard OCTR & 4 & 288 & $\begin{array}{l}\text { Risk Ratio (M-H, Random, 95\% } \\
\mathrm{Cl})\end{array}$ & $0.49[0.21,1.15]$ \\
\hline 8.2 ECTR vs modified OCTR & 1 & 60 & $\begin{array}{l}\text { Risk Ratio (M-H, Random, 95\% } \\
\mathrm{Cl} \text { ) }\end{array}$ & $2.0[1.01,3.95]$ \\
\hline $\begin{array}{l}9 \text { Numbness (dichotomous) at } 3 \text { months or } \\
\text { less }\end{array}$ & 5 & & $\begin{array}{l}\text { Risk Ratio (M-H, Random, 95\% } \\
\text { Cl) }\end{array}$ & Subtotals only \\
\hline 9.1 ECTR vs OCTR & 5 & 435 & $\begin{array}{l}\text { Risk Ratio (M-H, Random, 95\% } \\
\mathrm{Cl})\end{array}$ & $1.14[0.76,1.71]$ \\
\hline 10 Grip strength at 3 months or less & 6 & 560 & $\begin{array}{l}\text { Std. Mean Difference (Random, } \\
95 \% \mathrm{Cl} \text { ) }\end{array}$ & $0.36[0.09,0.63]$ \\
\hline 10.1 ECTR vs standard OCTR & 5 & 540 & $\begin{array}{l}\text { Std. Mean Difference (Random, } \\
95 \% \mathrm{Cl} \text { ) }\end{array}$ & $0.40[0.10,0.71]$ \\
\hline 10.2 ECTR vs modified OCTR & 1 & 20 & $\begin{array}{l}\text { Std. Mean Difference (Random, } \\
95 \% \mathrm{Cl} \text { ) }\end{array}$ & $0.14[-0.48,0.76]$ \\
\hline $\begin{array}{l}11 \text { Overall improvement at more than } 3 \\
\text { months }\end{array}$ & 4 & 317 & $\begin{array}{l}\text { Risk Ratio (M-H, Random, 95\% } \\
\mathrm{Cl})\end{array}$ & $1.04[0.95,1.14]$ \\
\hline 11.1 ECTR vs standard OCTR & 3 & 257 & $\begin{array}{l}\text { Risk Ratio (M-H, Random, 95\% } \\
\mathrm{Cl})\end{array}$ & $1.05[0.96,1.15]$ \\
\hline 11.2 ECTR vs modified OCTR & 1 & 60 & $\begin{array}{l}\text { Risk Ratio (M-H, Random, 95\% } \\
\mathrm{Cl})\end{array}$ & $0.89[0.59,1.35]$ \\
\hline $\begin{array}{l}12 \text { Overall satisfaction at more than } 3 \\
\text { months }\end{array}$ & 1 & & $\begin{array}{l}\text { Mean Difference (IV, Random, } \\
95 \% \mathrm{CI})\end{array}$ & Totals not selected \\
\hline 12.1 ECTR vs standard OCTR & 1 & & $\begin{array}{l}\text { Mean Difference (IV, Random, } \\
95 \% \mathrm{Cl} \text { ) }\end{array}$ & $0.0[0.0,0.0]$ \\
\hline $\begin{array}{l}13 \text { Symptom Severity Scale (Levine) at more } \\
\text { than } 3 \text { months }\end{array}$ & 2 & & $\begin{array}{l}\text { Mean Difference (IV, Random, } \\
95 \% \mathrm{Cl} \text { ) }\end{array}$ & Subtotals only \\
\hline 13.1 ECTR vs standard OCTR & 2 & 273 & $\begin{array}{l}\text { Mean Difference (IV, Random, } \\
95 \% \mathrm{Cl})\end{array}$ & $0.02[-0.18,0.22]$ \\
\hline $\begin{array}{l}14 \text { Function Status Scale at more than } 3 \\
\text { months }\end{array}$ & 2 & & $\begin{array}{l}\text { Mean Difference (IV, Random, } \\
95 \% \mathrm{Cl} \text { ) }\end{array}$ & Subtotals only \\
\hline
\end{tabular}




\begin{tabular}{|c|c|c|c|c|}
\hline Outcome or subgroup title & $\begin{array}{l}\text { No. of } \\
\text { studies }\end{array}$ & $\begin{array}{l}\text { No. of } \\
\text { partici- } \\
\text { pants }\end{array}$ & Statistical method & Effect size \\
\hline 14.1 ECTR vs standard OCTR & 2 & 273 & $\begin{array}{l}\text { Mean Difference (IV, Random, } \\
95 \% \mathrm{CI})\end{array}$ & $0.01[-0.14,0.16]$ \\
\hline 15 Pain at more than 3 months & 1 & & $\begin{array}{l}\text { Mean Difference (IV, Random, } \\
95 \% \mathrm{CI})\end{array}$ & Subtotals only \\
\hline 15.1 ECTR vs standard OCTR & 1 & 128 & $\begin{array}{l}\text { Mean Difference (IV, Random, } \\
95 \% \mathrm{CI})\end{array}$ & $-5.20[-12.65,2.25]$ \\
\hline $\begin{array}{l}16 \text { Pain (dichotomous) at more than } 3 \\
\text { months }\end{array}$ & 6 & & $\begin{array}{l}\text { Risk Ratio (M-H, Random, 95\% } \\
\mathrm{Cl} \text { ) }\end{array}$ & Subtotals only \\
\hline 16.1 ECTR vs standard OCTR & 6 & 407 & $\begin{array}{l}\text { Risk Ratio (M-H, Random, 95\% } \\
\mathrm{Cl} \text { ) }\end{array}$ & $0.88[0.57,1.38]$ \\
\hline 17 Numbness at more than 3 months & 1 & 192 & $\begin{array}{l}\text { Mean Difference (IV, Random, } \\
95 \% \mathrm{CI})\end{array}$ & $0.06[-0.04,0.16]$ \\
\hline 17.1 ECTR vs standard OCTR & 1 & 192 & $\begin{array}{l}\text { Mean Difference (IV, Random, } \\
95 \% \mathrm{CI})\end{array}$ & $0.06[-0.04,0.16]$ \\
\hline $\begin{array}{l}18 \text { Numbness (dichotomous) at more than } 3 \\
\text { months }\end{array}$ & 4 & & $\begin{array}{l}\text { Risk Ratio (M-H, Random, 95\% } \\
\mathrm{Cl} \text { ) }\end{array}$ & Subtotals only \\
\hline 18.1 ECTR vs standard OCTR & 4 & 234 & $\begin{array}{l}\text { Risk Ratio (M-H, Random, 95\% } \\
\mathrm{Cl})\end{array}$ & $0.64[0.31,1.35]$ \\
\hline 19 Grip strength at more than 3 months & 2 & 56 & $\begin{array}{l}\text { Std. Mean Difference (IV, Ran- } \\
\text { dom, 95\% CI) }\end{array}$ & $1.13[0.56,1.71]$ \\
\hline 19.1 ECTR vs standard OCTR & 2 & 56 & $\begin{array}{l}\text { Std. Mean Difference (IV, Ran- } \\
\text { dom, 95\% CI) }\end{array}$ & $1.13[0.56,1.71]$ \\
\hline 20 Time to return to work & 4 & & $\begin{array}{l}\text { Mean Difference (IV, Random, } \\
95 \% \mathrm{CI})\end{array}$ & Subtotals only \\
\hline 20.1 ECTR vs standard OCTR & 4 & 274 & $\begin{array}{l}\text { Mean Difference (IV, Random, } \\
95 \% \mathrm{CI})\end{array}$ & $-8.10[-14.28,-1.92]$ \\
\hline 21 Recurrence & 12 & 1228 & $\begin{array}{l}\text { Risk Ratio (M-H, Random, 95\% } \\
\mathrm{Cl})\end{array}$ & $0.81[0.46,1.42]$ \\
\hline 21.1 ECTR vs standard OCTR & 10 & 1132 & $\begin{array}{l}\text { Risk Ratio (M-H, Random, 95\% } \\
\mathrm{Cl})\end{array}$ & $0.75[0.41,1.36]$ \\
\hline 21.2 ECTR vs modified OCTR & 2 & 96 & $\begin{array}{l}\text { Risk Ratio (M-H, Random, 95\% } \\
\mathrm{Cl} \text { ) }\end{array}$ & $1.5[0.27,8.34]$ \\
\hline 22 Reoperations & 10 & 1116 & Risk Ratio (M-H, Fixed, 95\% Cl) & $1.06[0.54,2.08]$ \\
\hline 22.1 ECTR vs standard OCTR & 10 & 987 & Risk Ratio (M-H, Fixed, 95\% Cl) & $1.57[0.72,3.43]$ \\
\hline 22.2 ECTR vs modified OCTR & 1 & 129 & Risk Ratio (M-H, Fixed, 95\% Cl) & $0.17[0.02,1.37]$ \\
\hline
\end{tabular}




\begin{tabular}{|c|c|c|c|c|}
\hline Outcome or subgroup title & $\begin{array}{l}\text { No. of } \\
\text { studies }\end{array}$ & $\begin{array}{l}\text { No. of } \\
\text { partici- } \\
\text { pants }\end{array}$ & Statistical method & Effect size \\
\hline 23 Major complications & 15 & 1508 & $\begin{array}{l}\text { Risk Ratio (M-H, Random, 95\% } \\
\mathrm{Cl})\end{array}$ & $1.00[0.38,2.64]$ \\
\hline 23.1 ECTR vs standard OCTR & 12 & 1392 & $\begin{array}{l}\text { Risk Ratio (M-H, Random, 95\% } \\
\mathrm{Cl})\end{array}$ & $1.00[0.38,2.64]$ \\
\hline 23.2 ECTR vs modified OCTR & 3 & 116 & $\begin{array}{l}\text { Risk Ratio (M-H, Random, 95\% } \\
\mathrm{Cl})\end{array}$ & $0.0[0.0,0.0]$ \\
\hline 24 Minor complications & 18 & 1786 & $\begin{array}{l}\text { Risk Ratio (M-H, Random, 95\% } \\
\mathrm{Cl})\end{array}$ & $0.55[0.38,0.81]$ \\
\hline 24.1 ECTR vs standard OCTR & 16 & 1601 & $\begin{array}{l}\text { Risk Ratio (M-H, Random, 95\% } \\
\mathrm{Cl})\end{array}$ & $0.55[0.37,0.84]$ \\
\hline 24.2 ECTR vs modified OCTR & 3 & 185 & $\begin{array}{l}\text { Risk Ratio (M-H, Random, 95\% } \\
\mathrm{Cl})\end{array}$ & $0.64[0.04,9.37]$ \\
\hline 25 Total complications & 19 & 1850 & $\begin{array}{l}\text { Odds Ratio (M-H, Random, } \\
95 \% \mathrm{Cl})\end{array}$ & $0.60[0.40,0.90]$ \\
\hline 25.1 ECTR vs standard OCTR & 17 & 1665 & $\begin{array}{l}\text { Odds Ratio (M-H, Random, } \\
95 \% \mathrm{Cl})\end{array}$ & $0.60[0.39,0.90]$ \\
\hline 25.2 ECTR vs modified OCTR & 3 & 185 & $\begin{array}{l}\text { Odds Ratio (M-H, Random, } \\
95 \% \mathrm{Cl})\end{array}$ & $0.62[0.04,10.78]$ \\
\hline
\end{tabular}

Analysis 1.1. Comparison 1 Endoscopic versus open or mini-open carpal tunnel release, Outcome 1 Overall improvement at 3 months or less.

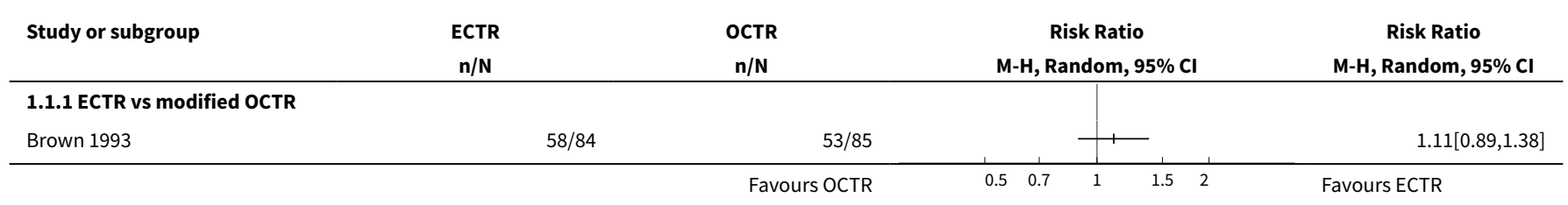

\section{Analysis 1.2. Comparison 1 Endoscopic versus open or mini-open carpal tunnel release, Outcome 2 Overall satisfaction at 3 months or less.}

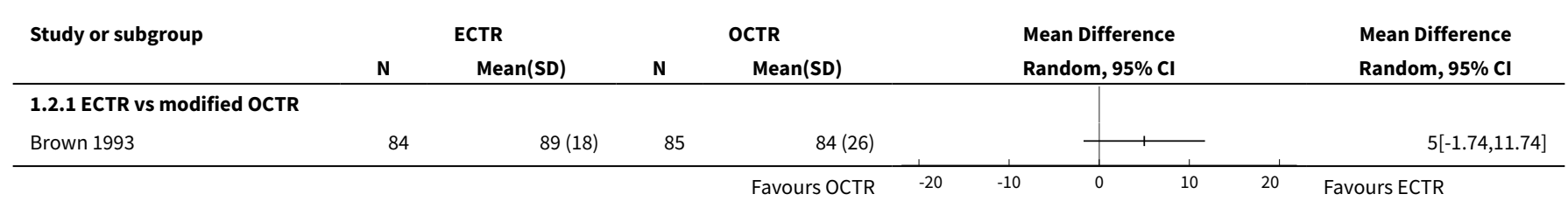


Analysis 1.3. Comparison 1 Endoscopic versus open or mini-open carpal tunnel release, Outcome 3 Symptom Severity Scale (Levine) at 3 months or less.

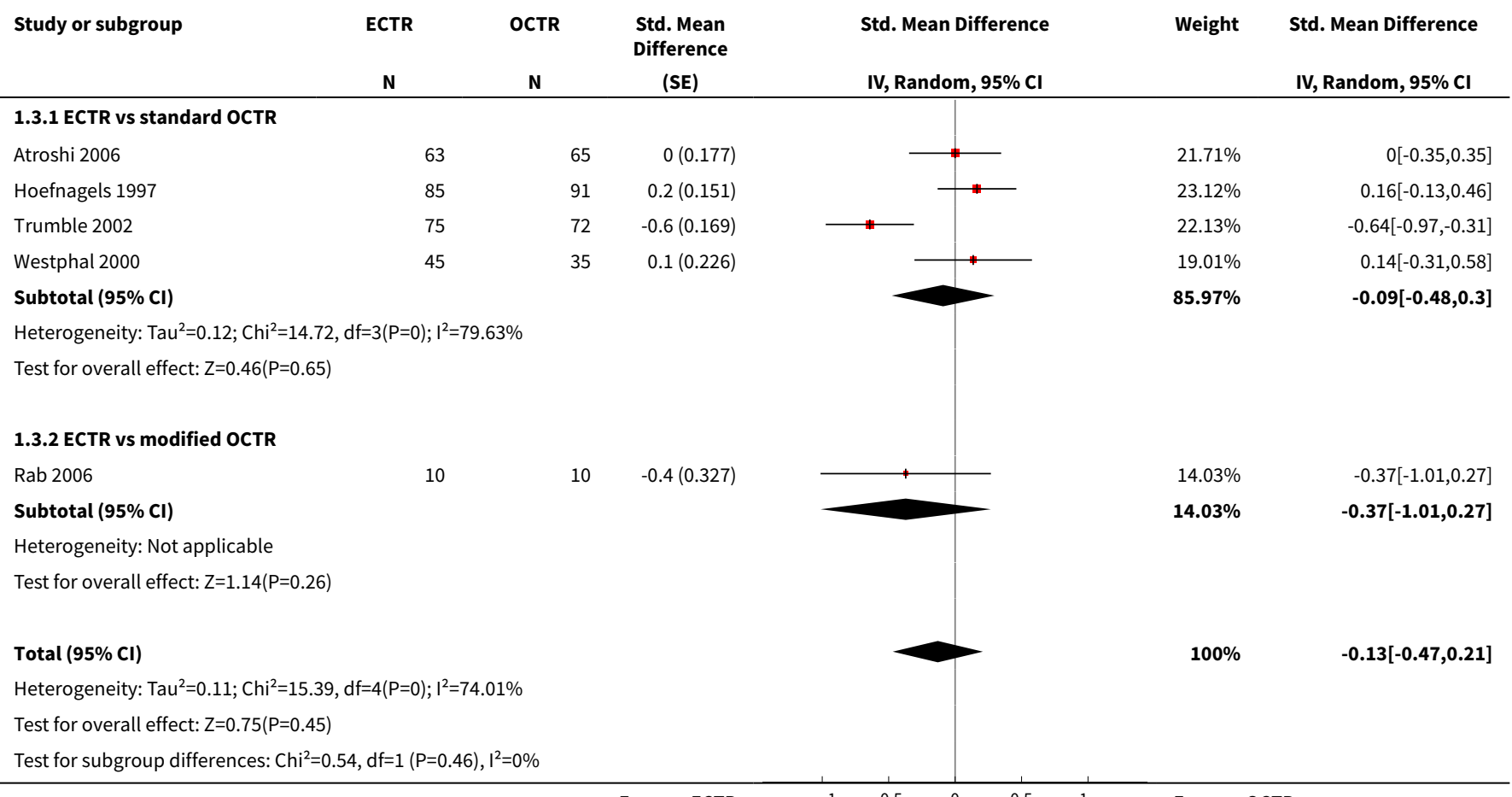

Analysis 1.4. Comparison 1 Endoscopic versus open or mini-open carpal tunnel release, Outcome 4 Function Status Scale at 3 months or less.

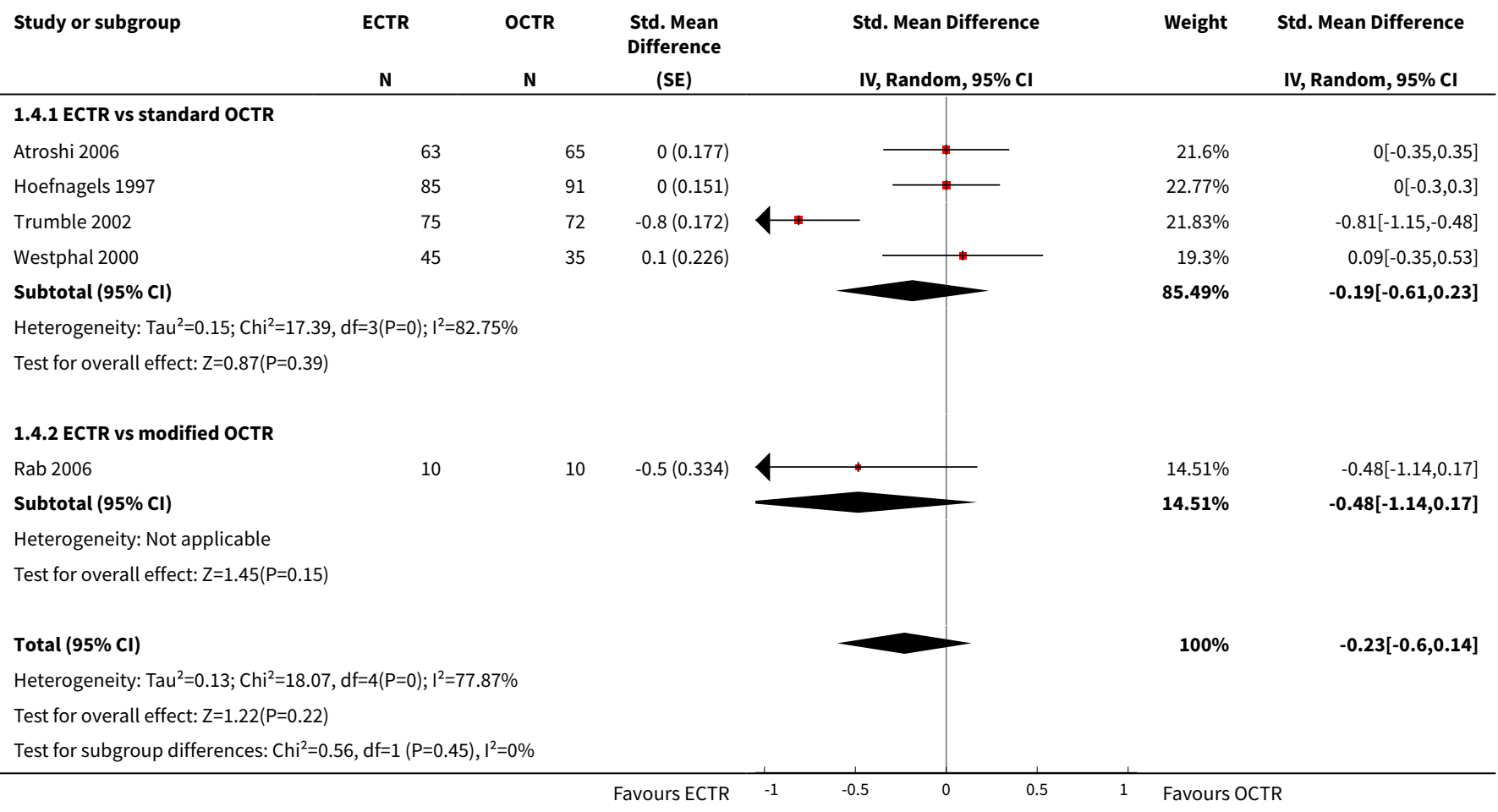


Analysis 1.5. Comparison 1 Endoscopic versus open or mini-open carpal tunnel release, Outcome 5 Pain at 3 months or less (corr $=0.5$ ).

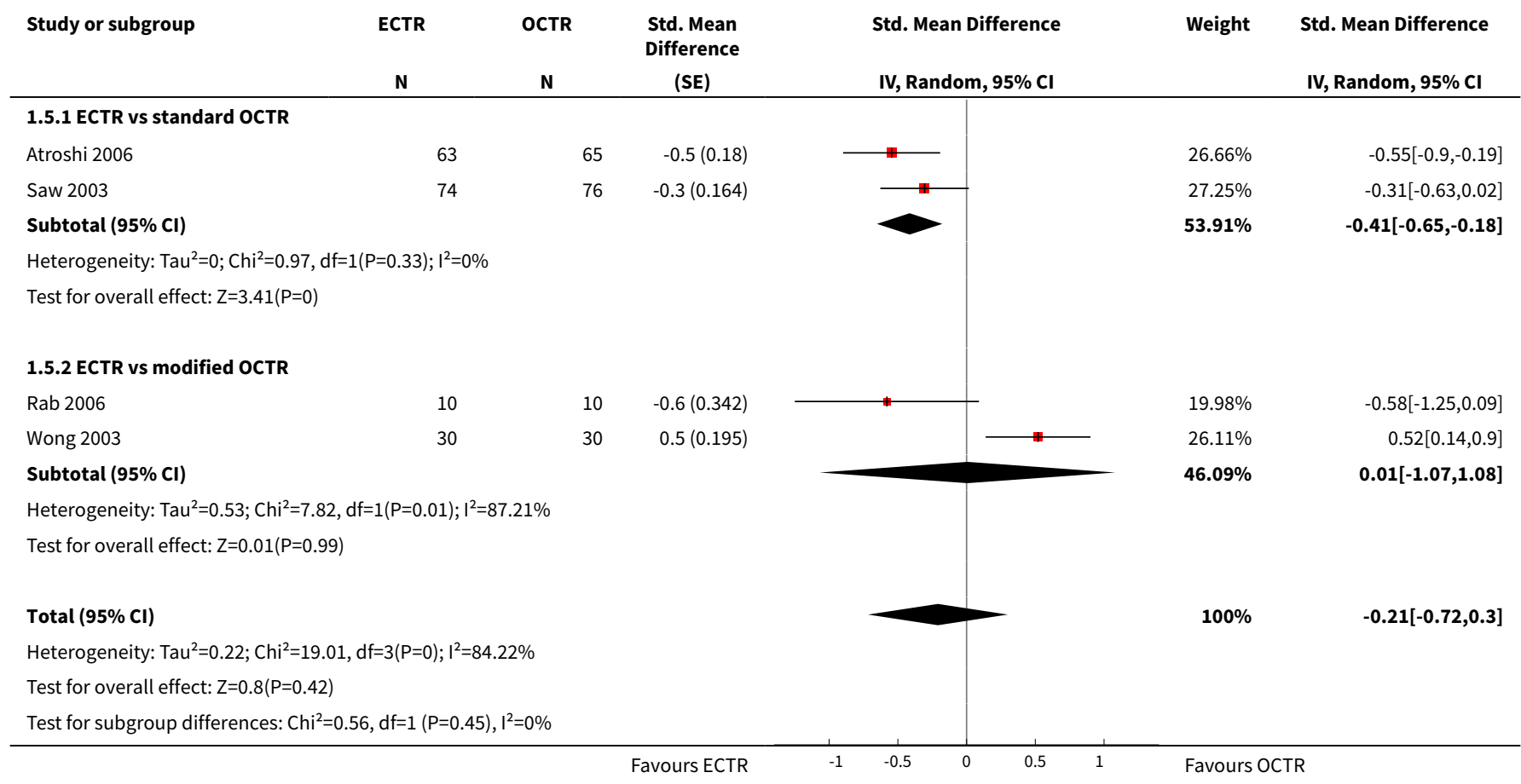

Analysis 1.6. Comparison 1 Endoscopic versus open or mini-open carpal tunnel release, Outcome 6 Pain at 3 months or less (corr $=0.9$ ).

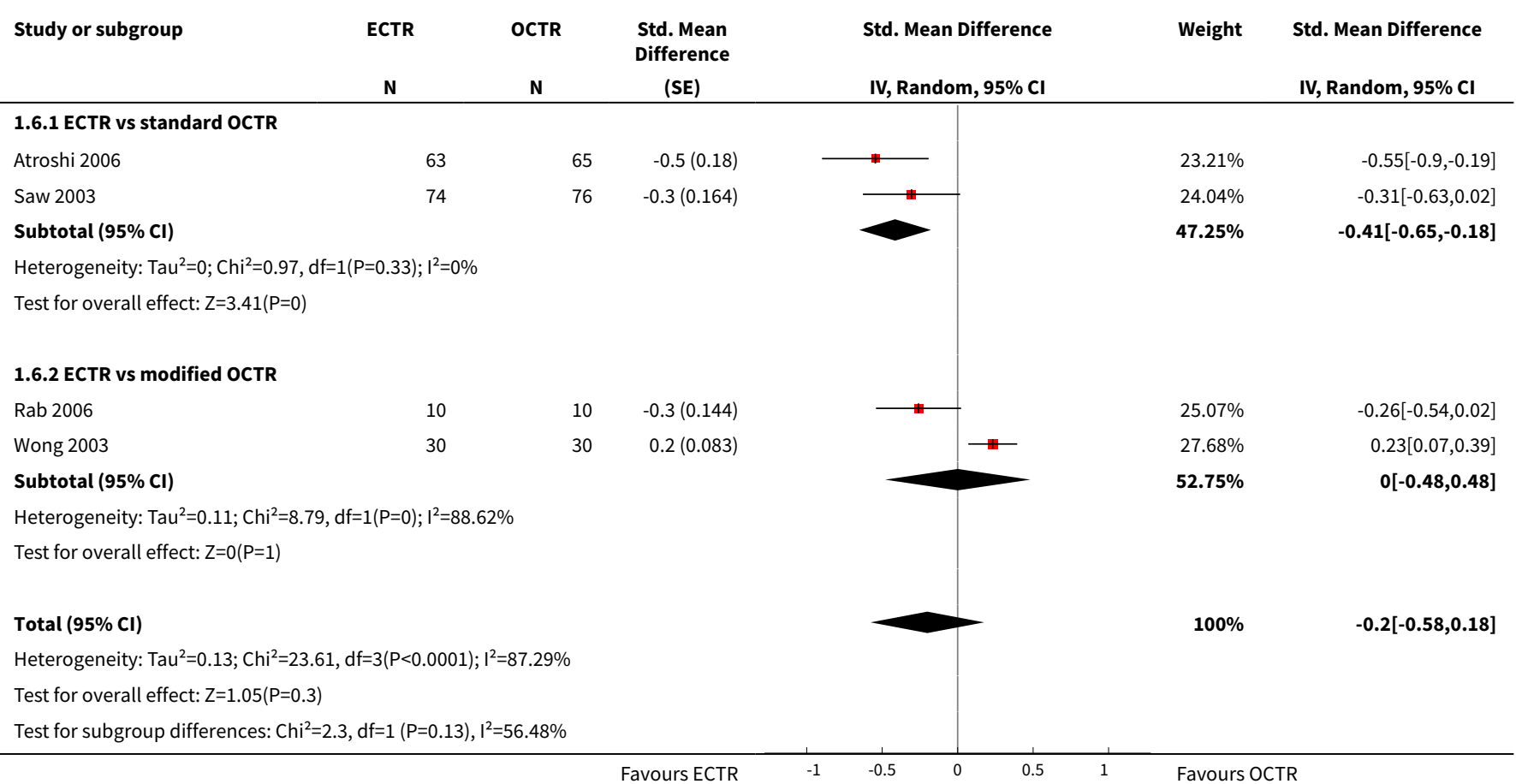


Analysis 1.7. Comparison 1 Endoscopic versus open or mini-open carpal tunnel release, Outcome 7 Pain at 3 months or less $($ corr $=\mathbf{0 . 1})$.

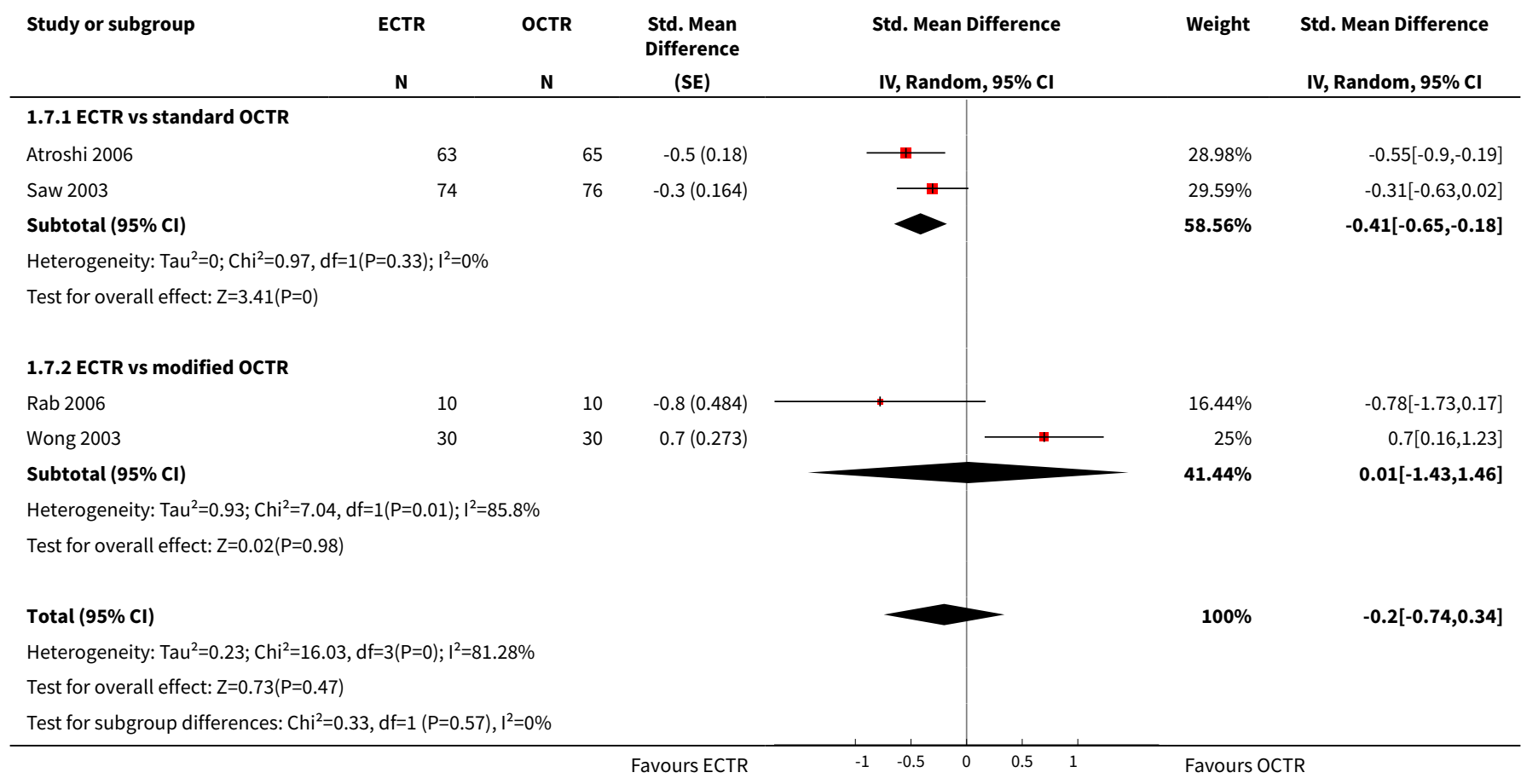

\section{Analysis 1.8. Comparison 1 Endoscopic versus open or mini-open carpal} tunnel release, Outcome 8 Pain (dichotomous) at $\mathbf{3}$ months or less.

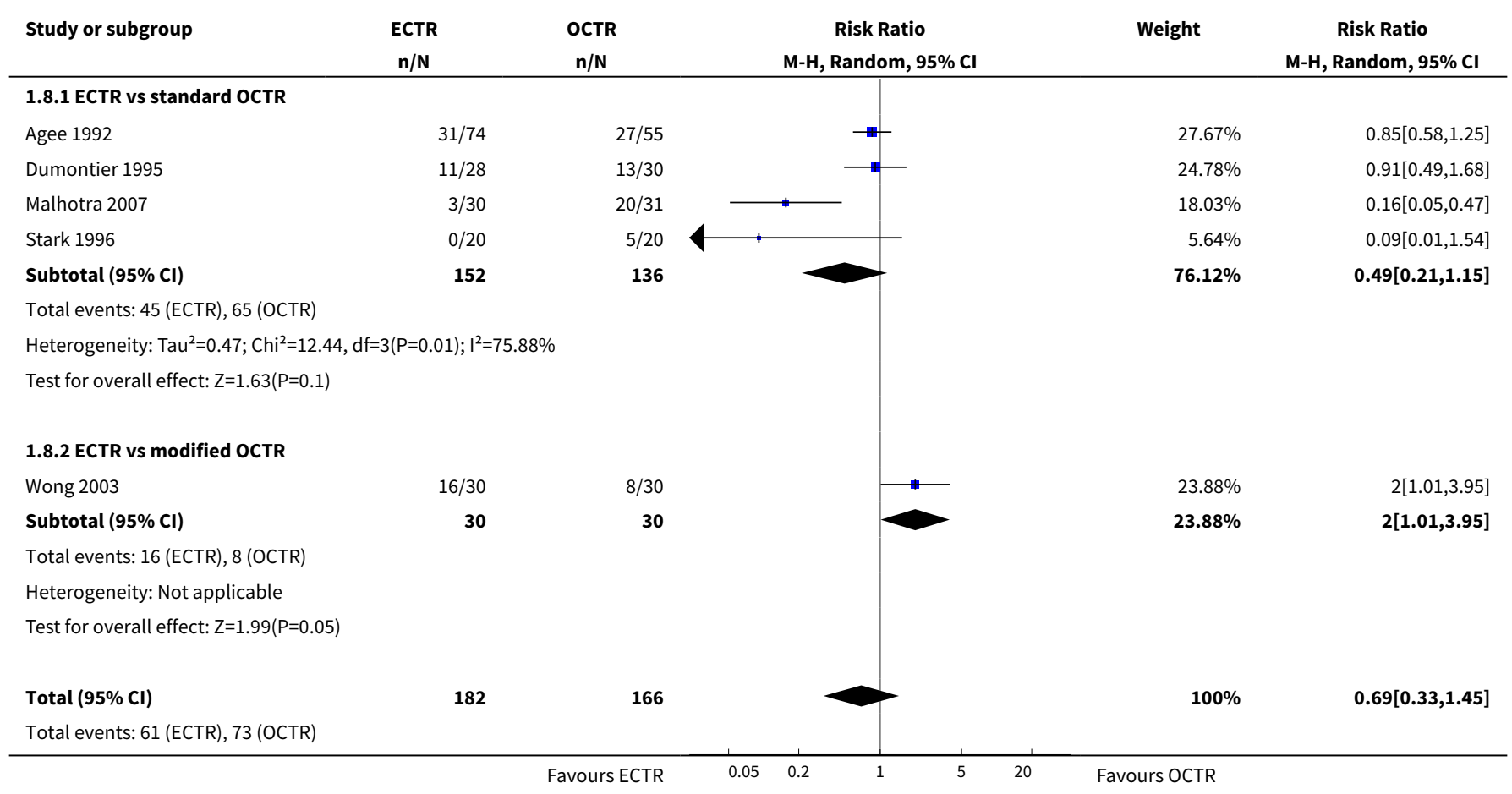




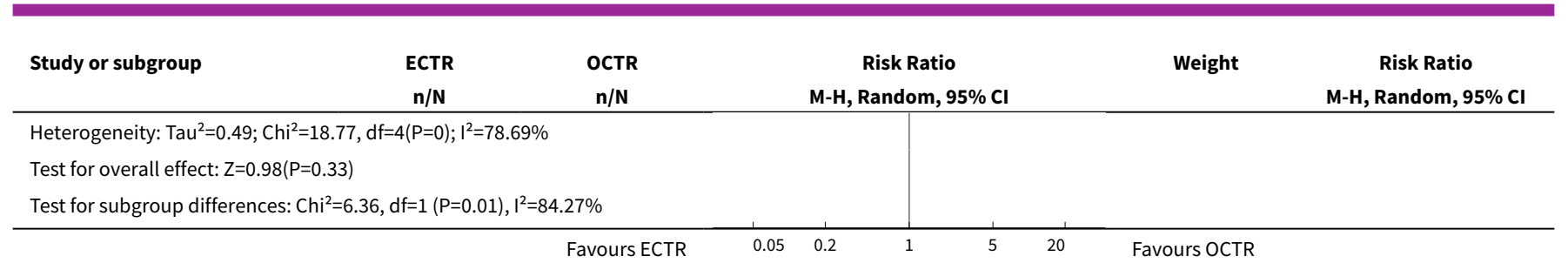

Analysis 1.9. Comparison 1 Endoscopic versus open or mini-open carpal tunnel release, Outcome 9 Numbness (dichotomous) at 3 months or less.

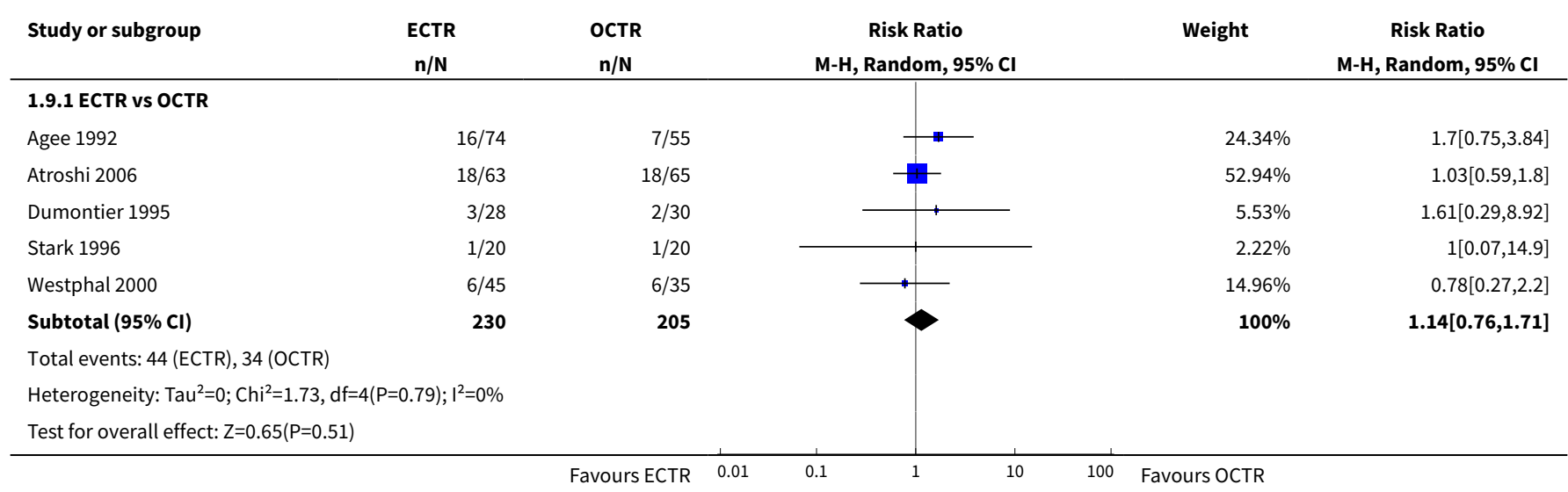

Analysis 1.10. Comparison 1 Endoscopic versus open or mini-open carpal tunnel release, Outcome 10 Grip strength at 3 months or less.

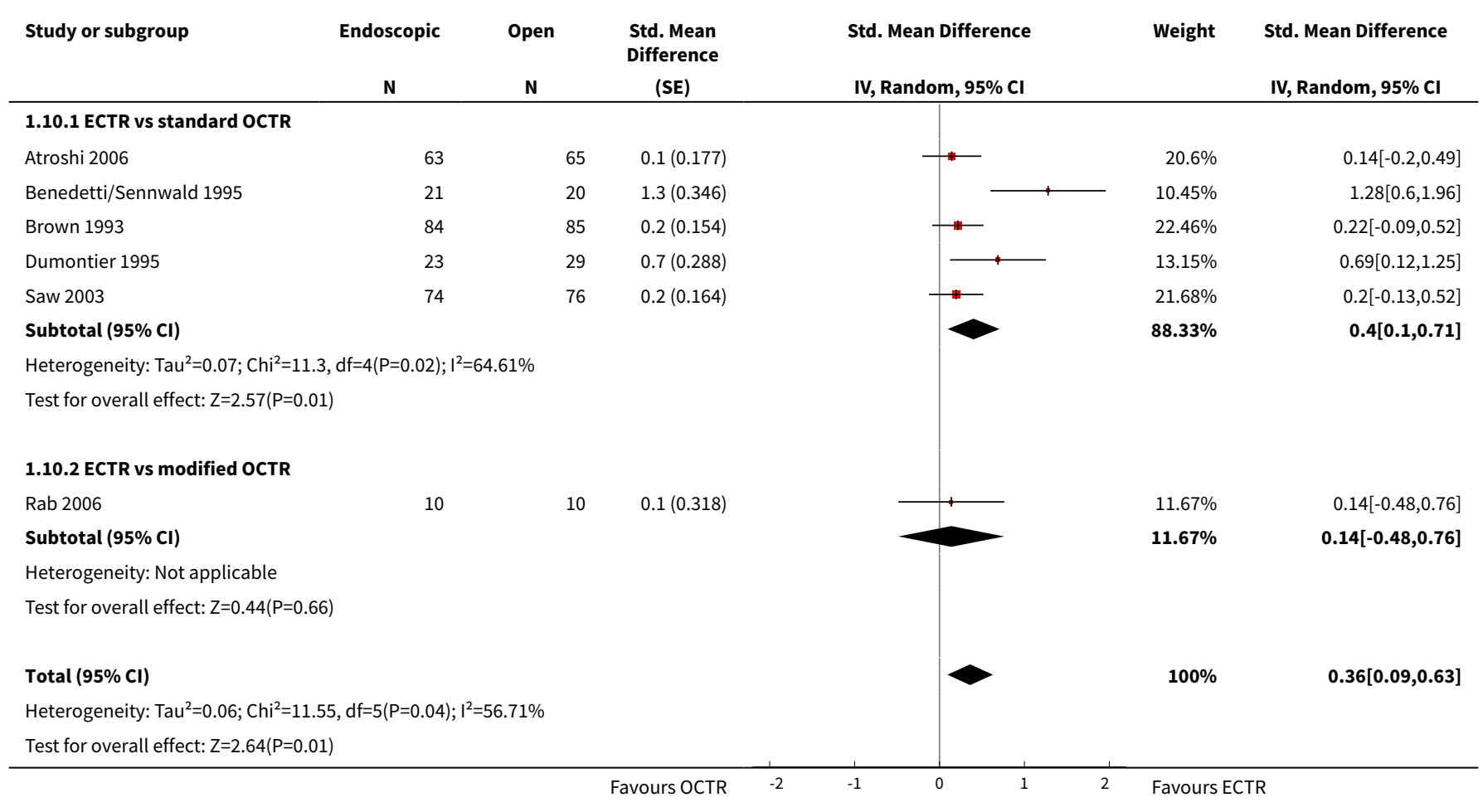




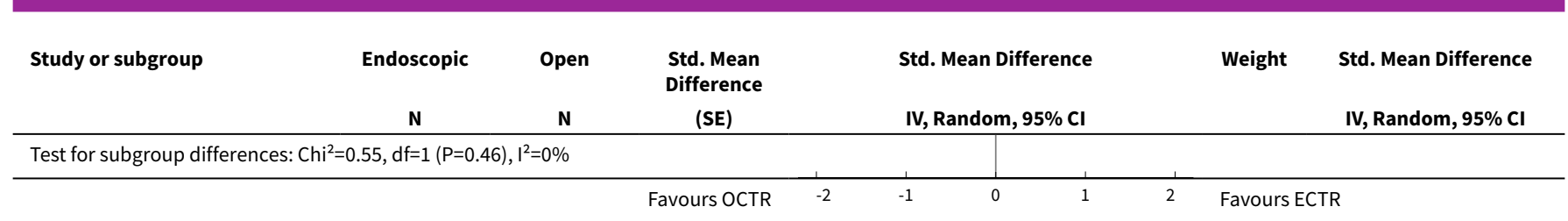

Analysis 1.11. Comparison 1 Endoscopic versus open or mini-open carpal tunnel release, Outcome 11 Overall improvement at more than 3 months.

\begin{tabular}{|c|c|c|c|c|c|}
\hline Study or subgroup & $\begin{array}{c}\text { ECTR } \\
n / N\end{array}$ & $\begin{array}{c}\text { OCTR } \\
n / N\end{array}$ & $\begin{array}{c}\text { Risk Ratio } \\
\text { M-H, Random, } 95 \% \mathrm{Cl}\end{array}$ & Weight & $\begin{array}{c}\text { Risk Ratio } \\
\text { M-H, Random, } 95 \% \mathrm{CI}\end{array}$ \\
\hline \multicolumn{6}{|c|}{ 1.11.1 ECTR vs standard OCTR } \\
\hline Atroshi 2006 & $54 / 63$ & $52 / 63$ & $-\mathbf{P}$ & $35.94 \%$ & $1.04[0.89,1.21]$ \\
\hline Malhotra 2007 & $25 / 30$ & $21 / 31$ & & $9.8 \%$ & $1.23[0.92,1.65]$ \\
\hline Tian 2007 & $32 / 34$ & $33 / 36$ & 5 & $49.45 \%$ & $1.03[0.9,1.17]$ \\
\hline Subtotal $(95 \% \mathrm{Cl})$ & 127 & 130 & & $95.18 \%$ & $1.05[0.96,1.15]$ \\
\hline \multicolumn{6}{|c|}{ Total events: 111 (ECTR), 106 (OCTR) } \\
\hline \multicolumn{6}{|c|}{ Heterogeneity: $\operatorname{Tau}^{2}=0 ; \mathrm{Chi}^{2}=1.47, \mathrm{df}=2(\mathrm{P}=0.48) ; \mathrm{I}^{2}=0 \%$} \\
\hline \multicolumn{6}{|c|}{ Test for overall effect: $Z=1.03(P=0.3)$} \\
\hline \multicolumn{6}{|c|}{ 1.11.2 ECTR vs modified OCTR } \\
\hline Wong 2003 & $17 / 30$ & $19 / 30$ & $\rightarrow$ & $4.82 \%$ & $0.89[0.59,1.35]$ \\
\hline Subtotal $(95 \% \mathrm{Cl})$ & 30 & 30 & & $4.82 \%$ & $0.89[0.59,1.35]$ \\
\hline \multicolumn{6}{|c|}{ Heterogeneity: Not applicable } \\
\hline \multicolumn{6}{|c|}{ Test for overall effect: $Z=0.53(P=0.6)$} \\
\hline Total $(95 \% \mathrm{Cl})$ & 157 & 160 & & $100 \%$ & $1.04[0.95,1.14]$ \\
\hline \multicolumn{6}{|c|}{ Total events: 128 (ECTR), 125 (OCTR) } \\
\hline \multicolumn{6}{|c|}{ Heterogeneity: $\mathrm{Tau}^{2}=0 ; \mathrm{Chi}^{2}=1.82, \mathrm{df}=3(\mathrm{P}=0.61) ; \mathrm{I}^{2}=0 \%$} \\
\hline \multicolumn{6}{|c|}{ Test for overall effect: $Z=0.89(P=0.37)$} \\
\hline \multicolumn{6}{|c|}{ Test for subgroup differences: $\mathrm{Chi}^{2}=0.55, \mathrm{df}=1(\mathrm{P}=0.46), \mathrm{I}^{2}=0 \%$} \\
\hline
\end{tabular}

Analysis 1.12. Comparison 1 Endoscopic versus open or mini-open carpal tunnel release, Outcome 12 Overall satisfaction at more than 3 months.

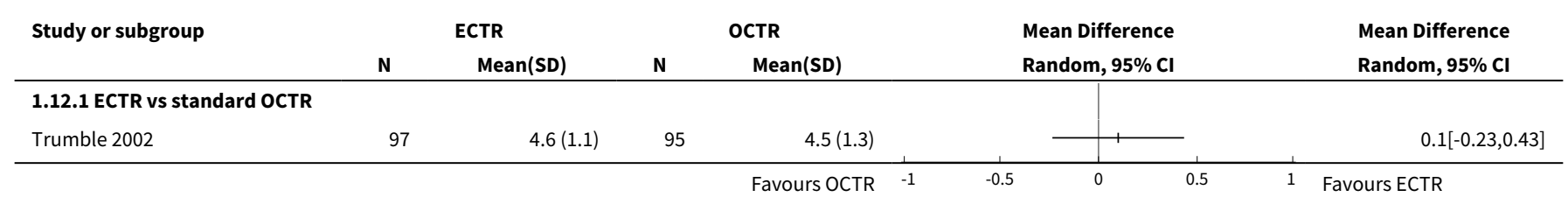


Analysis 1.13. Comparison 1 Endoscopic versus open or mini-open carpal tunnel release, Outcome 13 Symptom Severity Scale (Levine) at more than 3 months.

\begin{tabular}{|c|c|c|c|c|c|c|c|}
\hline \multirow[t]{2}{*}{ Study or subgroup } & \multicolumn{2}{|c|}{ ECTR } & \multicolumn{2}{|c|}{ OCTR } & \multirow{2}{*}{$\begin{array}{l}\text { Mean Difference } \\
\text { Random, 95\% Cl }\end{array}$} & \multirow[t]{2}{*}{ Weight } & \multirow{2}{*}{$\begin{array}{l}\text { Mean Difference } \\
\text { Random, } 95 \% \mathrm{Cl}\end{array}$} \\
\hline & $\mathbf{N}$ & $\operatorname{Mean}(S D)$ & $\mathbf{N}$ & Mean(SD) & & & \\
\hline \multicolumn{8}{|c|}{ 1.13.1 ECTR vs standard OCTR } \\
\hline Atroshi 2006 & 63 & $1.5(0.7)$ & 63 & $1.4(0.7)$ & & $67.63 \%$ & $0.03[-0.21,0.27]$ \\
\hline Trumble 2002 & 75 & $1.8(1.3)$ & 72 & $1.8(0.8)$ & & $32.37 \%$ & $0[-0.35,0.35]$ \\
\hline 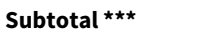 & 138 & & 135 & & & $100 \%$ & $0.02[-0.18,0.22]$ \\
\hline \multicolumn{8}{|c|}{ Heterogeneity: $\mathrm{Tau}^{2}=0 ; \mathrm{Chi}^{2}=0.02, \mathrm{df}=1(\mathrm{P}=0.89) ; \mathrm{I}^{2}=0 \%$} \\
\hline
\end{tabular}

Analysis 1.14. Comparison 1 Endoscopic versus open or mini-open carpal tunnel release, Outcome 14 Function Status Scale at more than 3 months.

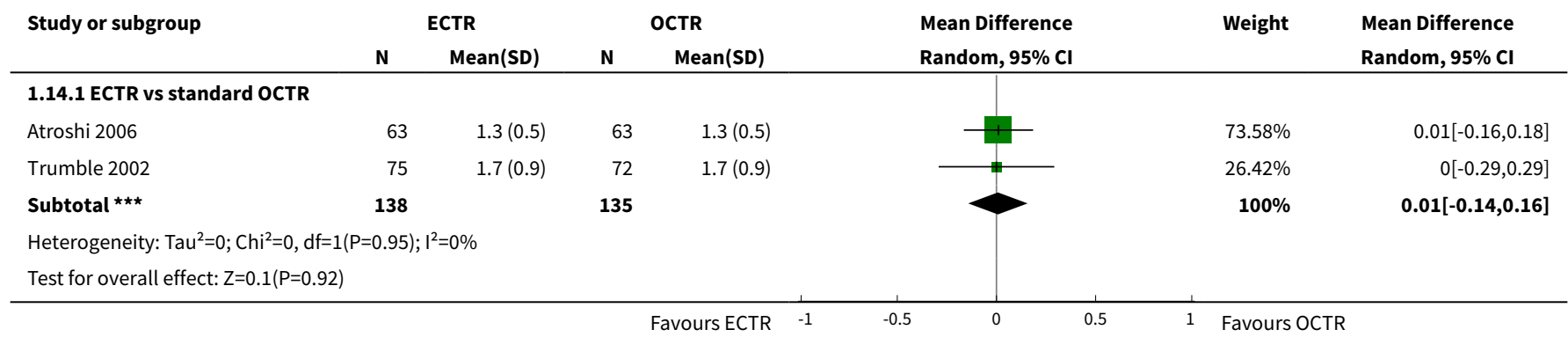

Analysis 1.15. Comparison 1 Endoscopic versus open or miniopen carpal tunnel release, Outcome 15 Pain at more than $\mathbf{3}$ months.

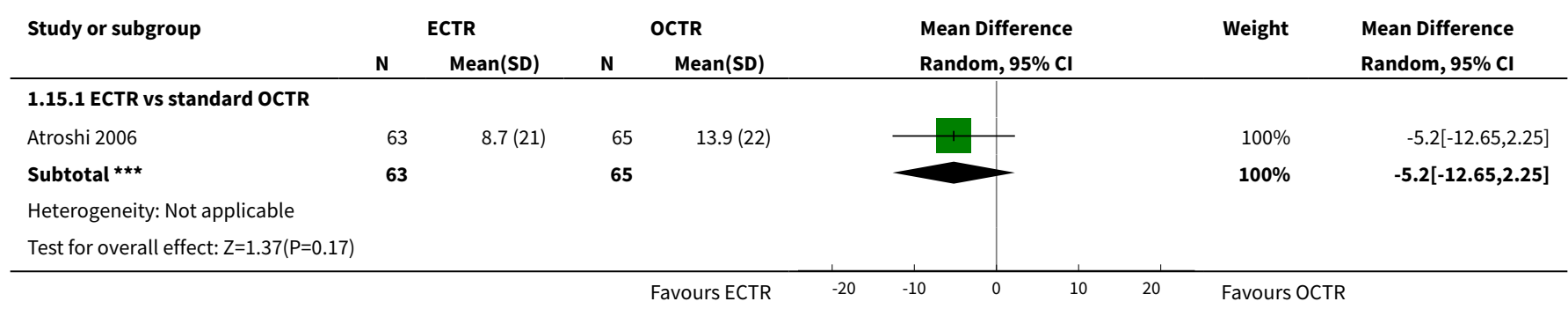

Analysis 1.16. Comparison 1 Endoscopic versus open or mini-open carpal tunnel release, Outcome 16 Pain (dichotomous) at more than $\mathbf{3}$ months.

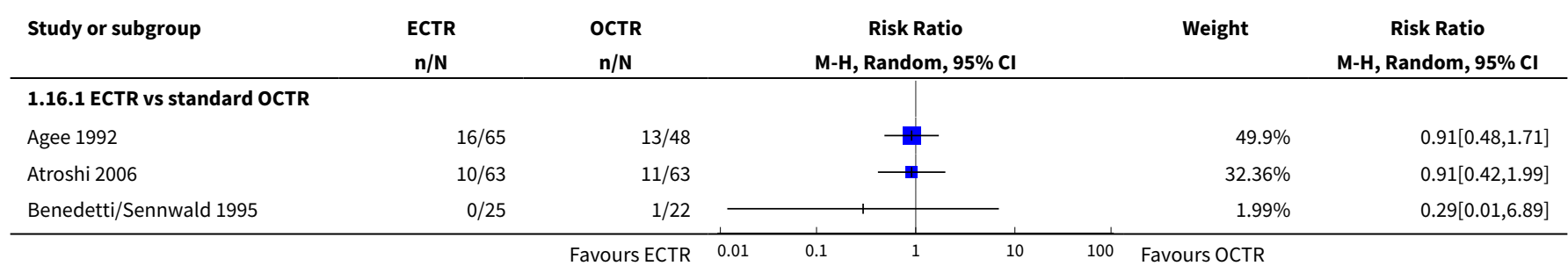




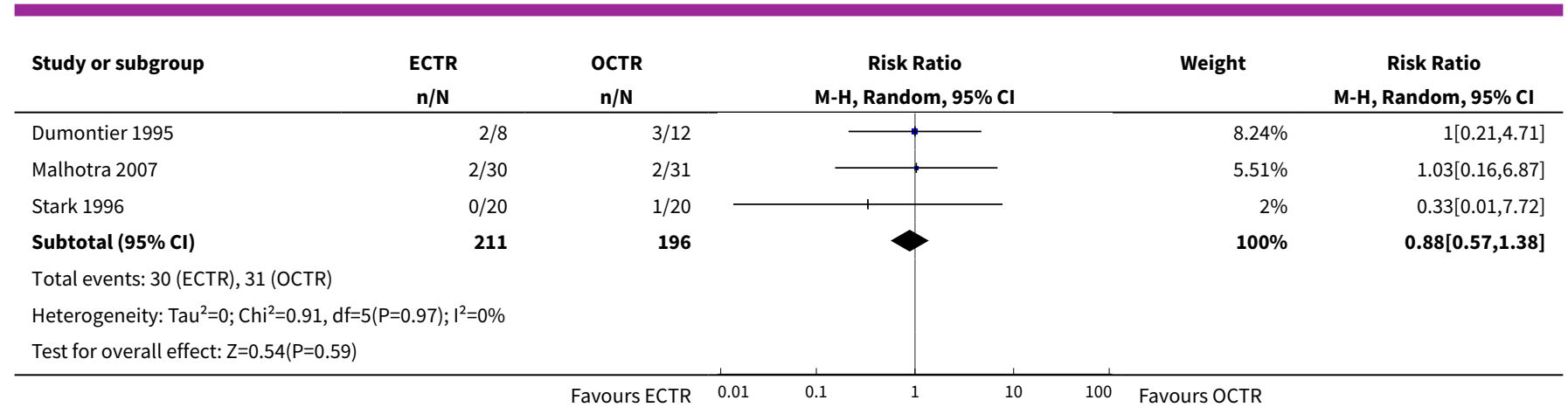

Analysis 1.17. Comparison 1 Endoscopic versus open or mini-open carpal tunnel release, Outcome 17 Numbness at more than 3 months.

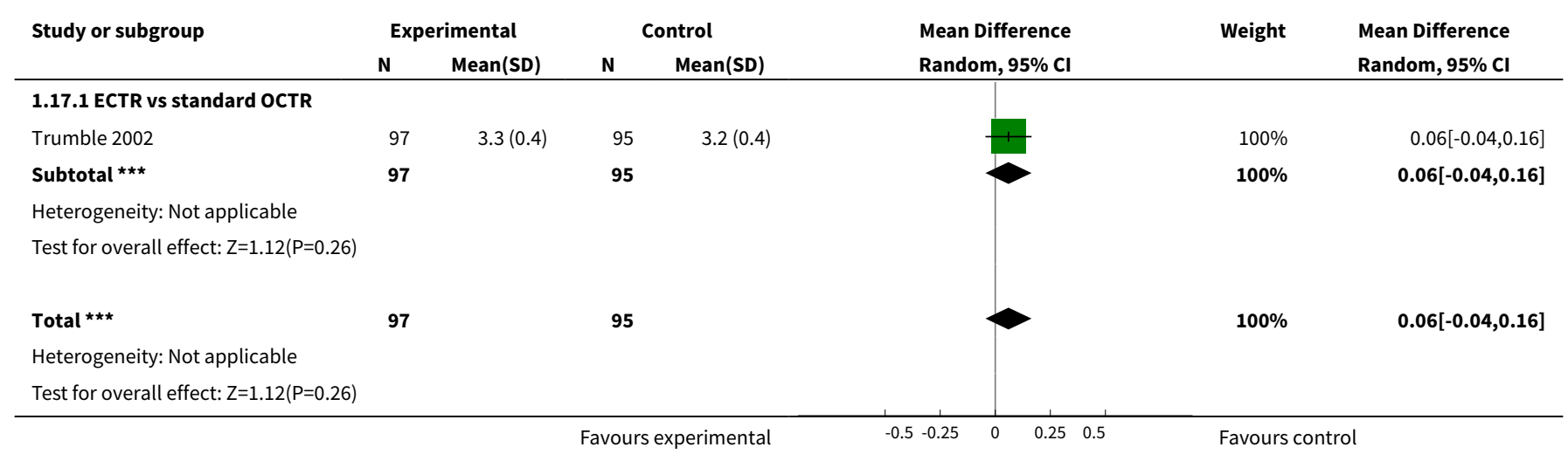

Analysis 1.18. Comparison 1 Endoscopic versus open or mini-open carpal tunnel release, Outcome 18 Numbness (dichotomous) at more than 3 months.

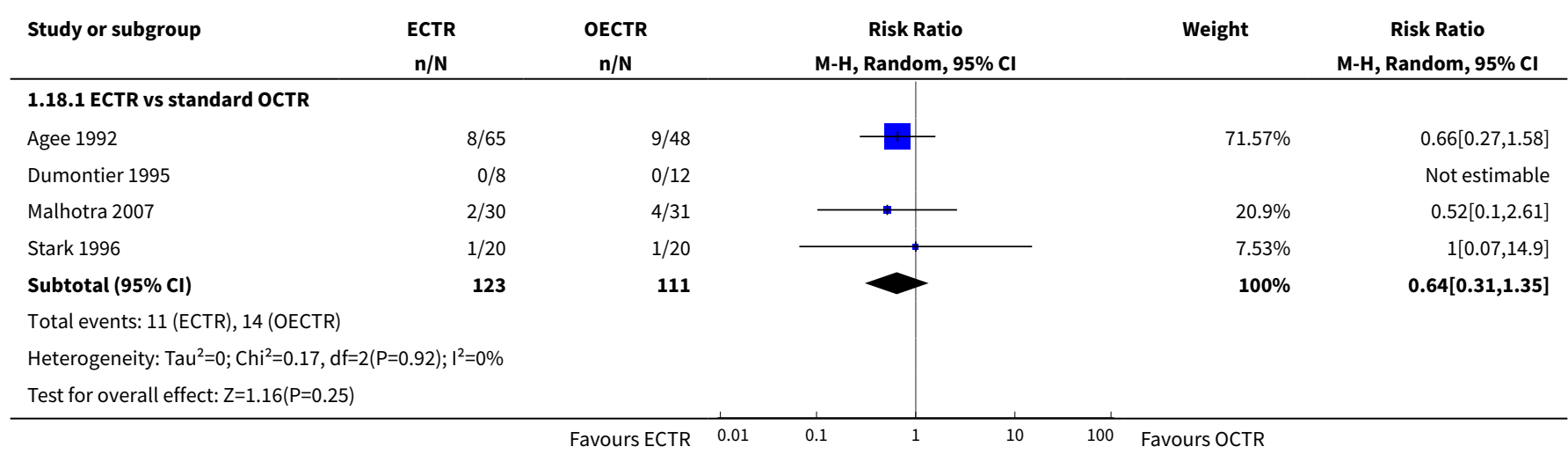


Analysis 1.19. Comparison 1 Endoscopic versus open or mini-open carpal tunnel release, Outcome 19 Grip strength at more than 3 months.

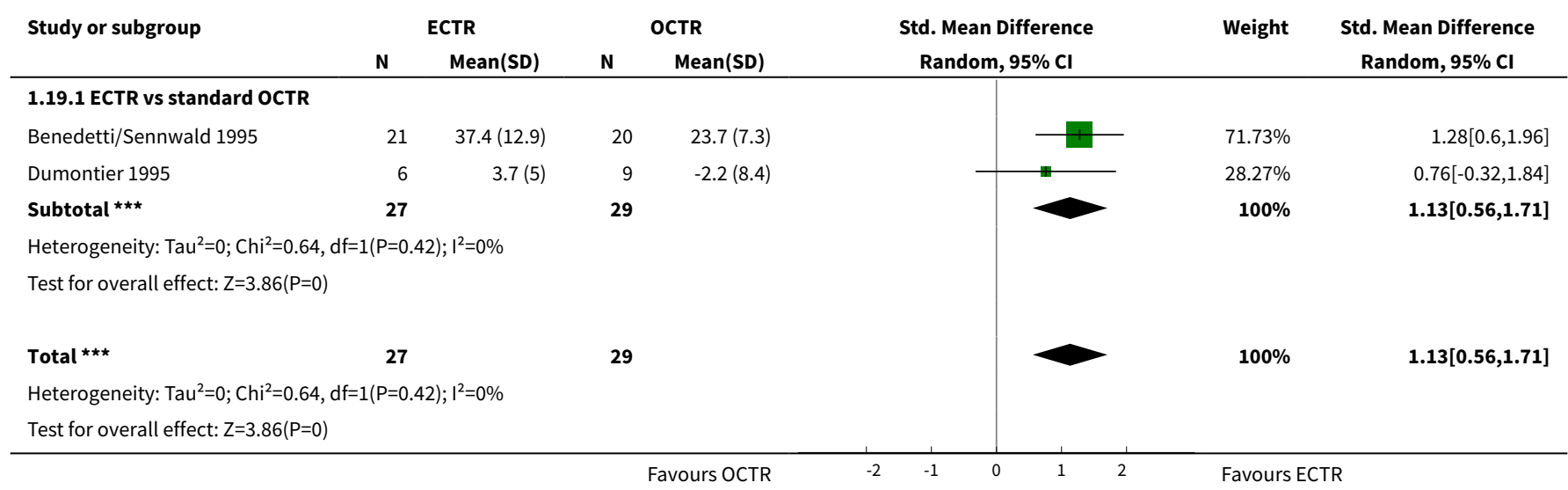

Analysis 1.20. Comparison 1 Endoscopic versus open or miniopen carpal tunnel release, Outcome 20 Time to return to work.

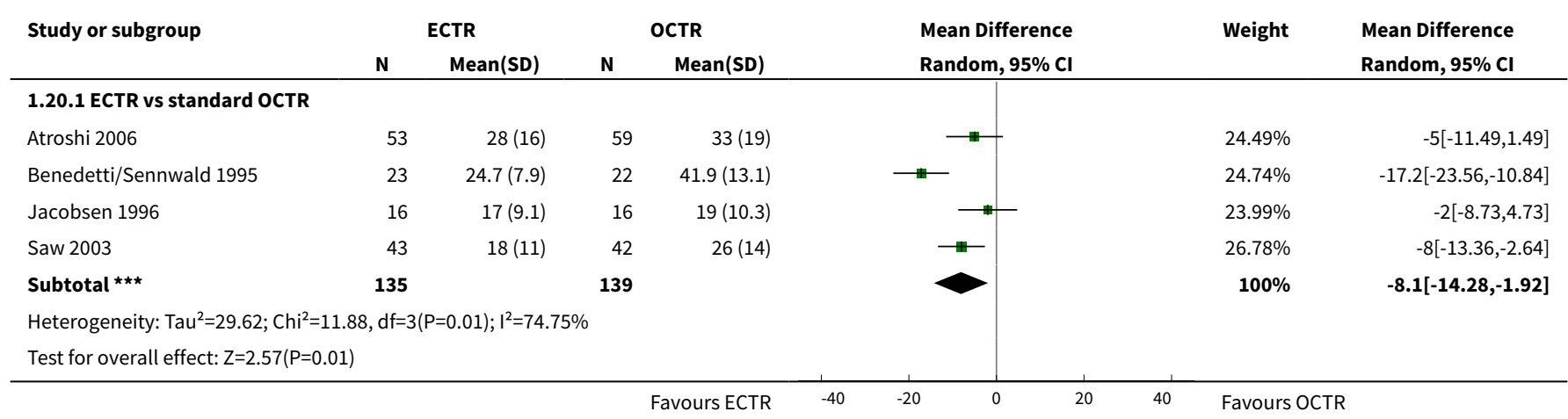

Analysis 1.21. Comparison 1 Endoscopic versus open or mini-open carpal tunnel release, Outcome 21 Recurrence.

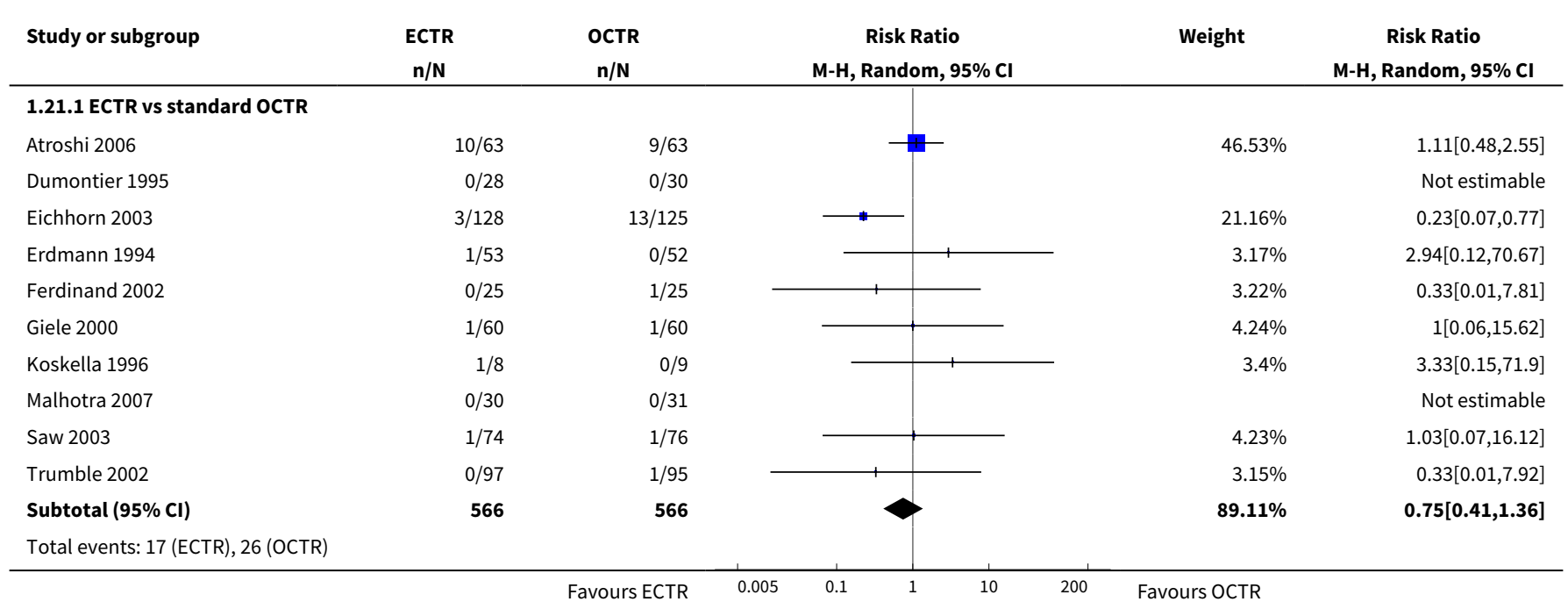




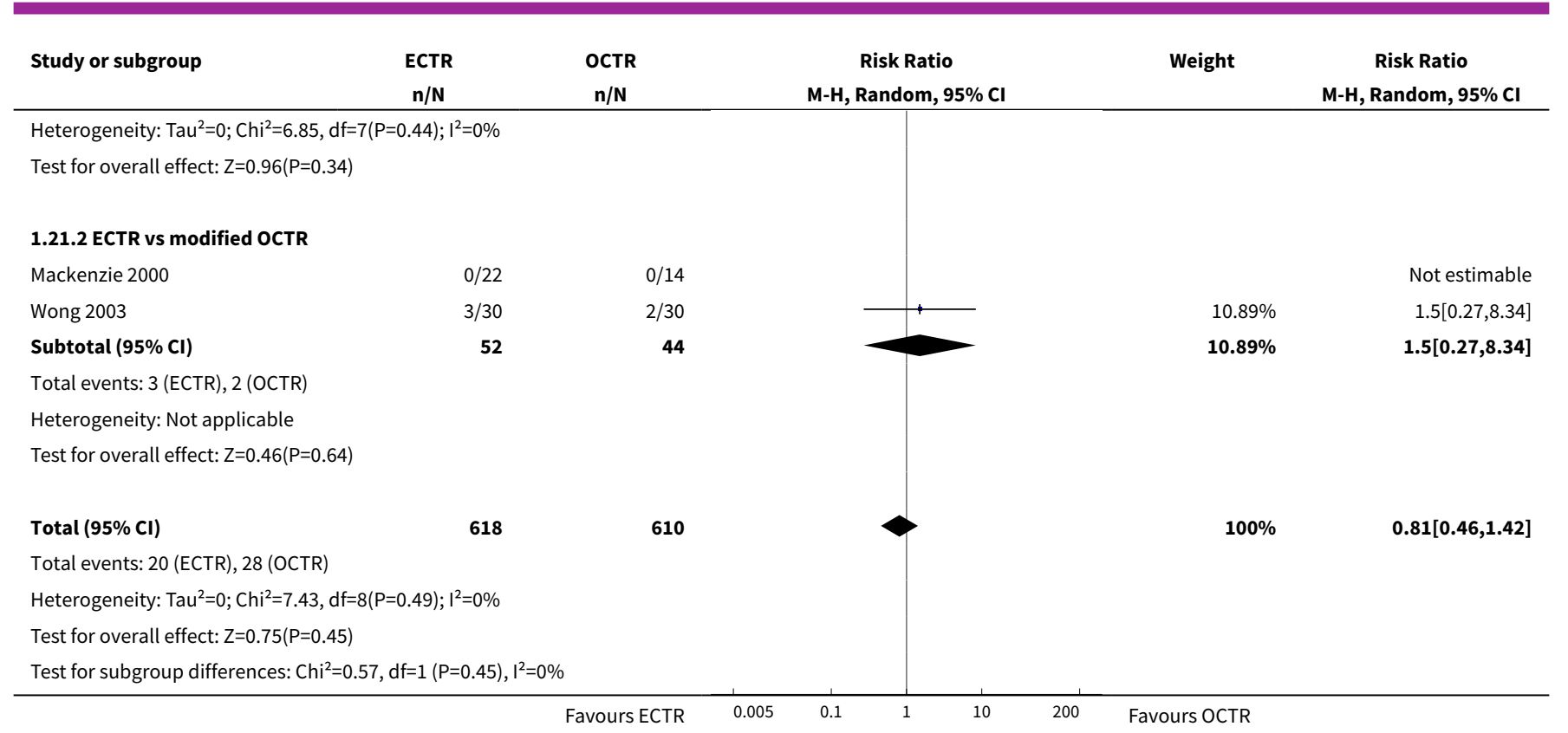

Analysis 1.22. Comparison 1 Endoscopic versus open or mini-open carpal tunnel release, Outcome 22 Reoperations.

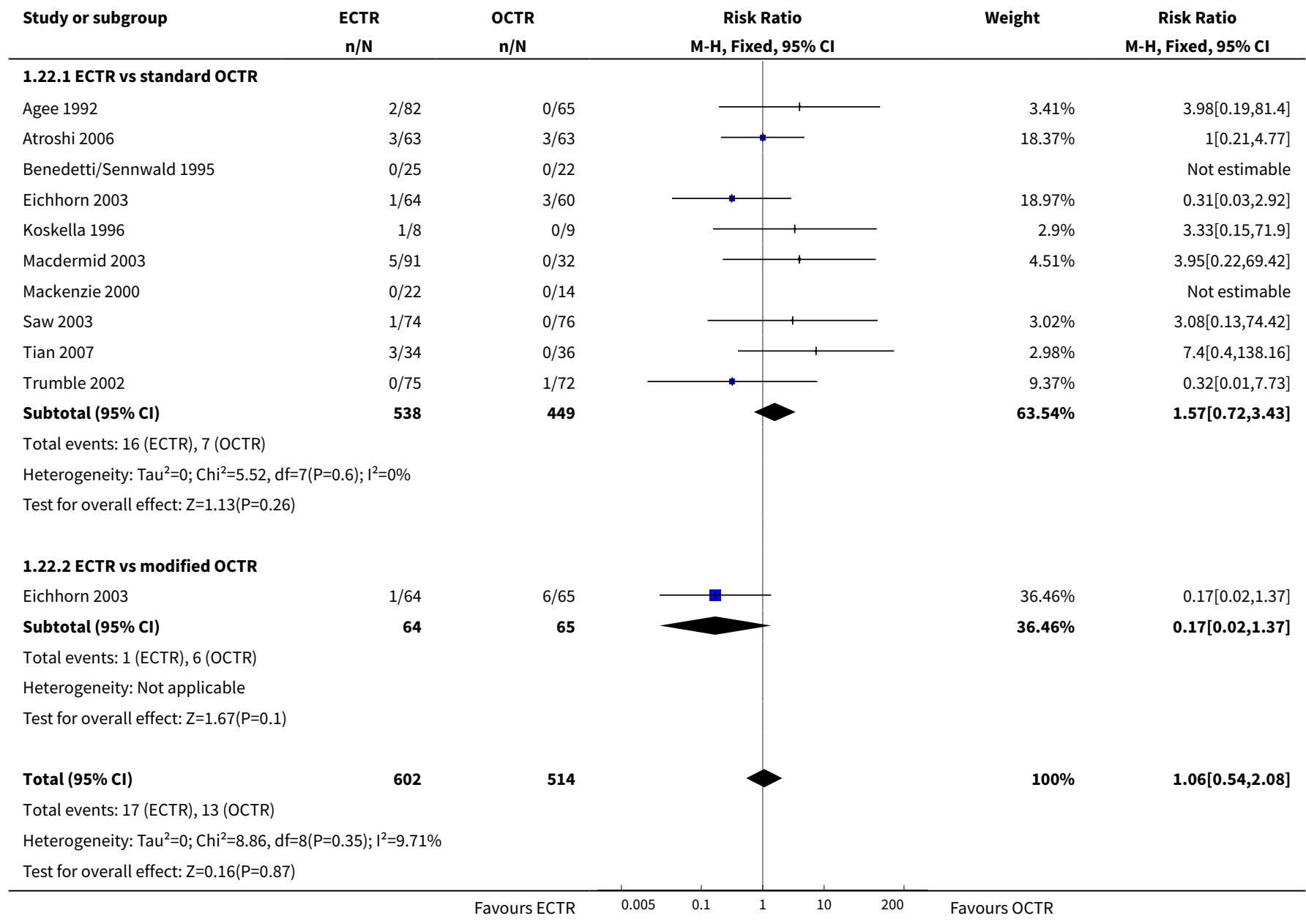




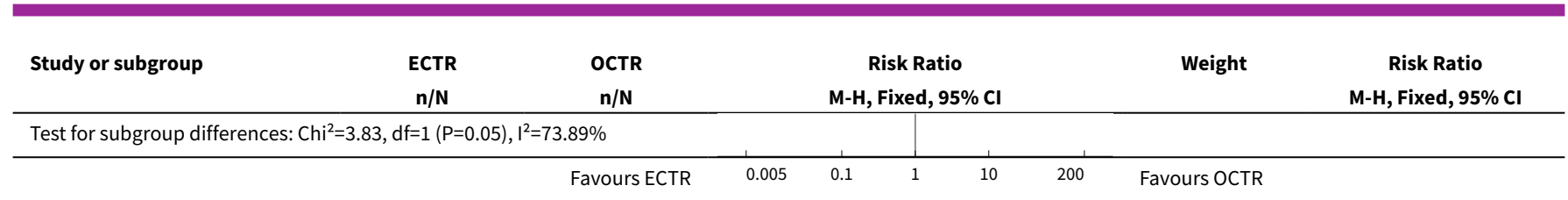

Analysis 1.23. Comparison 1 Endoscopic versus open or miniopen carpal tunnel release, Outcome 23 Major complications.

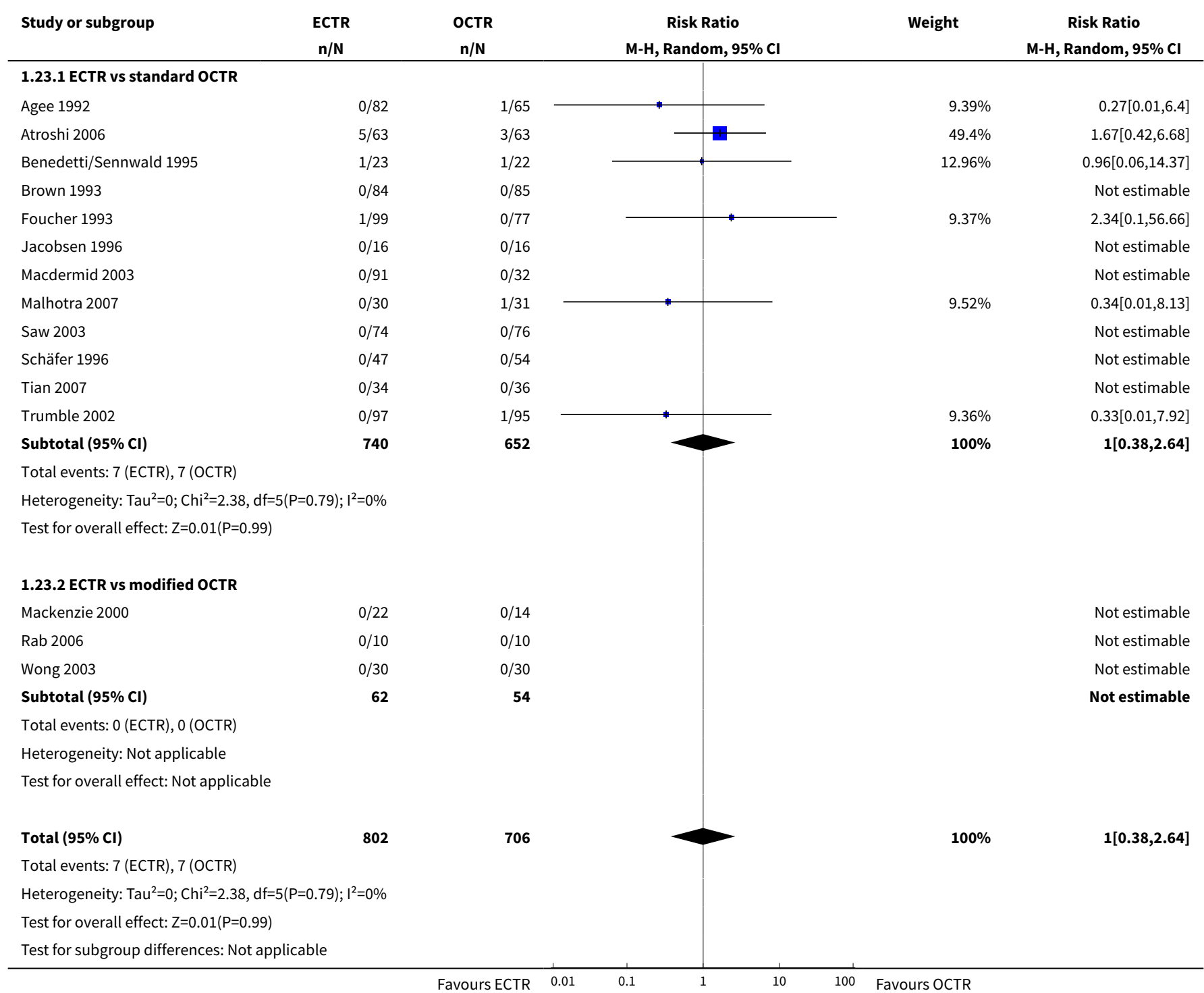


Analysis 1.24. Comparison 1 Endoscopic versus open or miniopen carpal tunnel release, Outcome 24 Minor complications.

\begin{tabular}{|c|c|c|c|c|c|}
\hline Study or subgroup & $\begin{array}{c}\text { ECTR } \\
\mathrm{n} / \mathrm{N} \\
\end{array}$ & $\begin{array}{l}\text { OCTR } \\
\mathrm{n} / \mathrm{N}\end{array}$ & $\begin{array}{c}\text { Risk Ratio } \\
\text { M-H, Random, } 95 \% \mathrm{Cl} \\
\end{array}$ & Weight & $\begin{array}{c}\text { Risk Ratio } \\
\text { M-H, Random, } 95 \% \mathrm{Cl} \\
\end{array}$ \\
\hline \multicolumn{6}{|c|}{ 1.24.1 ECTR vs standard OCTR } \\
\hline Agee 1992 & $2 / 82$ & $3 / 65$ & - & $4.45 \%$ & $0.53[0.09,3.07]$ \\
\hline Atroshi 2006 & $5 / 63$ & $8 / 63$ & - & $10.83 \%$ & $0.63[0.22,1.81]$ \\
\hline Benedetti/Sennwald 1995 & $5 / 23$ & $10 / 22$ & $\rightarrow$ & $14.06 \%$ & $0.48[0.19,1.18]$ \\
\hline Brown 1993 & $4 / 84$ & $0 / 85$ & & $1.71 \%$ & $9.11[0.5,166.54]$ \\
\hline Eichhorn 2003 & $0 / 64$ & $2 / 60$ & & $1.59 \%$ & $0.19[0.01,3.83]$ \\
\hline Erdmann 1994 & $3 / 53$ & $20 / 52$ & $\longrightarrow$ & $9.45 \%$ & $0.15[0.05,0.47]$ \\
\hline Ferdinand 2002 & $1 / 25$ & $1 / 25$ & & $1.95 \%$ & $1[0.07,15.12]$ \\
\hline Giele 2000 & $3 / 60$ & $3 / 60$ & & $5.55 \%$ & $1[0.21,4.76]$ \\
\hline Jacobsen 1996 & $3 / 16$ & $1 / 16$ & & $3.04 \%$ & $3[0.35,25.87]$ \\
\hline Malhotra 2007 & $0 / 30$ & $10 / 31$ & - & $1.85 \%$ & $0.05[0,0.8]$ \\
\hline Saw 2003 & $2 / 74$ & $3 / 76$ & & $4.44 \%$ & $0.68[0.12,3.98]$ \\
\hline Stark 1996 & $0 / 20$ & $1 / 20$ & 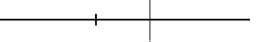 & $1.47 \%$ & $0.33[0.01,7.72]$ \\
\hline Tian 2007 & $12 / 34$ & $23 / 36$ & $\rightarrow-$ & $28.92 \%$ & $0.55[0.33,0.93]$ \\
\hline Trumble 2002 & $0 / 97$ & $1 / 95$ & & $1.43 \%$ & $0.33[0.01,7.92]$ \\
\hline Werber 1996 & $2 / 46$ & $0 / 44$ & & $1.6 \%$ & $4.79[0.24,97]$ \\
\hline Westphal 2000 & $3 / 45$ & $3 / 35$ & & $5.69 \%$ & $0.78[0.17,3.62]$ \\
\hline Subtotal (95\% Cl) & 816 & 785 & $>$ & $98.01 \%$ & $0.55[0.37,0.84]$ \\
\hline \multicolumn{6}{|c|}{ Total events: 45 (ECTR), 89 (OCTR) } \\
\hline \multicolumn{6}{|c|}{ Heterogeneity: $\operatorname{Tau}^{2}=0.1 ; \mathrm{Chi}^{2}=17.8, \mathrm{df}=15(\mathrm{P}=0.27) ; \mathrm{I}^{2}=15.73 \%$} \\
\hline \multicolumn{6}{|c|}{ Test for overall effect: $Z=2.79(P=0.01)$} \\
\hline \multicolumn{6}{|c|}{ 1.24.2 ECTR vs modified OCTR } \\
\hline Eichhorn 2003 & $0 / 64$ & $0 / 65$ & & & Not estimable \\
\hline Mackenzie 2000 & $1 / 22$ & $1 / 14$ & 1 & $1.99 \%$ & $0.64[0.04,9.37]$ \\
\hline Rab 2006 & $0 / 10$ & $0 / 10$ & & & Not estimable \\
\hline Subtotal $(95 \% \mathrm{Cl})$ & 96 & 89 & & $1.99 \%$ & $0.64[0.04,9.37]$ \\
\hline \multicolumn{6}{|c|}{ Total events: 1 (ECTR), 1 (OCTR) } \\
\hline \multicolumn{6}{|c|}{ Heterogeneity: Not applicable } \\
\hline \multicolumn{6}{|c|}{ Test for overall effect: $Z=0.33(P=0.74)$} \\
\hline Total $(95 \% \mathrm{Cl})$ & 912 & 874 & $>$ & $100 \%$ & $0.55[0.38,0.81]$ \\
\hline \multicolumn{6}{|c|}{ Total events: 46 (ECTR), 90 (OCTR) } \\
\hline \multicolumn{6}{|c|}{ Heterogeneity: $\operatorname{Tau}^{2}=0.06 ; \mathrm{Chi}^{2}=17.81, \mathrm{df}=16(\mathrm{P}=0.34) ; \mathrm{I}^{2}=10.17 \%$} \\
\hline \multicolumn{6}{|c|}{ Test for overall effect: $Z=3.02(P=0)$} \\
\hline Test for subgroup differenc & $d f=1(P=0.92), I$ & & & & \\
\hline
\end{tabular}

Analysis 1.25. Comparison 1 Endoscopic versus open or miniopen carpal tunnel release, Outcome 25 Total complications.

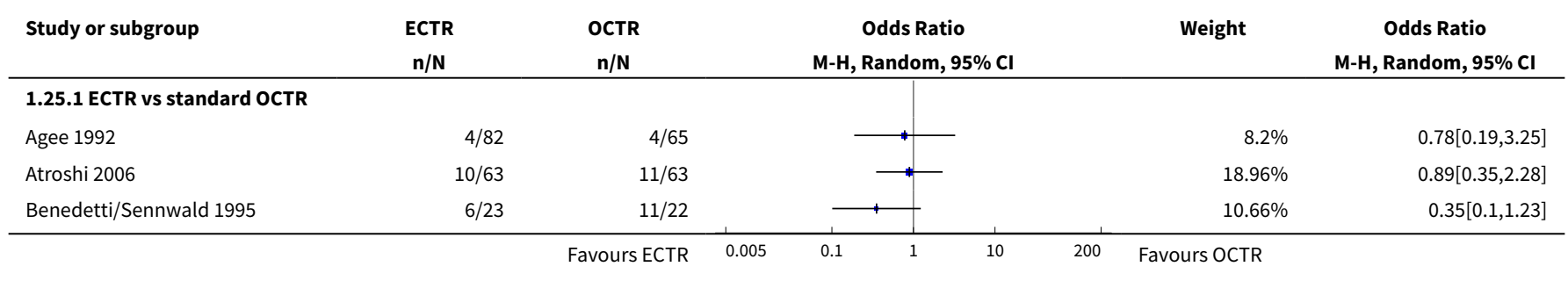




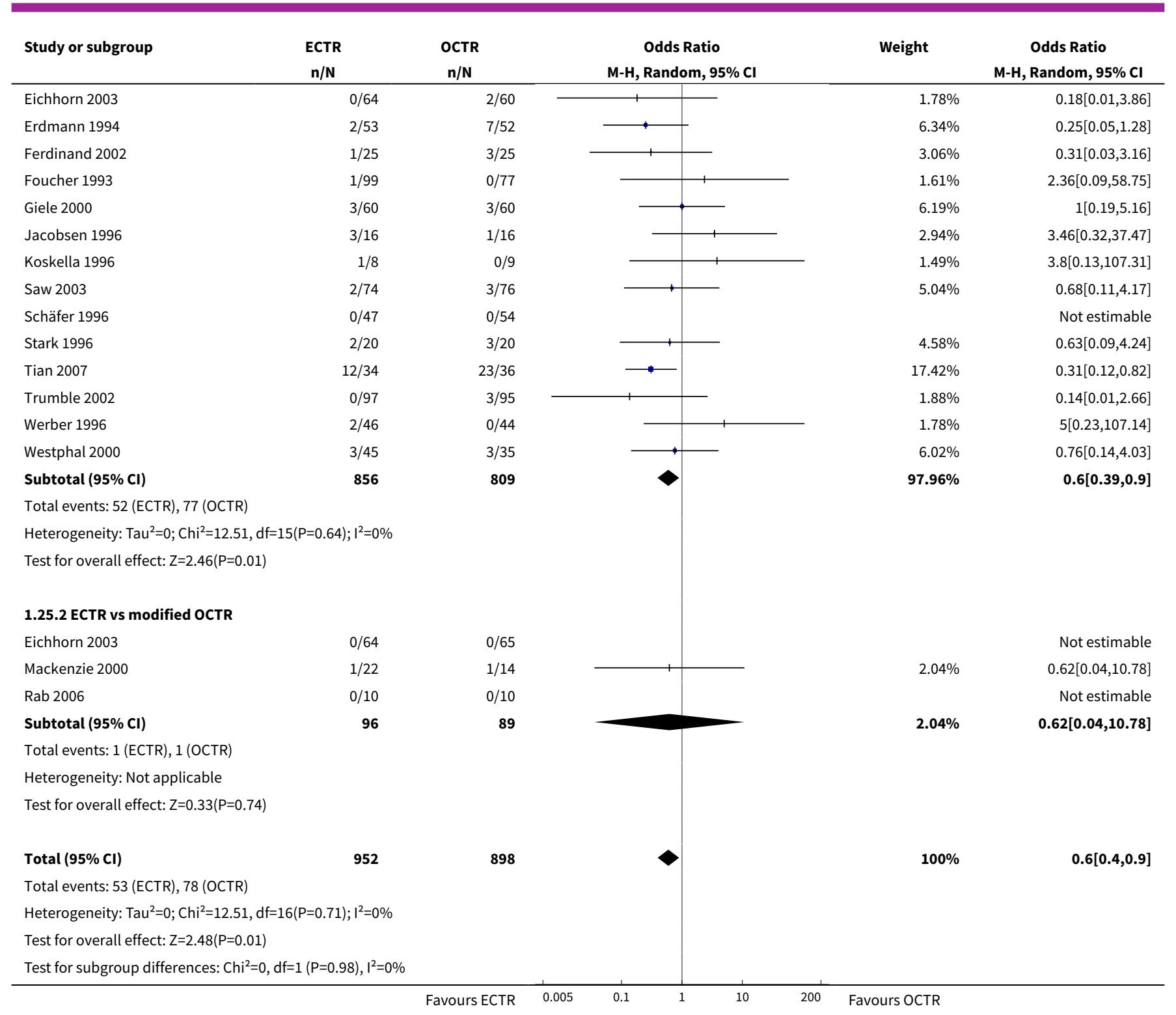

Comparison 2. One- or two-portal endoscopic versus open and mini-open carpal tunnel release

\begin{tabular}{lllll}
\hline Outcome or subgroup title & $\begin{array}{l}\text { No. of } \\
\text { studies }\end{array}$ & $\begin{array}{l}\text { No. of } \\
\text { partici- } \\
\text { pants }\end{array}$ & Statistical method & Effect size \\
\hline 1 Overall satisfaction at 3 months or less & 1 & 169 & $\begin{array}{l}\text { Mean Difference (IV, Random, } \\
95 \% \text { Cl) }\end{array}$ & $5.0[-1.74,11.74]$ \\
\hline 1.1 Two-portal ECTR vs OCTR & 1 & 169 & $\begin{array}{l}\text { Mean Difference (IV, Random, } \\
95 \% \text { Cl) }\end{array}$ & $5.0[-1.74,11.74]$ \\
\hline 2 Overall improvement at 3 months or less & 1 & 169 & $\begin{array}{l}\text { Odds Ratio (M-H, Random, } \\
95 \% \mathrm{Cl})\end{array}$ & $1.35[0.71,2.55]$ \\
\hline
\end{tabular}




\begin{tabular}{|c|c|c|c|c|}
\hline Outcome or subgroup title & $\begin{array}{l}\text { No. of } \\
\text { studies }\end{array}$ & $\begin{array}{l}\text { No. of } \\
\text { partici- } \\
\text { pants }\end{array}$ & Statistical method & Effect size \\
\hline 2.1 Two-portal ECTR vs OCTR & 1 & 169 & $\begin{array}{l}\text { Odds Ratio (M-H, Random, } \\
95 \% \mathrm{Cl})\end{array}$ & $1.35[0.71,2.55]$ \\
\hline $\begin{array}{l}3 \text { Symptom Severity Scale (Levine) at } 3 \\
\text { months or less }\end{array}$ & 5 & & $\begin{array}{l}\text { Std. Mean Difference (Ran- } \\
\text { dom, } 95 \% \mathrm{Cl} \text { ) }\end{array}$ & $-0.13[-0.47,0.21]$ \\
\hline 3.1 Two-portal ECTR vs OCTR & 2 & & $\begin{array}{l}\text { Std. Mean Difference (Ran- } \\
\text { dom, } 95 \% \mathrm{Cl} \text { ) }\end{array}$ & $-0.08[-0.39,0.22]$ \\
\hline 3.2 One-portal ECTR vs OCTR & 3 & & $\begin{array}{l}\text { Std. Mean Difference (Ran- } \\
\text { dom, } 95 \% \mathrm{Cl} \text { ) }\end{array}$ & $-0.12[-0.66,0.42]$ \\
\hline 4 Function Status Scale at 3 months or less & 5 & & $\begin{array}{l}\text { Std. Mean Difference (Ran- } \\
\text { dom, } 95 \% \mathrm{Cl} \text { ) }\end{array}$ & $-0.23[-0.60,0.14]$ \\
\hline 4.1 Two-portal ECTR vs OCTR & 2 & & $\begin{array}{l}\text { Std. Mean Difference (Ran- } \\
\text { dom, } 95 \% \mathrm{Cl} \text { ) }\end{array}$ & $-0.16[-0.60,0.29]$ \\
\hline 4.2 One-portal ECTR vs OCTR & 3 & & $\begin{array}{l}\text { Std. Mean Difference (Ran- } \\
\text { dom, } 95 \% \mathrm{Cl} \text { ) }\end{array}$ & $-0.25[-0.82,0.32]$ \\
\hline 5 Pain at 3 months or less (corr $=0.5$ ) & 4 & & $\begin{array}{l}\text { Std. Mean Difference (Ran- } \\
\text { dom, } 95 \% \mathrm{Cl} \text { ) }\end{array}$ & $-0.21[-0.72,0.30]$ \\
\hline 5.1 Two-portal ECTR vs OCTR & 3 & & $\begin{array}{l}\text { Std. Mean Difference (Ran- } \\
\text { dom, } 95 \% \mathrm{Cl} \text { ) }\end{array}$ & $-0.18[-0.96,0.59]$ \\
\hline 5.2 One-portal ECTR vs OCTR & 1 & & $\begin{array}{l}\text { Std. Mean Difference (Ran- } \\
\text { dom, } 95 \% \mathrm{Cl} \text { ) }\end{array}$ & $-0.31[-0.63,0.02]$ \\
\hline 6 Pain at 3 months or less (corr $=0.1$ ) & 4 & & $\begin{array}{l}\text { Std. Mean Difference (Ran- } \\
\text { dom, } 95 \% \mathrm{Cl} \text { ) }\end{array}$ & $-0.20[-0.74,0.34]$ \\
\hline 6.1 Two-portal ECTR vs OCTR & 3 & & $\begin{array}{l}\text { Std. Mean Difference (Ran- } \\
\text { dom, } 95 \% \mathrm{Cl} \text { ) }\end{array}$ & $-0.18[-1.10,0.74]$ \\
\hline 6.2 One-portal ECTR vs OCTR & 1 & & $\begin{array}{l}\text { Std. Mean Difference (Ran- } \\
\text { dom, } 95 \% \mathrm{Cl} \text { ) }\end{array}$ & $-0.31[-0.63,0.02]$ \\
\hline 7 Pain at 3 months or less (corr $=0.9$ ) & 4 & & $\begin{array}{l}\text { Std. Mean Difference (Ran- } \\
\text { dom, } 95 \% \mathrm{Cl} \text { ) }\end{array}$ & $-0.20[-0.58,0.18]$ \\
\hline 7.1 Two-portal ECTR vs OCTR & 3 & & $\begin{array}{l}\text { Std. Mean Difference (Ran- } \\
\text { dom, } 95 \% \mathrm{Cl} \text { ) }\end{array}$ & $-0.17[-0.65,0.30]$ \\
\hline 7.2 One-portal ECTR vs OCTR & 1 & & $\begin{array}{l}\text { Std. Mean Difference (Ran- } \\
\text { dom, } 95 \% \mathrm{Cl} \text { ) }\end{array}$ & $-0.31[-0.63,0.02]$ \\
\hline 8 Pain (dichotomous) at 3 months or less & 5 & 348 & $\begin{array}{l}\text { Odds Ratio (M-H, Random, } \\
95 \% \mathrm{Cl})\end{array}$ & $0.50[0.14,1.73]$ \\
\hline 8.1 Two-portal ECTR vs OCTR & 3 & 247 & $\begin{array}{l}\text { Odds Ratio (M-H, Random, } \\
95 \% \mathrm{Cl})\end{array}$ & $1.18[0.50,2.78]$ \\
\hline
\end{tabular}




\begin{tabular}{|c|c|c|c|c|}
\hline Outcome or subgroup title & $\begin{array}{l}\text { No. of } \\
\text { studies }\end{array}$ & $\begin{array}{l}\text { No. of } \\
\text { partici- } \\
\text { pants }\end{array}$ & Statistical method & Effect size \\
\hline 8.2 One-portal ECTR vs OCTR & 2 & 101 & $\begin{array}{l}\text { Odds Ratio (M-H, Random, } \\
95 \% \mathrm{Cl})\end{array}$ & $0.06[0.02,0.22]$ \\
\hline $\begin{array}{l}9 \text { Numbness (dichotomous) at } 3 \text { months or } \\
\text { less }\end{array}$ & 5 & 435 & $\begin{array}{l}\text { Odds Ratio (M-H, Random, } \\
95 \% \mathrm{Cl})\end{array}$ & $1.20[0.72,2.01]$ \\
\hline 9.1 Two-portal ECTR vs OCTR & 2 & 186 & $\begin{array}{l}\text { Odds Ratio (M-H, Random, } \\
95 \% \mathrm{Cl})\end{array}$ & $1.12[0.55,2.28]$ \\
\hline 9.2 One-portal ECTR vs OCTR & 3 & 249 & $\begin{array}{l}\text { Odds Ratio (M-H, Random, } \\
95 \% \mathrm{Cl})\end{array}$ & $1.30[0.62,2.71]$ \\
\hline 10 Grip strength at 3 months or less & 6 & 560 & $\begin{array}{l}\text { Std. Mean Difference (Ran- } \\
\text { dom, } 95 \% \mathrm{Cl} \text { ) }\end{array}$ & $0.36[0.09,0.63]$ \\
\hline 10.1 Two-portal ECTR vs OCTR & 3 & 349 & $\begin{array}{l}\text { Std. Mean Difference (Ran- } \\
\text { dom, } 95 \% \mathrm{Cl} \text { ) }\end{array}$ & $0.27[0.02,0.53]$ \\
\hline 10.2 One-portal ECTR vs OCTR & 3 & 211 & $\begin{array}{l}\text { Std. Mean Difference (Ran- } \\
\text { dom, } 95 \% \mathrm{Cl} \text { ) }\end{array}$ & $0.50[-0.14,1.13]$ \\
\hline 11 Overall satisfaction at more than 3 months & 1 & 192 & $\begin{array}{l}\text { Mean Difference (IV, Random, } \\
95 \% \mathrm{CI})\end{array}$ & $0.10[-0.23,0.43]$ \\
\hline 11.1 One-portal ECTR vs OCTR & 1 & 192 & $\begin{array}{l}\text { Mean Difference (IV, Random, } \\
95 \% \mathrm{CI})\end{array}$ & $0.10[-0.23,0.43]$ \\
\hline $\begin{array}{l}12 \text { Overall improvement at more than } 3 \\
\text { months }\end{array}$ & 4 & 317 & $\begin{array}{l}\text { Odds Ratio (M-H, Random, } \\
95 \% \mathrm{Cl})\end{array}$ & $1.26[0.71,2.25]$ \\
\hline 12.1 Two-portal ECTR vs OCTR & 2 & 186 & $\begin{array}{l}\text { Odds Ratio (M-H, Random, } \\
95 \% \mathrm{Cl})\end{array}$ & $1.00[0.49,2.02]$ \\
\hline 12.2 One-portal ECTR vs OCTR & 2 & 131 & $\begin{array}{l}\text { Odds Ratio (M-H, Random, } \\
95 \% \mathrm{Cl})\end{array}$ & $2.05[0.74,5.69]$ \\
\hline $\begin{array}{l}13 \text { Symptom Severity Scale (Levine) at more } \\
\text { than } 3 \text { months }\end{array}$ & 2 & 273 & $\begin{array}{l}\text { Mean Difference (IV, Random, } \\
95 \% \mathrm{CI})\end{array}$ & $0.02[-0.18,0.22]$ \\
\hline 13.1 Two-portal ECTR vs OCTR & 1 & 126 & $\begin{array}{l}\text { Mean Difference (IV, Random, } \\
95 \% \mathrm{CI})\end{array}$ & $0.03[-0.21,0.27]$ \\
\hline 13.2 One-portal ECTR vs OCTR & 1 & 147 & $\begin{array}{l}\text { Mean Difference (IV, Random, } \\
95 \% \mathrm{CI} \text { ) }\end{array}$ & $0.0[-0.35,0.35]$ \\
\hline $\begin{array}{l}14 \text { Function Status Scale at more than } 3 \\
\text { months }\end{array}$ & 2 & 273 & $\begin{array}{l}\text { Mean Difference (IV, Random, } \\
95 \% \mathrm{CI} \text { ) }\end{array}$ & $0.01[-0.14,0.16]$ \\
\hline 14.1 Two-portal ECTR vs OCTR & 1 & 126 & $\begin{array}{l}\text { Mean Difference (IV, Random, } \\
95 \% \mathrm{CI})\end{array}$ & $0.01[-0.16,0.18]$ \\
\hline 14.2 One-portal ECTR vs OCTR & 1 & 147 & $\begin{array}{l}\text { Mean Difference (IV, Random, } \\
95 \% \mathrm{CI} \text { ) }\end{array}$ & $0.0[-0.29,0.29]$ \\
\hline
\end{tabular}




\begin{tabular}{|c|c|c|c|c|}
\hline Outcome or subgroup title & $\begin{array}{l}\text { No. of } \\
\text { studies }\end{array}$ & $\begin{array}{l}\text { No. of } \\
\text { partici- } \\
\text { pants }\end{array}$ & Statistical method & Effect size \\
\hline 15 Pain at more than 3 months & 1 & 128 & $\begin{array}{l}\text { Mean Difference (IV, Random, } \\
95 \% \mathrm{CI})\end{array}$ & $-5.20[-12.65,2.25]$ \\
\hline 15.1 Two-portal ECTR vs OCTR & 1 & 128 & $\begin{array}{l}\text { Mean Difference (IV, Random, } \\
95 \% \mathrm{CI})\end{array}$ & $-5.20[-12.65,2.25]$ \\
\hline 16 Pain (dichotomous) at more than 3 months & 6 & 407 & $\begin{array}{l}\text { Odds Ratio (M-H, Random, } \\
95 \% \mathrm{Cl})\end{array}$ & $0.85[0.48,1.48]$ \\
\hline 16.1 Two-portal ECTR vs OCTR & 2 & 146 & $\begin{array}{l}\text { Odds Ratio (M-H, Random, } \\
95 \% \mathrm{Cl})\end{array}$ & $0.91[0.39,2.14]$ \\
\hline 16.2 One-portal ECTR vs OCTR & 4 & 261 & $\begin{array}{l}\text { Odds Ratio (M-H, Random, } \\
95 \% \mathrm{Cl})\end{array}$ & $0.80[0.38,1.69]$ \\
\hline 17 Numbness at more than 3 months & 1 & 192 & $\begin{array}{l}\text { Mean Difference (IV, Random, } \\
95 \% \mathrm{CI})\end{array}$ & $0.06[-0.04,0.16]$ \\
\hline 17.1 One-portal ECTR vs OCTR & 1 & 192 & $\begin{array}{l}\text { Mean Difference (IV, Random, } \\
95 \% \mathrm{CI})\end{array}$ & $0.06[-0.04,0.16]$ \\
\hline $\begin{array}{l}18 \text { Numbness (dichotomous) at more than } 3 \\
\text { months }\end{array}$ & 4 & 234 & $\begin{array}{l}\text { Odds Ratio (M-H, Random, } \\
95 \% \mathrm{Cl})\end{array}$ & $0.60[0.26,1.42]$ \\
\hline 18.1 Two-portal ECTR vs OCTR & 1 & 20 & $\begin{array}{l}\text { Odds Ratio (M-H, Random, } \\
95 \% \mathrm{Cl})\end{array}$ & $0.0[0.0,0.0]$ \\
\hline 18.2 One-portal ECTR vs OCTR & 3 & 214 & $\begin{array}{l}\text { Odds Ratio (M-H, Random, } \\
95 \% \mathrm{Cl})\end{array}$ & $0.60[0.26,1.42]$ \\
\hline 19 Grip strength at more than 3 months & 2 & 56 & $\begin{array}{l}\text { Std. Mean Difference (IV, Ran- } \\
\text { dom, } 95 \% \mathrm{CI} \text { ) }\end{array}$ & $1.13[0.56,1.71]$ \\
\hline 19.1 Two-portal ECTR vs OCTR & 1 & 15 & $\begin{array}{l}\text { Std. Mean Difference (IV, Ran- } \\
\text { dom, } 95 \% \mathrm{CI} \text { ) }\end{array}$ & $0.76[-0.32,1.84]$ \\
\hline 19.2 One-portal ECTR vs OCTR & 1 & 41 & $\begin{array}{l}\text { Std. Mean Difference (IV, Ran- } \\
\text { dom, } 95 \% \mathrm{CI} \text { ) }\end{array}$ & $1.28[0.60,1.96]$ \\
\hline 20 Time to return to work & 4 & 274 & $\begin{array}{l}\text { Mean Difference (IV, Random, } \\
95 \% \mathrm{CI})\end{array}$ & $-8.09[-14.27,-1.91]$ \\
\hline 20.1 Two-portal ECTR vs OCTR & 2 & 144 & $\begin{array}{l}\text { Mean Difference (IV, Random, } \\
95 \% \mathrm{CI} \text { ) }\end{array}$ & $-3.53[-8.17,1.10]$ \\
\hline 20.2 One-portal ECTR vs OCTR & 2 & 130 & $\begin{array}{l}\text { Mean Difference (IV, Random, } \\
95 \% \mathrm{CI} \text { ) }\end{array}$ & $-12.43[-21.44,-3.42]$ \\
\hline 21 Recurrence & 12 & 1228 & $\begin{array}{l}\text { Odds Ratio (M-H, Random, } \\
95 \% \mathrm{Cl})\end{array}$ & $0.76[0.41,1.43]$ \\
\hline 21.1 Two-portal ECTR vs OCTR & 5 & 602 & $\begin{array}{l}\text { Odds Ratio (M-H, Random, } \\
95 \% \mathrm{Cl})\end{array}$ & $0.78[0.26,2.37]$ \\
\hline
\end{tabular}




\begin{tabular}{|c|c|c|c|c|}
\hline Outcome or subgroup title & $\begin{array}{l}\text { No. of } \\
\text { studies }\end{array}$ & $\begin{array}{l}\text { No. of } \\
\text { partici- } \\
\text { pants }\end{array}$ & Statistical method & Effect size \\
\hline 21.2 One-portal ECTR vs OCTR & 5 & 489 & $\begin{array}{l}\text { Odds Ratio (M-H, Random, } \\
95 \% \mathrm{Cl})\end{array}$ & $0.51[0.09,3.00]$ \\
\hline 21.3 Non-defined ECTR vs OCTR & 2 & 137 & $\begin{array}{l}\text { Odds Ratio (M-H, Random, } \\
95 \% \mathrm{Cl})\end{array}$ & $1.73[0.20,14.78]$ \\
\hline 22 Reoperations & 10 & 1116 & $\begin{array}{l}\text { Odds Ratio (M-H, Fixed, 95\% } \\
\text { Cl) }\end{array}$ & $1.06[0.53,2.10]$ \\
\hline 22.1 Two-portal ECTR vs OCTR & 3 & 502 & $\begin{array}{l}\text { Odds Ratio (M-H, Fixed, 95\% } \\
\mathrm{Cl} \text { ) }\end{array}$ & $0.60[0.25,1.47]$ \\
\hline 22.2 One-portal ECTR vs OCTR & 6 & 597 & $\begin{array}{l}\text { Odds Ratio (M-H, Fixed, 95\% } \\
\mathrm{Cl} \text { ) }\end{array}$ & $2.59[0.68,9.85]$ \\
\hline 22.3 Non-defined ECTR vs OCTR & 1 & 17 & $\begin{array}{l}\text { Odds Ratio (M-H, Fixed, 95\% } \\
\mathrm{Cl} \text { ) }\end{array}$ & $3.8[0.13,107.31]$ \\
\hline 23 Major complications & 15 & 1508 & $\begin{array}{l}\text { Odds Ratio (M-H, Random, } \\
95 \% \mathrm{Cl})\end{array}$ & $0.59[0.24,1.46]$ \\
\hline 23.1 Two-portal ECTR vs OCTR & 6 & 530 & $\begin{array}{l}\text { Odds Ratio (M-H, Random, } \\
95 \% \mathrm{Cl})\end{array}$ & $0.59[0.18,1.92]$ \\
\hline 23.2 One-portal ECTR vs OCTR & 9 & 978 & $\begin{array}{l}\text { Odds Ratio (M-H, Random, } \\
95 \% \mathrm{Cl})\end{array}$ & $0.59[0.15,2.40]$ \\
\hline 24 Minor complications & 18 & 1786 & $\begin{array}{l}\text { Odds Ratio (M-H, Random, } \\
95 \% \mathrm{Cl})\end{array}$ & $0.49[0.29,0.83]$ \\
\hline 24.1 Two-portal ECTR vs OCTR & 6 & 705 & $\begin{array}{l}\text { Odds Ratio (M-H, Random, } \\
95 \% \mathrm{Cl})\end{array}$ & $0.66[0.14,3.10]$ \\
\hline 24.2 One-portal ECTR vs OCTR & 11 & 961 & $\begin{array}{l}\text { Odds Ratio (M-H, Random, } \\
95 \% \mathrm{Cl})\end{array}$ & $0.42[0.24,0.74]$ \\
\hline 24.3 Non-defined ECTR vs OCTR & 1 & 120 & $\begin{array}{l}\text { Odds Ratio (M-H, Random, } \\
95 \% \mathrm{Cl})\end{array}$ & $1.0[0.19,5.16]$ \\
\hline 25 Total complications & 19 & 1850 & $\begin{array}{l}\text { Odds Ratio (M-H, Random, } \\
95 \% \mathrm{Cl})\end{array}$ & $0.60[0.40,0.90]$ \\
\hline 25.1 Two-portal ECTR vs OCTR & 4 & 504 & $\begin{array}{l}\text { Odds Ratio (M-H, Random, } \\
95 \% \mathrm{Cl})\end{array}$ & $0.55[0.22,1.39]$ \\
\hline 25.2 One-portal ECTR vs OCTR & 13 & 1209 & $\begin{array}{l}\text { Odds Ratio (M-H, Random, } \\
95 \% \mathrm{Cl})\end{array}$ & $0.54[0.33,0.90]$ \\
\hline 25.3 Non-defined ECTR vs OCTR & 2 & 137 & $\begin{array}{l}\text { Odds Ratio (M-H, Random, } \\
95 \% \mathrm{Cl})\end{array}$ & $1.30[0.30,5.66]$ \\
\hline
\end{tabular}


Analysis 2.1. Comparison 2 One- or two-portal endoscopic versus open and miniopen carpal tunnel release, Outcome 1 Overall satisfaction at 3 months or less.

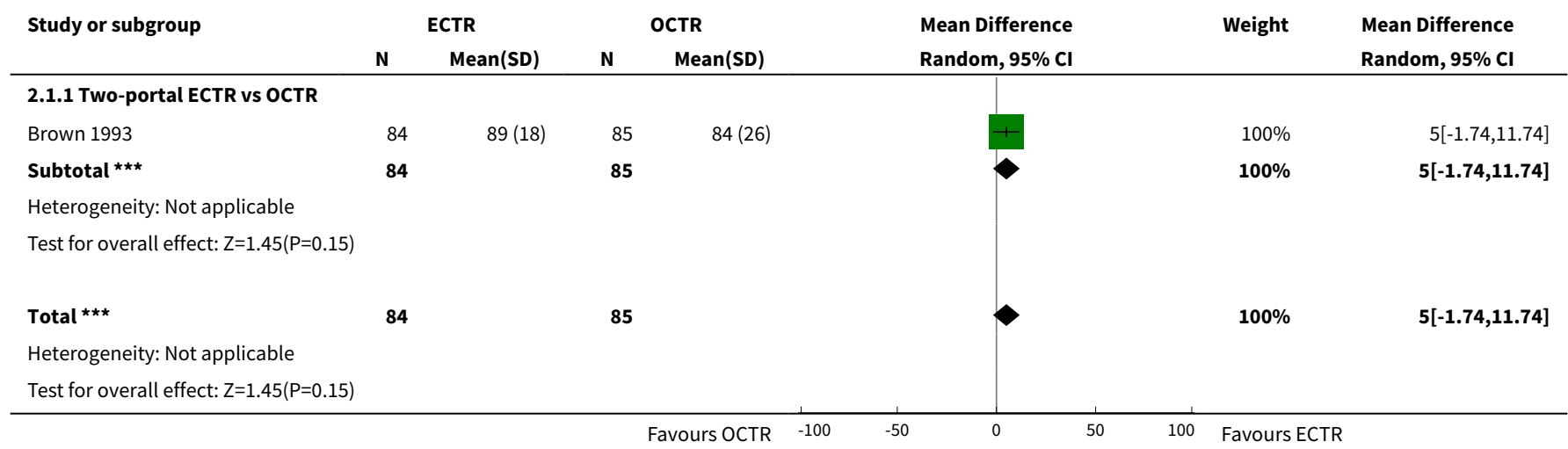

Analysis 2.2. Comparison 2 One- or two-portal endoscopic versus open and miniopen carpal tunnel release, Outcome 2 Overall improvement at 3 months or less.

\begin{tabular}{|c|c|c|c|c|c|}
\hline Study or subgroup & $\begin{array}{c}\text { ECTR } \\
n / N\end{array}$ & $\begin{array}{c}\text { OCTR } \\
\mathrm{n} / \mathrm{N}\end{array}$ & $\begin{array}{c}\text { Odds Ratio } \\
\text { M-H, Random, } 95 \% \mathrm{Cl}\end{array}$ & Weight & $\begin{array}{c}\text { Odds Ratio } \\
\text { M-H, Random, } 95 \% \mathrm{Cl}\end{array}$ \\
\hline \multicolumn{6}{|c|}{ 2.2.1 Two-portal ECTR vs OCTR } \\
\hline Brown 1993 & $58 / 84$ & $53 / 85$ & & $100 \%$ & $1.35[0.71,2.55]$ \\
\hline Subtotal $(95 \% \mathrm{CI})$ & 84 & 85 & & $100 \%$ & $1.35[0.71,2.55]$ \\
\hline \multicolumn{6}{|c|}{ Total events: 58 (ECTR), 53 (OCTR) } \\
\hline \multicolumn{6}{|c|}{ Heterogeneity: Not applicable } \\
\hline \multicolumn{6}{|c|}{ Test for overall effect: $\mathrm{Z}=0.92(\mathrm{P}=0.36)$} \\
\hline Total $(95 \% \mathrm{Cl})$ & 84 & 85 & & $100 \%$ & $1.35[0.71,2.55]$ \\
\hline \multicolumn{6}{|c|}{ Total events: 58 (ECTR), 53 (OCTR) } \\
\hline \multicolumn{6}{|c|}{ Heterogeneity: Not applicable } \\
\hline \multicolumn{6}{|c|}{ Test for overall effect: $Z=0.92(P=0.36)$} \\
\hline
\end{tabular}

Analysis 2.3. Comparison 2 One- or two-portal endoscopic versus open and mini-open carpal tunnel release, Outcome 3 Symptom Severity Scale (Levine) at 3 months or less.

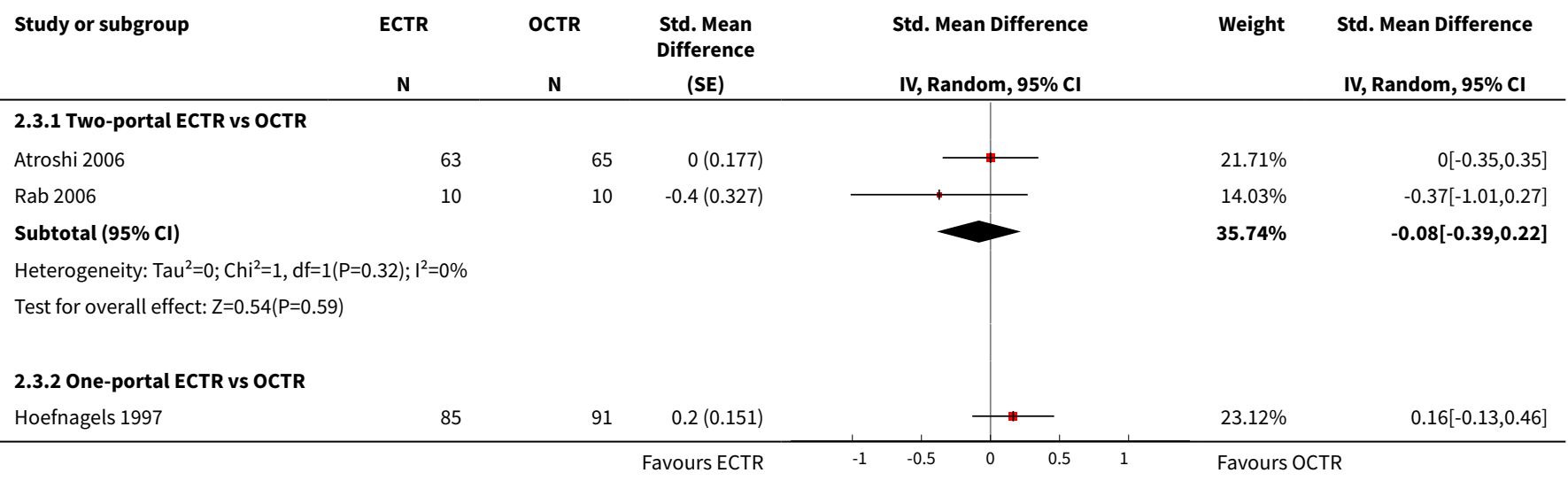




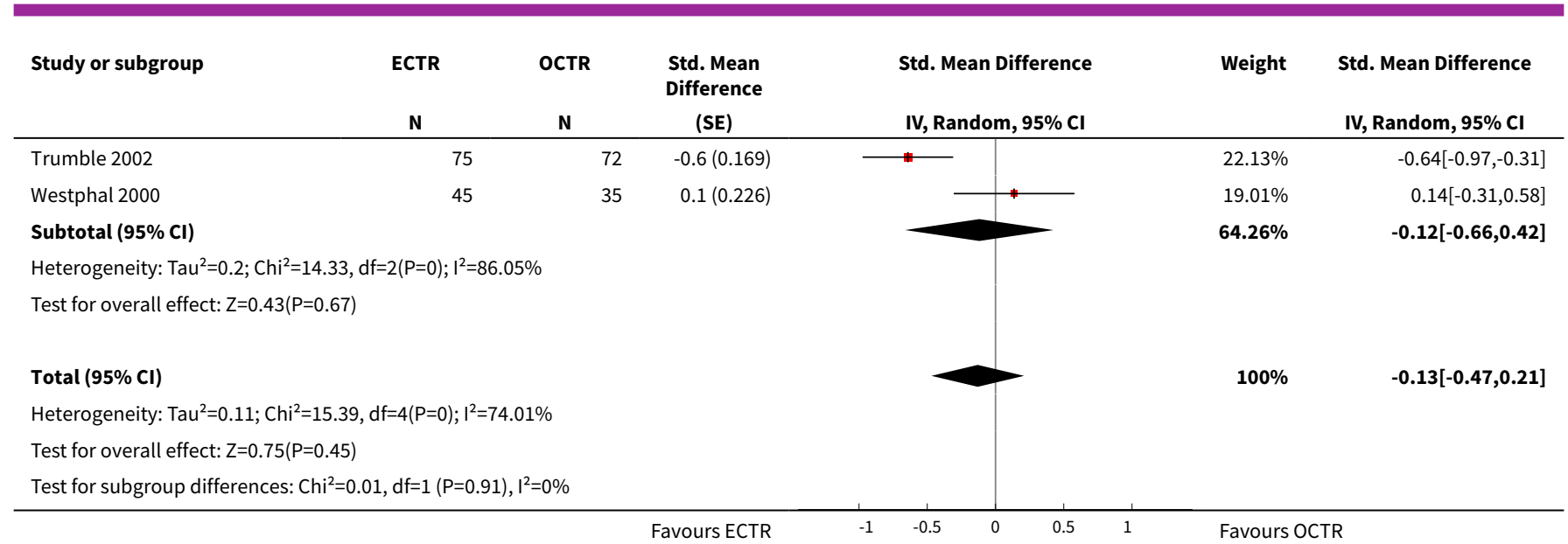

Analysis 2.4. Comparison 2 One- or two-portal endoscopic versus open and miniopen carpal tunnel release, Outcome 4 Function Status Scale at 3 months or less.

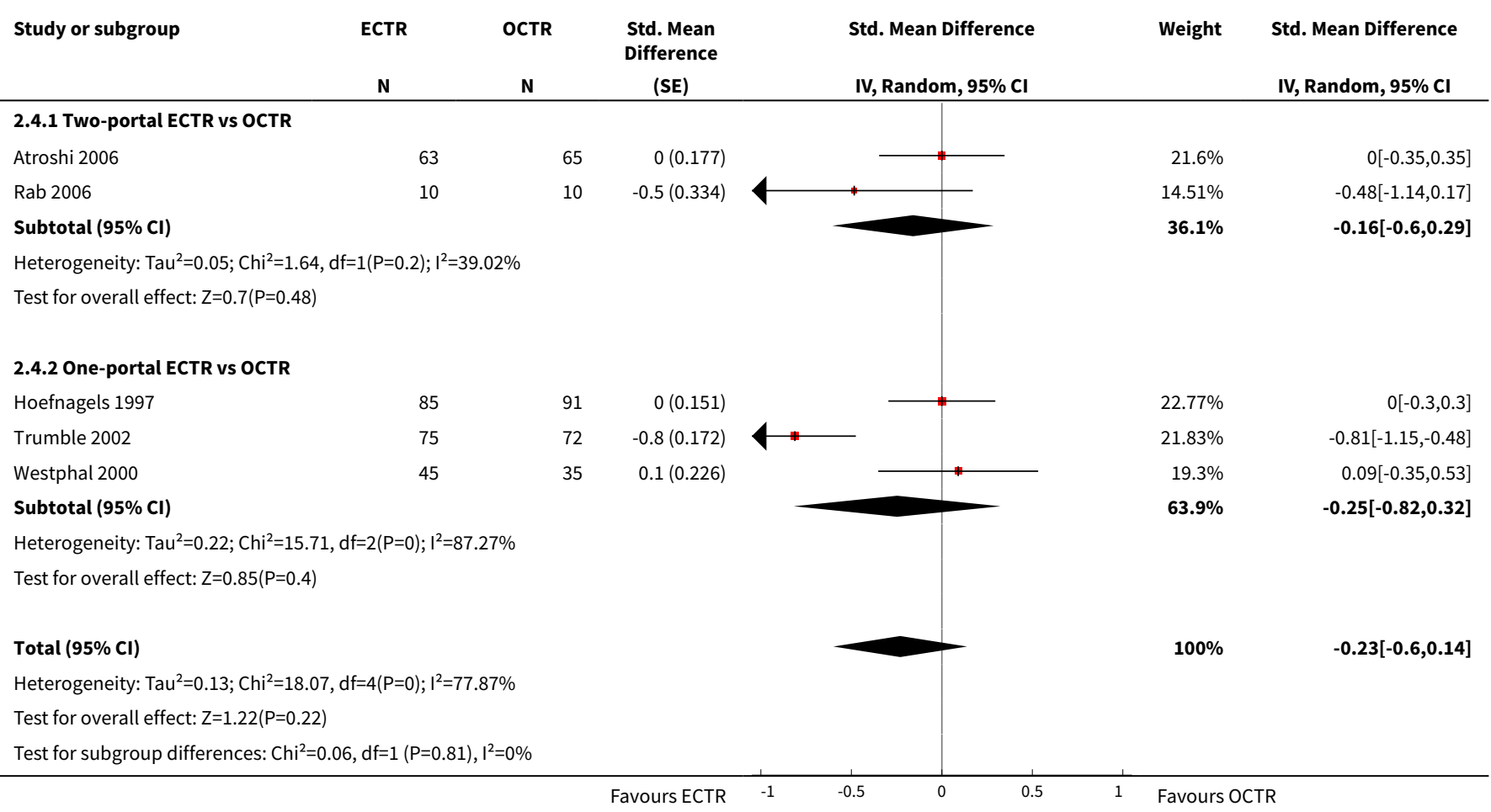

Analysis 2.5. Comparison 2 One- or two-portal endoscopic versus open and miniopen carpal tunnel release, Outcome 5 Pain at 3 months or less (corr $=0.5$ ).

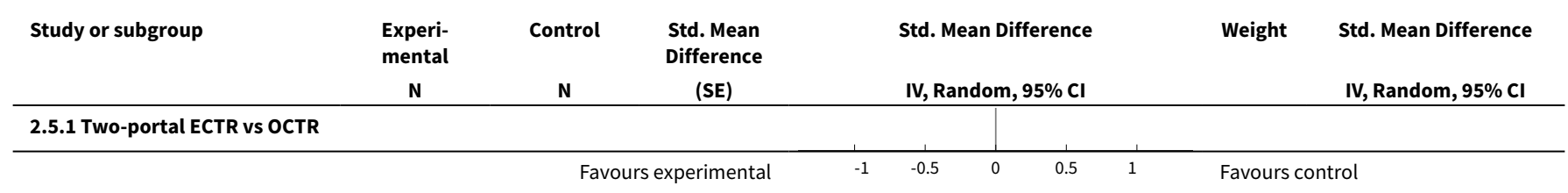




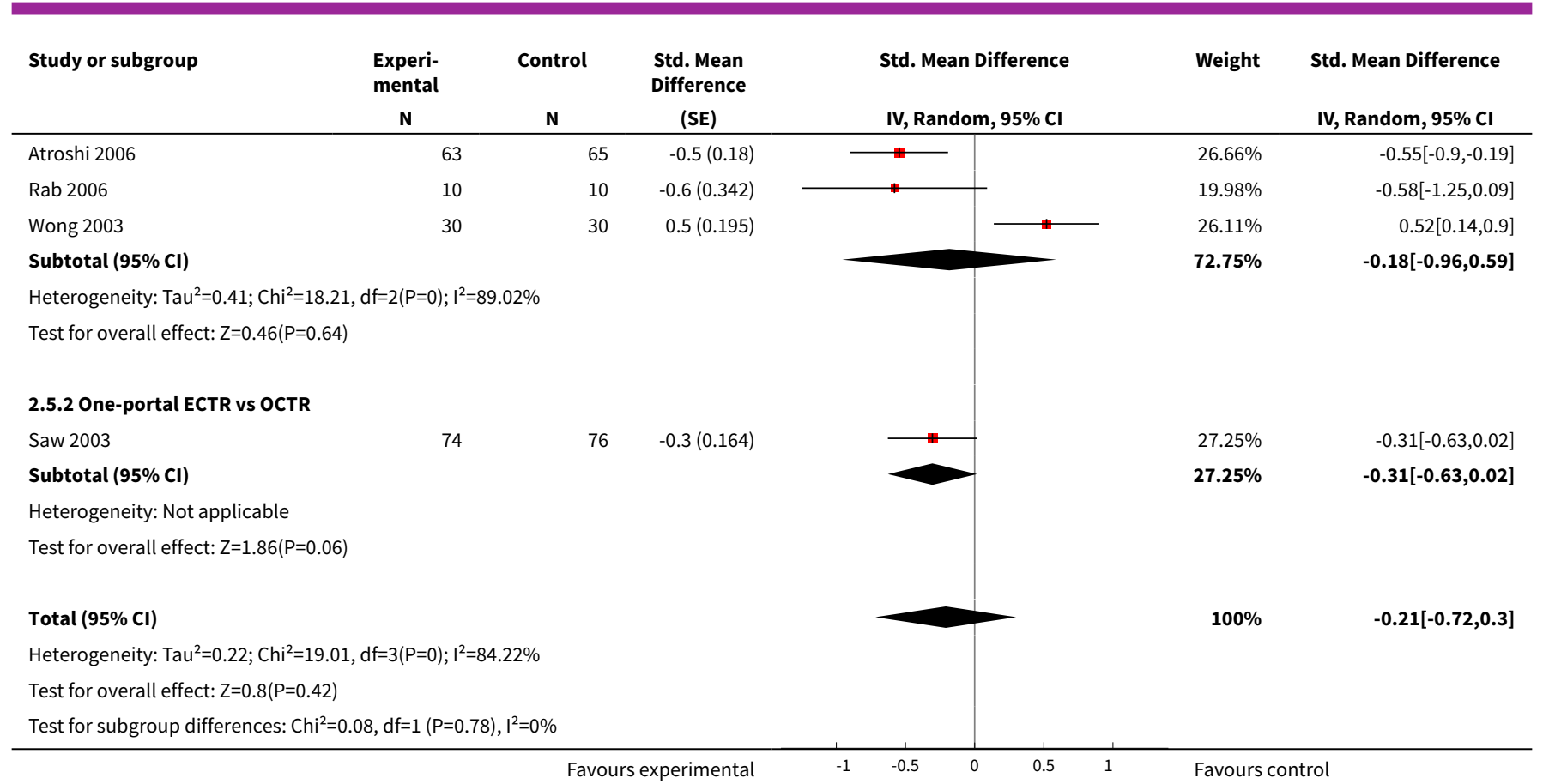

\section{Analysis 2.6. Comparison 2 One- or two-portal endoscopic versus open and mini-} open carpal tunnel release, Outcome 6 Pain at 3 months or less (corr $=\mathbf{0 . 1}$ ).

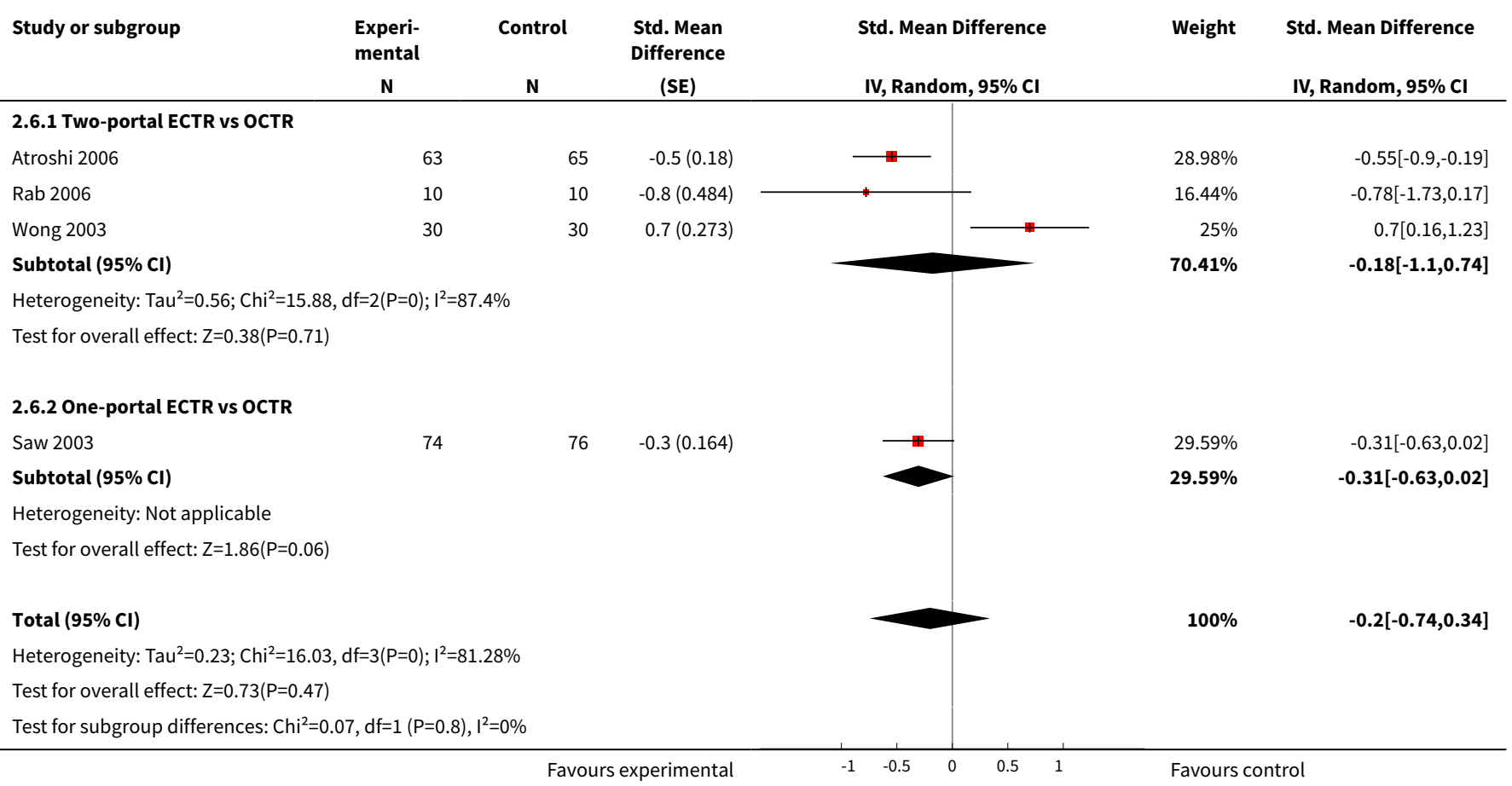


Analysis 2.7. Comparison 2 One- or two-portal endoscopic versus open and miniopen carpal tunnel release, Outcome 7 Pain at 3 months or less (corr $=0.9$ ).

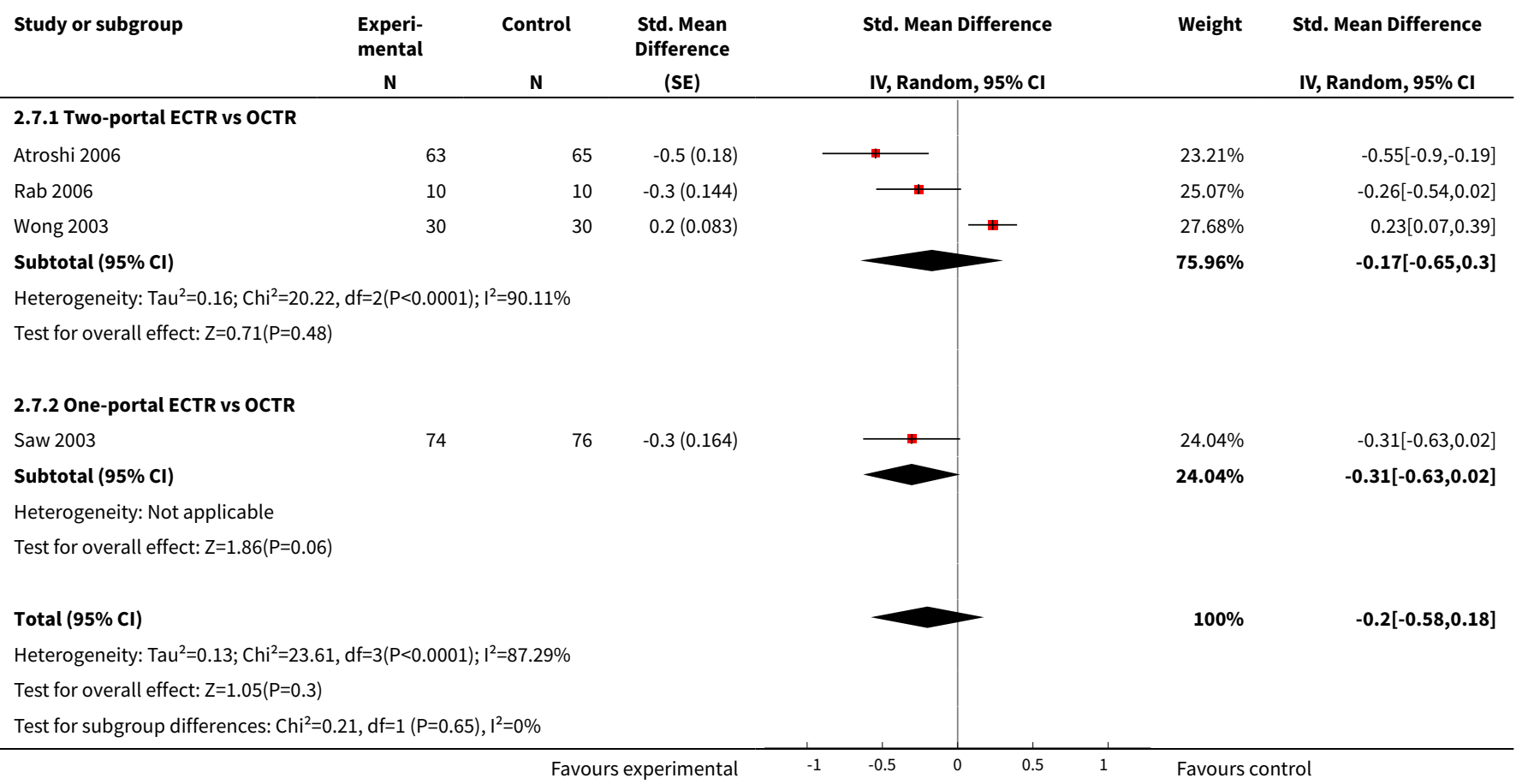

Analysis 2.8. Comparison 2 One- or two-portal endoscopic versus open and miniopen carpal tunnel release, Outcome 8 Pain (dichotomous) at 3 months or less.

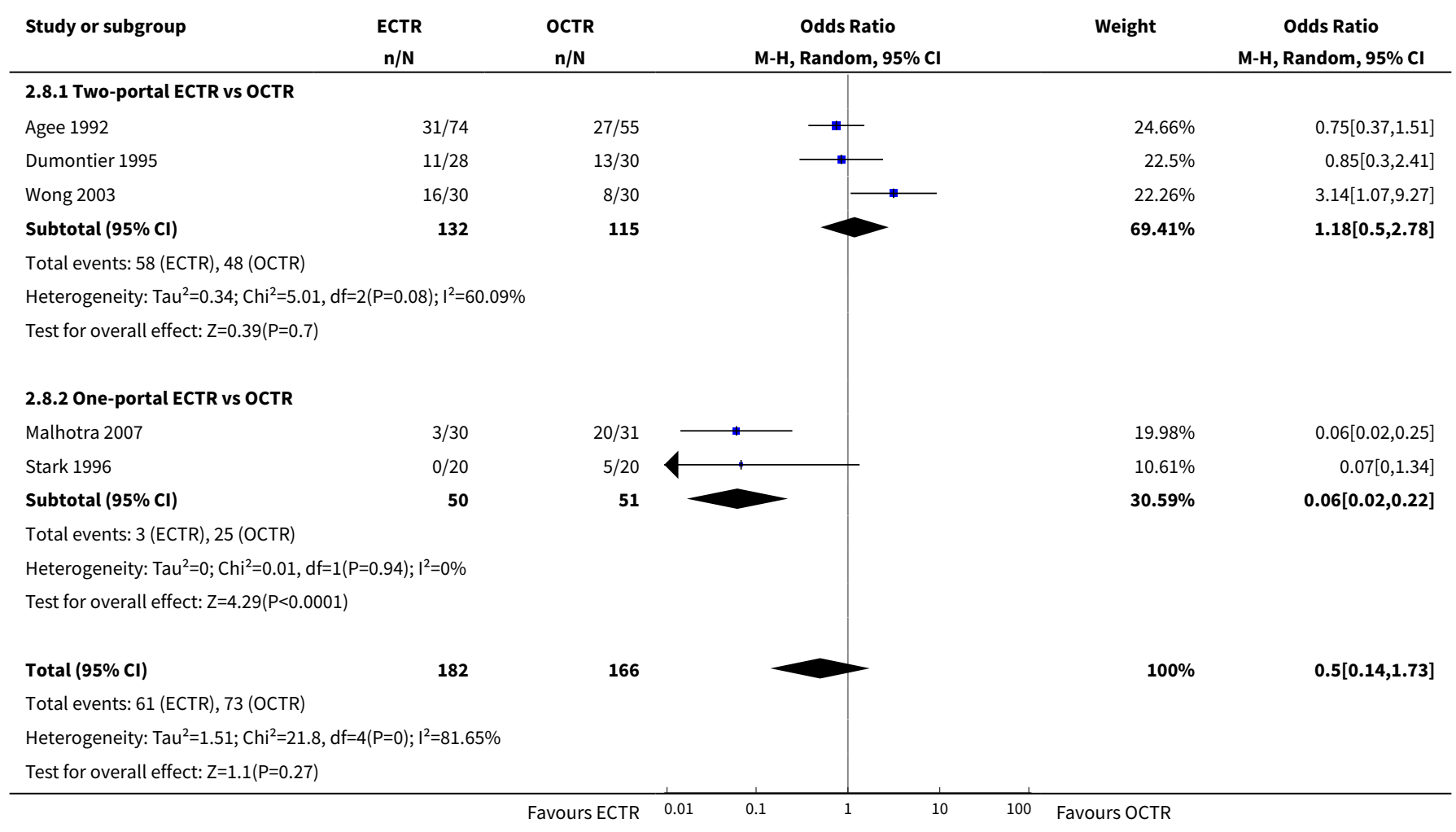




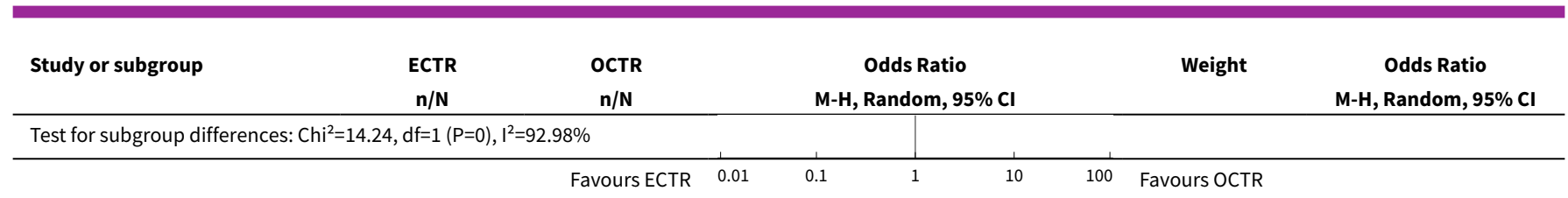

Analysis 2.9. Comparison 2 One- or two-portal endoscopic versus open and miniopen carpal tunnel release, Outcome 9 Numbness (dichotomous) at 3 months or less.

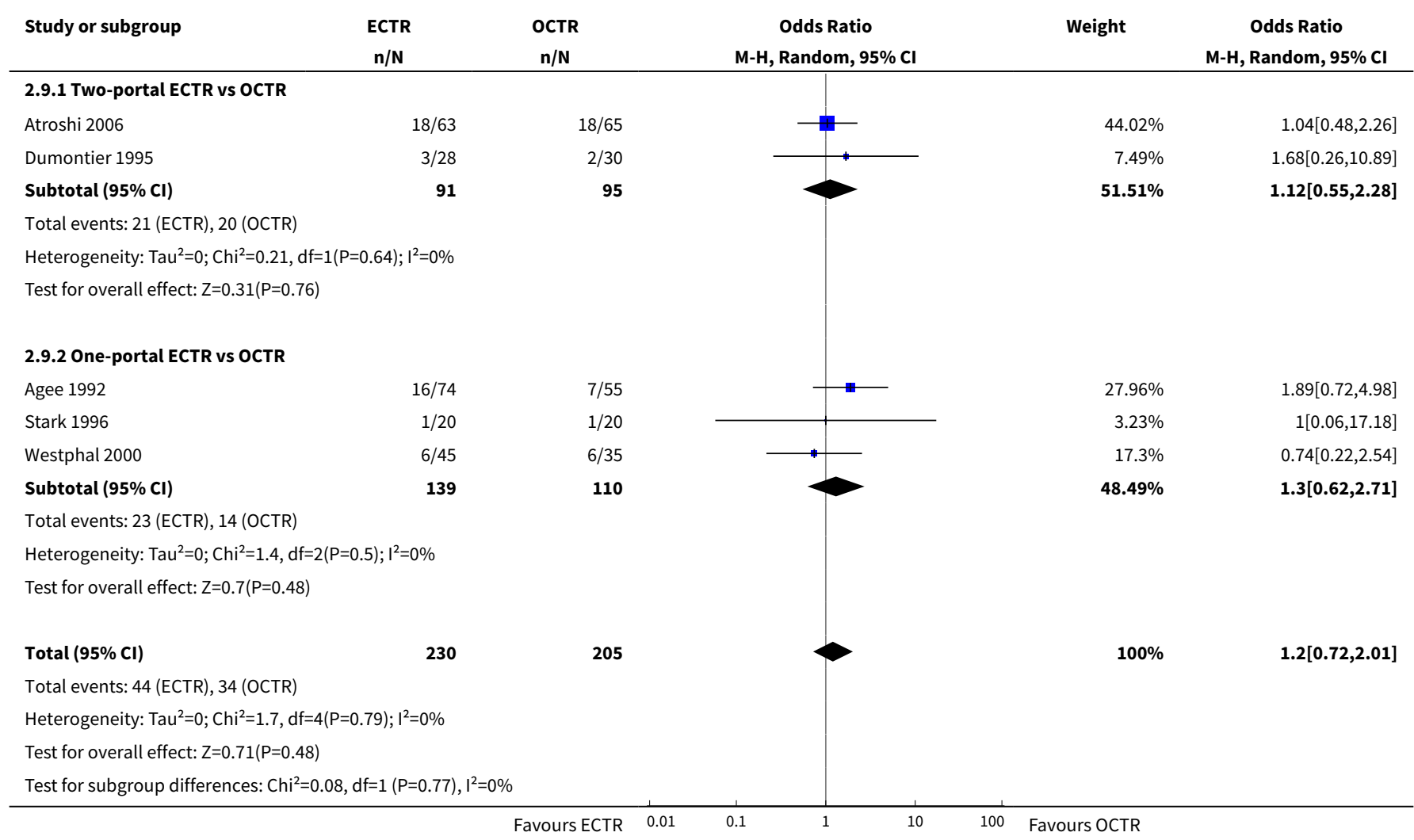

Analysis 2.10. Comparison 2 One- or two-portal endoscopic versus open and mini-open carpal tunnel release, Outcome 10 Grip strength at 3 months or less.

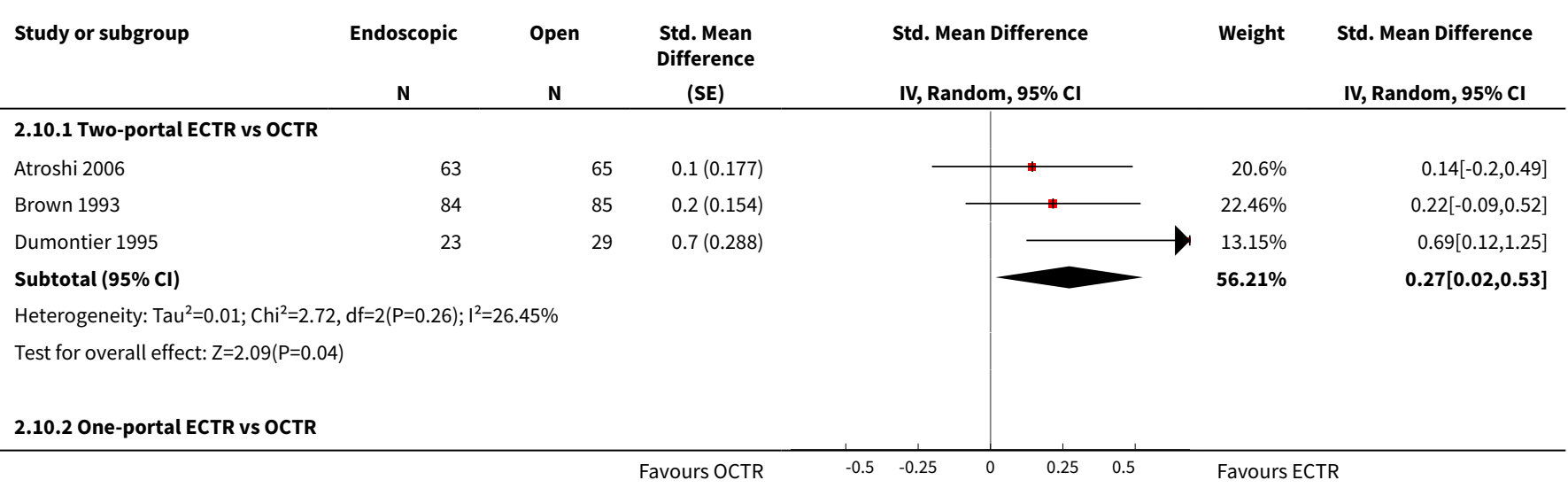




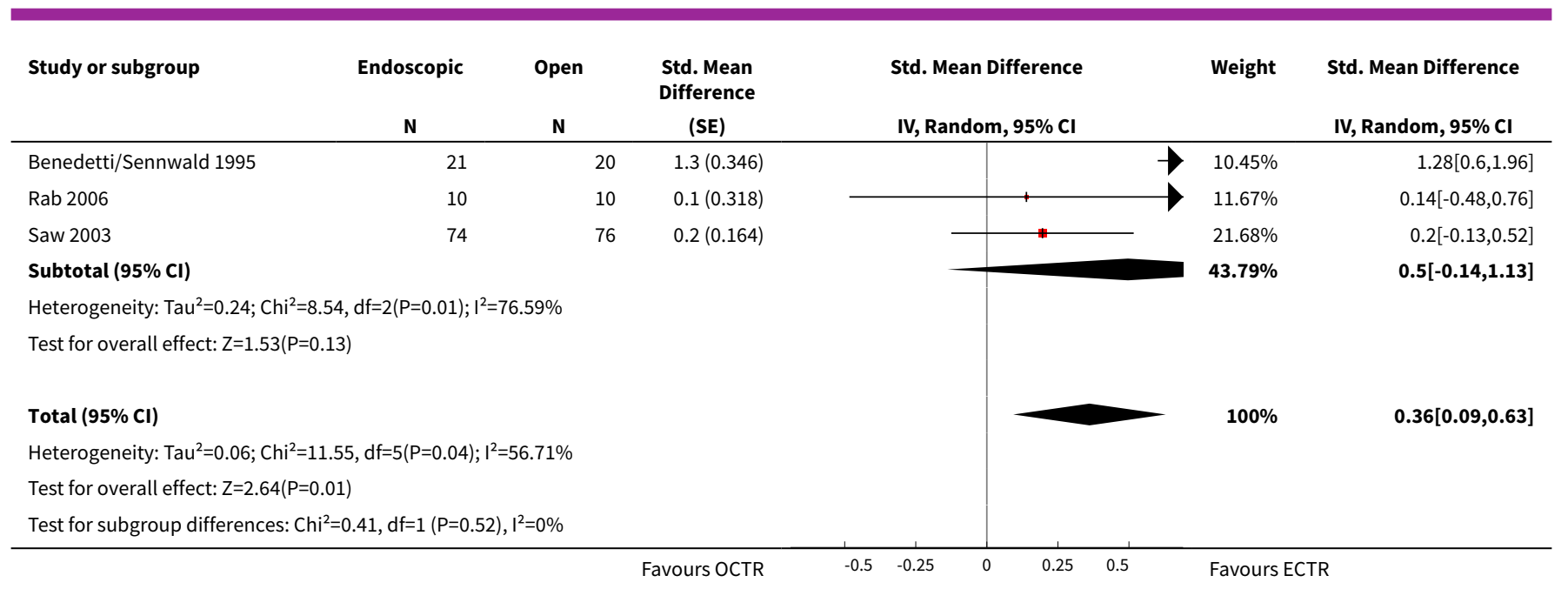

Analysis 2.11. Comparison 2 One- or two-portal endoscopic versus open and miniopen carpal tunnel release, Outcome 11 Overall satisfaction at more than 3 months.

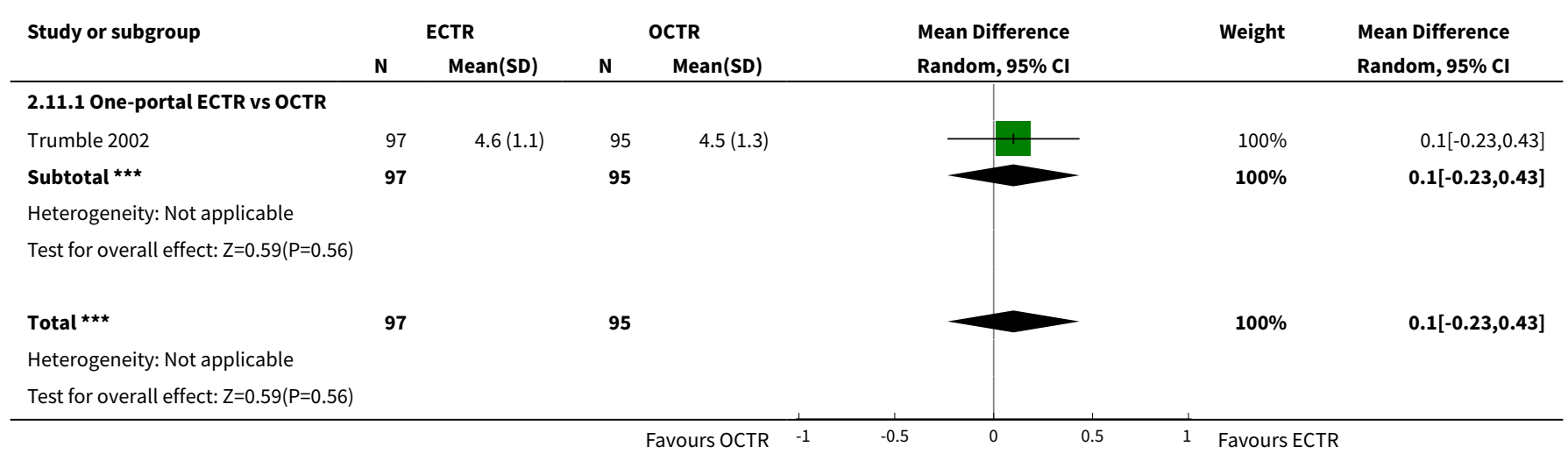

Analysis 2.12. Comparison 2 One- or two-portal endoscopic versus open and miniopen carpal tunnel release, Outcome 12 Overall improvement at more than 3 months.

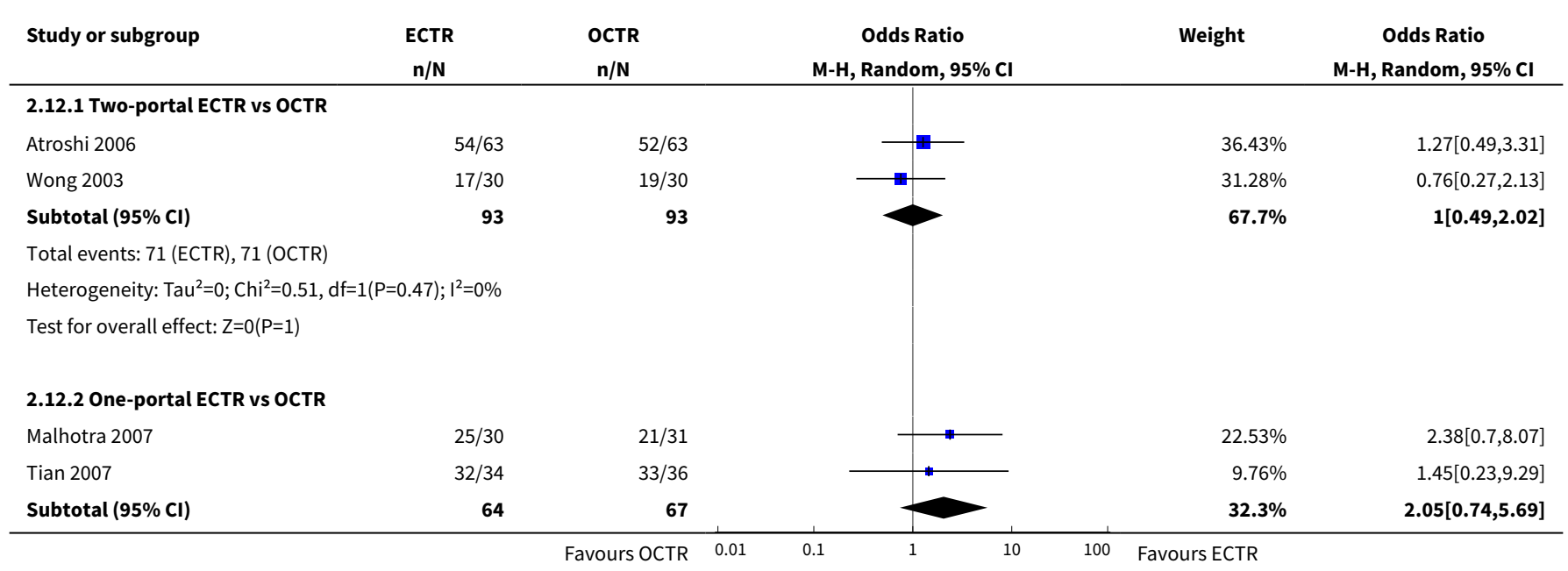




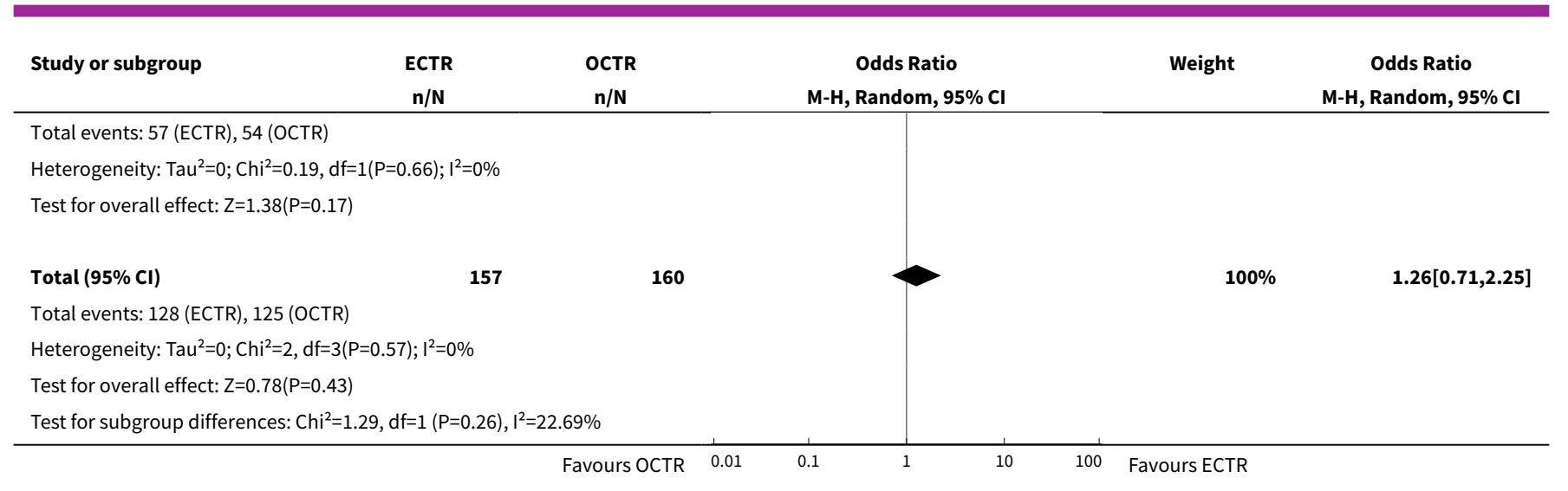

Analysis 2.13. Comparison 2 One- or two-portal endoscopic versus open and mini-open carpal tunnel release, Outcome 13 Symptom Severity Scale (Levine) at more than 3 months.

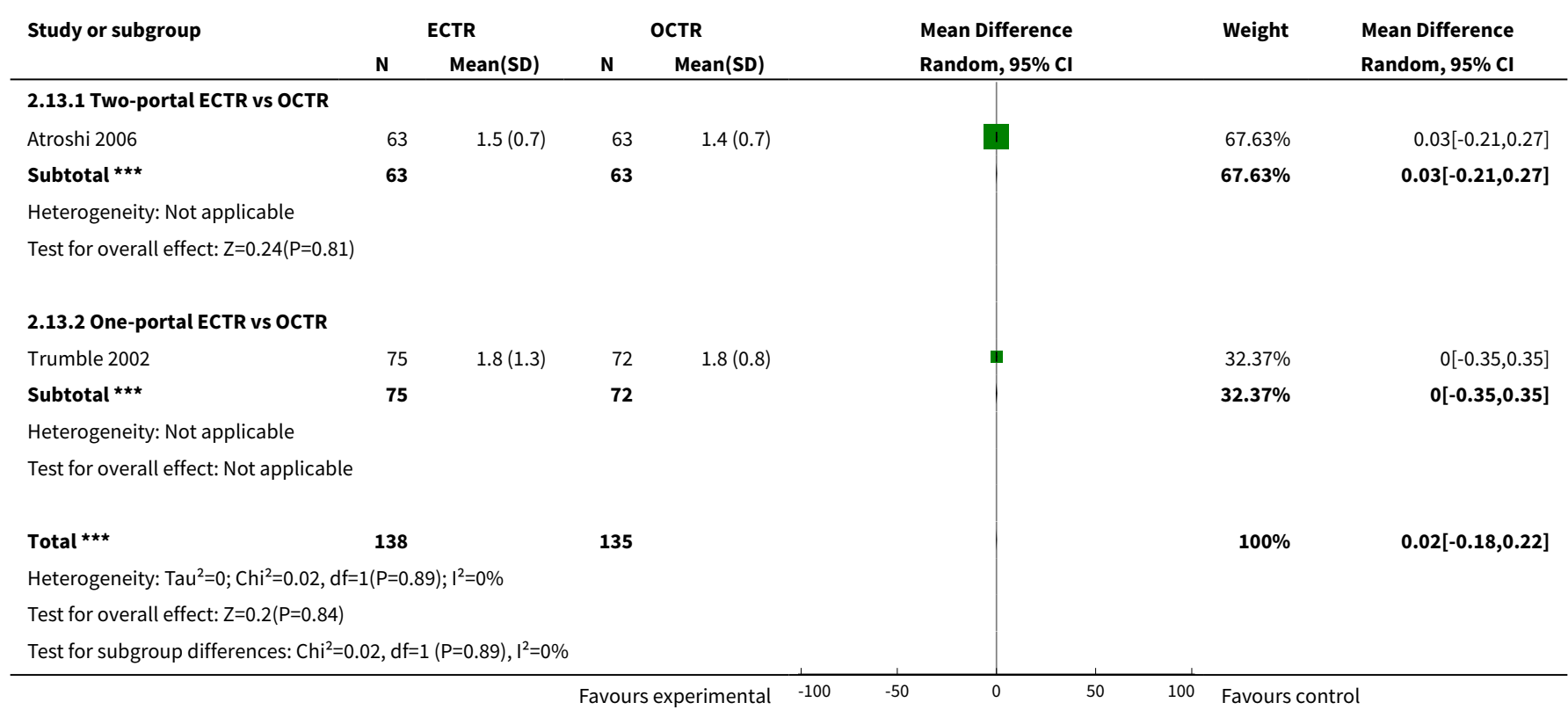

Analysis 2.14. Comparison 2 One- or two-portal endoscopic versus open and miniopen carpal tunnel release, Outcome 14 Function Status Scale at more than 3 months.

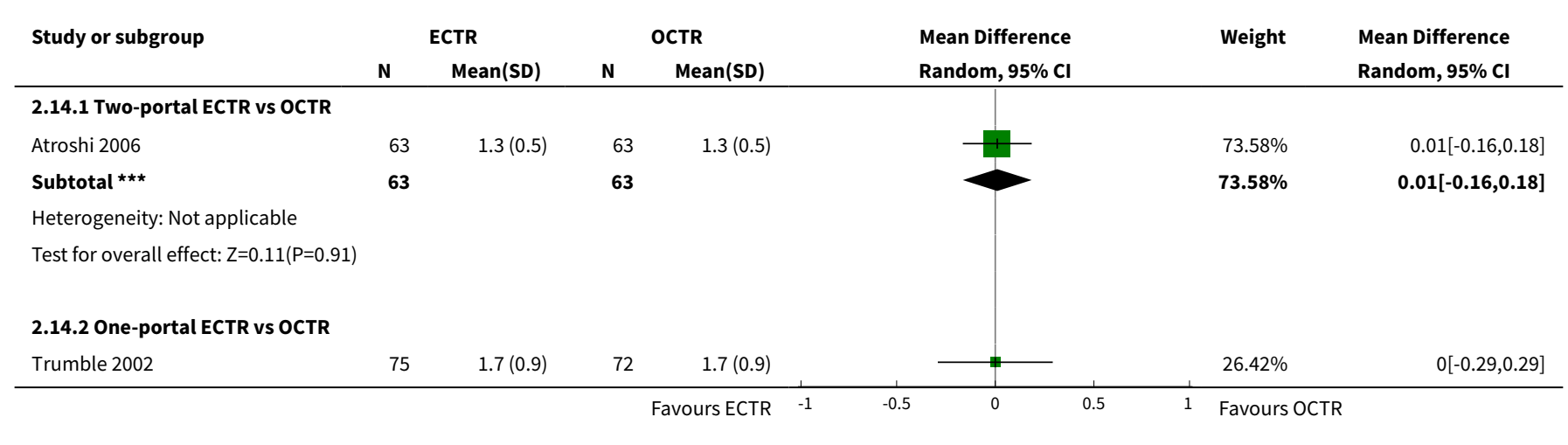




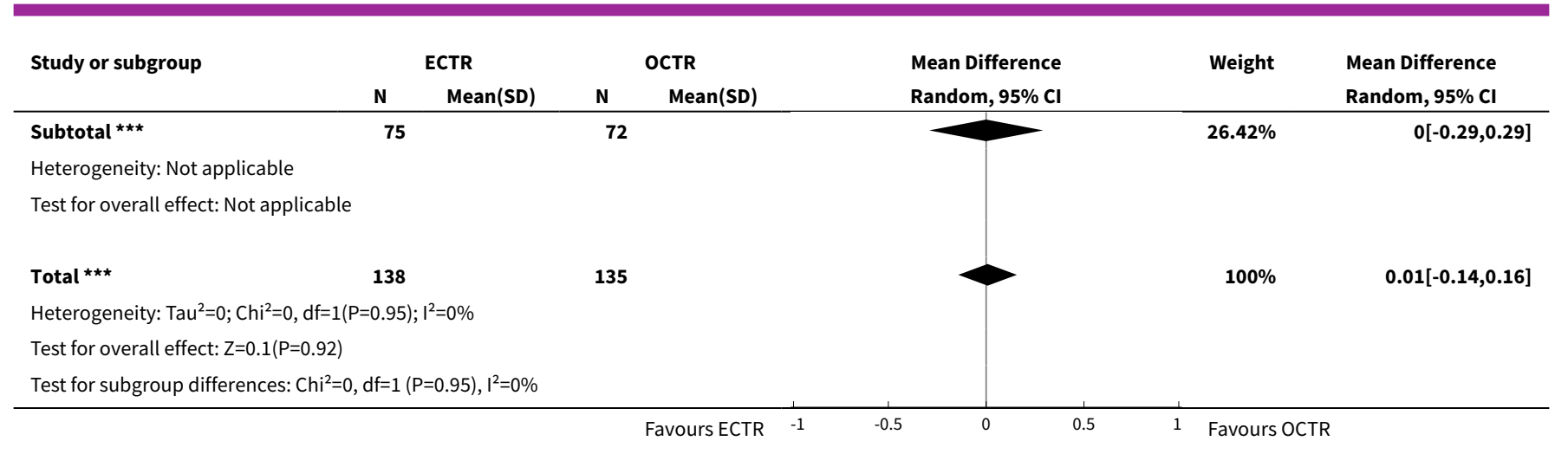

Analysis 2.15. Comparison 2 One- or two-portal endoscopic versus open and mini-open carpal tunnel release, Outcome 15 Pain at more than 3 months.

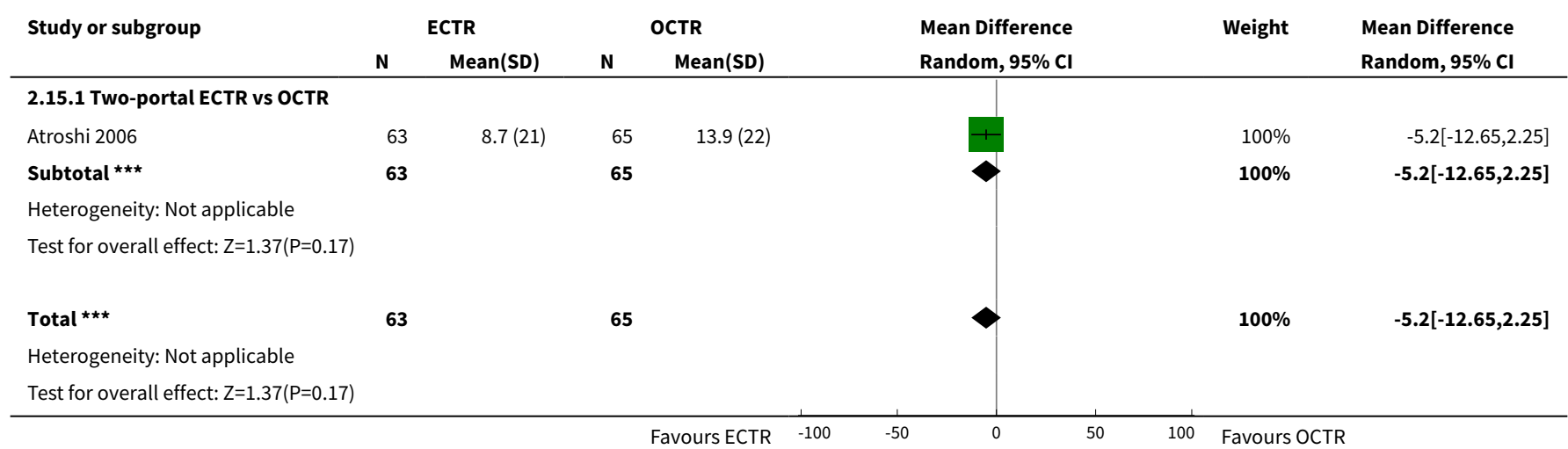

Analysis 2.16. Comparison 2 One- or two-portal endoscopic versus open and miniopen carpal tunnel release, Outcome 16 Pain (dichotomous) at more than 3 months.

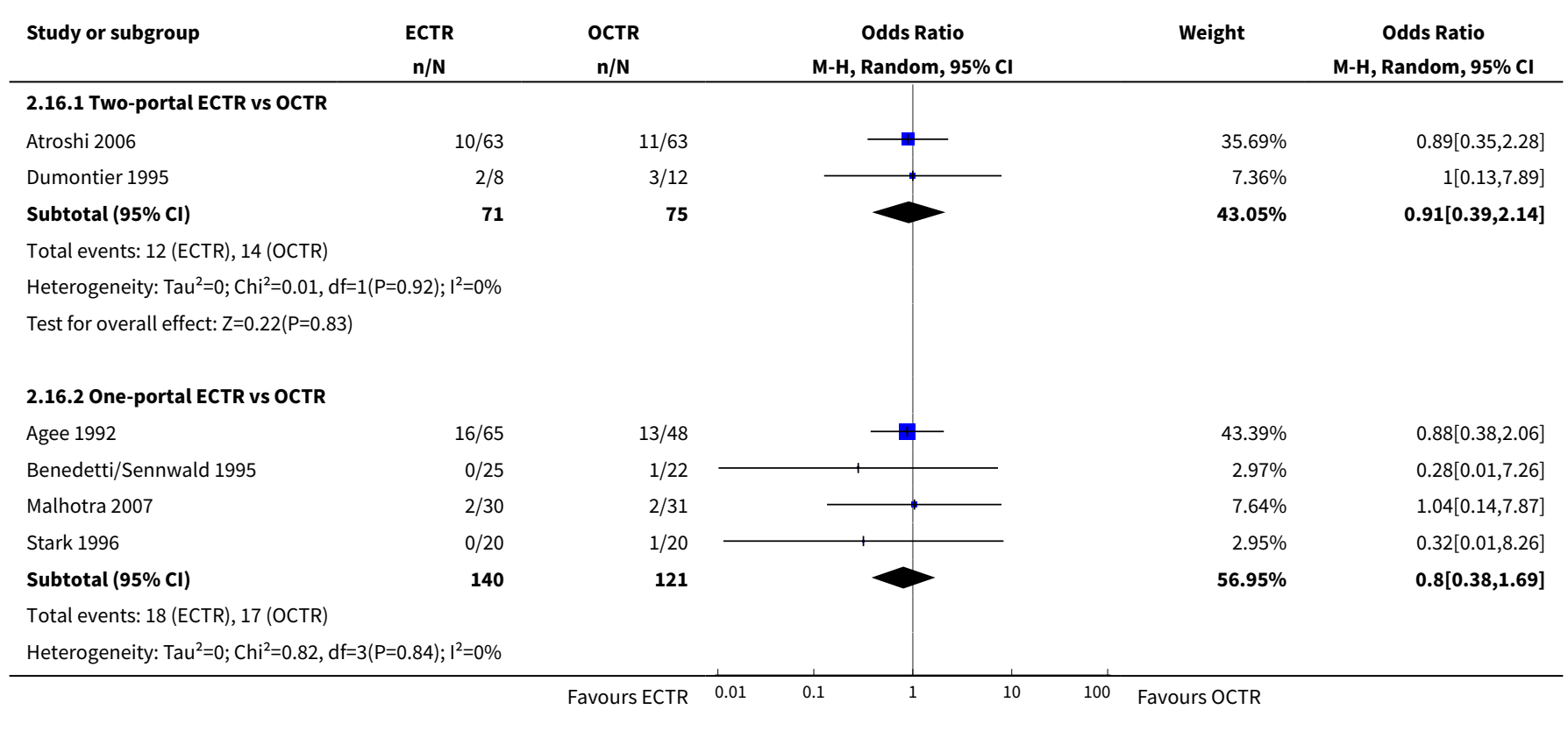




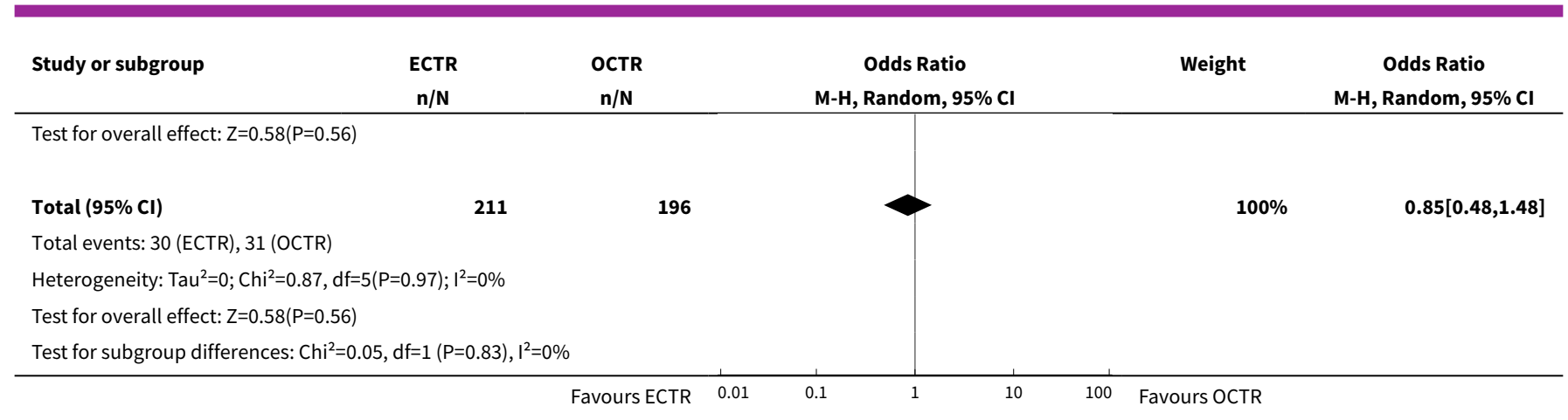

Analysis 2.17. Comparison 2 One- or two-portal endoscopic versus open and mini-open carpal tunnel release, Outcome 17 Numbness at more than 3 months.

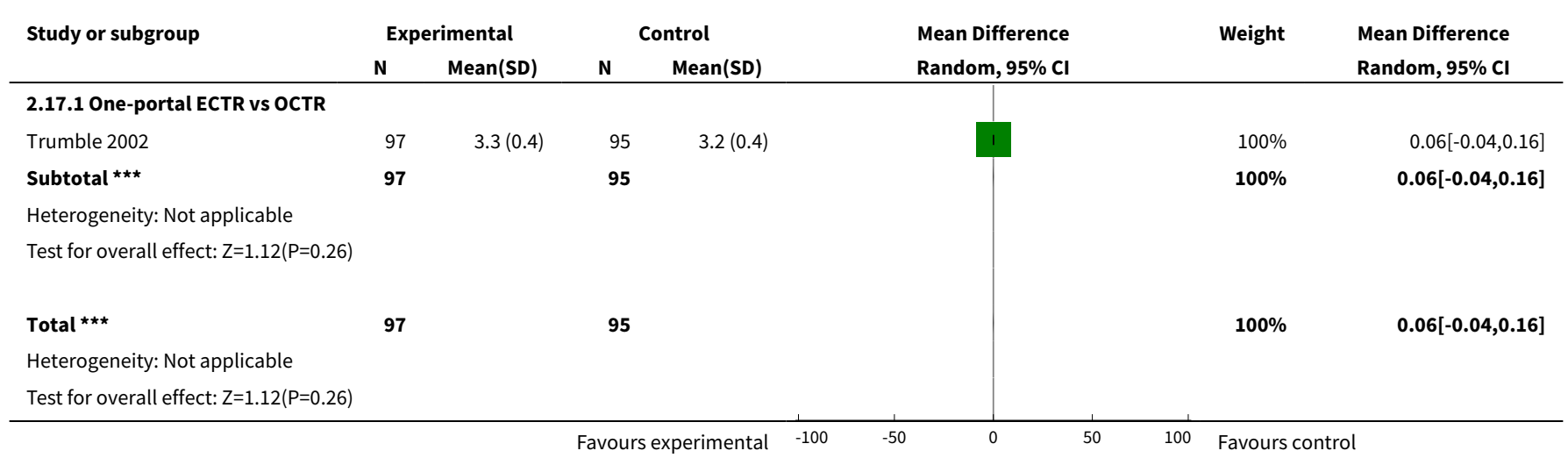

\section{Analysis 2.18. Comparison 2 One- or two-portal endoscopic versus open and mini-open carpal tunnel release, Outcome 18 Numbness (dichotomous) at more than 3 months.}

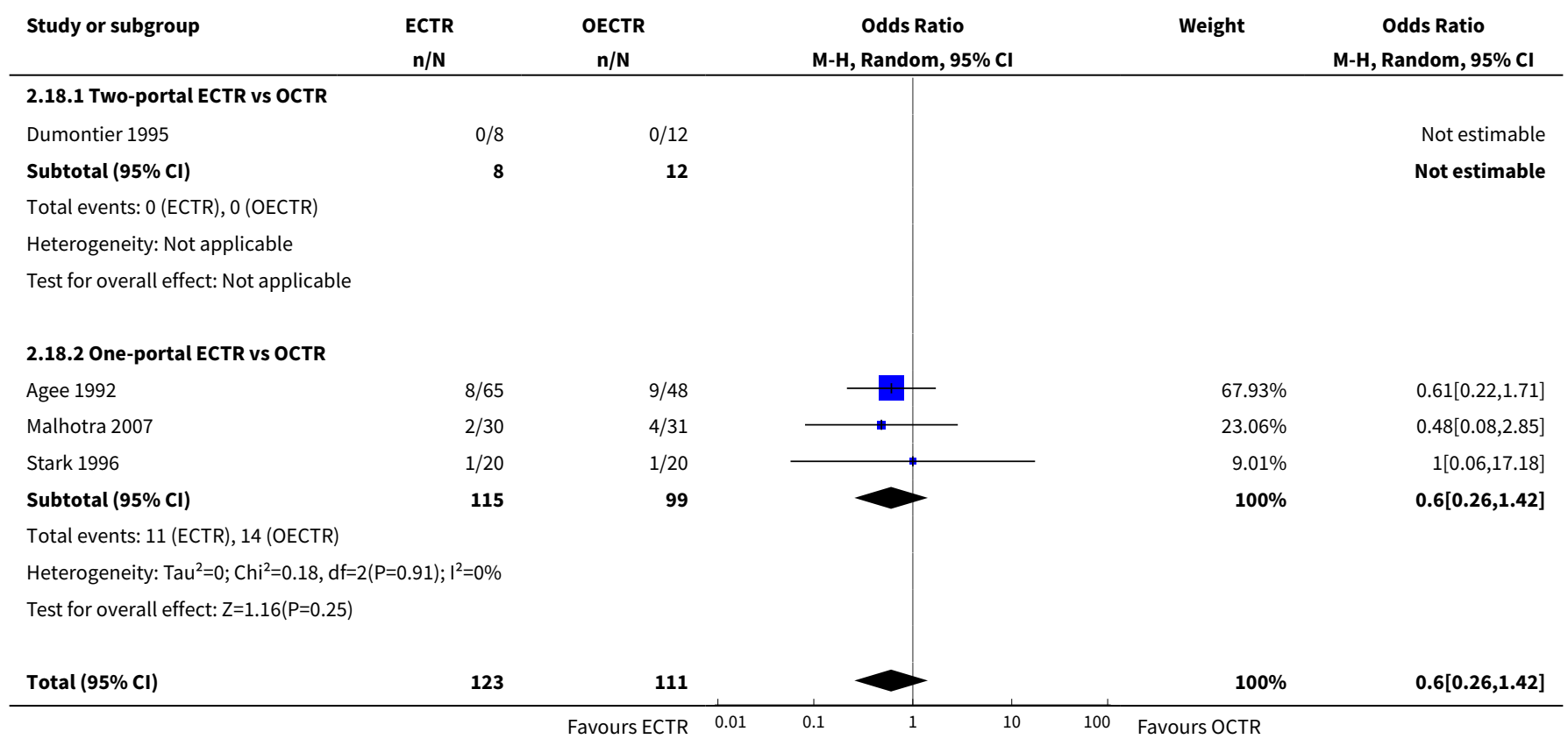




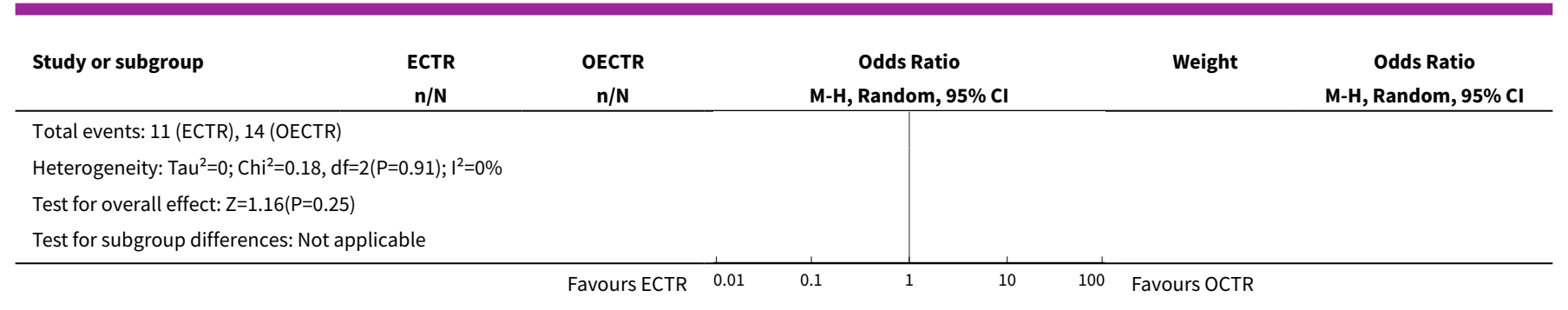

Analysis 2.19. Comparison 2 One- or two-portal endoscopic versus open and miniopen carpal tunnel release, Outcome 19 Grip strength at more than 3 months.

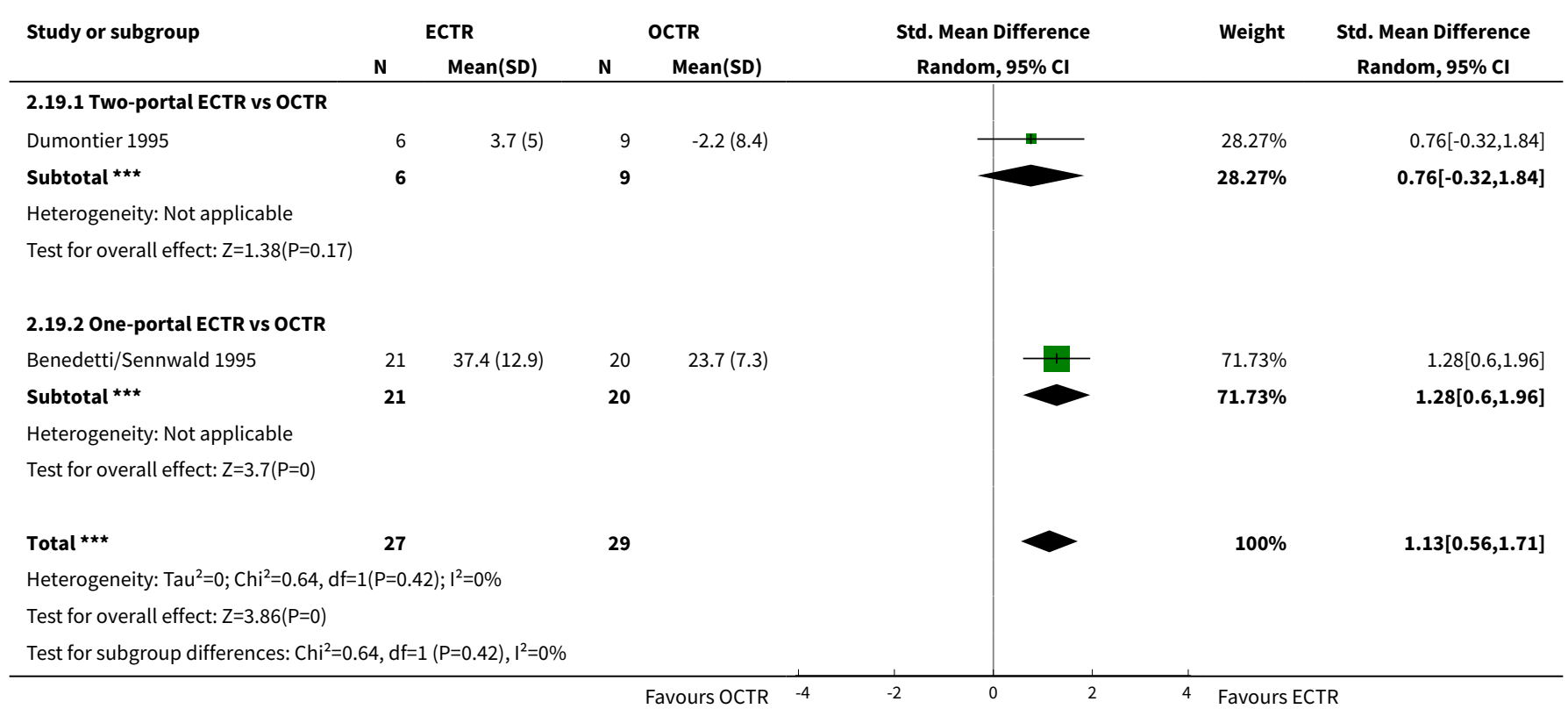

Analysis 2.20. Comparison 2 One- or two-portal endoscopic versus open and mini-open carpal tunnel release, Outcome 20 Time to return to work.

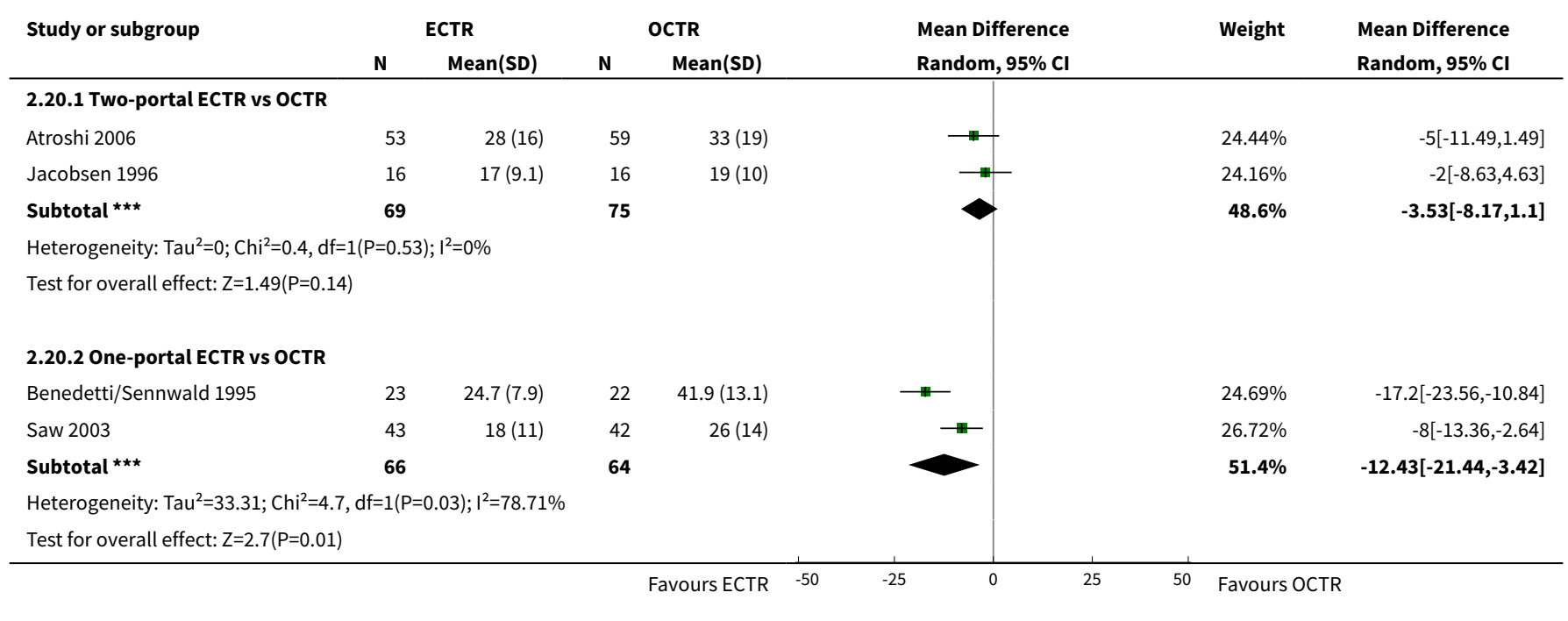




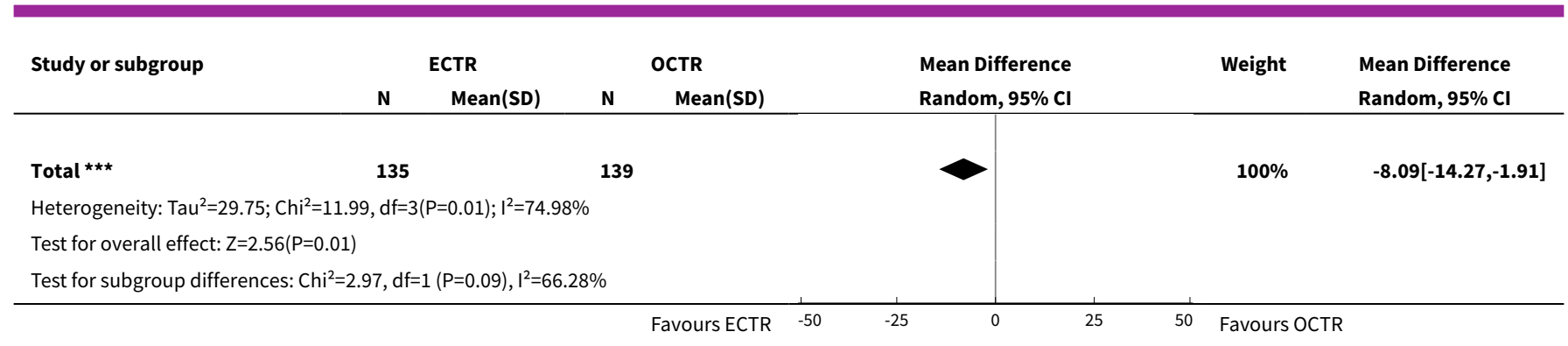

Analysis 2.21. Comparison 2 One- or two-portal endoscopic versus open and mini-open carpal tunnel release, Outcome 21 Recurrence.

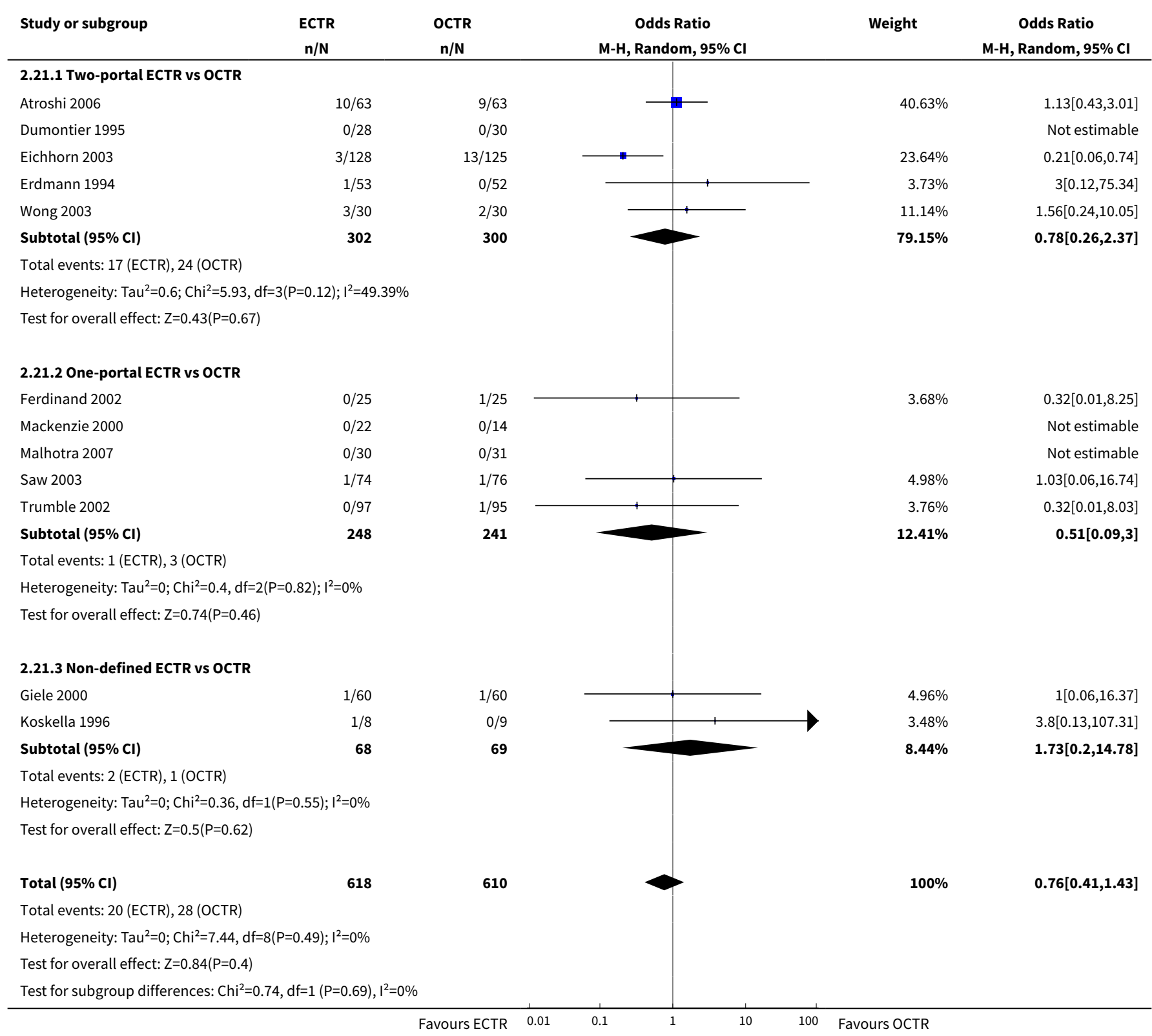


Analysis 2.22. Comparison 2 One- or two-portal endoscopic versus open and mini-open carpal tunnel release, Outcome 22 Reoperations.

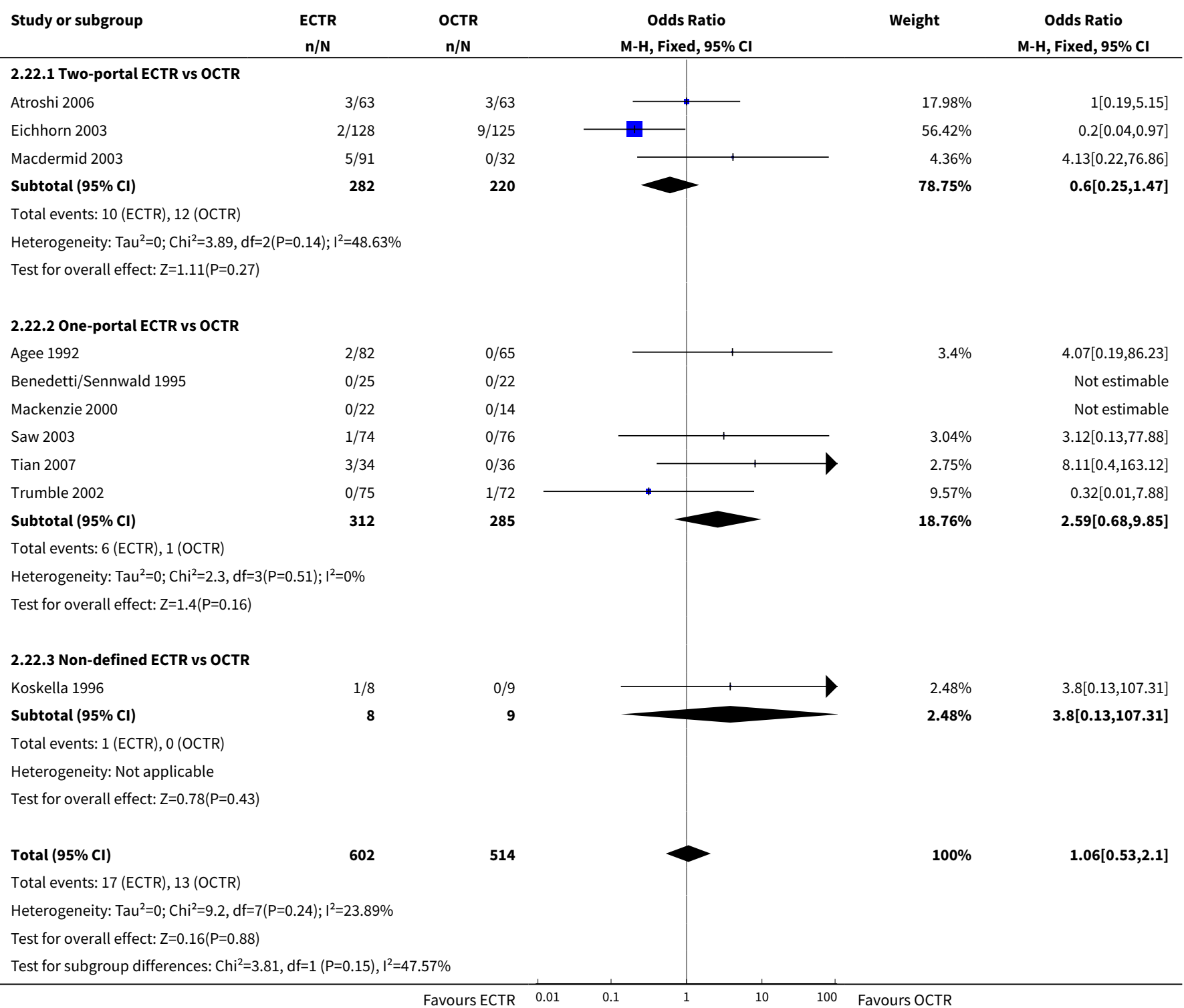

Analysis 2.23. Comparison 2 One- or two-portal endoscopic versus open and mini-open carpal tunnel release, Outcome 23 Major complications.

\begin{tabular}{|c|c|c|c|c|c|}
\hline Study or subgroup & $\begin{array}{c}\text { ECTR } \\
n / N\end{array}$ & $\begin{array}{c}\text { OCTR } \\
n / N\end{array}$ & $\begin{array}{c}\text { Odds Ratio } \\
\text { M-H, Random, } 95 \% \mathrm{Cl}\end{array}$ & Weight & $\begin{array}{c}\text { Odds Ratio } \\
\text { M-H, Random, } 95 \% \mathrm{Cl}\end{array}$ \\
\hline \multicolumn{6}{|c|}{ 2.23.1 Two-portal ECTR vs OCTR } \\
\hline Atroshi 2006 & $5 / 63$ & $8 / 63$ & 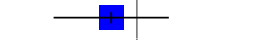 & $58.62 \%$ & $0.59[0.18,1.92]$ \\
\hline Brown 1993 & $0 / 84$ & $0 / 85$ & & & Not estimable \\
\hline Jacobsen 1996 & $0 / 16$ & $0 / 16$ & & & Not estimable \\
\hline Macdermid 2003 & $0 / 91$ & $0 / 32$ & & & Not estimable \\
\hline
\end{tabular}




\begin{tabular}{|c|c|c|c|c|c|}
\hline Study or subgroup & $\begin{array}{c}\text { ECTR } \\
n / N\end{array}$ & $\begin{array}{c}\text { OCTR } \\
\mathrm{n} / \mathrm{N}\end{array}$ & $\begin{array}{c}\text { Odds Ratio } \\
\text { M-H, Random, } 95 \% \mathrm{Cl}\end{array}$ & Weight & $\begin{array}{c}\text { Odds Ratio } \\
\text { M-H, Random, } 95 \% \mathrm{Cl}\end{array}$ \\
\hline Wong 2003 & $0 / 30$ & $0 / 30$ & & & Not estimable \\
\hline Subtotal $(95 \% \mathrm{Cl})$ & 294 & 236 & & $58.62 \%$ & $0.59[0.18,1.92]$ \\
\hline \multicolumn{6}{|c|}{ Total events: 5 (ECTR), 8 (OCTR) } \\
\hline \multicolumn{6}{|c|}{ Heterogeneity: Not applicable } \\
\hline \multicolumn{6}{|c|}{ Test for overall effect: $Z=0.87(P=0.38)$} \\
\hline \multicolumn{6}{|c|}{ 2.23.2 One-portal ECTR vs OCTR } \\
\hline Agee 1992 & $0 / 82$ & $1 / 65$ & & $7.84 \%$ & $0.26[0.01,6.5]$ \\
\hline Benedetti/Sennwald 1995 & $1 / 23$ & $1 / 22$ & & $10.09 \%$ & $0.95[0.06,16.27]$ \\
\hline Foucher 1993 & $1 / 99$ & $0 / 77$ & $\longrightarrow$ & $7.85 \%$ & $2.36[0.09,58.75]$ \\
\hline Mackenzie 2000 & $0 / 22$ & $0 / 14$ & & & Not estimable \\
\hline Malhotra 2007 & $0 / 30$ & $1 / 31$ & & $7.73 \%$ & $0.33[0.01,8.51]$ \\
\hline Saw 2003 & $0 / 74$ & $0 / 76$ & & & Not estimable \\
\hline Schäfer 1996 & $0 / 47$ & $0 / 54$ & & & Not estimable \\
\hline Tian 2007 & $0 / 34$ & $0 / 36$ & & & Not estimable \\
\hline Trumble 2002 & $0 / 97$ & $1 / 95$ & & $7.86 \%$ & $0.32[0.01,8.03]$ \\
\hline Subtotal $(95 \% \mathrm{Cl})$ & 508 & 470 & & $41.38 \%$ & $0.59[0.15,2.4]$ \\
\hline \multicolumn{6}{|c|}{ Total events: 2 (ECTR), 4 (OCTR) } \\
\hline \multicolumn{6}{|c|}{ Heterogeneity: $\mathrm{Tau}^{2}=0 ; \mathrm{Chi}^{2}=1.33, \mathrm{df}=4(\mathrm{P}=0.86) ; \mathrm{I}^{2}=0 \%$} \\
\hline \multicolumn{6}{|c|}{ Test for overall effect: $Z=0.73(P=0.46)$} \\
\hline Total $(95 \% \mathrm{Cl})$ & 802 & 706 & & $100 \%$ & $0.59[0.24,1.46]$ \\
\hline \multicolumn{6}{|c|}{ Total events: 7 (ECTR), 12 (OCTR) } \\
\hline \multicolumn{6}{|c|}{ Heterogeneity: $\mathrm{Tau}^{2}=0 ; \mathrm{Chi}^{2}=1.33, \mathrm{df}=5(\mathrm{P}=0.93) ; \mathrm{I}^{2}=0 \%$} \\
\hline \multicolumn{6}{|c|}{ Test for overall effect: $\mathrm{Z}=1.14(\mathrm{P}=0.26)$} \\
\hline Test for subgroup differenc & $L(P=1), I^{2}=0 \%$ & & & & \\
\hline
\end{tabular}

Analysis 2.24. Comparison 2 One- or two-portal endoscopic versus open and mini-open carpal tunnel release, Outcome 24 Minor complications.

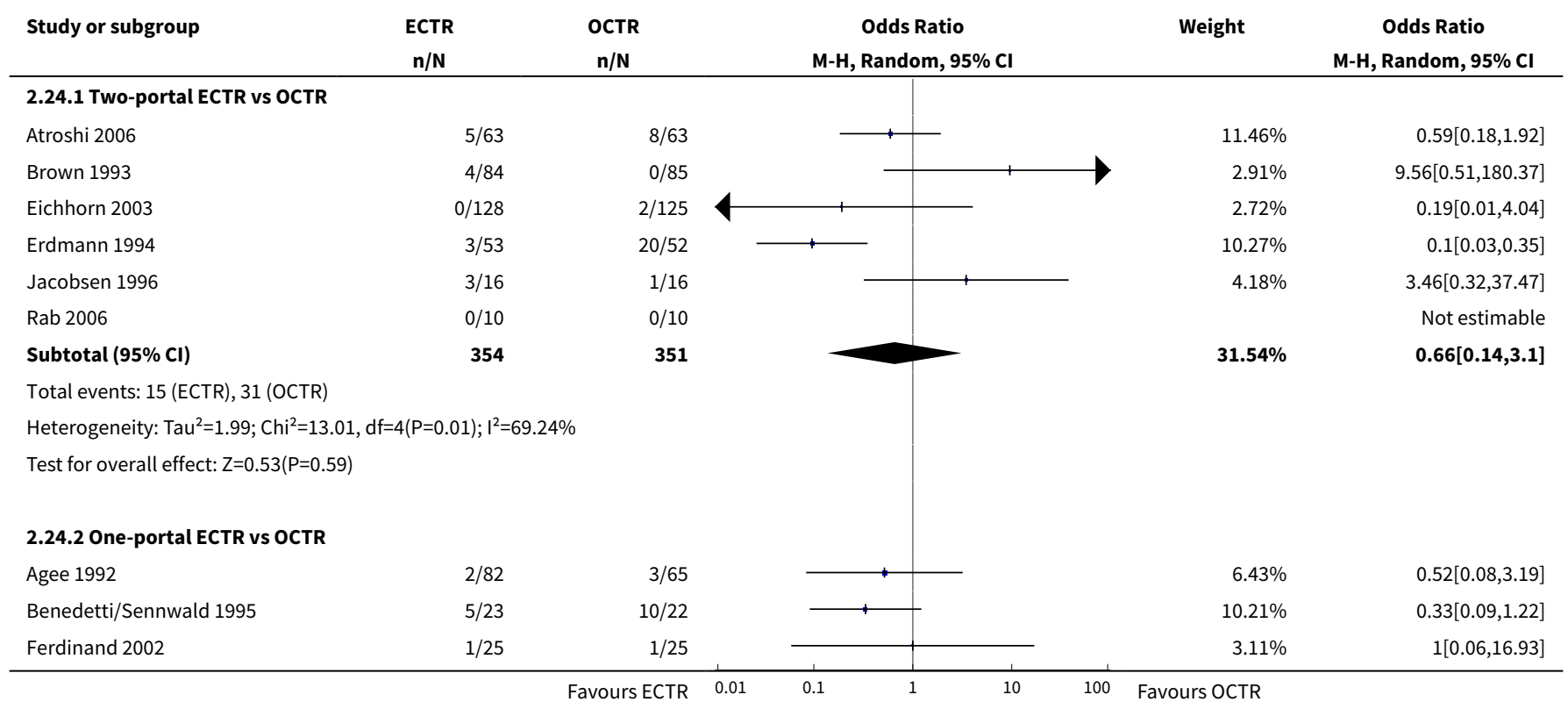




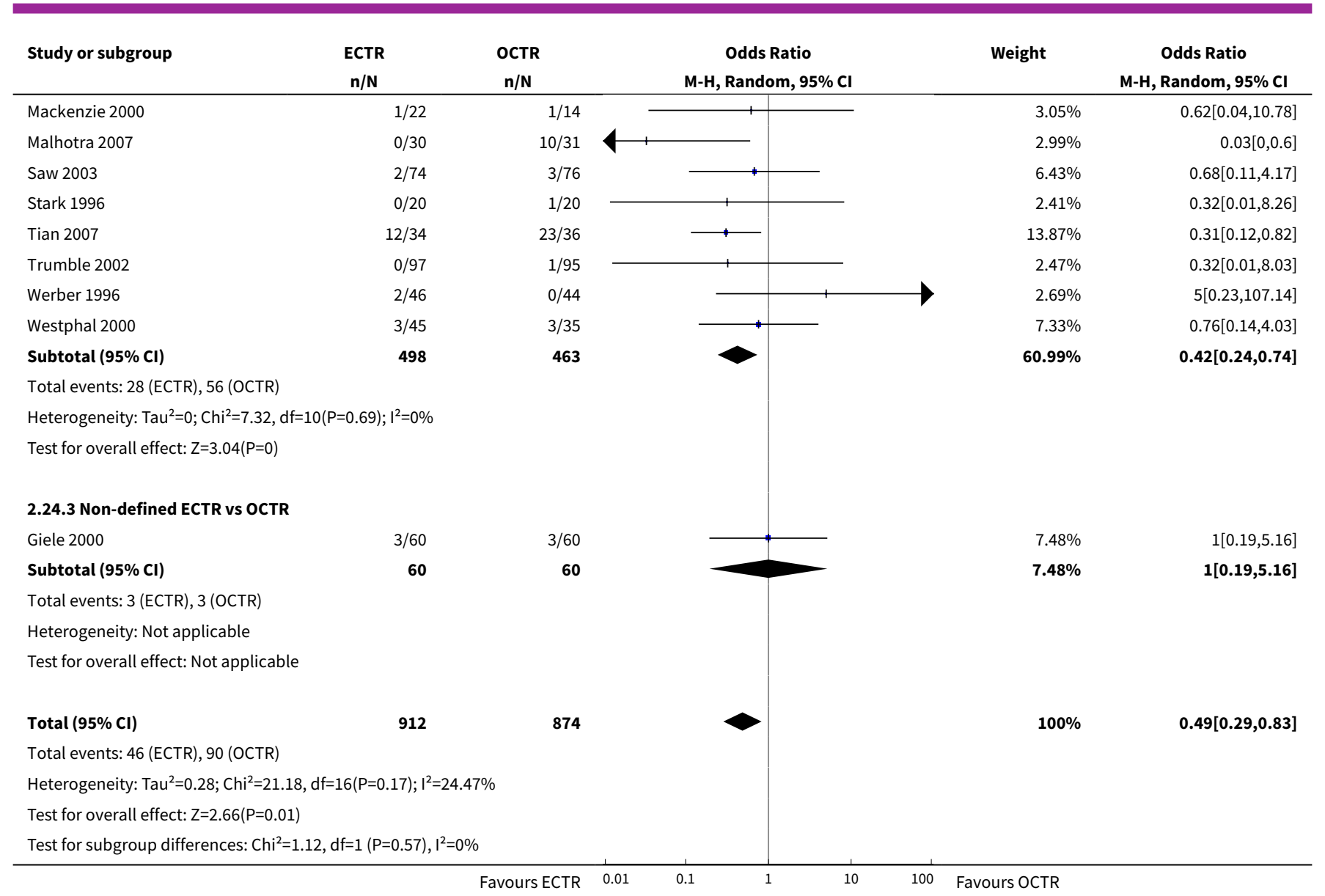

Analysis 2.25. Comparison 2 One- or two-portal endoscopic versus open and mini-open carpal tunnel release, Outcome 25 Total complications.

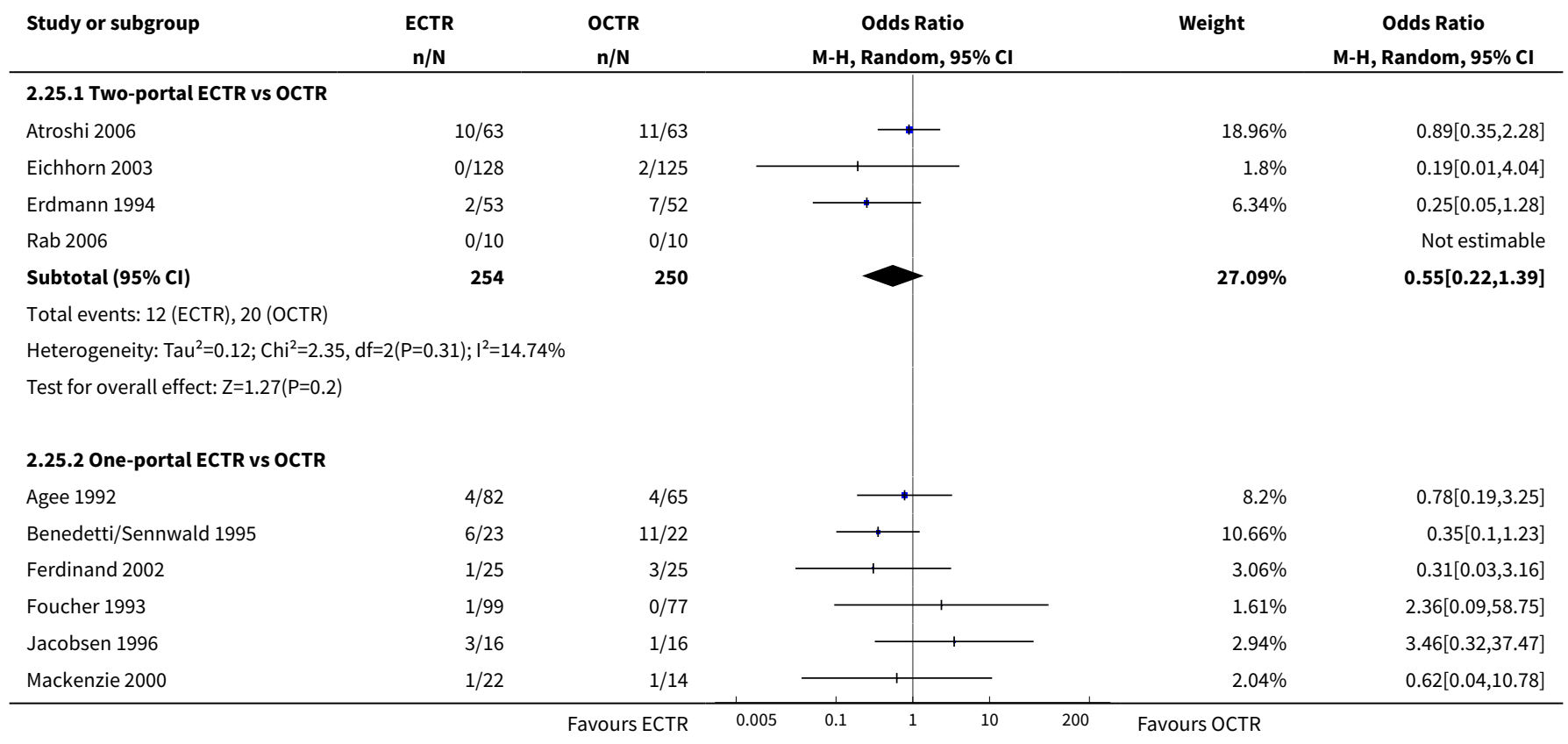




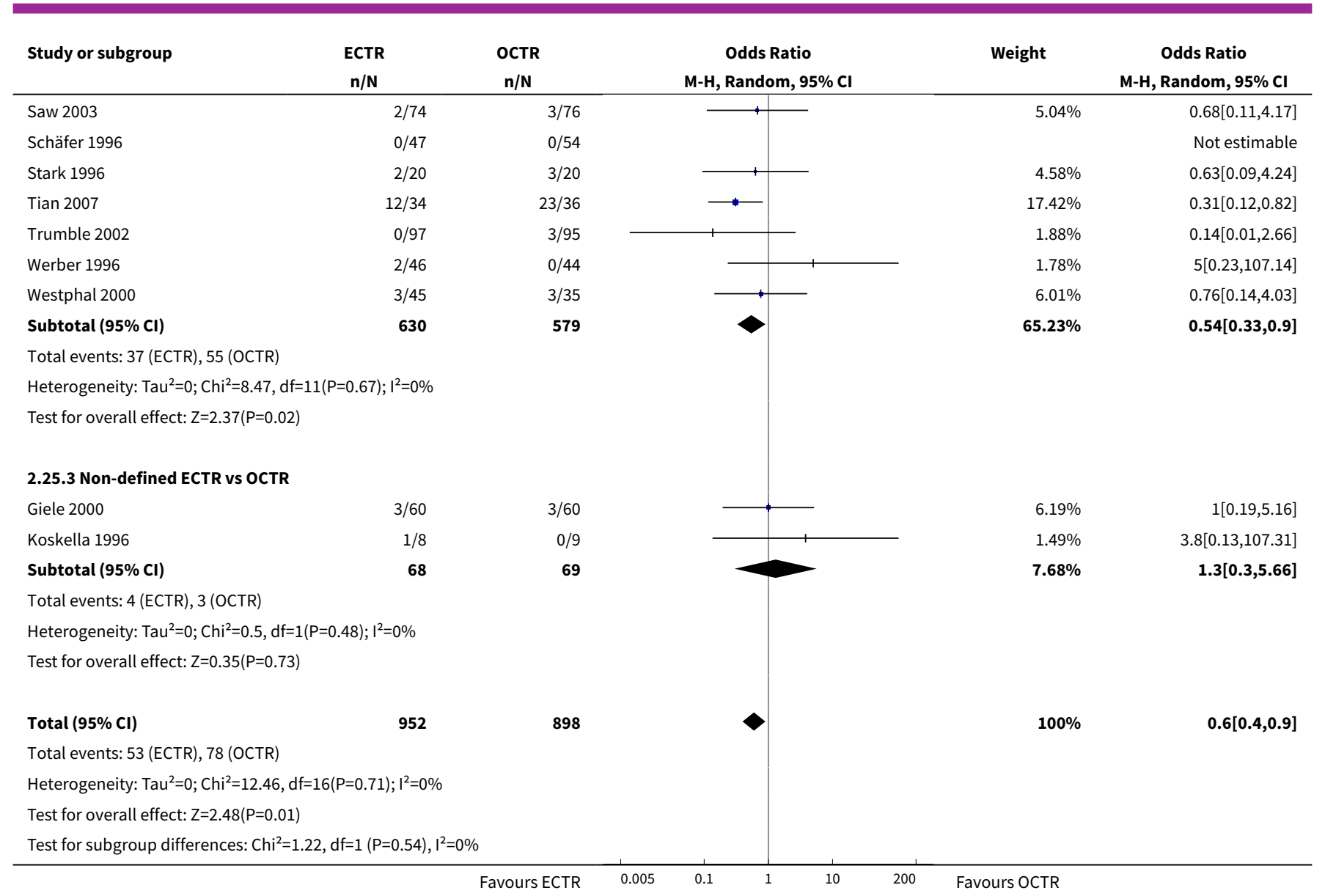

\section{Comparison 3. Sensitivity analysis 1 (low risk of bias for incomplete outcome data)}

\begin{tabular}{|c|c|c|c|c|}
\hline Outcome or subgroup title & $\begin{array}{l}\text { No. of } \\
\text { studies }\end{array}$ & $\begin{array}{l}\text { No. of } \\
\text { partici- } \\
\text { pants }\end{array}$ & Statistical method & Effect size \\
\hline $\begin{array}{l}1 \text { Symptom Severity Scale (Levine) at } 3 \\
\text { months or less }\end{array}$ & 3 & & $\begin{array}{l}\text { Std. Mean Difference (Random, } \\
95 \% \mathrm{Cl} \text { ) }\end{array}$ & $0.03[-0.20,0.27]$ \\
\hline 1.1 ECTR vs standard OCTR & 2 & & $\begin{array}{l}\text { Std. Mean Difference (Random, } \\
95 \% \mathrm{Cl} \text { ) }\end{array}$ & $0.10[-0.13,0.32]$ \\
\hline 1.2 ECTR vs modified OCTR & 1 & & $\begin{array}{l}\text { Std. Mean Difference (Random, } \\
95 \% \mathrm{Cl} \text { ) }\end{array}$ & $-0.37[-1.01,0.27]$ \\
\hline 2 Function Status Scale at 3 months or less & 3 & & $\begin{array}{l}\text { Std. Mean Difference (Random, } \\
95 \% \mathrm{Cl} \text { ) }\end{array}$ & $-0.05[-0.26,0.16]$ \\
\hline 2.1 ECTR vs standard OCTR & 2 & & $\begin{array}{l}\text { Std. Mean Difference (Random, } \\
95 \% \mathrm{Cl} \text { ) }\end{array}$ & $0.0[-0.22,0.22]$ \\
\hline 2.2 ECTR vs modified OCTR & 1 & & $\begin{array}{l}\text { Std. Mean Difference (Random, } \\
95 \% \mathrm{Cl} \text { ) }\end{array}$ & $-0.48[-1.14,0.17]$ \\
\hline
\end{tabular}




\begin{tabular}{|c|c|c|c|c|}
\hline Outcome or subgroup title & $\begin{array}{l}\text { No. of } \\
\text { studies }\end{array}$ & $\begin{array}{l}\text { No. of } \\
\text { partici- } \\
\text { pants }\end{array}$ & Statistical method & Effect size \\
\hline 3 Pain at 3 months or less (corr $=0.5$ ) & 3 & & $\begin{array}{l}\text { Std. Mean Difference (Random, } \\
95 \% \mathrm{Cl} \text { ) }\end{array}$ & $-0.43[-0.66,-0.21]$ \\
\hline 3.1 ECTR vs standard OCTR & 2 & & $\begin{array}{l}\text { Std. Mean Difference (Random, } \\
95 \% \mathrm{Cl} \text { ) }\end{array}$ & $-0.41[-0.65,-0.18]$ \\
\hline 3.2 ECTR vs modified OCTR & 1 & & $\begin{array}{l}\text { Std. Mean Difference (Random, } \\
95 \% \mathrm{Cl} \text { ) }\end{array}$ & $-0.58[-1.25,0.09]$ \\
\hline 4 Pain at 3 months or less (corr $=0.1$ ) & 3 & & $\begin{array}{l}\text { Std. Mean Difference (Random, } \\
95 \% \mathrm{Cl} \text { ) }\end{array}$ & $-0.44[-0.67,-0.21]$ \\
\hline 4.1 ECTR vs standard OCTR & 2 & & $\begin{array}{l}\text { Std. Mean Difference (Random, } \\
95 \% \mathrm{Cl} \text { ) }\end{array}$ & $-0.41[-0.65,-0.18]$ \\
\hline 4.2 ECTR vs modified OCTR & 1 & & $\begin{array}{l}\text { Std. Mean Difference (Random, } \\
95 \% \mathrm{Cl} \text { ) }\end{array}$ & $-0.78[-1.73,0.17]$ \\
\hline 5 Pain at 3 months or less (corr $=0.9)$ & 3 & & $\begin{array}{l}\text { Std. Mean Difference (Random, } \\
95 \% \mathrm{Cl} \text { ) }\end{array}$ & $-0.35[-0.53,-0.17]$ \\
\hline 5.1 ECTR vs standard OCTR & 2 & & $\begin{array}{l}\text { Std. Mean Difference (Random, } \\
95 \% \mathrm{Cl} \text { ) }\end{array}$ & $-0.41[-0.65,-0.18]$ \\
\hline 5.2 ECTR vs modified OCTR & 1 & & $\begin{array}{l}\text { Std. Mean Difference (Random, } \\
95 \% \mathrm{Cl} \text { ) }\end{array}$ & $-0.26[-0.54,0.02]$ \\
\hline 6 Grip strength at 3 months or less & 4 & & $\begin{array}{l}\text { Std. Mean Difference (Random, } \\
95 \% \mathrm{Cl} \text { ) }\end{array}$ & $0.37[-0.03,0.77]$ \\
\hline 6.1 ECTR vs standard OCTR & 3 & & $\begin{array}{l}\text { Std. Mean Difference (Random, } \\
95 \% \mathrm{Cl} \text { ) }\end{array}$ & $0.45[-0.07,0.97]$ \\
\hline 6.2 ECTR vs modified OCTR & 1 & & $\begin{array}{l}\text { Std. Mean Difference (Random, } \\
95 \% \mathrm{Cl} \text { ) }\end{array}$ & $0.14[-0.48,0.76]$ \\
\hline $\begin{array}{l}7 \text { Pain (dichotomous) at more than } 3 \\
\text { months }\end{array}$ & 3 & & $\begin{array}{l}\text { Risk Ratio (M-H, Random, 95\% } \\
\mathrm{CI})\end{array}$ & Subtotals only \\
\hline 7.1 ECTR vs OCTR & 3 & 213 & $\begin{array}{l}\text { Risk Ratio (M-H, Random, 95\% } \\
\mathrm{Cl})\end{array}$ & $0.81[0.39,1.69]$ \\
\hline $\begin{array}{l}8 \text { Numbness (dichotomous) at more than } 3 \\
\text { months }\end{array}$ & 1 & & $\begin{array}{l}\text { Risk Ratio (M-H, Random, 95\% } \\
\text { Cl) }\end{array}$ & Subtotals only \\
\hline 8.1 ECTR vs OCTR & 1 & 40 & $\begin{array}{l}\text { Risk Ratio (M-H, Random, 95\% } \\
\mathrm{Cl} \text { ) }\end{array}$ & $1.0[0.07,14.90]$ \\
\hline 9 Time to return to work & 4 & & $\begin{array}{l}\text { Mean Difference (IV, Random, } \\
95 \% \mathrm{CI})\end{array}$ & Subtotals only \\
\hline 9.1 ECTR vs OCTR & 4 & 274 & $\begin{array}{l}\text { Mean Difference (IV, Random, } \\
95 \% \mathrm{CI} \text { ) }\end{array}$ & $-8.10[-14.28,-1.92]$ \\
\hline
\end{tabular}




\begin{tabular}{|c|c|c|c|c|}
\hline Outcome or subgroup title & $\begin{array}{l}\text { No. of } \\
\text { studies }\end{array}$ & $\begin{array}{l}\text { No. of } \\
\text { partici- } \\
\text { pants }\end{array}$ & Statistical method & Effect size \\
\hline 10 Reoperations & 3 & 323 & $\begin{array}{l}\text { Risk Ratio (M-H, Random, 95\% } \\
\mathrm{Cl} \text { ) }\end{array}$ & $1.24[0.31,5.05]$ \\
\hline 10.1 ECTR vs standard OCTR & 3 & 323 & $\begin{array}{l}\text { Risk Ratio (M-H, Random, 95\% } \\
\mathrm{Cl} \text { ) }\end{array}$ & $1.24[0.31,5.05]$ \\
\hline 10.2 ECTR vs modified OCTR & 0 & 0 & $\begin{array}{l}\text { Risk Ratio (M-H, Random, 95\% } \\
\mathrm{Cl} \text { ) }\end{array}$ & $0.0[0.0,0.0]$ \\
\hline 11 Major complications & 6 & 474 & $\begin{array}{l}\text { Risk Ratio (M-H, Random, 95\% } \\
\mathrm{Cl} \text { ) }\end{array}$ & $1.48[0.43,5.11]$ \\
\hline 11.1 ECTR vs standard OCTR & 5 & 454 & $\begin{array}{l}\text { Risk Ratio (M-H, Random, 95\% } \\
\mathrm{Cl} \text { ) }\end{array}$ & $1.48[0.43,5.11]$ \\
\hline 11.2 ECTR vs modified OCTR & 1 & 20 & $\begin{array}{l}\text { Risk Ratio (M-H, Random, 95\% } \\
\text { Cl) }\end{array}$ & $0.0[0.0,0.0]$ \\
\hline 12 Minor complications & 6 & 413 & $\begin{array}{l}\text { Risk Ratio (M-H, Random, 95\% } \\
\text { Cl) }\end{array}$ & $0.62[0.34,1.13]$ \\
\hline 12.1 ECTR vs standard OCTR & 5 & 393 & $\begin{array}{l}\text { Risk Ratio (M-H, Random, 95\% } \\
\mathrm{Cl} \text { ) }\end{array}$ & $0.62[0.34,1.13]$ \\
\hline 12.2 ECTR vs modified OCTR & 1 & 20 & $\begin{array}{l}\text { Risk Ratio (M-H, Random, 95\% } \\
\mathrm{Cl} \text { ) }\end{array}$ & $0.0[0.0,0.0]$ \\
\hline 13 Total complications & 7 & 514 & $\begin{array}{l}\text { Risk Ratio (M-H, Random, 95\% } \\
\text { Cl) }\end{array}$ & $0.75[0.45,1.23]$ \\
\hline 13.1 ECTR vs standard OCTR & 6 & 494 & $\begin{array}{l}\text { Risk Ratio (M-H, Random, 95\% } \\
\mathrm{Cl} \text { ) }\end{array}$ & $0.75[0.45,1.23]$ \\
\hline 13.2 ECTR vs modified OCTR & 1 & 20 & $\begin{array}{l}\text { Risk Ratio (M-H, Random, 95\% } \\
\text { Cl) }\end{array}$ & $0.0[0.0,0.0]$ \\
\hline
\end{tabular}

Analysis 3.1. Comparison 3 Sensitivity analysis 1 (low risk of bias for incomplete outcome data), Outcome 1 Symptom Severity Scale (Levine) at 3 months or less.

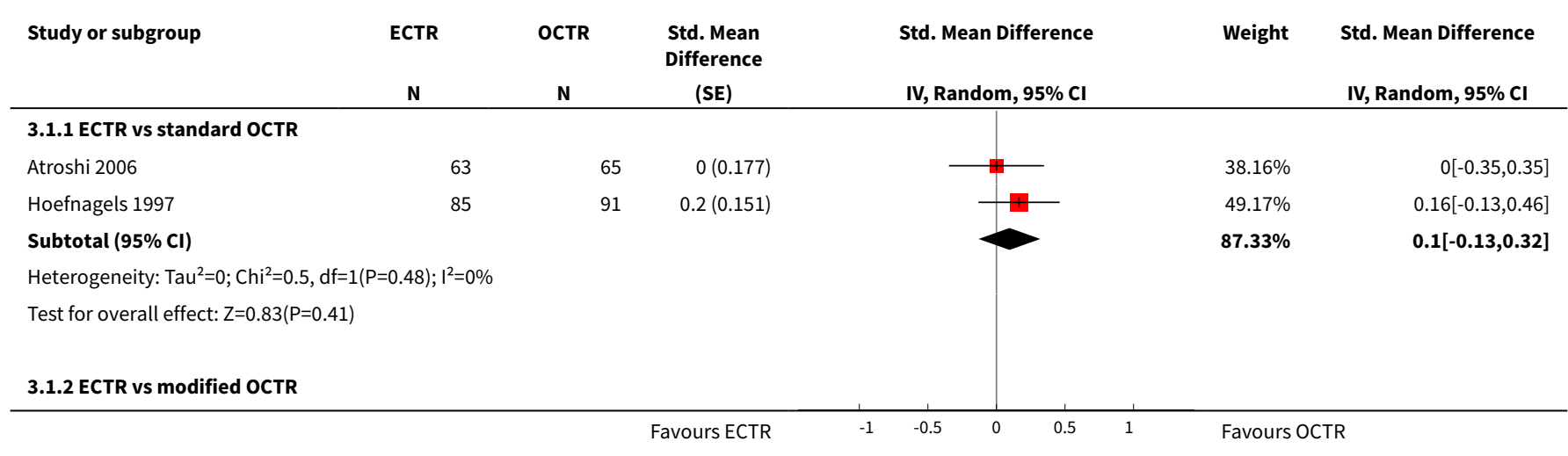




\begin{tabular}{|c|c|c|c|c|c|c|}
\hline \multirow[t]{2}{*}{ Study or subgroup } & ECTR & OCTR & $\begin{array}{l}\text { Std. Mean } \\
\text { Difference }\end{array}$ & \multirow{2}{*}{$\begin{array}{l}\text { Std. Mean Difference } \\
\text { IV, Random, } 95 \% \mathrm{CI}\end{array}$} & \multirow[t]{2}{*}{ Weight } & \multirow{2}{*}{$\begin{array}{l}\text { Std. Mean Difference } \\
\text { IV, Random, } 95 \% \mathrm{CI}\end{array}$} \\
\hline & $\mathbf{N}$ & $\mathbf{N}$ & (SE) & & & \\
\hline Rab 2006 & 10 & 10 & $-0.4(0.327)$ & + & $12.67 \%$ & $-0.37[-1.01,0.27]$ \\
\hline Subtotal $(95 \% \mathrm{Cl})$ & & & & & $12.67 \%$ & $-0.37[-1.01,0.27]$ \\
\hline \multicolumn{7}{|c|}{ Heterogeneity: Not applicable } \\
\hline \multicolumn{7}{|c|}{ Test for overall effect: $Z=1.14(P=0.26)$} \\
\hline Total $(95 \% \mathrm{Cl})$ & & & & & $100 \%$ & $0.03[-0.2,0.27]$ \\
\hline \multicolumn{7}{|c|}{ Heterogeneity: $\operatorname{Tau}^{2}=0.01 ; \mathrm{Chi}^{2}=2.32, \mathrm{df}=2(\mathrm{P}=0.31) ;\left.\right|^{2}=13.61 \%$} \\
\hline \multicolumn{7}{|c|}{ Test for overall effect: $\mathrm{Z}=0.28(\mathrm{P}=0.78)$} \\
\hline \multicolumn{7}{|c|}{ Test for subgroup differences: $\mathrm{Chi}^{2}=1.81, \mathrm{df}=1(\mathrm{P}=0.18), \mathrm{I}^{2}=44.88 \%$} \\
\hline & & & Favours ECTR & -0.5 & Favours & \\
\hline
\end{tabular}

Analysis 3.2. Comparison 3 Sensitivity analysis 1 (low risk of bias for incomplete outcome data), Outcome 2 Function Status Scale at 3 months or less.

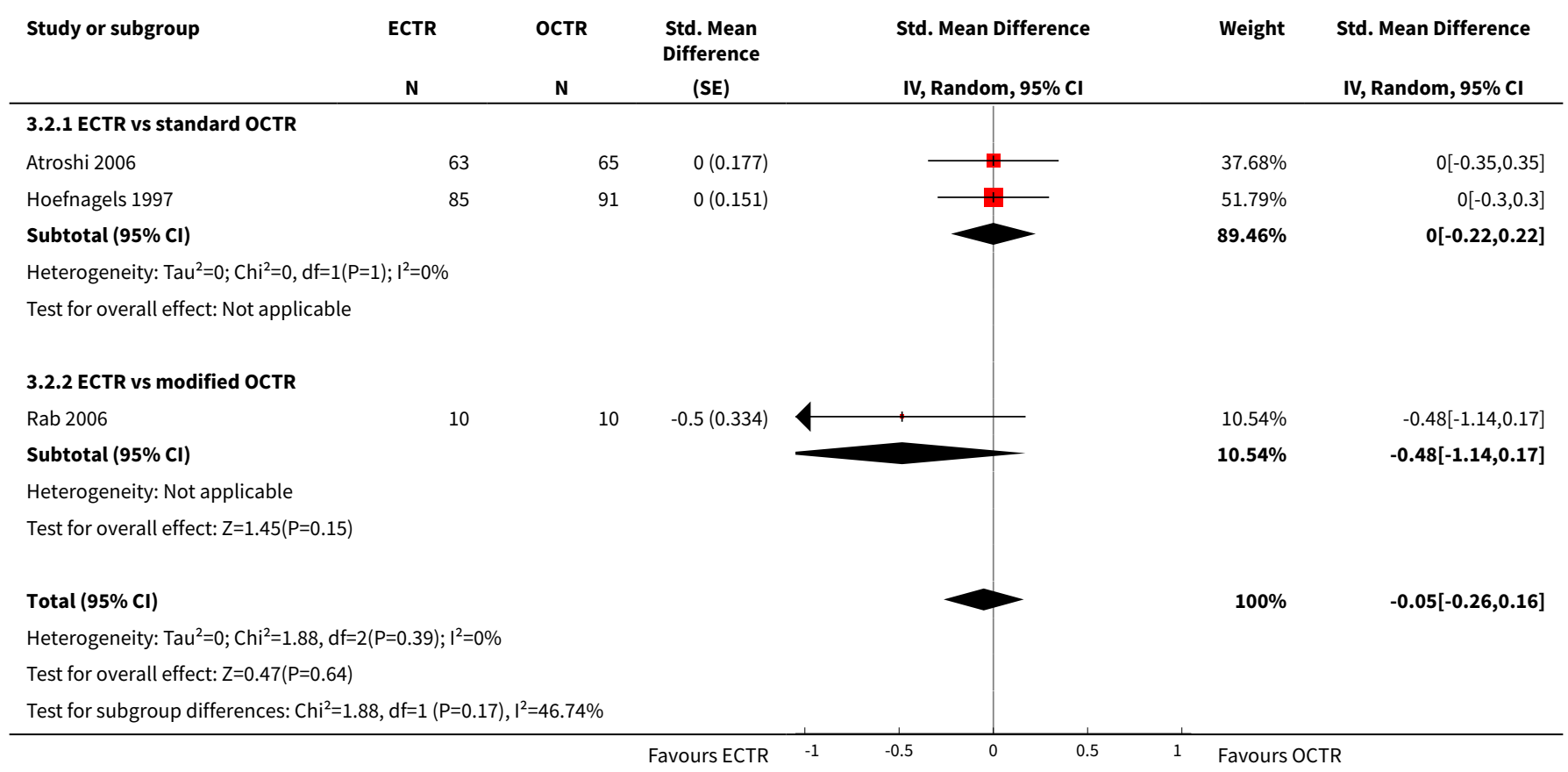

Analysis 3.3. Comparison 3 Sensitivity analysis 1 (low risk of bias for incomplete outcome data), Outcome 3 Pain at 3 months or less (corr $=0.5$ ).

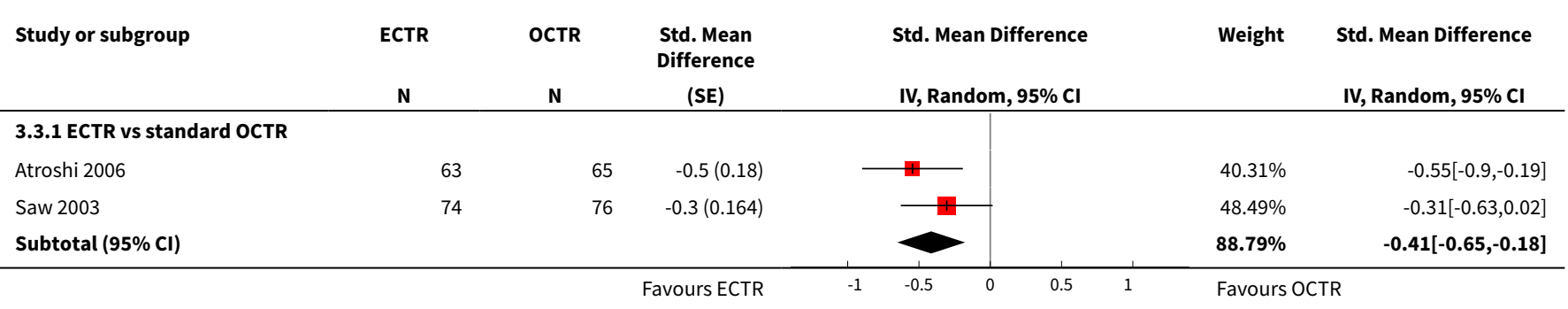




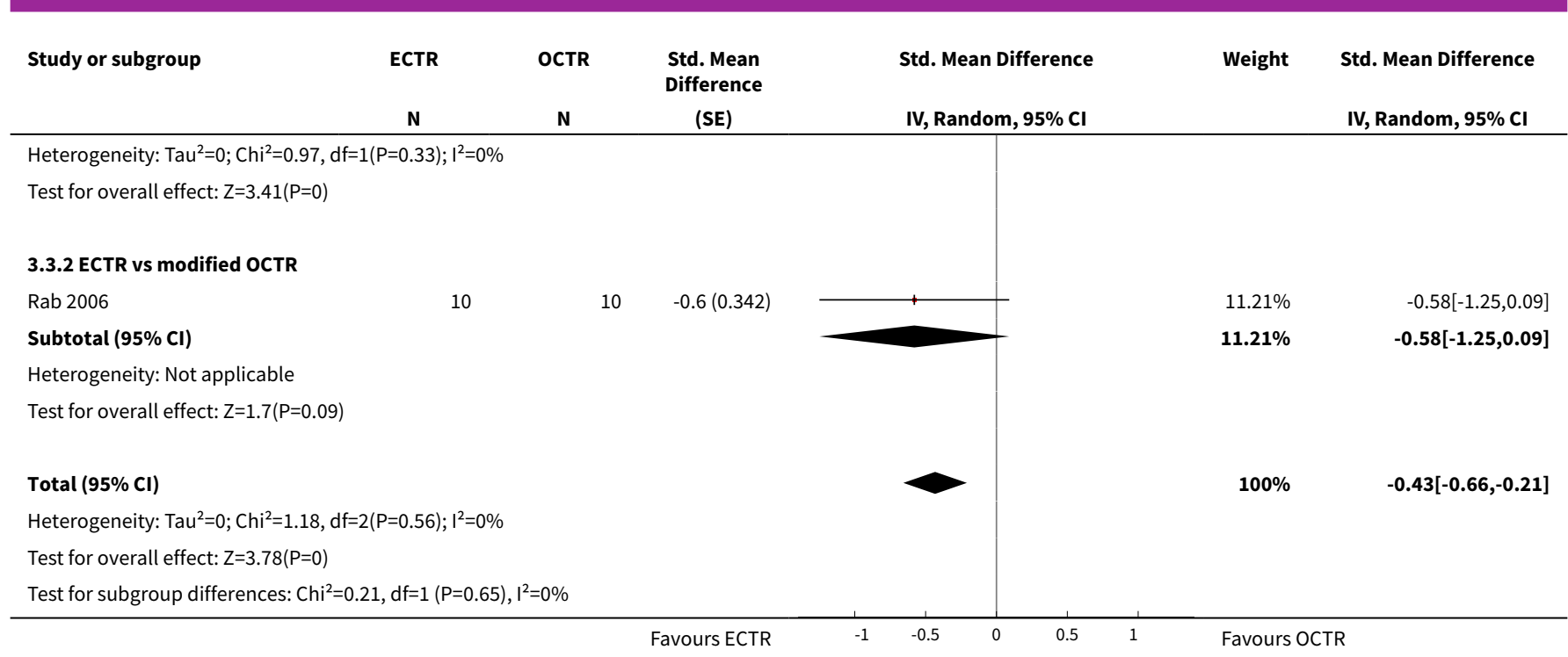

Analysis 3.4. Comparison 3 Sensitivity analysis 1 (low risk of bias for incomplete outcome data), Outcome 4 Pain at 3 months or less (corr $=\mathbf{0 . 1}$ ).

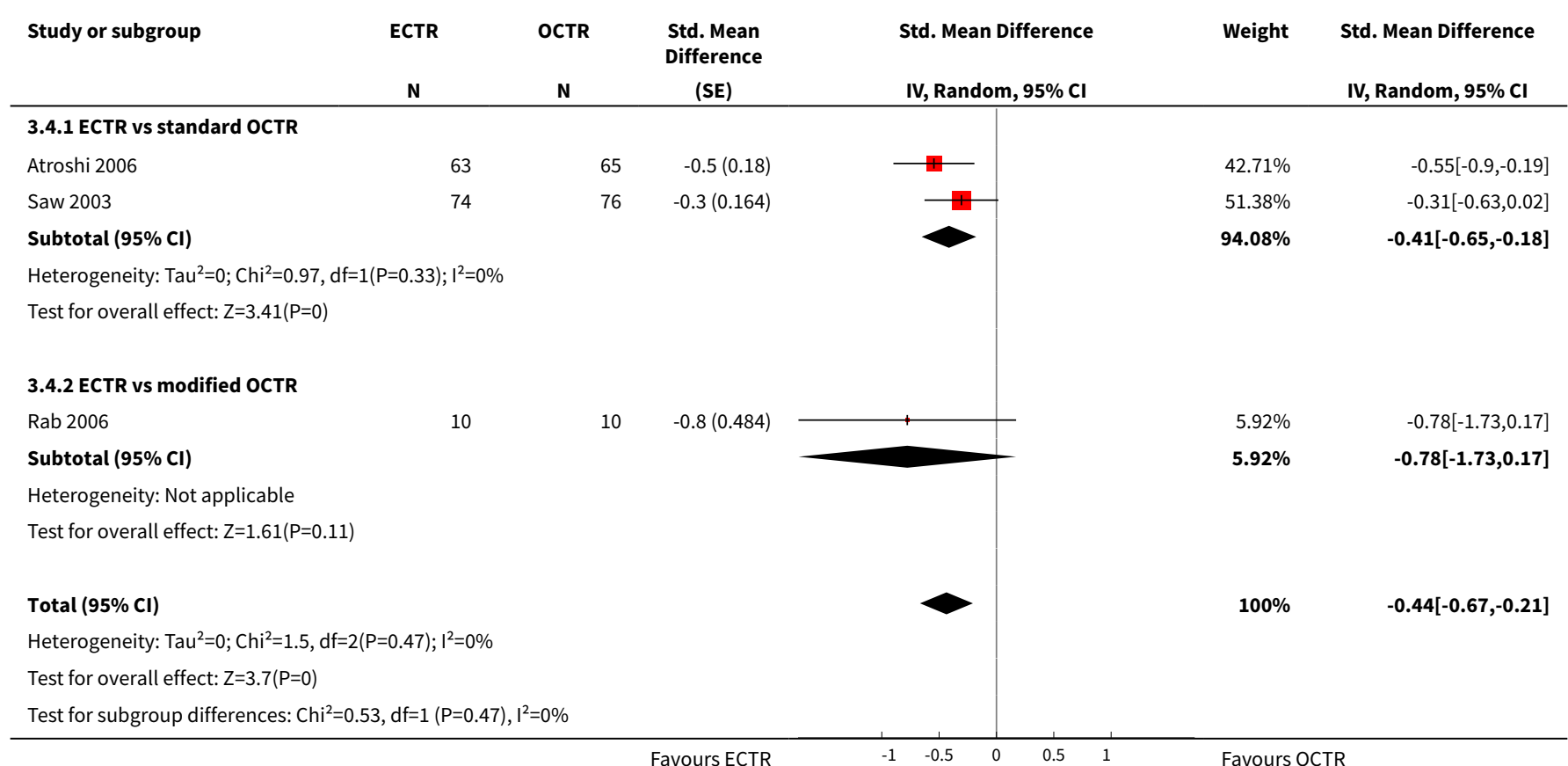


Analysis 3.5. Comparison 3 Sensitivity analysis 1 (low risk of bias for incomplete outcome data), Outcome 5 Pain at 3 months or less (corr $=0.9$ ).

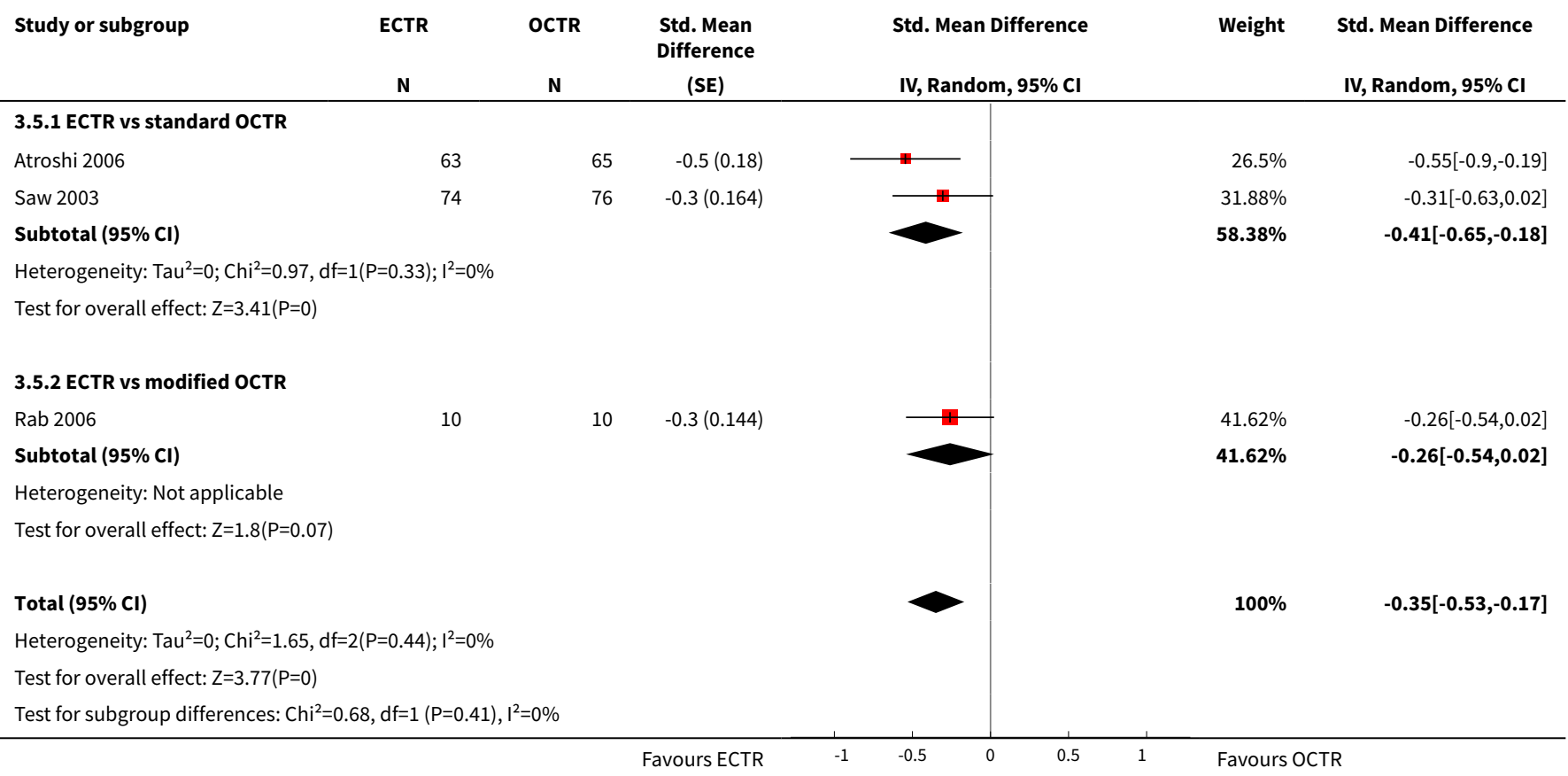

Analysis 3.6. Comparison 3 Sensitivity analysis 1 (low risk of bias for incomplete outcome data), Outcome 6 Grip strength at 3 months or less.

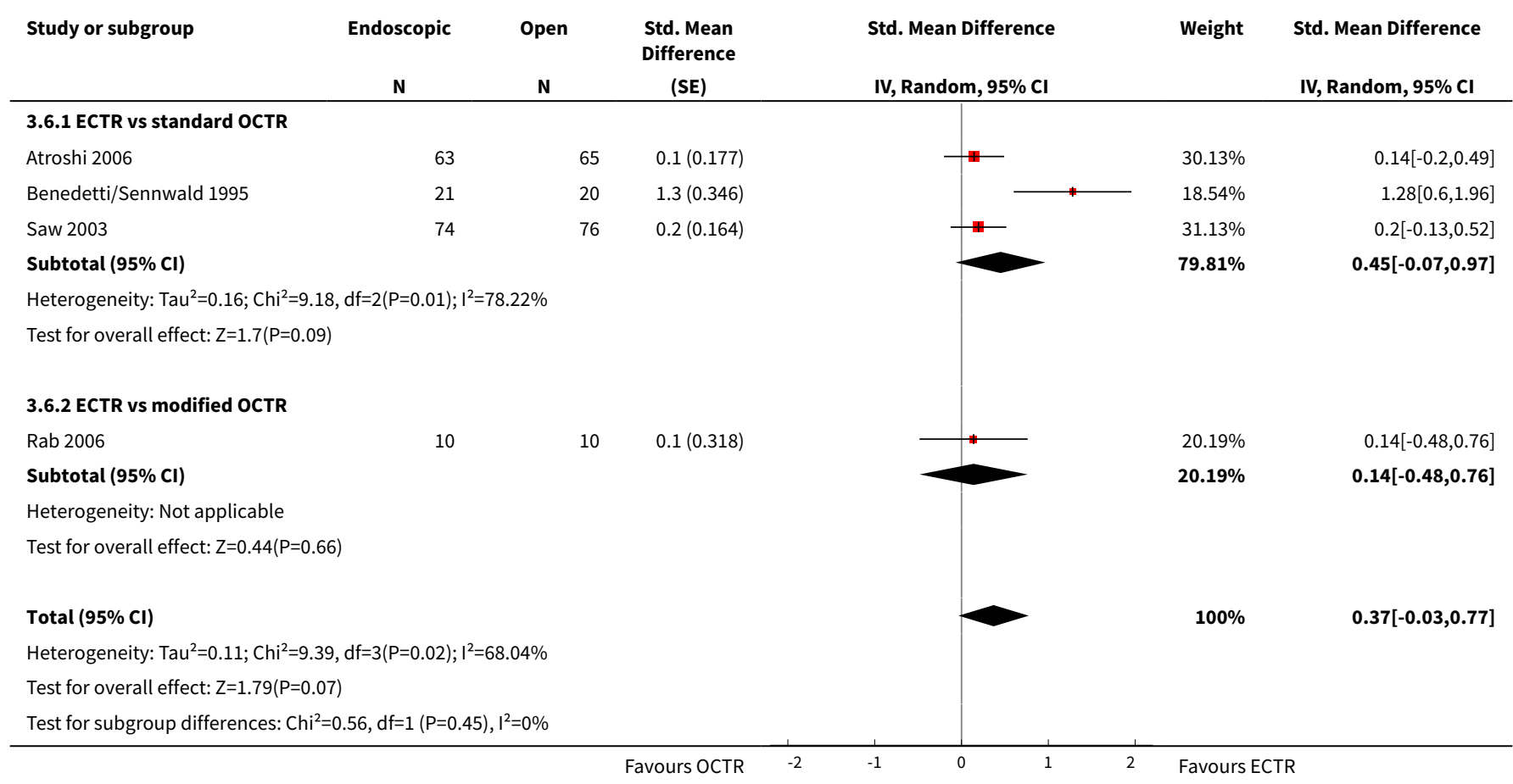


Analysis 3.7. Comparison 3 Sensitivity analysis 1 (low risk of bias for incomplete outcome data), Outcome 7 Pain (dichotomous) at more than $\mathbf{3}$ months.

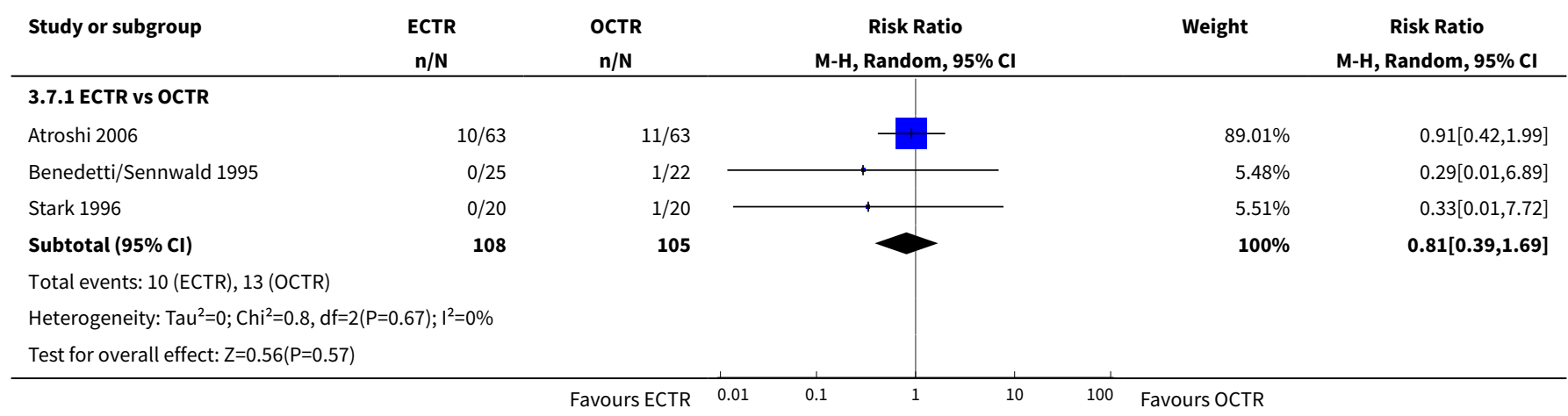

Analysis 3.8. Comparison 3 Sensitivity analysis 1 (low risk of bias for incomplete outcome data), Outcome 8 Numbness (dichotomous) at more than 3 months.

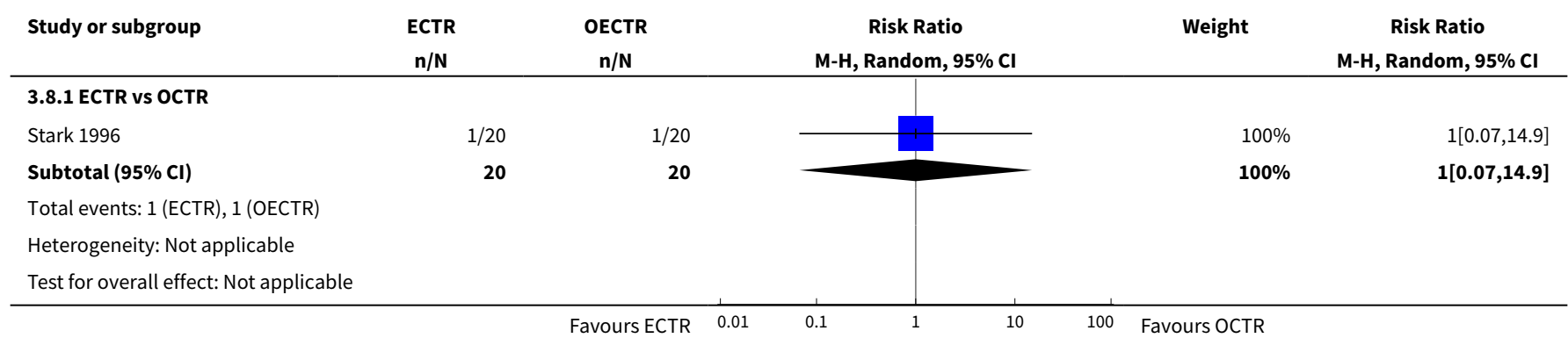

Analysis 3.9. Comparison 3 Sensitivity analysis 1 (low risk of bias for incomplete outcome data), Outcome 9 Time to return to work.

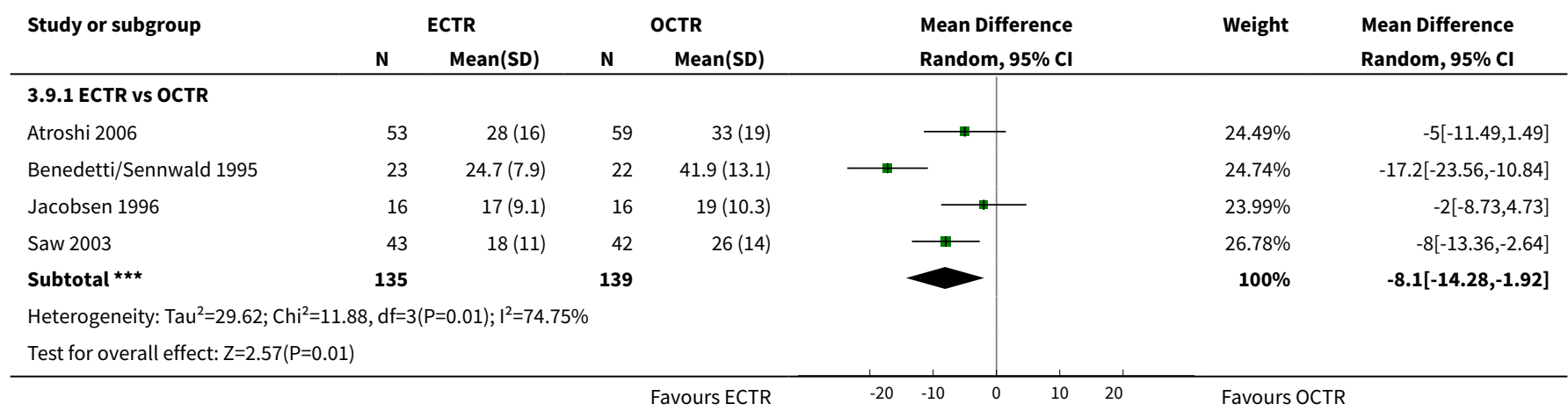


Analysis 3.10. Comparison 3 Sensitivity analysis 1 (low risk of bias for incomplete outcome data), Outcome 10 Reoperations.

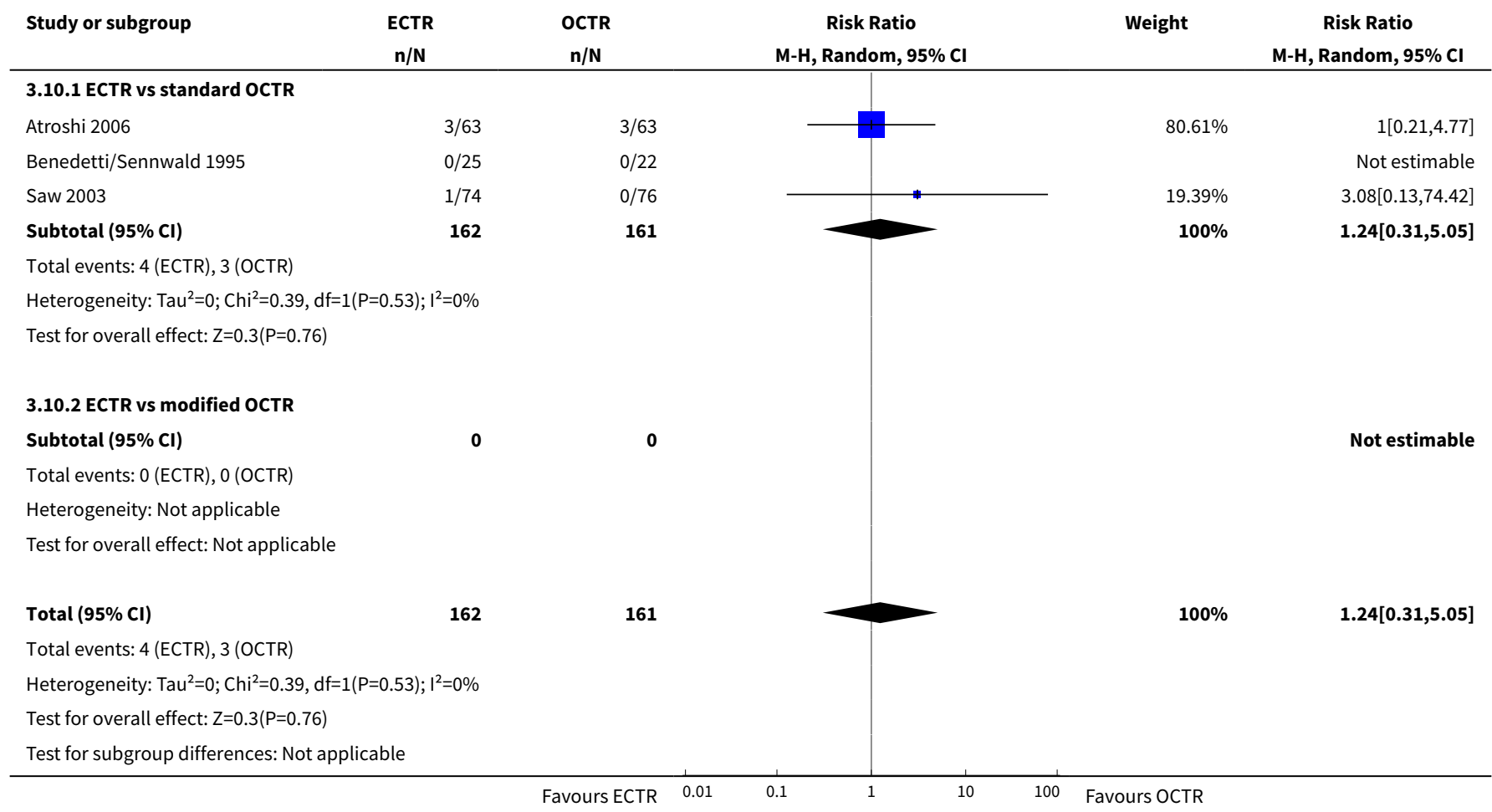

Analysis 3.11. Comparison 3 Sensitivity analysis 1 (low risk of bias for incomplete outcome data), Outcome 11 Major complications.

\begin{tabular}{|c|c|c|c|c|c|}
\hline Study or subgroup & $\begin{array}{c}\text { ECTR } \\
n / N\end{array}$ & $\begin{array}{c}\text { OCTR } \\
\mathrm{n} / \mathrm{N}\end{array}$ & $\begin{array}{c}\text { Risk Ratio } \\
\text { M-H, Random, } 95 \% \text { Cl }\end{array}$ & Weight & $\begin{array}{c}\text { Risk Ratio } \\
\text { M-H, Random, 95\% Cl }\end{array}$ \\
\hline \multicolumn{6}{|l|}{ 3.11.1 ECTR vs standard OCTR } \\
\hline Atroshi 2006 & $5 / 63$ & $3 / 63$ & - & $79.21 \%$ & $1.67[0.42,6.68]$ \\
\hline Benedetti/Sennwald 1995 & $1 / 23$ & $1 / 22$ & & $20.79 \%$ & $0.96[0.06,14.37]$ \\
\hline Jacobsen 1996 & $0 / 16$ & $0 / 16$ & & & Not estimable \\
\hline Saw 2003 & $0 / 74$ & $0 / 76$ & & & Not estimable \\
\hline Schäfer 1996 & $0 / 47$ & $0 / 54$ & & & Not estimable \\
\hline Subtotal $(95 \% \mathrm{Cl})$ & 223 & 231 & & $100 \%$ & $1.48[0.43,5.11]$ \\
\hline \multicolumn{6}{|l|}{ Total events: 6 (ECTR), 4 (OCTR) } \\
\hline \multicolumn{6}{|c|}{ Heterogeneity: $\mathrm{Tau}^{2}=0 ; \mathrm{Chi}^{2}=0.13, \mathrm{df}=1(\mathrm{P}=0.72) ; \mathrm{I}^{2}=0 \%$} \\
\hline \multicolumn{6}{|c|}{ Test for overall effect: $Z=0.63(P=0.53)$} \\
\hline \multicolumn{6}{|l|}{ 3.11.2 ECTR vs modified OCTR } \\
\hline Subtotal $(95 \% \mathrm{CI})$ & 10 & 10 & & & Not estimable \\
\hline \multicolumn{6}{|l|}{ Total events: 0 (ECTR), 0 (OCTR) } \\
\hline \multicolumn{6}{|l|}{ Heterogeneity: Not applicable } \\
\hline \multicolumn{6}{|c|}{ Test for overall effect: Not applicable } \\
\hline Total $(95 \% \mathrm{Cl})$ & 233 & 241 & & $100 \%$ & $1.48[0.43,5.11]$ \\
\hline \multicolumn{6}{|l|}{ Total events: 6 (ECTR), 4 (OCTR) } \\
\hline & & $\begin{array}{ll}\text { Favours ECTR } 0.01 \\
\end{array}$ & 0.1 & 100 Favours OCTR & \\
\hline
\end{tabular}




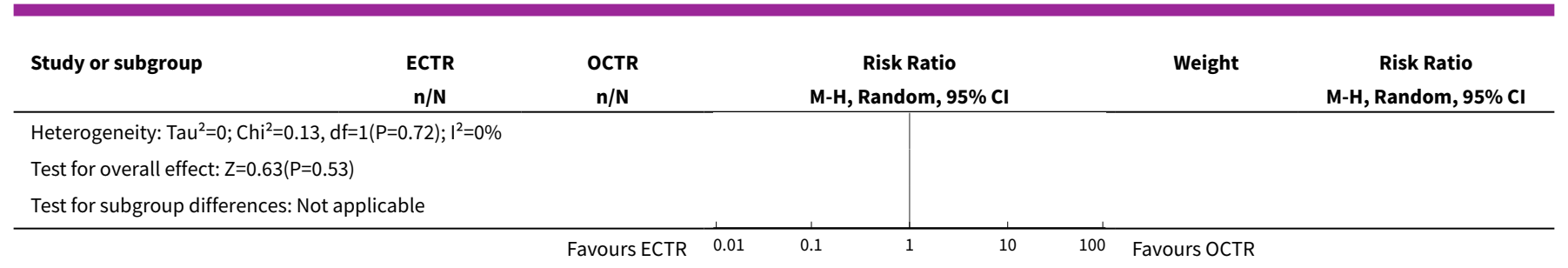

Analysis 3.12. Comparison 3 Sensitivity analysis 1 (low risk of bias

for incomplete outcome data), Outcome 12 Minor complications.

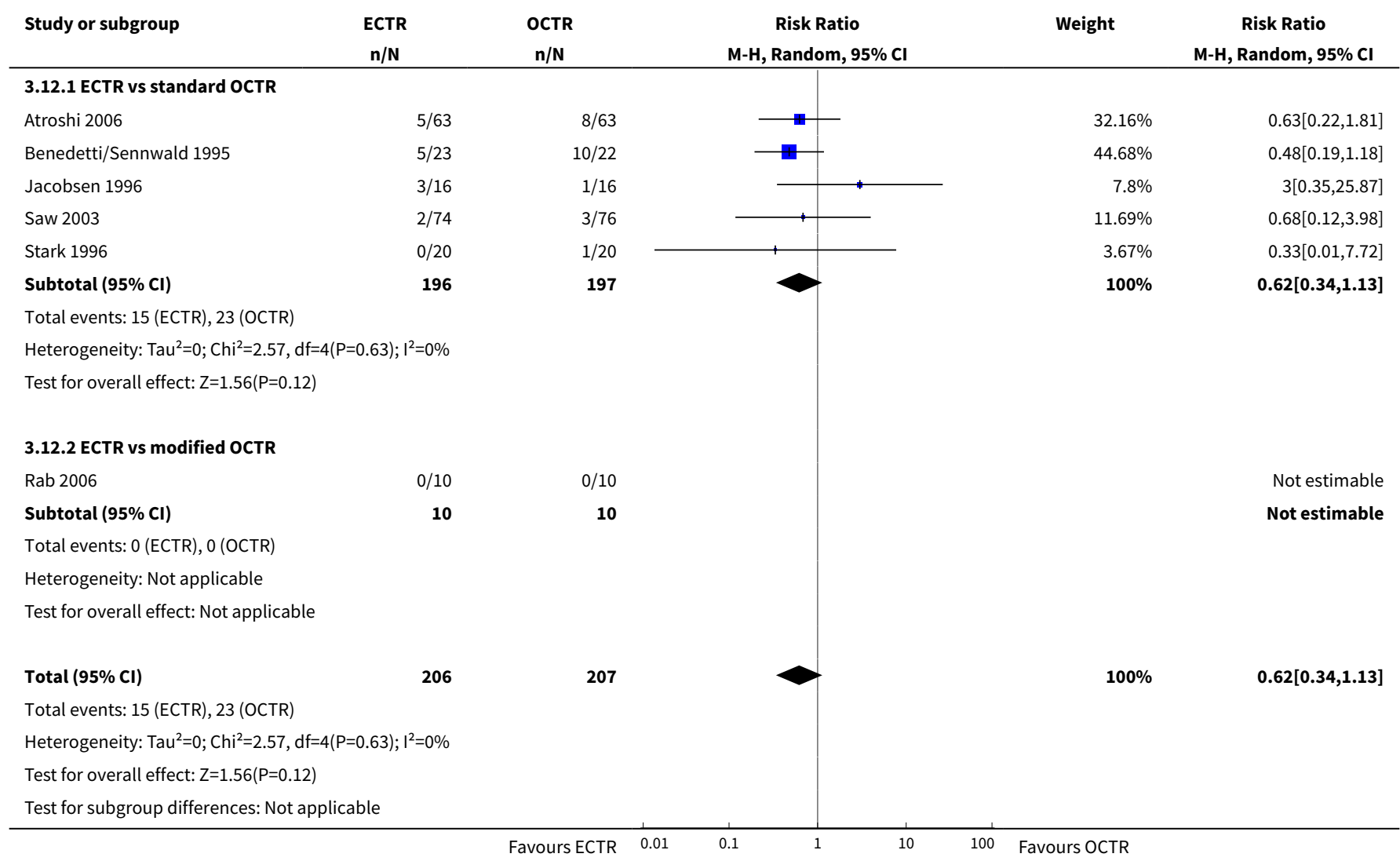

Analysis 3.13. Comparison 3 Sensitivity analysis 1 (low risk of bias for incomplete outcome data), Outcome 13 Total complications.

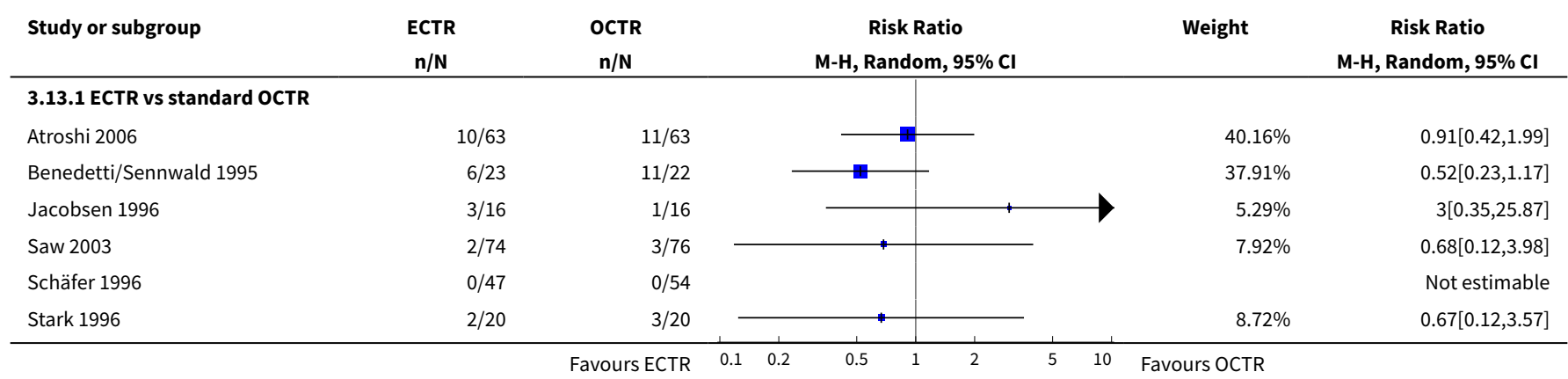




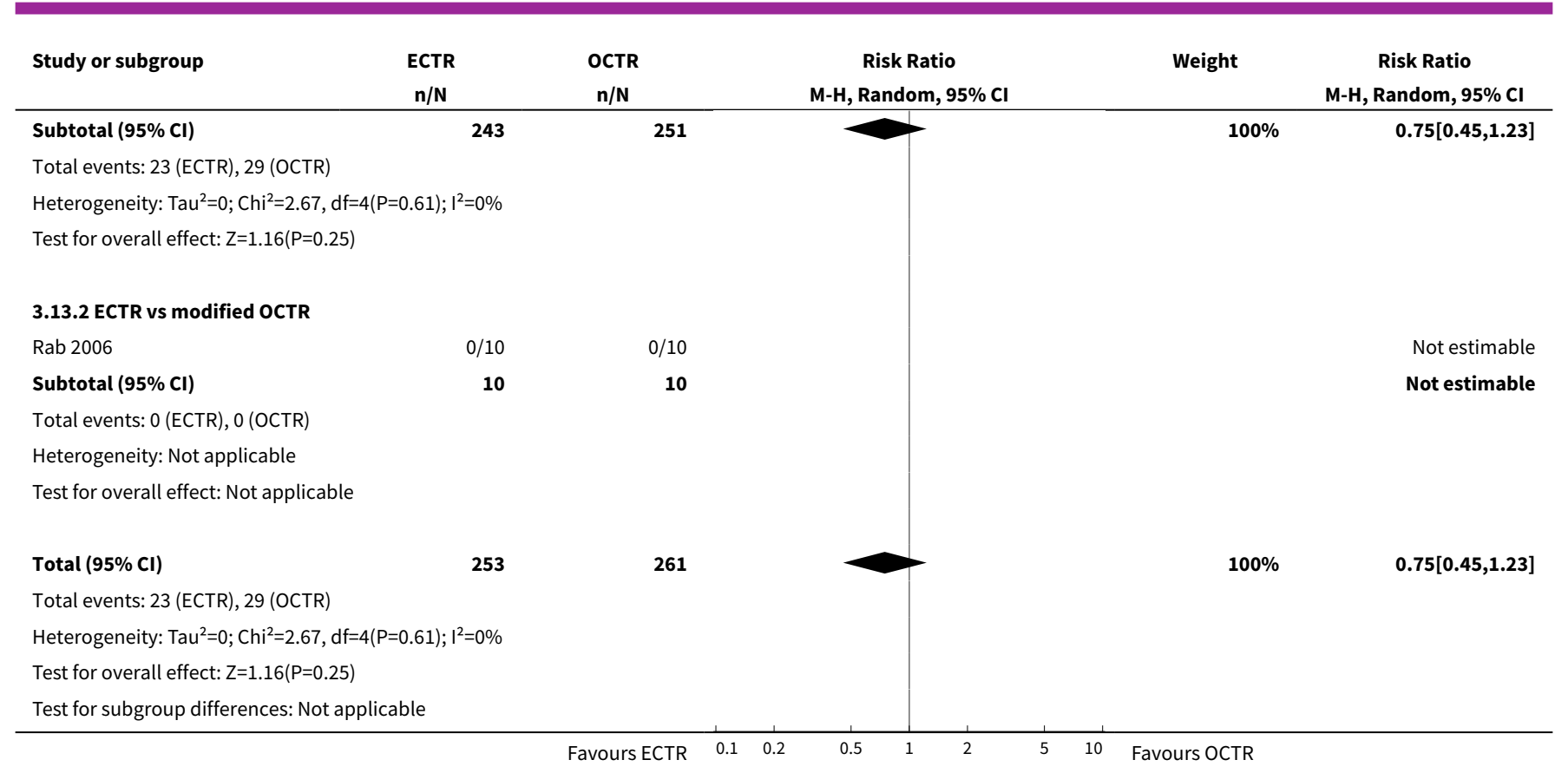

Comparison 4. Sensitivity analysis 2 (exclusion of inappropriate adjustment for bilateral involvement)

\begin{tabular}{|c|c|c|c|c|}
\hline Outcome or subgroup title & $\begin{array}{l}\text { No. of } \\
\text { studies }\end{array}$ & $\begin{array}{l}\text { No. of } \\
\text { partici- } \\
\text { pants }\end{array}$ & Statistical method & Effect size \\
\hline $\begin{array}{l}1 \text { Overall improvement at more than } 3 \\
\text { months }\end{array}$ & 3 & 247 & $\begin{array}{l}\text { Risk Ratio (M-H, Random, 95\% } \\
\mathrm{Cl})\end{array}$ & $1.06[0.93,1.20]$ \\
\hline 1.1 ECTR vs standard OCTR & 2 & 187 & $\begin{array}{l}\text { Risk Ratio (M-H, Random, 95\% } \\
\mathrm{Cl} \text { ) }\end{array}$ & $1.08[0.94,1.25]$ \\
\hline 1.2 ECTR vs modified OCTR & 1 & 60 & $\begin{array}{l}\text { Risk Ratio (M-H, Random, 95\% } \\
\mathrm{Cl})\end{array}$ & $0.89[0.59,1.35]$ \\
\hline $\begin{array}{l}2 \text { Symptom Severity Scale (Levine) at } 3 \\
\text { months or less }\end{array}$ & 4 & & $\begin{array}{l}\text { Std. Mean Difference (Random, } \\
95 \% \mathrm{Cl} \text { ) }\end{array}$ & $0.06[-0.13,0.25]$ \\
\hline 2.1 ECTR vs standard OCTR & 3 & & $\begin{array}{l}\text { Std. Mean Difference (Random, } \\
95 \% \mathrm{Cl} \text { ) }\end{array}$ & $0.10[-0.10,0.30]$ \\
\hline 2.2 ECTR vs modified OCTR & 1 & & $\begin{array}{l}\text { Std. Mean Difference (Random, } \\
95 \% \mathrm{Cl} \text { ) }\end{array}$ & $-0.37[-1.01,0.27]$ \\
\hline 3 Pain at 3 months or less (corr $=0.5$ ) & 3 & & $\begin{array}{l}\text { Std. Mean Difference (Random, } \\
95 \% \mathrm{Cl} \text { ) }\end{array}$ & $-0.18[-0.96,0.59]$ \\
\hline 3.1 ECTR vs standard OCTR & 1 & & $\begin{array}{l}\text { Std. Mean Difference (Random, } \\
95 \% \mathrm{Cl} \text { ) }\end{array}$ & $-0.55[-0.90,-0.19]$ \\
\hline 3.2 ECTR vs modified OCTR & 2 & & $\begin{array}{l}\text { Std. Mean Difference (Random, } \\
95 \% \mathrm{Cl} \text { ) }\end{array}$ & $0.01[-1.07,1.08]$ \\
\hline
\end{tabular}




\begin{tabular}{|c|c|c|c|c|}
\hline Outcome or subgroup title & $\begin{array}{l}\text { No. of } \\
\text { studies }\end{array}$ & $\begin{array}{l}\text { No. of } \\
\text { partici- } \\
\text { pants }\end{array}$ & Statistical method & Effect size \\
\hline 4 Pain at 3 months or less (corr $=0.1$ ) & 3 & & $\begin{array}{l}\text { Std. Mean Difference (Random, } \\
95 \% \mathrm{Cl} \text { ) }\end{array}$ & $-0.18[-1.10,0.74]$ \\
\hline 4.1 ECTR vs standard OCTR & 1 & & $\begin{array}{l}\text { Std. Mean Difference (Random, } \\
95 \% \mathrm{Cl} \text { ) }\end{array}$ & $-0.55[-0.90,-0.19]$ \\
\hline 4.2 ECTR vs modified OCTR & 2 & & $\begin{array}{l}\text { Std. Mean Difference (Random, } \\
95 \% \mathrm{Cl} \text { ) }\end{array}$ & $0.01[-1.43,1.46]$ \\
\hline 5 Pain at 3 months or less (corr $=0.9$ ) & 3 & & $\begin{array}{l}\text { Std. Mean Difference (Random, } \\
95 \% \mathrm{Cl} \text { ) }\end{array}$ & $-0.17[-0.65,0.30]$ \\
\hline 5.1 ECTR vs standard OCTR & 1 & & $\begin{array}{l}\text { Std. Mean Difference (Random, } \\
95 \% \mathrm{Cl} \text { ) }\end{array}$ & $-0.55[-0.90,-0.19]$ \\
\hline 5.2 ECTR vs modified OCTR & 2 & & $\begin{array}{l}\text { Std. Mean Difference (Random, } \\
95 \% \mathrm{Cl} \text { ) }\end{array}$ & $0.00[-0.48,0.48]$ \\
\hline 6 Pain (dichotomous) at 3 months or less & 4 & 308 & $\begin{array}{l}\text { Risk Ratio (M-H, Random, 95\% } \\
\mathrm{Cl})\end{array}$ & $0.78[0.38,1.62]$ \\
\hline 6.1 ECTR vs standard OCTR & 3 & 248 & $\begin{array}{l}\text { Risk Ratio (M-H, Random, 95\% } \\
\mathrm{Cl})\end{array}$ & $0.57[0.25,1.30]$ \\
\hline 6.2 ECTR vs modified OCTR & 1 & 60 & $\begin{array}{l}\text { Risk Ratio (M-H, Random, 95\% } \\
\mathrm{Cl})\end{array}$ & $2.0[1.01,3.95]$ \\
\hline $\begin{array}{l}7 \text { Pain (dichotomous) at more than } 3 \\
\text { months }\end{array}$ & 5 & & $\begin{array}{l}\text { Risk Ratio (M-H, Random, 95\% } \\
\mathrm{Cl})\end{array}$ & Subtotals only \\
\hline 7.1 ECTR vs OCTR & 5 & 367 & $\begin{array}{l}\text { Risk Ratio (M-H, Random, 95\% } \\
\mathrm{Cl})\end{array}$ & $0.90[0.58,1.41]$ \\
\hline $\begin{array}{l}8 \text { Numbness (dichotomous) at } 3 \text { months or } \\
\text { less }\end{array}$ & 4 & & $\begin{array}{l}\text { Risk Ratio (M-H, Random, 95\% } \\
\mathrm{Cl})\end{array}$ & Subtotals only \\
\hline 8.1 ECTR vs OCTR & 4 & 395 & $\begin{array}{l}\text { Risk Ratio (M-H, Random, 95\% } \\
\text { Cl) }\end{array}$ & $1.15[0.76,1.72]$ \\
\hline $\begin{array}{l}9 \text { Numbness (dichotomous) at more than } 3 \\
\text { months }\end{array}$ & 3 & & $\begin{array}{l}\text { Risk Ratio (M-H, Random, 95\% } \\
\text { Cl) }\end{array}$ & Subtotals only \\
\hline 9.1 ECTR vs OCTR & 3 & 194 & $\begin{array}{l}\text { Risk Ratio (M-H, Random, 95\% } \\
\text { Cl) }\end{array}$ & $0.62[0.29,1.34]$ \\
\hline $\begin{array}{l}10 \text { Function Status Scale at } 3 \text { months or } \\
\text { less }\end{array}$ & 4 & & $\begin{array}{l}\text { Std. Mean Difference (Random, } \\
95 \% \mathrm{Cl} \text { ) }\end{array}$ & $-0.02[-0.22,0.17]$ \\
\hline 10.1 ECTR vs standard OCTR & 3 & & $\begin{array}{l}\text { Std. Mean Difference (Random, } \\
95 \% \mathrm{Cl} \text { ) }\end{array}$ & $0.02[-0.18,0.22]$ \\
\hline 10.2 ECTR vs modified OCTR & 1 & & $\begin{array}{l}\text { Std. Mean Difference (Random, } \\
95 \% \mathrm{Cl} \text { ) }\end{array}$ & $-0.48[-1.14,0.17]$ \\
\hline
\end{tabular}




\begin{tabular}{|c|c|c|c|c|}
\hline Outcome or subgroup title & $\begin{array}{l}\text { No. of } \\
\text { studies }\end{array}$ & $\begin{array}{l}\text { No. of } \\
\text { partici- } \\
\text { pants }\end{array}$ & Statistical method & Effect size \\
\hline 11 Grip strength at 3 months or less & 4 & & $\begin{array}{l}\text { Std. Mean Difference (Random, } \\
95 \% \mathrm{Cl} \text { ) }\end{array}$ & $0.52[0.03,1.02]$ \\
\hline 11.1 ECTR vs standard OCTR & 3 & & $\begin{array}{l}\text { Std. Mean Difference (Random, } \\
95 \% \mathrm{Cl} \text { ) }\end{array}$ & $0.65[0.00,1.31]$ \\
\hline 11.2 ECTR vs modified OCTR & 1 & & $\begin{array}{l}\text { Std. Mean Difference (Random, } \\
95 \% \mathrm{Cl} \text { ) }\end{array}$ & $0.14[-0.48,0.76]$ \\
\hline 12 Recurrence & 7 & 713 & $\begin{array}{l}\text { Risk Ratio (M-H, Random, 95\% } \\
\text { Cl) }\end{array}$ & $0.74[0.30,1.81]$ \\
\hline 12.1 ECTR vs standard OCTR & 6 & 653 & $\begin{array}{l}\text { Risk Ratio (M-H, Random, 95\% } \\
\mathrm{Cl})\end{array}$ & $0.62[0.20,1.92]$ \\
\hline 12.2 ECTR vs modified OCTR & 1 & 60 & $\begin{array}{l}\text { Risk Ratio (M-H, Random, 95\% } \\
\text { Cl) }\end{array}$ & $1.5[0.27,8.34]$ \\
\hline 13 Reoperations & 5 & 696 & $\begin{array}{l}\text { Risk Ratio (M-H, Random, 95\% } \\
\mathrm{Cl})\end{array}$ & $0.76[0.25,2.35]$ \\
\hline 13.1 ECTR vs standard OCTR & 5 & 567 & $\begin{array}{l}\text { Risk Ratio (M-H, Random, 95\% } \\
\text { Cl) }\end{array}$ & $1.11[0.37,3.29]$ \\
\hline 13.2 ECTR vs modified OCTR & 1 & 129 & $\begin{array}{l}\text { Risk Ratio (M-H, Random, 95\% } \\
\text { Cl) }\end{array}$ & $0.17[0.02,1.37]$ \\
\hline 14 Major complications & 9 & 859 & $\begin{array}{l}\text { Risk Ratio (M-H, Random, 95\% } \\
\text { Cl) }\end{array}$ & $1.12[0.40,3.11]$ \\
\hline 14.1 ECTR vs standard OCTR & 7 & 779 & $\begin{array}{l}\text { Risk Ratio (M-H, Random, 95\% } \\
\mathrm{Cl} \text { ) }\end{array}$ & $1.12[0.40,3.11]$ \\
\hline 14.2 ECTR vs modified OCTR & 2 & 80 & $\begin{array}{l}\text { Risk Ratio (M-H, Random, 95\% } \\
\text { Cl) }\end{array}$ & $0.0[0.0,0.0]$ \\
\hline 15 Minor complications & 9 & 872 & $\begin{array}{l}\text { Risk Ratio (M-H, Random, 95\% } \\
\mathrm{Cl})\end{array}$ & $0.54[0.32,0.94]$ \\
\hline 15.1 ECTR vs standard OCTR & 8 & 723 & $\begin{array}{l}\text { Risk Ratio (M-H, Random, 95\% } \\
\mathrm{Cl})\end{array}$ & $0.54[0.32,0.94]$ \\
\hline 15.2 ECTR vs modified OCTR & 2 & 149 & $\begin{array}{l}\text { Risk Ratio (M-H, Random, 95\% } \\
\mathrm{Cl})\end{array}$ & $0.0[0.0,0.0]$ \\
\hline 16 Total complications & 10 & 1088 & $\begin{array}{l}\text { Risk Ratio (M-H, Random, 95\% } \\
\mathrm{Cl} \text { ) }\end{array}$ & $0.72[0.45,1.14]$ \\
\hline 16.1 ECTR vs standard OCTR & 9 & 939 & $\begin{array}{l}\text { Risk Ratio (M-H, Random, 95\% } \\
\mathrm{Cl} \text { ) }\end{array}$ & $0.72[0.45,1.14]$ \\
\hline 16.2 ECTR vs modified OCTR & 2 & 149 & $\begin{array}{l}\text { Risk Ratio (M-H, Random, 95\% } \\
\text { Cl) }\end{array}$ & $0.0[0.0,0.0]$ \\
\hline
\end{tabular}


Analysis 4.1. Comparison 4 Sensitivity analysis 2 (exclusion of inappropriate adjustment for bilateral involvement), Outcome 1 Overall improvement at more than 3 months.

\begin{tabular}{|c|c|c|c|c|c|}
\hline Study or subgroup & $\begin{array}{c}\text { ECTR } \\
n / N\end{array}$ & $\begin{array}{l}\text { OCTR } \\
n / N\end{array}$ & $\begin{array}{c}\text { Risk Ratio } \\
\text { M-H, Random, } 95 \% \mathrm{Cl}\end{array}$ & Weight & $\begin{array}{c}\text { Risk Ratio } \\
\text { M-H, Random, } 95 \% \text { CI }\end{array}$ \\
\hline \multicolumn{6}{|c|}{ 4.1.1 ECTR vs standard OCTR } \\
\hline Atroshi 2006 & $54 / 63$ & $52 / 63$ & & $71.1 \%$ & $1.04[0.89,1.21]$ \\
\hline Malhotra 2007 & $25 / 30$ & $21 / 31$ & & $19.38 \%$ & $1.23[0.92,1.65]$ \\
\hline Subtotal $(95 \% \mathrm{Cl})$ & 93 & 94 & & $90.47 \%$ & $1.08[0.94,1.25]$ \\
\hline \multicolumn{6}{|c|}{ Total events: 79 (ECTR), 73 (OCTR) } \\
\hline \multicolumn{6}{|c|}{ Test for overall effect: $Z=1.05(P=0.29)$} \\
\hline \multicolumn{6}{|c|}{ 4.1.2 ECTR vs modified OCTR } \\
\hline Wong 2003 & $17 / 30$ & $19 / 30$ & $\because$ & $9.53 \%$ & $0.89[0.59,1.35]$ \\
\hline Subtotal $(95 \% \mathrm{CI})$ & 30 & 30 & & $9.53 \%$ & $0.89[0.59,1.35]$ \\
\hline \multicolumn{6}{|c|}{ Total events: 17 (ECTR), 19 (OCTR) } \\
\hline \multicolumn{6}{|c|}{ Heterogeneity: Not applicable } \\
\hline \multicolumn{6}{|c|}{ Test for overall effect: $Z=0.53(P=0.6)$} \\
\hline Total $(95 \% \mathrm{Cl})$ & 123 & 124 & & $100 \%$ & $1.06[0.93,1.2]$ \\
\hline \multicolumn{6}{|c|}{ Total events: 96 (ECTR), 92 (OCTR) } \\
\hline \multicolumn{6}{|c|}{ Heterogeneity: $\operatorname{Tau}^{2}=0 ; \mathrm{Chi}^{2}=1.72, \mathrm{df}=2(\mathrm{P}=0.42) ; \mathrm{I}^{2}=0 \%$} \\
\hline \multicolumn{6}{|c|}{ Test for overall effect: $Z=0.86(P=0.39)$} \\
\hline Test for subgroup dif & $=1(P=0.4), I^{2}$ & & & & \\
\hline
\end{tabular}

Analysis 4.2. Comparison 4 Sensitivity analysis 2 (exclusion of inappropriate adjustment for bilateral involvement), Outcome 2 Symptom Severity Scale (Levine) at 3 months or less.

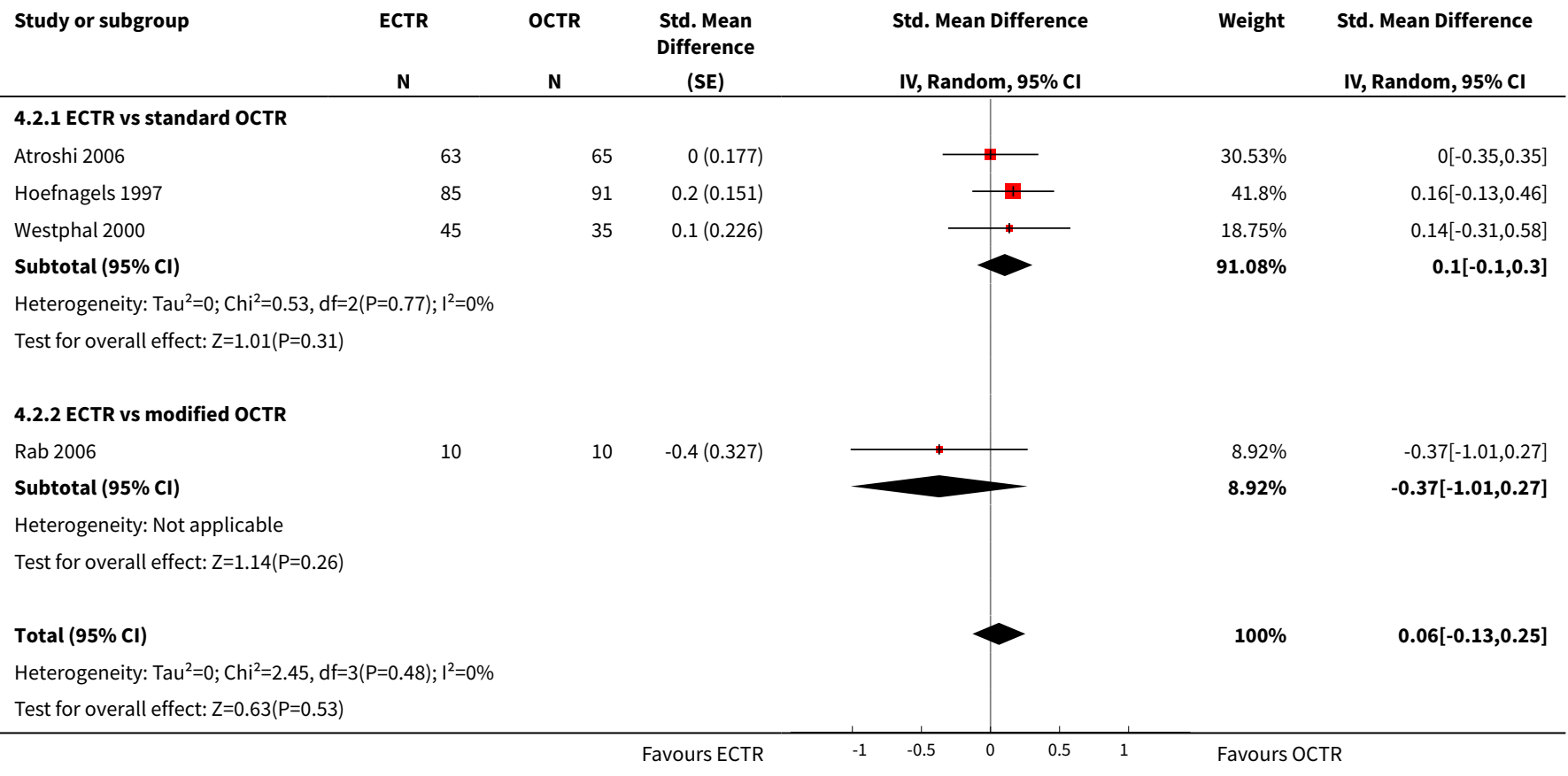




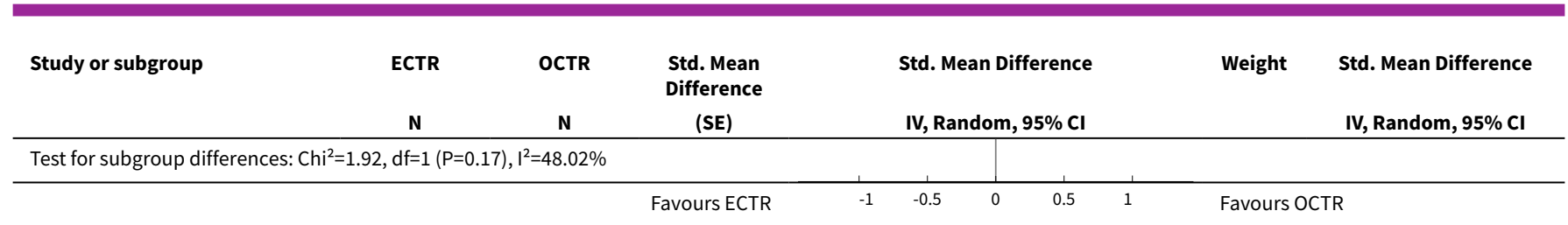

Analysis 4.3. Comparison 4 Sensitivity analysis 2 (exclusion of inappropriate adjustment for bilateral involvement), Outcome 3 Pain at 3 months or less (corr $=0.5$ ).

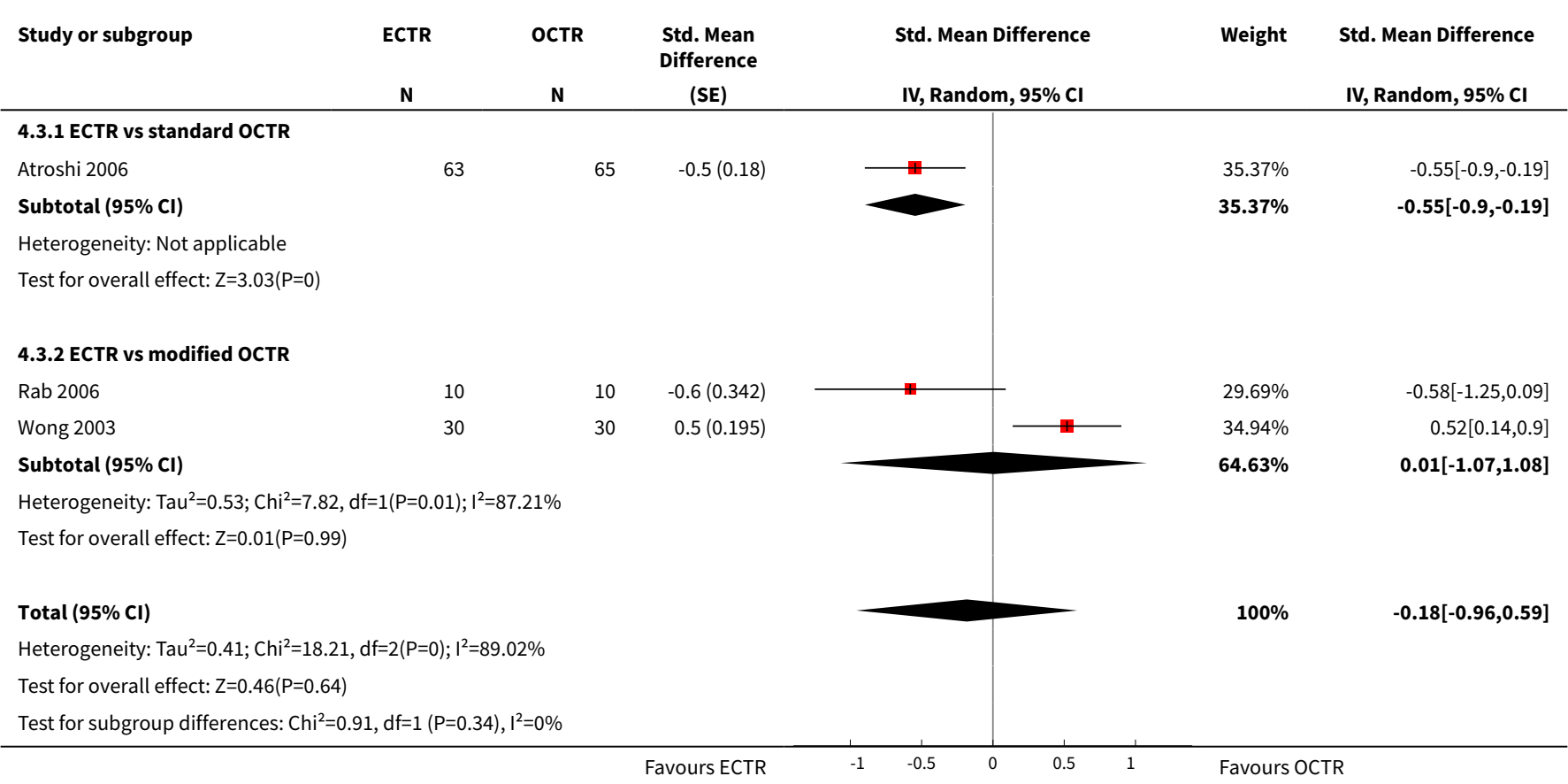

Analysis 4.4. Comparison 4 Sensitivity analysis 2 (exclusion of inappropriate adjustment for bilateral involvement), Outcome 4 Pain at 3 months or less (corr $=0.1$ ).

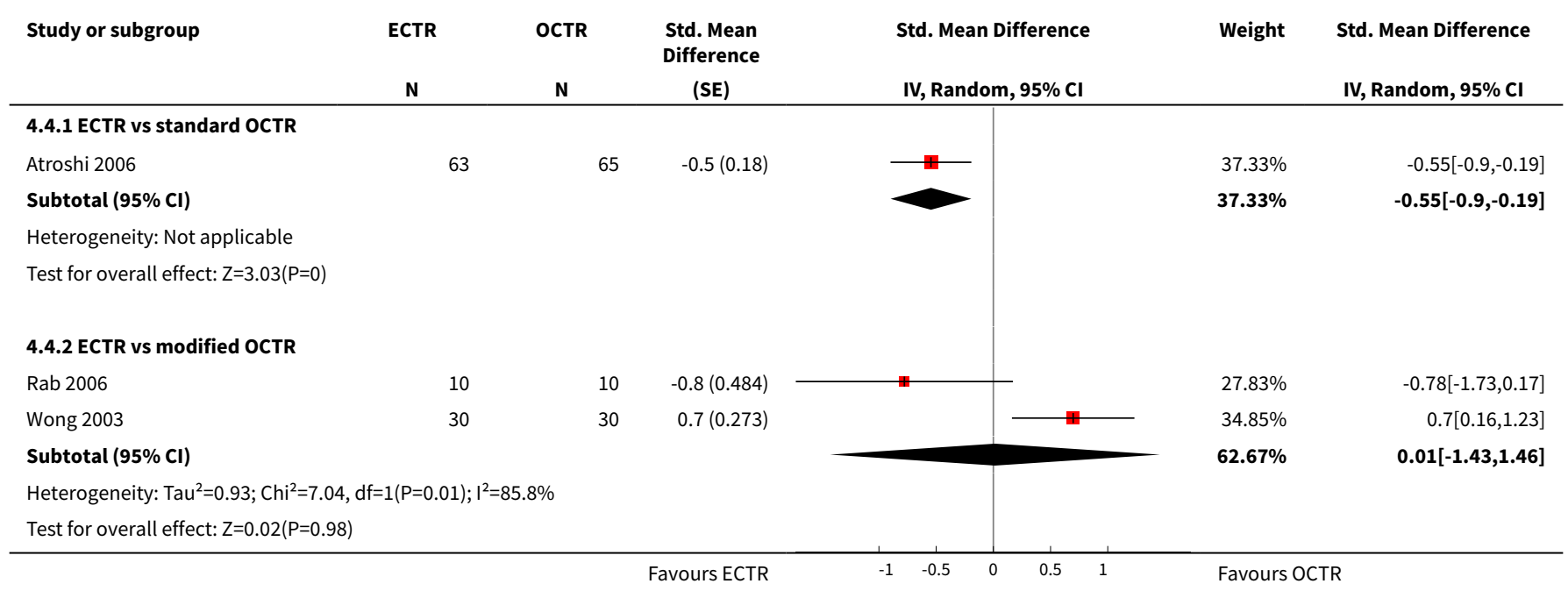




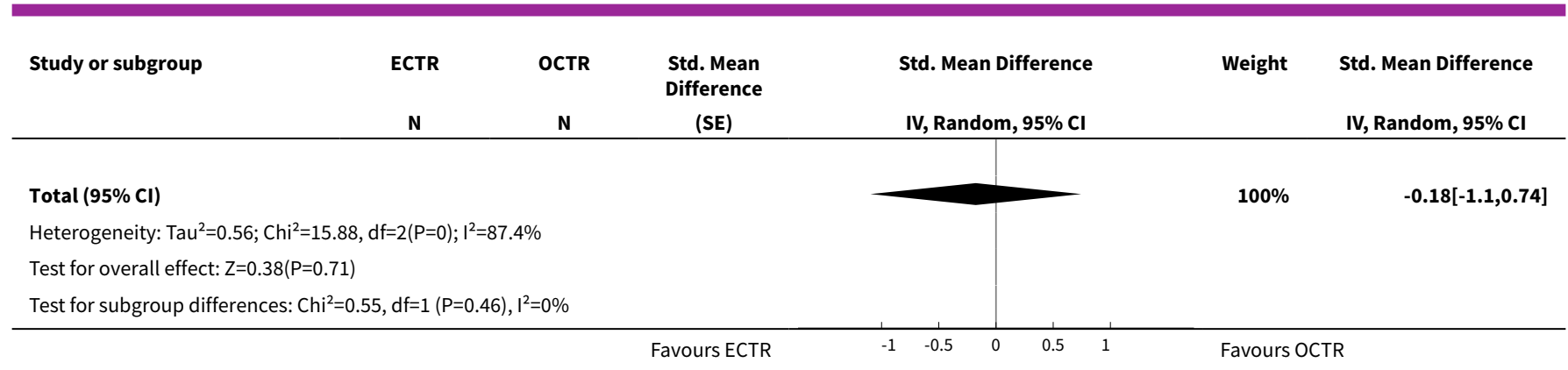

Analysis 4.5. Comparison 4 Sensitivity analysis 2 (exclusion of inappropriate adjustment for bilateral involvement), Outcome 5 Pain at 3 months or less (corr $=0.9$ ).

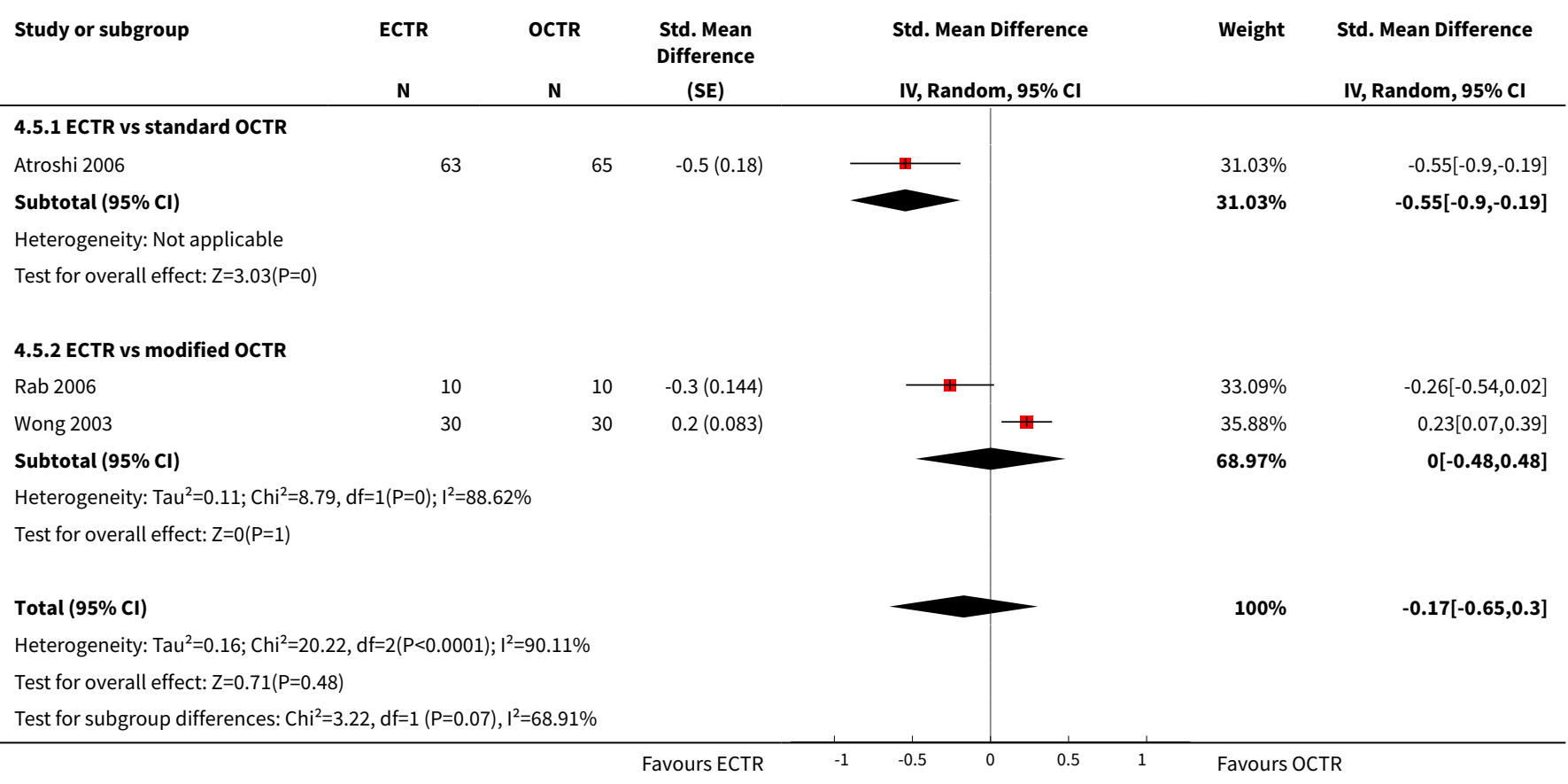

Analysis 4.6. Comparison 4 Sensitivity analysis 2 (exclusion of inappropriate adjustment for bilateral involvement), Outcome 6 Pain (dichotomous) at 3 months or less.

\begin{tabular}{|c|c|c|c|c|c|}
\hline Study or subgroup & $\begin{array}{c}\text { ECTR } \\
n / N\end{array}$ & $\begin{array}{c}\text { OCTR } \\
\mathrm{n} / \mathrm{N}\end{array}$ & $\begin{array}{c}\text { Risk Ratio } \\
\text { M-H, Random, } 95 \% \mathrm{CI}\end{array}$ & Weight & $\begin{array}{c}\text { Risk Ratio } \\
\text { M-H, Random, } 95 \% \mathrm{CI}\end{array}$ \\
\hline \multicolumn{6}{|c|}{ 4.6.1 ECTR vs standard OCTR } \\
\hline Agee 1992 & $31 / 74$ & $27 / 55$ & $\longrightarrow$ & $29.79 \%$ & $0.85[0.58,1.25]$ \\
\hline Dumontier 1995 & $11 / 28$ & $13 / 30$ & - & $26.33 \%$ & $0.91[0.49,1.68]$ \\
\hline Malhotra 2007 & $3 / 30$ & $20 / 31$ & & $18.6 \%$ & $0.16[0.05,0.47]$ \\
\hline Subtotal $(95 \% \mathrm{CI})$ & 132 & 116 & & $74.73 \%$ & $0.57[0.25,1.3]$ \\
\hline \multicolumn{6}{|c|}{ Total events: 45 (ECTR), 60 (OCTR) } \\
\hline \multicolumn{6}{|c|}{ Heterogeneity: $\mathrm{Tau}^{2}=0.39 ; \mathrm{Chi}^{2}=9.62, \mathrm{df}=2(\mathrm{P}=0.01) ; \mathrm{I}^{2}=79.22 \%$} \\
\hline \multicolumn{6}{|c|}{ Test for overall effect: $\mathrm{Z}=1.33(\mathrm{P}=0.18)$} \\
\hline
\end{tabular}




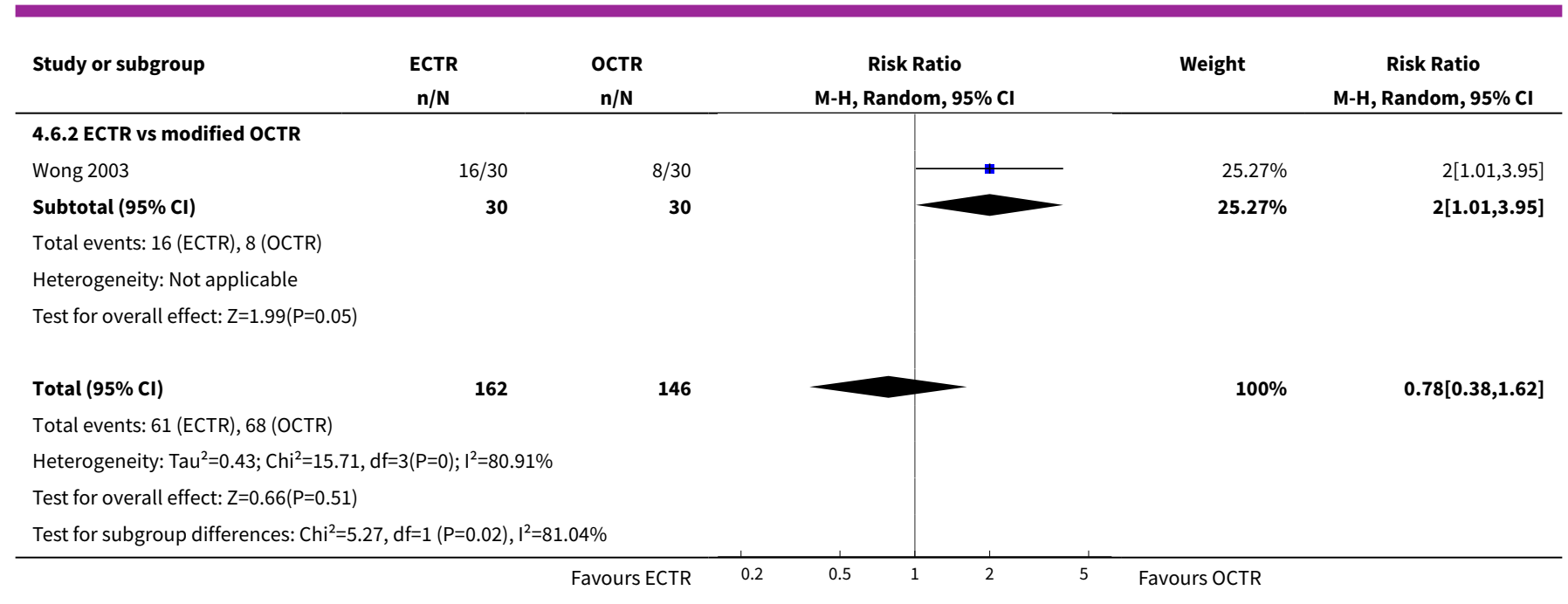

Analysis 4.7. Comparison 4 Sensitivity analysis 2 (exclusion of inappropriate adjustment for bilateral involvement), Outcome 7 Pain (dichotomous) at more than $\mathbf{3}$ months.

\begin{tabular}{|c|c|c|c|c|c|}
\hline Study or subgroup & $\begin{array}{c}\text { ECTR } \\
\mathrm{n} / \mathrm{N}\end{array}$ & $\begin{array}{c}\text { OCTR } \\
\mathrm{n} / \mathrm{N}\end{array}$ & $\begin{array}{c}\text { Risk Ratio } \\
\text { M-H, Random, } 95 \% \mathrm{CI}\end{array}$ & Weight & $\begin{array}{c}\text { Risk Ratio } \\
\text { M-H, Random, } 95 \% \text { CI }\end{array}$ \\
\hline \multicolumn{6}{|l|}{ 4.7.1 ECTR vs OCTR } \\
\hline Agee 1992 & $16 / 65$ & $13 / 48$ & & $50.92 \%$ & $0.91[0.48,1.71]$ \\
\hline Atroshi 2006 & $10 / 63$ & $11 / 63$ & & $33.02 \%$ & $0.91[0.42,1.99]$ \\
\hline Benedetti/Sennwald 1995 & $0 / 25$ & $1 / 22$ & & $2.03 \%$ & $0.29[0.01,6.89]$ \\
\hline Dumontier 1995 & $2 / 8$ & $3 / 12$ & - & $8.41 \%$ & $1[0.21,4.71]$ \\
\hline Malhotra 2007 & $2 / 30$ & $2 / 31$ & & $5.62 \%$ & $1.03[0.16,6.87]$ \\
\hline Subtotal $(95 \% \mathrm{Cl})$ & 191 & 176 & & $100 \%$ & $0.9[0.58,1.41]$ \\
\hline \multicolumn{6}{|c|}{ Total events: 30 (ECTR), 30 (OCTR) } \\
\hline \multicolumn{6}{|c|}{ Heterogeneity: $\mathrm{Tau}^{2}=0 ; \mathrm{Chi}^{2}=0.52, \mathrm{df}=4(\mathrm{P}=0.97) ; \mathrm{I}^{2}=0 \%$} \\
\hline \multicolumn{6}{|c|}{ Test for overall effect: $Z=0.45(P=0.65)$} \\
\hline
\end{tabular}

\section{Analysis 4.8. Comparison 4 Sensitivity analysis 2 (exclusion of inappropriate adjustment for bilateral involvement), Outcome 8 Numbness (dichotomous) at 3 months or less.}

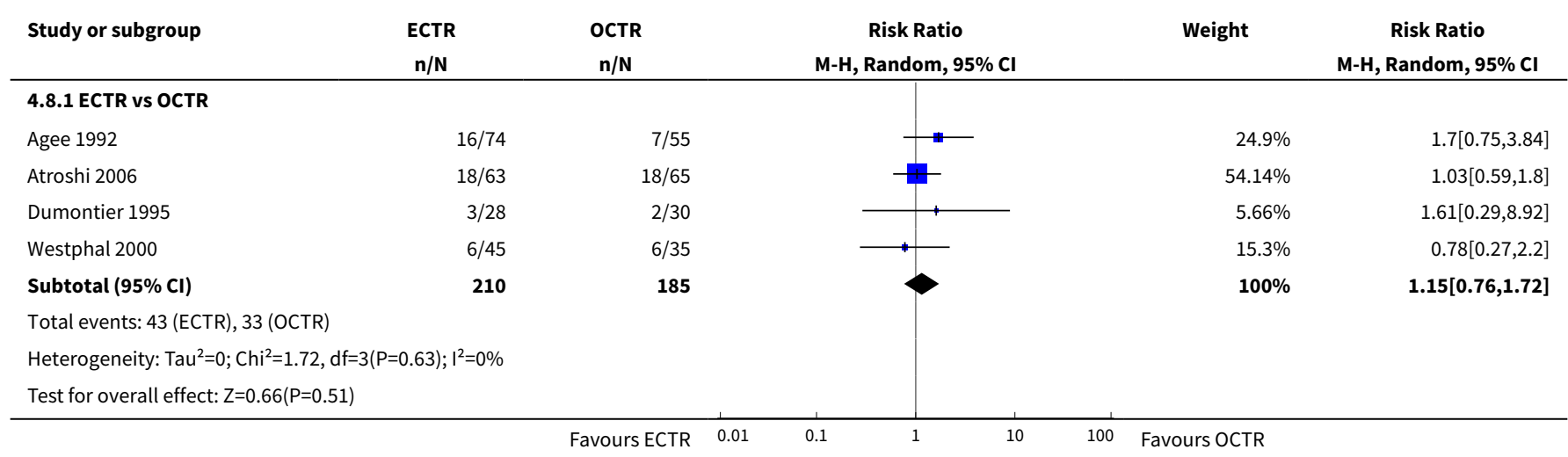


Analysis 4.9. Comparison 4 Sensitivity analysis 2 (exclusion of inappropriate adjustment for bilateral involvement), Outcome 9 Numbness (dichotomous) at more than 3 months.

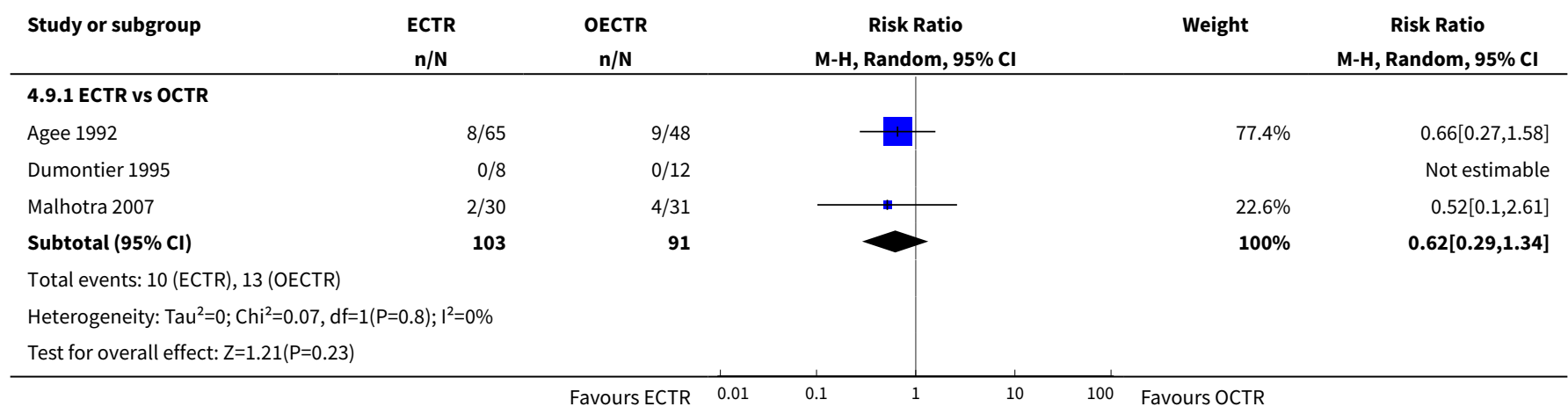

Analysis 4.10. Comparison 4 Sensitivity analysis 2 (exclusion of inappropriate adjustment for bilateral involvement), Outcome 10 Function Status Scale at $\mathbf{3}$ months or less.

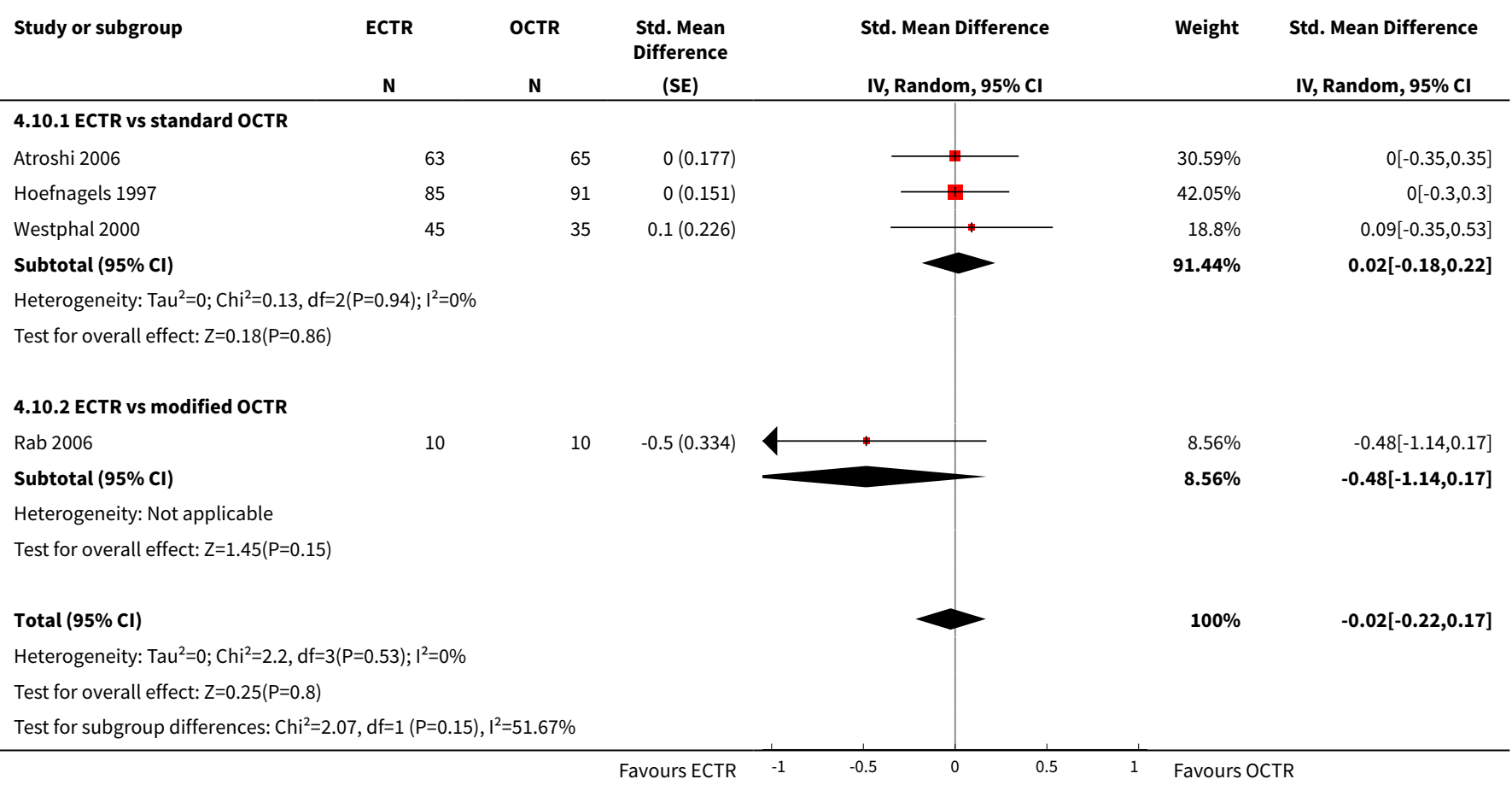

Analysis 4.11. Comparison 4 Sensitivity analysis 2 (exclusion of inappropriate adjustment for bilateral involvement), Outcome 11 Grip strength at 3 months or less.

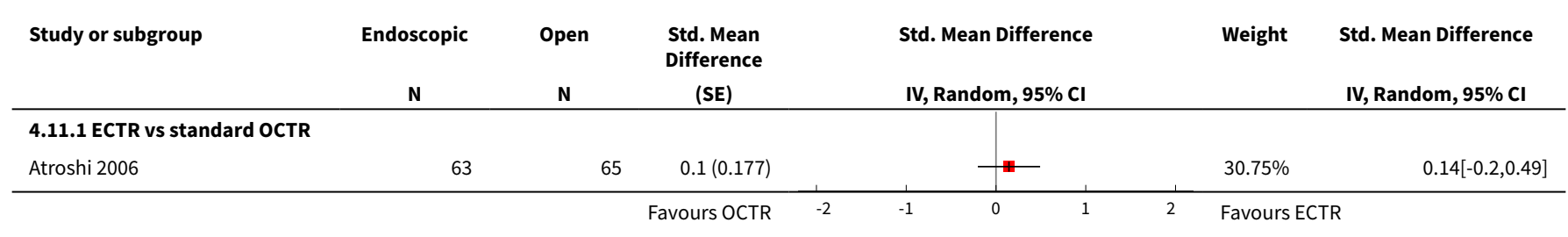




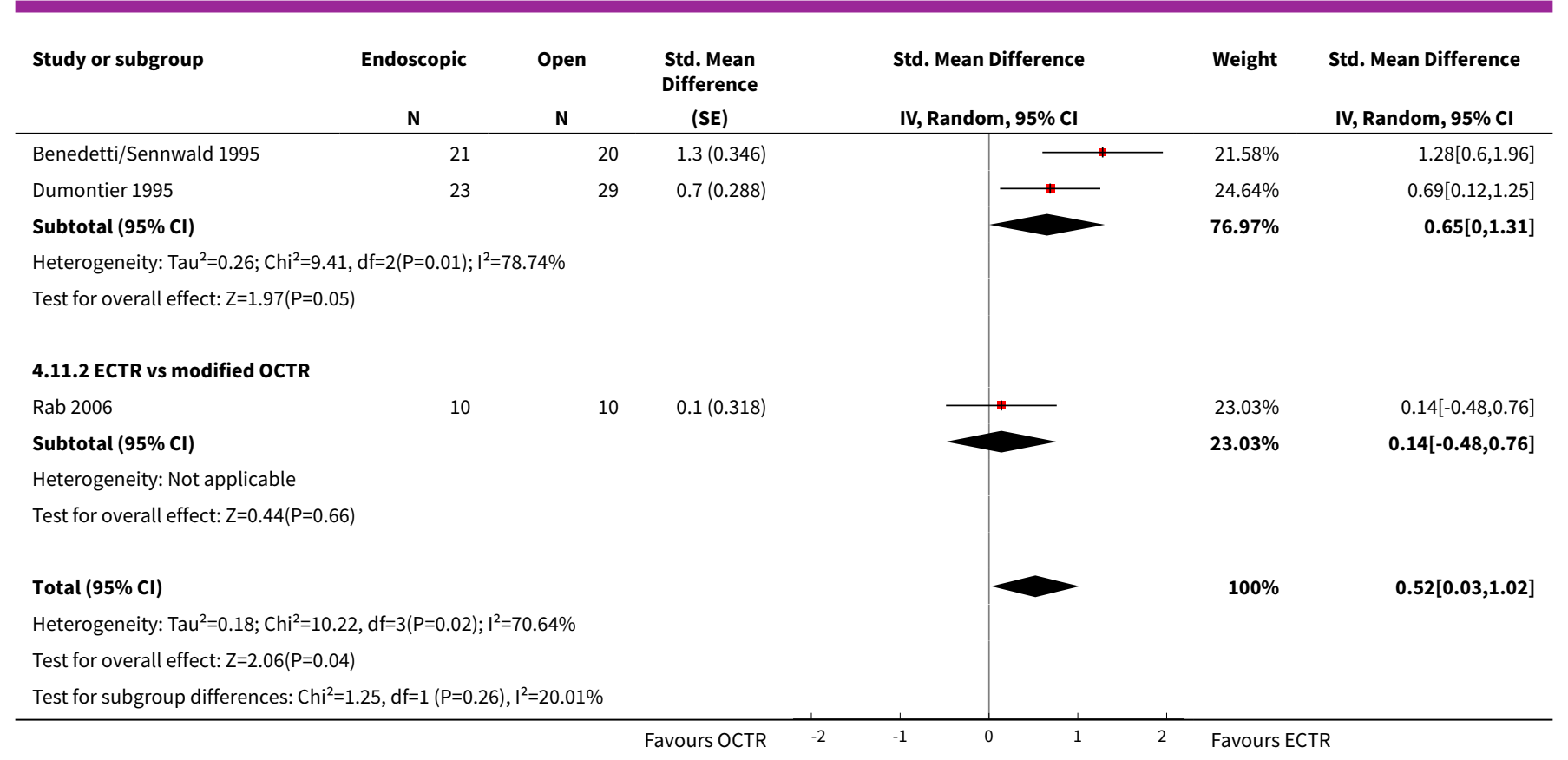

Analysis 4.12. Comparison 4 Sensitivity analysis 2 (exclusion of inappropriate adjustment for bilateral involvement), Outcome 12 Recurrence.

\begin{tabular}{|c|c|c|c|c|c|}
\hline Study or subgroup & $\begin{array}{c}\text { ECTR } \\
\mathrm{n} / \mathrm{N}\end{array}$ & $\begin{array}{c}\text { OCTR } \\
\mathrm{n} / \mathrm{N}\end{array}$ & $\begin{array}{c}\text { Risk Ratio } \\
\text { M-H, Random, } 95 \% \text { Cl }\end{array}$ & Weight & $\begin{array}{c}\text { Risk Ratio } \\
\text { M-H, Random, } 95 \% \text { Cl }\end{array}$ \\
\hline \multicolumn{6}{|c|}{ 4.12.1 ECTR vs standard OCTR } \\
\hline Atroshi 2006 & $10 / 63$ & $9 / 63$ & - & $39.19 \%$ & $1.11[0.48,2.55]$ \\
\hline Dumontier 1995 & $0 / 28$ & $0 / 30$ & & & Not estimable \\
\hline Eichhorn 2003 & $3 / 128$ & $13 / 125$ & $\longrightarrow$ & $27.96 \%$ & $0.23[0.07,0.77]$ \\
\hline Erdmann 1994 & $1 / 53$ & $0 / 52$ & $\longrightarrow$ & $7.03 \%$ & $2.94[0.12,70.67]$ \\
\hline Malhotra 2007 & $0 / 30$ & $0 / 31$ & & & Not estimable \\
\hline Subtotal $(95 \% \mathrm{CI})$ & 327 & 326 & & $81.31 \%$ & $0.62[0.2,1.92]$ \\
\hline \multicolumn{6}{|c|}{ Total events: 14 (ECTR), 23 (OCTR) } \\
\hline \multicolumn{6}{|c|}{ Heterogeneity: $\mathrm{Tau}^{2}=0.56 ; \mathrm{Chi}^{2}=5.57, \mathrm{df}=3(\mathrm{P}=0.13) ; \mathrm{I}^{2}=46.14 \%$} \\
\hline \multicolumn{6}{|c|}{ Test for overall effect: $Z=0.82(P=0.41)$} \\
\hline Wong 2003 & $3 / 30$ & $2 / 30$ & $\rightarrow$ & $18.69 \%$ & $1.5[0.27,8.34]$ \\
\hline Subtotal $(95 \% \mathrm{Cl})$ & 30 & 30 & & $18.69 \%$ & $1.5[0.27,8.34]$ \\
\hline \multicolumn{6}{|c|}{ Total events: 3 (ECTR), 2 (OCTR) } \\
\hline \multicolumn{6}{|c|}{ Heterogeneity: Not applicable } \\
\hline \multicolumn{6}{|c|}{ Test for overall effect: $Z=0.46(P=0.64)$} \\
\hline Total $(95 \% \mathrm{Cl})$ & 357 & 356 & & $100 \%$ & $0.74[0.3,1.81]$ \\
\hline \multicolumn{6}{|c|}{ Total events: 17 (ECTR), 25 (OCTR) } \\
\hline \multicolumn{6}{|c|}{ Heterogeneity: $\mathrm{Tau}^{2}=0.36 ; \mathrm{Chi}^{2}=6.24, \mathrm{df}=4(\mathrm{P}=0.18) ; \mathrm{I}^{2}=35.94 \%$} \\
\hline \multicolumn{6}{|c|}{ Test for overall effect: $Z=0.66(P=0.51)$} \\
\hline Test for subgroup dif & $=1(P=0.4), I^{2}=$ & & & & \\
\hline
\end{tabular}


Analysis 4.13. Comparison 4 Sensitivity analysis 2 (exclusion of inappropriate adjustment for bilateral involvement), Outcome 13 Reoperations.

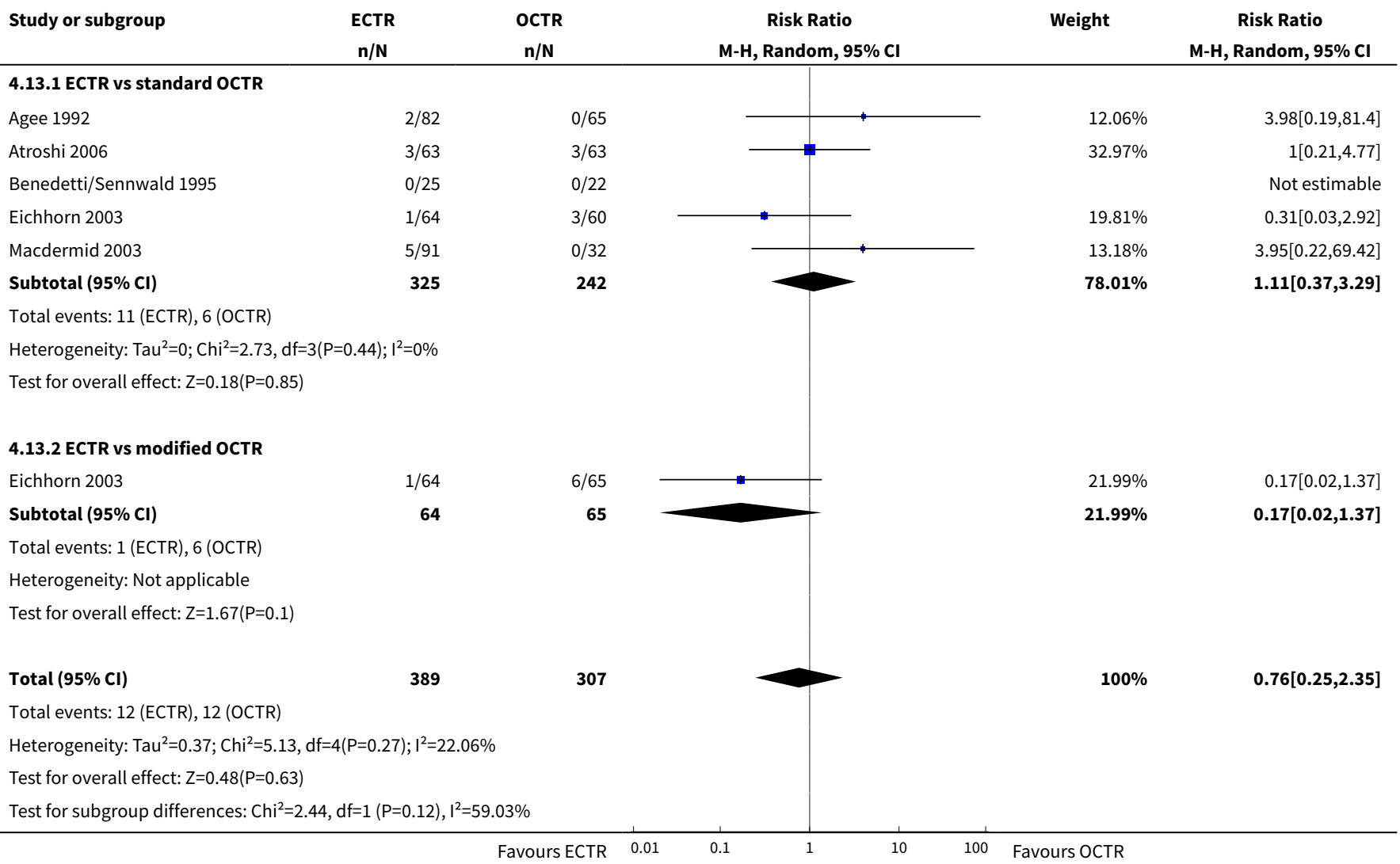

\section{Analysis 4.14. Comparison 4 Sensitivity analysis 2 (exclusion of inappropriate adjustment for bilateral involvement), Outcome 14 Major complications.}

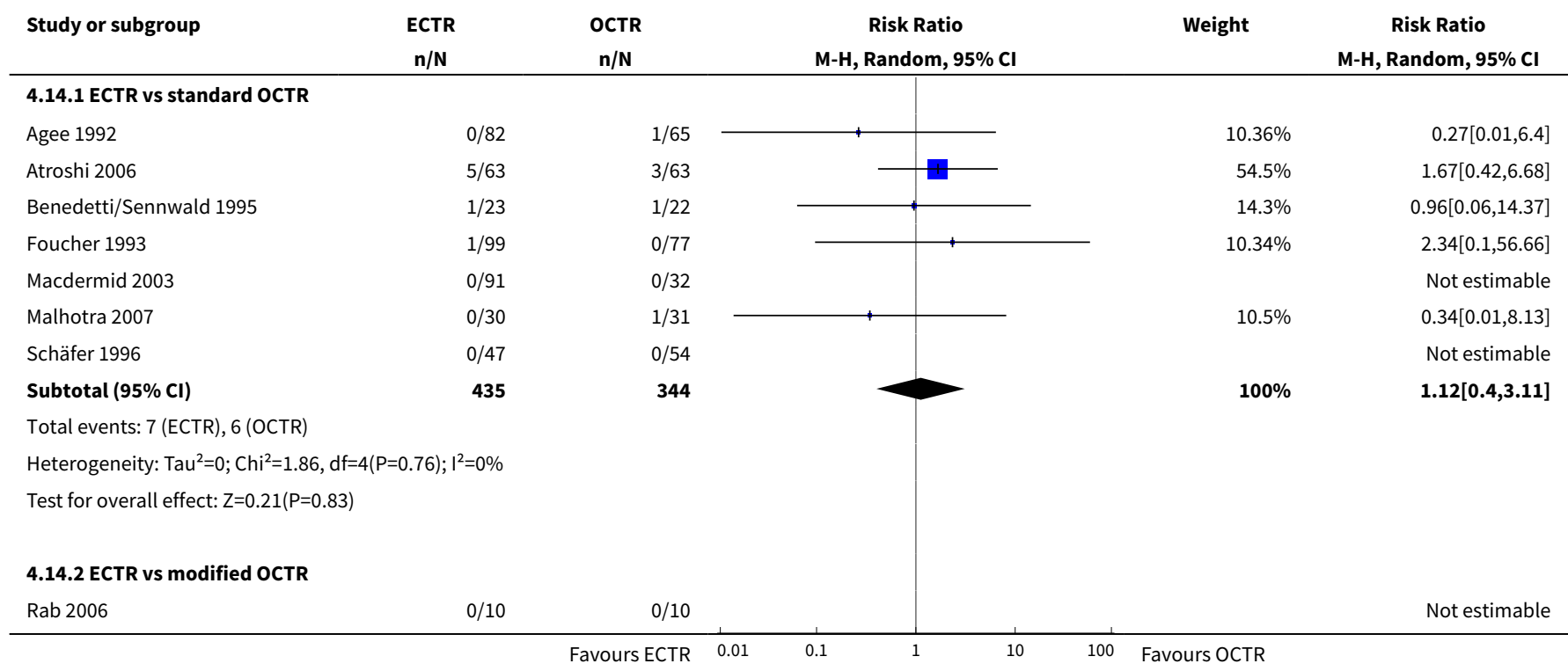




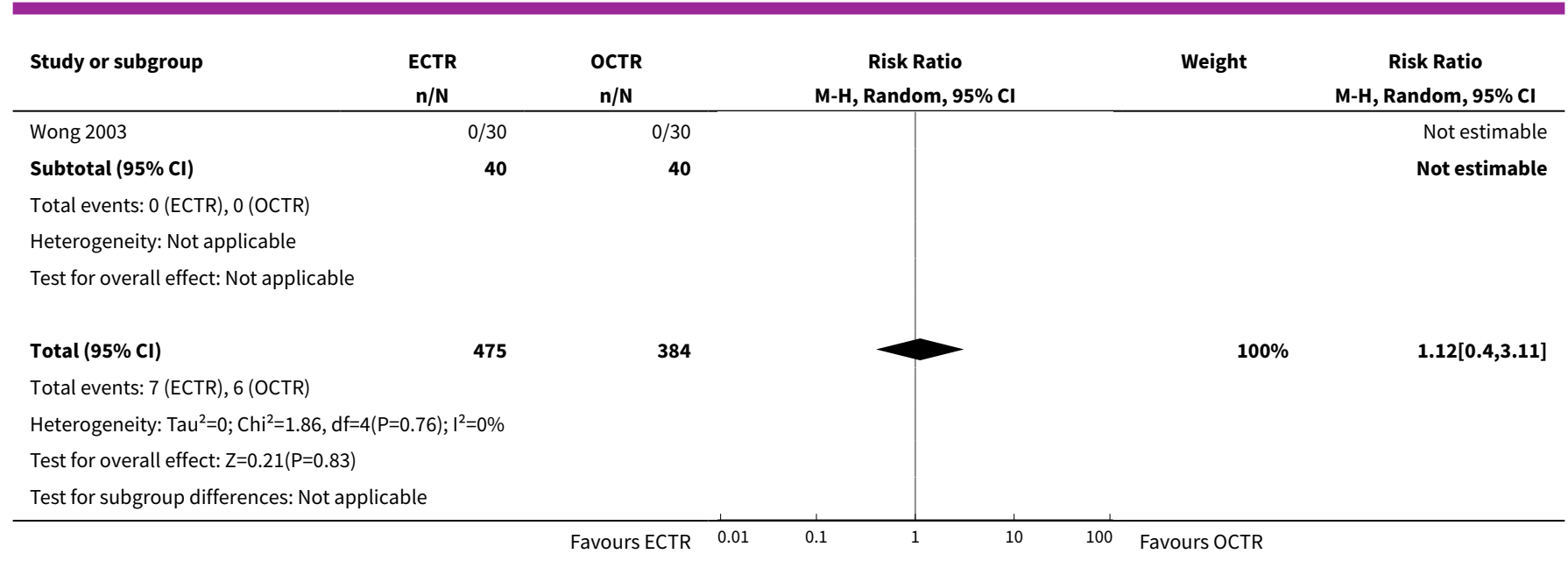

\section{Analysis 4.15. Comparison 4 Sensitivity analysis 2 (exclusion of inappropriate adjustment for bilateral involvement), Outcome 15 Minor complications.}

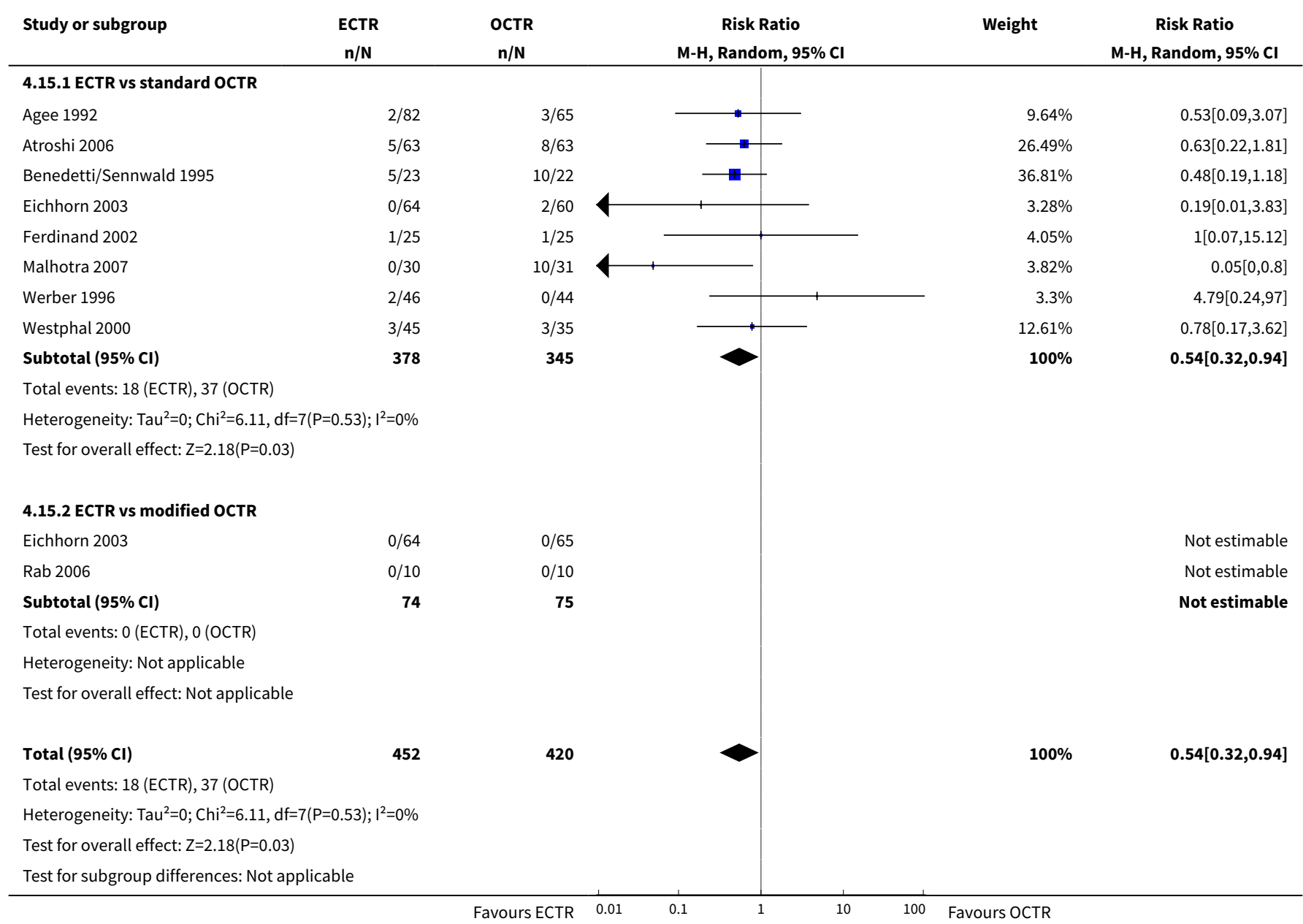


Analysis 4.16. Comparison 4 Sensitivity analysis 2 (exclusion of inappropriate adjustment for bilateral involvement), Outcome 16 Total complications.

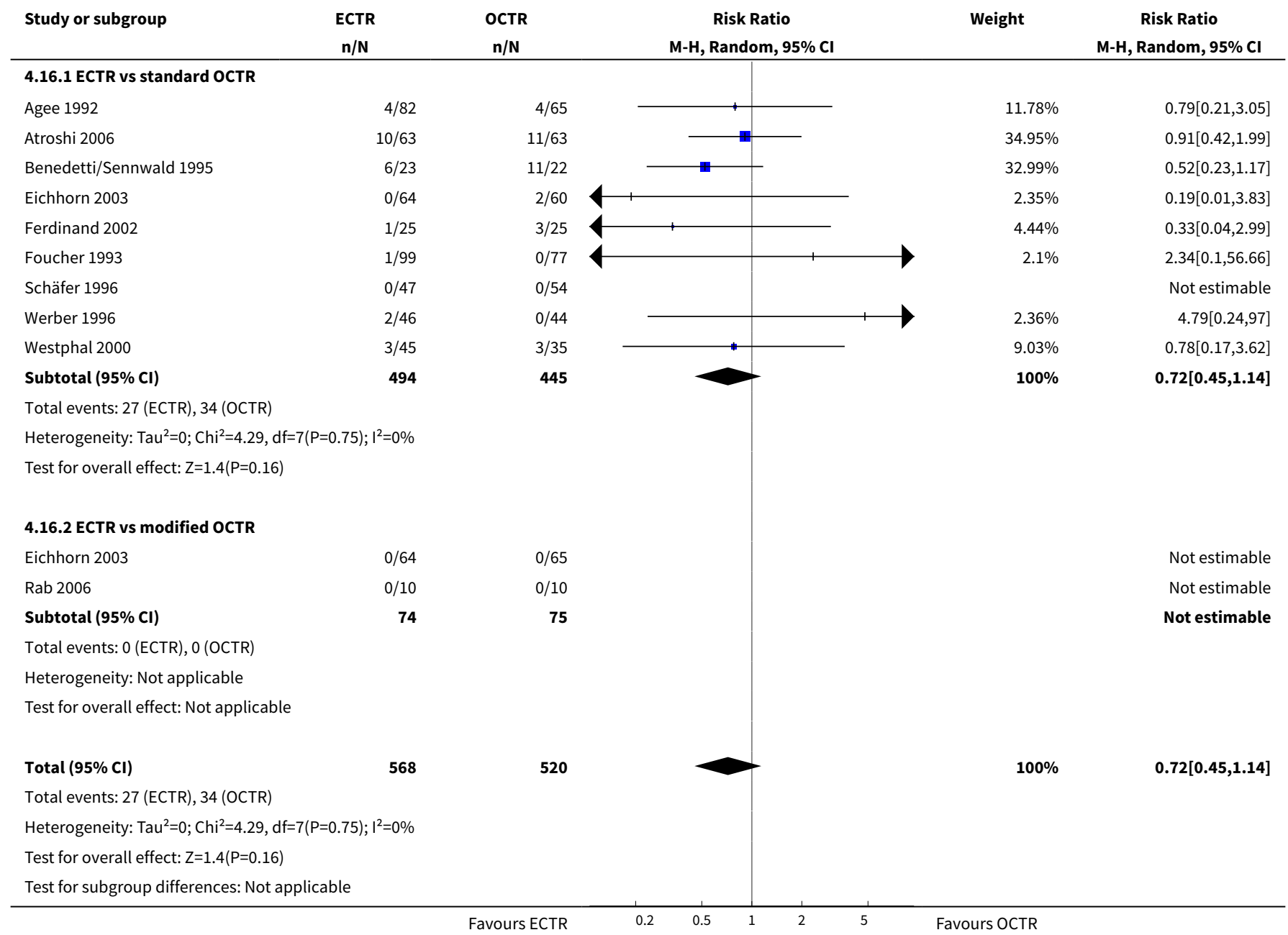

\section{ADDITIONAL TABLES}

Table 1. Endoscopic versus open carpal tunnel release

\begin{tabular}{|c|c|c|c|c|}
\hline $\begin{array}{l}\text { Refer- } \\
\text { ences }\end{array}$ & Symptoms $\leq 3$ months & $\begin{array}{l}\text { Symptoms } \geq 3 \\
\text { months }\end{array}$ & $\begin{array}{l}\text { Return to work / ac- } \\
\text { tivities of daily liv- } \\
\text { ing }\end{array}$ & Complications \\
\hline Agee 1992 & $\begin{array}{l}\text { Results of } 97 \text { adequately ran- } \\
\text { domised participants with unilat- } \\
\text { eral CTS not presented separate- } \\
\text { ly. At } 3 \text { months, } 42 \% \text { of ECTR and } \\
49 \% \text { of OCTR participants still had } \\
\text { pain. } 22 \% \text { of ECTR and } 13 \% \text { of OC- } \\
\text { TR participants still had numb- } \\
\text { ness. No significant differences }\end{array}$ & $\begin{array}{l}\text { Results of } 97 \text { ad- } \\
\text { equately ran- } \\
\text { domised patients } \\
\text { with unilateral } \\
\text { CTS not present- } \\
\text { ed separately. At } 6 \\
\text { months, } 25 \% \text { of EC- } \\
\text { TR and } 27 \% \text { of OC- } \\
\text { TR patients still had } \\
\text { pain. } 12 \% \text { of ECTR } \\
\text { and } 19 \% \text { of OCTR }\end{array}$ & $\begin{array}{l}\text { Median } 25 \text { (ECTR) } \\
\text { and } 46.5 \text { (OCTR) days } \\
\text { (significant differ- } \\
\text { ence between the } \\
\text { groups) }\end{array}$ & $\begin{array}{l}\text { ECTR: re-operation needed with } \\
\text { OCTR in } 2 \text { of } 82 \text { participants; tran- } \\
\text { sient ulnar neurapraxia (2) OCTR: } \\
\text { injury to deep motor branch of ul- } \\
\text { nar nerve (1); bowstringing of dig- } \\
\text { ital flexor tendons (1); wound de- } \\
\text { hiscence (2) }\end{array}$ \\
\hline
\end{tabular}


Table 1. Endoscopic versus open carpal tunnel release (Continued)

patients still had

numbness. No sig-

nificant differences

\begin{tabular}{|c|c|c|c|}
\hline $\begin{array}{l}\text { Atroshi } \\
2006\end{array}$ & $\begin{array}{l}\text { Mean SSS (Levine) after } 3 \text { months: } \\
\text { ECTR 1.5; OCTR } 1.5 \\
\text { Mean FSS (Levine) after } 3 \text { months: } \\
\text { ECTR 1.3; OCTR } 1.3 \text { Difference in } \\
\text { mean pain scores ( } 0 \text { to } 100) \text { after } \\
3 \text { months }-13.3 \text { ( } 95 \% \text { Cl - } 21.3 \text { to } \\
-5.3 \text { ) in favour of ECTR }\end{array}$ & $\begin{array}{l}\text { Mean SSS (Levine) } \\
\text { after } 12 \text { months: } \\
\text { ECTR } 1.4 \text {; OCTR } \\
1.4 \text { (NS). Mean } \\
\text { FSS (Levine) af- } \\
\text { ter } 12 \text { months: EC- } \\
\text { TR } 1.3 \text {; OCTR } 1.2 \\
\text { (NS). Difference in } \\
\text { mean pain scores } \\
\text { (0 to } 100 \text { ) after } 12 \\
\text { months -5.8 ( } 95 \% \\
\text { Cl - } 13.3 \text { to - } 1.7) \\
\text { in favour of EC- } \\
\text { TR. Outcomes re- } \\
\text { mained similar at } 5 \\
\text { years }\end{array}$ & $\begin{array}{l}\text { Not on sick leave be- } \\
\text { fore surgery: } \mathrm{MD}-5 \\
\text { days ( } 95 \% \mathrm{Cl}-11.5 \text { to } \\
1.5 \text { days) in favour of } \\
\text { ECTR. On sick leave } \\
\text { before } \\
\text { surgery: MD } 8 \text { days } \\
\text { ( } 95 \% \mathrm{Cl}-62.5 \text { to } 78.5 \\
\text { days) in favour of } \\
\text { OCTR. MD for all pa- } \\
\text { tients }-4.89 \text { days, } \\
95 \% \mathrm{Cl}-11.35 \text { to } 1.57 \\
\text { days favours ECTR } \\
\text { patients }\end{array}$ \\
\hline
\end{tabular}

Repeat surgery at 1 year: ECTR 2/63 (3\%); OCTR 1/65 (2\%). No other complications. Between 1 year and 5 years postoperatively. 2 participants in the open group and 1 participant in the endoscopic group had OCTR because of recurrent symptoms

\begin{tabular}{lll}
\hline Benedet- $\quad$ Not assessed & Not assessed & Mean 24 (ECTR) and \\
ti/Sen- & & 42 (OCTR) days (sig- \\
nwald & nificant difference \\
1995 & between the groups)
\end{tabular}

1 conversion to OCTR and 1 transient neurapraxia after ECTR. 1 painful hypertrophic scar and 1 reflex sympathetic dystrophy after OCTR

$\begin{array}{ll}\text { Brown } & \text { Improvement in symptoms } \\ 1993 & \text { (paraesthesiae, numbness) in } 99 \% \\ \text { of hands (ECTR) and } 98 \% \text { of hands } \\ \text { (OCTR) after } 12 \text { weeks (difference } \\ 1 \%, 95 \% \text { Cl - 3\% to } 5 \% \text { ) }\end{array}$

Not assessed
Mean SSS (Levine)
ECTR 1.4; OCTR
FSS (Levine) af-
an pain scores
months $-5.8(95 \%$
R. Outcomes re
years

\section{Median 14 (ECTR) and 28 (OCTR) days (significant differ- ence between the groups)}

Significantly more scar tenderness after OCTR vs ECTR after 12 weeks (no significant differences after 3 and 6 weeks). No significant differences between the groups in tenderness of the thenar eminence at 3, 6 and 12 weeks. 1 partial transection of the superficial palmar arch, 1 digital-nerve contusion, 1 ulnar-nerve neurapraxia and 1 wound haematoma after ECTR

Transient reflex sympathetic dystrophy in 4 participants ( 2 in each group)
Dumon- Persisting paraesthesiae after

tier 19953 months: 7\% (OCTR) vs 11\%

(ECTR). Persisting pain after 3 months: $43.3 \%$ (OCTR) vs $38.5 \%$ (ECTR)
Paraesthesiae completely disappeared in all patients after 6 months. Persisting pain after 6 months: $28 \%$ (OCTR) vs $25 \%$ (ECTR)
Percentage of participants returned to work (OCTR vs ECTR): $72 \%$ vs $45 \%$ after 1 month; $90 \%$ vs $72 \%$ after 3 months
Overall severity score (scale 1 to 6 ) after $>1$ year: OCTR 2.2; ECTR 2.1
Postoperative infections: 2 after OCTR; none after ECTR Recurrences: ECTR 3/128 (2\%), OCTR

$4 / 60(7 \%)$

Need for repeated surgery: ECTR 2/128 (2\%), OCTR 3/60 (5\%)

\begin{tabular}{lllll}
\hline $\begin{array}{l}\text { Erdmann } \\
1994\end{array}$ & $\begin{array}{l}\text { Significantly more improvement } \\
\text { in carpal tunnel pain in favour of } \\
\text { ECTR after 1, } 2 \text { and 4 weeks, but }\end{array}$ & $\begin{array}{l}\text { No significant dif- } \\
\text { ference in carpal } \\
\text { tunnel pain be- } \\
\text { tween the groups }\end{array}$ & $\begin{array}{l}\text { Mean 14 (ECTR) and } \\
\text { 39 (OCTR) days (on- } \\
\text { ly participants not si- } \\
\text { multaneously oper- }\end{array}$ & $\begin{array}{l}\text { incomplete release after ECTR. } 1 \\
\text { incound infection, } 1 \text { scar tethering }\end{array}$ \\
\end{tabular}

Endoscopic release for carpal tunnel syndrome (Review) 
Table 1. Endoscopic versus open carpal tunnel release (Continued)

no significant difference between

the groups after 3 months

after 6 and 12

months ated on both hands)

(significant difference between the groups) and 5 scar hypertrophy after OCTR
Not applicable (all participants had bilateral CTS)
3 conversions to OCTR after ECTR. 1 persisting wound pain in each group. 1 persisting symptoms and 1 superficial nerve injury after OCTR vs 48)

No data presented

No significant differences in time to 1 algodystrophy and 2 conversions to OCTR after ECTR return to work between the groups (all 17 days)

\begin{tabular}{ll}
\hline Giele $2000 \quad$ & $60 \%$ to $70 \%$ of participants pre- \\
& ferred ECTR. Outcome scores \\
& significantly higher in the ECTR \\
& group (8.1 vs 6.1). Symptoms re- \\
& solved faster in the ECTR hands in \\
& the first 12 days but the 2 meth- \\
& ods became equally successful \\
& thereafter. 2-point discrimina- \\
& tion, pinch and grip strength re- \\
& covered faster in the ECTR hands, \\
& but equal by the 8th week
\end{tabular}

Not assessed

Not assessed

Hoef- Mean symptom severity score af-

nagels

1997 ter 3 months: $1.6 \pm 0.7$ after ECTR; $1.5 \pm 0.5$ after OCTR (no significant difference)

\section{Longer than 4 weeks' absence from work in $16 \%$ (ECTR); $13 \%$ (OCTR) (difference $3 \%, 95 \% \mathrm{Cl}-7$ to 14 )}

1 death, 2 participants with no symptomatic relief, 1 in each group. 3 hands in ECTR group with 3rd web space neurapraxia and 1 in the OCTR. 2 wound dehiscences and infections in the OCTR group

\begin{tabular}{ll}
\hline Incoll & All participants preferred the EC- \\
2004 & TR side at 1,2 and 6 weeks. EC- \\
& TR was associated with less pain, \\
& greater ease of use, improved \\
& strength and better motion
\end{tabular}

\begin{tabular}{lll}
\hline Jacobsen Not assessed Not assessed \\
1996
\end{tabular}

Koskella Not presented
1996
Not presented

\section{Mean 17 (ECTR) and 19 (OCTR) days (no significant difference between the groups) \\ The patients under- going ECTR tended to regain functional use of their operated hand slightly soon- er than the group un- dergoing OCTR}

\section{Macder- mid 2003}

\section{After a mean of 3.2 years lower satis- faction scores after \\ No significant differ- ences (no quantita- tive data presented)} ECTR ( $85 \%$ vs 93\%)
3 transient numbness on the radial side of the ring finger after ECTR. 1 prolonged wound secretion after OCTR

1 incomplete release in the ECTR group whose symptoms improved after subsequent OCTR 


\section{Table 1. Endoscopic versus open carpal tunnel release (Continued)}

\begin{tabular}{|c|c|c|}
\hline $\begin{array}{l}\text { Malhotra } \\
2007\end{array}$ & $\begin{array}{l}\text { At } 1 \text { month, the incidence of local } \\
\text { pain and scar tenderness was sig- } \\
\text { nificantly higher in OCTR ( } 20 / 31 \\
\text { reported mild local pain and } 19 \\
\text { reported scar tenderness as com- } \\
\text { pared to only } 3 \text { participants who } \\
\text { reported local pain in the ECTR). } \\
17 / 30 \text { and } 14 / 31 \text { in ECTR and OC- } \\
\text { TR group respectively reported } \\
\text { early relief (in } 3 \text { days) }\end{array}$ & $\begin{array}{l}\text { At } 6 \text { months, no } \\
\text { differences in grip } \\
\text { strength. No dif- } \\
\text { ferences could be } \\
\text { noted from electro- } \\
\text { physiological exam- } \\
\text { ination }\end{array}$ \\
\hline
\end{tabular}

Average time to return to daily activities was 16 days for ECTR and 20 days for OCTR
Scar tenderness in 9 OCTR participants. No incision site-related complication in the ECTR group. 2 in the OCTR group had symptoms consistent with reflex sympathetic dystrophy, none in the ECTR group

\begin{tabular}{ll}
\hline Saw 2003 Area under the curve analysis of \\
SSS (Levine) after 3 months: EC- \\
TR 120 (IQR 21); OCTR 119 (IQR 19) \\
(P = 0.70). Area under the curve \\
analysis of FSS (Levine) after 3 \\
months: ECTR 109 (IQR 22); OCTR \\
108 (IQR 24) (P = 0.98)
\end{tabular}

Schäfer Not assessed

Allc

All outcomes mea-

sured at 9 months postoperative-

ly. Night pain disappeared in both groups. Thenar atrophy was present in $17 \%$ and $15 \%$ of the participants in the OCTR and ECTR groups respectively. The means for the OCTR and ECTR groups were: grip strength 19.9 Kp vs $21 \mathrm{Kp}, 2$-point discrimination tests $3.2 \mathrm{~mm}$ vs $3.1 \mathrm{~mm}$

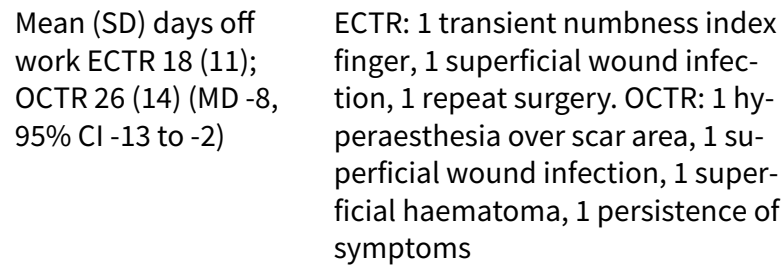

ECTR: 1 transient numbness index finger, 1 superficial wound infection, 1 repeat surgery. OCTR: 1 hyperaesthesia over scar area, 1 superficial wound infection, 1 superficial haematoma, 1 persistence of symptoms

\section{Mean days off work: No complications reported} ECTR 4.9 weeks; OCTR 5.7 weeks
Sick leave tended to be shorter after ECTR (not significant)
Pillar pain less frequent in the ECTR group (significant at 6 weeks) sia. Earlier return of grip strength and wrist motion (significant at 1 and 3 weeks) in the ECTR group

$\begin{array}{lll}\text { Stark } 1996 \begin{array}{l}\text { Matched pairs. Pain completely } \\ \text { relieved in } 20 / 20 \text { (ECTR) vs } 15 / 20\end{array} & \begin{array}{l}\text { Matched pairs. Pain } \\ \text { completely relieved }\end{array} \\ \text { hands (OCTR) after } 3 \text { months. Per- } & \text { in } 20 / 20 \text { hands } \\ \text { sisting paraesthesiae in } 1 / 20 \text { (EC- } & \text { (ECTR) vs } 19 / 20 \\ \text { TR) vs } 1 / 20 \text { (OCTR) after 3 months } & \text { hands (OCTR) after } \\ & 8 \text { months. Persist- } \\ & \text { ing paraesthesiae in } \\ & 1 / 20 \text { hands (ECTR) } \\ & \text { vs } 1 / 20 \text { hands (OC- } \\ & \text { TR) after } 8 \text { months }\end{array}$

$\begin{array}{ll}\text { Tian } 2007 & \text { Rate of scar tenderness: ECTR } \\ & \text { 36\%, OCTR 65\% (significant). No } \\ & \text { differences in 2-point discrimina- }\end{array}$

\section{Not assessed}

Mean 20 (ECTR) vs $30 \quad 1$ subcutaneous hematoma and (OCTR) days (signif- 1 loss of strength and mobility icant difference be- in the wrist after ECTR. 2 loss of tween the groups) strength and 1 swollen/stiff fingers after OCTR 
Table 1. Endoscopic versus open carpal tunnel release (Continued) tion. Operation time was shorter in ECTR group (12 min vs $38 \mathrm{~min}$ )

OCTR 28 days $(\mathrm{P}<$ $0.01)$

OCTR (final outcome for those participants not mentioned)

\begin{tabular}{|c|c|c|c|}
\hline $\begin{array}{l}\text { Trumble } \\
2002\end{array}$ & $\begin{array}{l}\text { After } 12 \text { weeks, better scores for } \\
\text { satisfaction ( } 4.4 \text { vs } 4.0 \text {, non-signif- } \\
\text { icant), SSS (Levine) ( } 1.8 \text { vs } 2.5 \text {, sig- } \\
\text { nificant) and FSS (Levine) (1.7 vs } \\
2.4 \text {, significant) }\end{array}$ & $\begin{array}{l}\text { After } 12 \text { months, no } \\
\text { significant differ- } \\
\text { ences for satisfac- } \\
\text { tion ( } 4.6 \text { vs } 4.5) \text {, SSS } \\
\text { (Levine) (1.8 vs } 1.8 \text { ) } \\
\text { and FSS (Levine) } \\
\text { (1.7 vs } 1.7 \text { ) }\end{array}$ & $\begin{array}{l}\text { Median } 18 \text { days (EC- } \\
\text { TR) and } 38 \text { days (OC- } \\
\text { TR) (significant dif- } \\
\text { ference between the } \\
\text { groups) }\end{array}$ \\
\hline
\end{tabular}

(1.7 vs 1.7)

\begin{tabular}{ll}
\hline Tüzüner & Longitudinal excursion and volar \\
2008 & displacement of the median nerve \\
& were calculated. No statistically \\
& significant difference in pre- and \\
post-release longitudinal excur- & sion changes between ECTR and \\
& OCTR groups
\end{tabular}

\begin{tabular}{lll}
\hline $\begin{array}{l}\text { Werber Not assessed } \\
1996\end{array}$ & Not assessed & Patients with ECTR \\
& returned earlier to \\
& work and had less \\
& pain
\end{tabular}

After OCTR, 2 reflex sympathetic dystrophy and 1 repeat procedure (no complications after ECTR)
Not assessed
Not assessed
Not assessed
No nerve, tendon or vessel le- sions were observed. 2 partici- pants in the ECTR group reported paraesthesias in the ulnar nerve. In 8 participants, the endoscopic method had to be changed into open procedure

\begin{tabular}{llll}
\hline $\begin{array}{l}\text { Westphal } \\
2000\end{array}$ & $\begin{array}{l}\text { SSS (variant of Levine) after 3 } \\
\text { months: ECTR 11.0 (3.7); OCTR }\end{array}$ & Mean 34.5 days (EC- & 3 patients in each group had ten- \\
& $10.6(2.6)$ & TR) vs 36 days (OC- & derness at 3 months \\
& Mean FSS (variant of Levine) after & (no significant dif- \\
3 months: ECTR 10.2 (4.5); OCTR & ference between the \\
$9.8(4.4)$ & groups) \\
\hline
\end{tabular}

ECTR: endoscopic carpal tunnel release; FSS: Functional Status Score; IQR: interquartile range; OCTR: open carpal tunnel release; SSS: Symptom Severity Score

Table 2. Endoscopic versus modified open carpal tunnel release

\begin{tabular}{|c|c|c|c|c|}
\hline $\begin{array}{l}\text { Refer- } \\
\text { ences }\end{array}$ & Symptoms $\leq 3$ months & Symptoms $>3$ months & $\begin{array}{l}\text { Return to } \\
\text { work / ac- } \\
\text { tivities of } \\
\text { daily liv- } \\
\text { ing }\end{array}$ & Complications \\
\hline $\begin{array}{l}\text { Eichhorn } \\
2003\end{array}$ & - & $\begin{array}{l}\text { Mean overall severity score (scale } 1 \text { to } \\
6 \text { ) after > } 1 \text { year: ECTR } 2.1 \text {; mini inci- } \\
\text { sion } 2.2\end{array}$ & $\begin{array}{l}\text { Not as- } \\
\text { sessed }\end{array}$ & $\begin{array}{l}\text { None } \\
\text { Recurrences: ECTR } \\
\text { 2\%; mini incision 14\% } \\
\text { Need for repeated } \\
\text { surgery: ECTR 2\%; mi- } \\
\text { ni-incision 9\% }\end{array}$ \\
\hline $\begin{array}{l}\text { Mackenzie } \\
2000\end{array}$ & No quantitative data presented & Not assessed & $\begin{array}{l}\text { Not as- } \\
\text { sessed }\end{array}$ & $\begin{array}{l}1 \text { pillar pain in each } \\
\text { group }\end{array}$ \\
\hline
\end{tabular}


Table 2. Endoscopic versus modified open carpal tunnel release (Continued)

\begin{tabular}{|c|c|c|c|c|}
\hline Rab 2006 & $\begin{array}{l}\text { At } 12 \text { weeks: mean SSS (Levine) ECTR } \\
\text { 14.7; modified OCTR } 16.8(P=0.27) \\
\text { Mean FSS (Levine) ECTR 10.3; modified } \\
\text { OCTR } 12.3(P=0.16) \\
\text { Pain (VAS) ECTR } 0.3 \text {; modified OCTR } 1.7 \\
(P=0.10)\end{array}$ & $\begin{array}{l}\text { At } 12 \text { months } \\
\text { Mean SSS (Levine): ECTR 14.0; modi- } \\
\text { fied OCTR } 12.8(P=0.49) \\
\text { Mean FSS (Levine): ECTR } 11.1 \text {; modi- } \\
\text { fied OCTR } 9.9(P=0.39) \\
\text { Pain (VAS): ECTR 0.6; modified OCTR } \\
0.2(P=0.43 \text { ) }\end{array}$ & $\begin{array}{l}\text { Not as- } \\
\text { sessed }\end{array}$ & No complications \\
\hline $\begin{array}{l}\text { Sørensen } \\
1997\end{array}$ & $\begin{array}{l}\text { No differences in terms of pain and dis- } \\
\text { appearance of paraesthesia. Earlier re- } \\
\text { turn of grip strength (significant at } 1 \text {, } \\
2 \text { and } 3 \text { weeks) and wrist motion (sig- } \\
\text { nificant at } 1 \text { and } 3 \text { weeks) in the ECTR } \\
\text { group }\end{array}$ & - & $\begin{array}{l}\text { Sick leave } \\
\text { tended to } \\
\text { be shorter } \\
\text { after ECTR } \\
\text { (not sig- } \\
\text { nificant) }\end{array}$ & $\begin{array}{l}\text { Pillar pain less fre- } \\
\text { quent in the ECTR } \\
\text { group (significant at } 6 \\
\text { weeks) }\end{array}$ \\
\hline $\begin{array}{l}\text { Wong } \\
2003\end{array}$ & $\begin{array}{l}\text { Statistically significant difference in } \\
\text { reduction of wound pain at } 2 \text { and } 4 \\
\text { weeks in favour of modified OCTR, but } \\
\text { not after } 8 \text { and } 16 \text { weeks }\end{array}$ & $\begin{array}{l}\text { At } 12 \text { months, complete relief or min- } \\
\text { imal symptoms: ECTR } 27 / 30 \text { hands } \\
(90 \%) \text {; modified OCTR } 27 / 29 \text { hands } \\
(93 \%) \\
\text { Preference: for ECTR 6; for modified } \\
\text { OCTR 13; no preference } 10\end{array}$ & $\begin{array}{l}\text { Not as- } \\
\text { sessed }\end{array}$ & $\begin{array}{l}3 \text { ECTR and } 2 \text { OCTR } \\
\text { participants had no } \\
\text { change or only partial } \\
\text { relief at } 12 \text { months }\end{array}$ \\
\hline
\end{tabular}

ADL: activities of daily living; ECTR: endoscopic carpal tunnel release; FSS: Functional Status Score; OCTR: open carpal tunnel release; SSS: Symptom Severity Score: VAS: visual analogue scale.

\section{AP PE N DICES}

\section{Appendix 1. Cochrane Neuromuscular Disease Group Specialized Register search strategy}

\#1 MeSH DESCRIPTOR Carpal Tunnel Syndrome [REFERENCE] [STANDARD]

\#2 "carpal tunnel" [REFERENCE] [STANDARD]

\#3 ("nerve entrapment" or "nerve compression" or "entrapment neuropath*") and carpal [REFERENCE] [STANDARD]

\#4 \#1 or \#2 or \#3 [REFERENCE] [STANDARD]

\#5 endoscop* or octr or ectr [REFERENCE] [STANDARD]

\#6 \#4 and \#5 [REFERENCE] [STANDARD]

$\# 7$ (\#4 and \#5) AND (INREGISTER) [REFERENCE] [STANDARD]

\section{Appendix 2. The Cochrane Library (CENTRAL)}

\#1 "Carpal Tunnel Syndrome"

\#2 ("nerve entrapment" or "nerve compression" or "entrapment neuropathy" or "entrapment neuropathies")

\#3 carpal

$\# 4 \# 1$ or (\#2 and \#3)

\#5 endoscop* or OCTR or ECTR or releas*

$\# 6$ \#4 and \#5

\section{Appendix 3. MEDLINE (OvidSP) search strategy}

Database: Ovid MEDLINE(R) <1946 to November Week 1 2013>

Search Strategy:

1 randomized controlled trial.pt. (389866)

2 controlled clinical trial.pt. (89904)

3 randomized.ab. (287333)

4 placebo.ab. (156850)

5 drug therapy.fs. (1767223) 
6 randomly.ab. (199448)

7 trial.ab. (302482)

8 groups.ab. (1276425)

9 or/1-8 (3299027)

10 exp animals/ not humans.sh. (4060470)

119 not 10 (2809295)

12 Carpal Tunnel Syndrome.mp. or Carpal Tunnel Syndrome/ (7915)

13 (carp\$ tunn\$ or tunn\$ syndrom\$ or carp\$ syndrom\$).mp. (9575)

14 (nerve entrapment or nerve compression or entrapment neuropath\$).mp. (11216)

15 median nerve entrapment.mp. (99)

16 nerve compression syndromes/ (9072)

17 or/12-16 (19390)

18 endoscop\$.mp. (159054)

19 OCTR.mp. (35)

20 ECTR.mp. (59)

21 releas\$.mp. $(600120)$

22 or/18-21 (757515)

2311 and 17 and 22 (328)

\section{Appendix 4. EMBASE (OvidSP) search strategy}

Database: Embase <1980 to 2013 Week 46>

Search Strategy:

1 crossover-procedure/ (38971)

2 double-blind procedure/ (118651)

3 randomized controlled trial/ (360008)

4 single-blind procedure/ (18506)

5 (random\$ or factorial\$ or crossover $\$$ or cross over $\$$ or cross-over $\$$ or placebo $\$$ or (doubl\$ adj blind\$) or (singl\$ adj blind\$) or assign\$ or allocat\$ or volunteer\$).tw. (1303033)

6 or/1-5 (1385895)

7 exp animals/ (19025289)

8 exp humans/ (14995220)

97 not ( 7 and 8) (4030069)

106 not 9 (1245034)

11 limit 10 to embase (962420)

12 Carpal Tunnel Syndrome.mp. or Carpal Tunnel Syndrome/ (11573)

13 (carp\$ tunn\$ or tunn\$ syndrom\$ or carp\$ syndrom\$).mp. (14487)

14 (nerve entrapment or nerve compression or entrapment neuropath\$).mp. (13134)

15 nerve compression/ (11098)

16 or/12-15 (25116)

17 carpal tunnel release/ (61)

18 (endoscop\$ or releas\$ or OCTR or ECTR).mp. (1055110)

19 or/17-18 (1055110)

2011 and 16 and 19 (201)

\section{Appendix 5. Search for ongoing trials}

Databases: http://www.clinicaltrials.gov, http://www.controlled-trials.com (ISRCTN Register, Action Medical Research (UK), The Wellcome Trust (UK), UK trials (UK)), http://www.ukctg.nihr.ac.uk/default.aspx and http://www.who.int/ictrp/en/

\# "carpal tunnel"

\section{CONTRIBUTIONS OF AUTHORS}

Conceiving the review: Rob Scholten (RS), Haris S Vasiliadis (HSV)

Designing the first drafts of the title proposal and the review protocol: HSV

Feedback for the final title proposal and protocol: Georgia Salanti (GS), RS, Ian Shrier (IS)

Co-ordinating the review: HSV

Data collection for the review: HSV, PG

Undertaking manual searches: HSV

Screening search results:HSV, PG, IS

Organizing retrieval of papers: HSV, RS 
Screening retrieved papers against inclusion criteria: HSV, PG, IS

Appraising quality of papers: HSV, PG

Abstracting data from papers: HSV, PG

Writing to authors of papers for additional information: HSV

Providing additional data about papers: RS

Obtaining and screening data on unpublished studies: HSV

Data management for the review: HSV, GS

Entering data into RevMan 5: HSV

Analysis of data: HSV, GS. RS, IS

Interpretation of data: HSV, GS, IS, RS

Writing the review: HSV, GS

Securing funding for the review: not applicable

Performing previous work that was the foundation of the present study: RS

Guarantor of the review (one author): HSV

Statistical analysis: HSV, GS

\section{DECLARATIONS OF INTEREST}

HSV received travel support from manufacturer of instrumentation for mini-open and endoscopic release to attend orthopaedic conference. Additionally, he is the Principal Investigator in an ongoing RCT comparing ECTR versus mini-open carpal tunnel release.

PG, GS, IS, RS: none known.

\section{SOURCES OF SUPPORT}

\section{Internal sources}

- Haris S Vasiliadis, Greece.

none

- Petros Georgoulas, Greece.

none

- Ian Shrier, Canada.

- Georgia Salanti, Greece.

GS received funding from the European Research Council (IMMA 260559)

- Rob JPM Scholten, Netherlands.

\section{External sources}

- None, Not specified.

\section{DIFFERENCES BETWEEN PROTOCOLAND REVIEW}

Although we planned to assess the analysis taking out studies with high or unclear risk of bias for allocation concealment, this was not done. Only two studies would have been included in the analysis (Atroshi 2006; Tüzüner 2008), and therefore no valuable information would have been found.

\section{INDEX TERMS}

\section{Medical Subject Headings (MeSH)}

Carpal Tunnel Syndrome [ ${ }^{\star}$ surgery]; Endoscopy [ ${ }^{*}$ methods]; Randomized Controlled Trials as Topic; Return to Work; Time Factors; Treatment Outcome

\section{MeSH check words}

Humans 